\title{
Simulating the effect of wind on the performance of axial flow fans in air-cooled steam condenser systems \\ by
}

Neil Fourie

Thesis presented in partial fulfilment of the requirements for the degree of Master of Engineering (Mechanical) in the

Faculty of Engineering at Stellenbosch University

Department of Mechanical and Mechatronic Engineering University of Stellenbosch

Private Bag X1, 7602 Matieland, South Africa

Supervisors:

Dr S.J. van der Spuy Prof T.W. von Backström

December 2014 


\section{Declaration}

By submitting this thesis electronically, I declare that the entirety of the work contained therein is my own, original work, that I am the sole author thereof (save to the extent explicitly otherwise stated), that reproduction and publication thereof by Stellenbosch University will not infringe any third party rights and that I have not previously in its entirety or in part submitted it for obtaining any qualification.

Date:

Copyright (C) 2014 Stellenbosch University All rights reserved. 


\title{
Abstract
}

\section{Simulating the effect of wind on the performance of axial flow fans in air-cooled steam condenser systems}

\author{
N. Fourie \\ Department of Mechanical and Mechatronic Engineering \\ University of Stellenbosch \\ Private Bag X1, 7602 Matieland, South Africa \\ Thesis: MEng (Mech) \\ December 2014
}

The use of air-cooled steam condensers (ACSCs) is the preferred cooling method in the chemical and power industry due to stringent environmental and water use regulations. The performance of ACSCs is however highly dependent on the influence of windy conditions. Research has shown that the presence of wind reduces the performance of ACSCs. It has been found that cross-winds (wind perpendicular to the longest side of the ACSC) cause distorted inlet flow conditions, particularly at the upstream peripheral fans near the symmetry plane of the ACSC. These fans are subjected to what is referred to as ' 2 - $\mathrm{D}$ ' wind conditions, which are characterised by flow separation on the upstream edge of the fan inlets. Experimental investigations into inlet flow distortion have simulated these conditions by varying the fan platform height. Low platform heights resulted in higher levels of inlet flow distortion, as also found to exist with high cross-wind speeds. This investigation determines the performance of various fan configurations (representative of configurations used in the SouthAfrican power industry) subjected to distorted inlet flow conditions through experimental and numerical investigations. The similarity between platform height and cross-wind effects is also investigated and a correlation between system volumetric effectiveness, platform height and cross-wind velocity is found. 


\section{Uittreksel}

\section{Simulasie van die invloed van wind op die werkverrigting van aksiaalwaaiers in lug-verkoelde stoom kondensor stelsels}

("Simulating the effect of wind on the performance of axial flow fans in air-cooled steam condenser systems")

N. Fourie

Departement van Meganiese en Megatroniese Ingenieurswese

Universiteit van Stellenbosch

Privaatsak X1, 7602 Matieland, Suid Afrika

Tesis: MIng (Meg)

Desember 2014

Die gebruik van lugverkoelde stoom kondensors (LVSK's) word verkies as 'n verkoelingsmetode in die chemiese- en kragvoorsieningsindustrie as gevolg van streng omgewings- en waterverbruiksregulasies. Die werkverrigting van LVSK's word egter grootliks beïnvloed deur die teenwoordigheid van wind. Navorsing het gewys dat die teenwoordigheid van wind die werkverrigting van LVSK's verminder. Daar was gevind dat kruiswinde (wind loodreg tot die langste sy van die LVSK) versteurde inlaat vloeitoestande veroorsaak, veral by waaiers wat aan die stroomop kant van die LVSK naby die simmetrievlak geleë is. Hierdie waaiers word blootgestel aan na wat verwys word as '2-D' windtoestande wat gekenmerk word deur vloeiwegbreking wat plaasvind by die stroomop rand van die waaierinlate. Eksperimentele ondersoeke van inlaat vloeiversteurings het hierdie toestande gesimuleer deur die waaier platformhoogte te verstel. Lae platform hoogtes het gelei tot hoër vlakke van inlaat vloeiversteuring, soortgelyk aan wat gevind word met hoë kruiswindsnelhede. Hierdie ondersoek gebruik numeriese en eksperimentele metodes om die werkverrigting van verskeie waaierkonfigurasies (verteenwoordigend van konfigurasies wat gebruik word in die Suid-Afrikaanse kragvoorsieningsindustrie) wat blootgestel word aan versteurde inlaat vloeitoestande te bepaal. Die ooreenkoms tussen platformhoogte en kruiswind effekte word ook ondersoek en 'n korrelasie tussen die sisteem volumetriese effektiwiteit, platformhoogte en kruiswindsnelheid word bepaal. 


\section{Acknowledgements}

My acknowledgements go to my parents, family, and friends for their amazing support, love and friendship. Thank you for always helping me smile and enjoy life, throughout the good and bad times.

To my amazing wife and best friend, Maureen. Thank you for the sunshine you bring to my life everyday.

To my supervisors, Dr. Johan van der Spuy and Prof. Theo von Backström. Thank you for your support, guidance and patience. I have learned so much from you and always enjoy our discussions. I appreciate the extra mile that you were always willing to walk, not only for this project, but also for issues unrelated to this project.

To the workshop and laboratory staff of the Department of Mechanical and Mechatronic Engineering. A very special thanks to Ferdi, Graham, Calvin, Maurisha and Juliun who were always willing to help and share conversation during the long hours spent in the workshop and laboratory. I will dearly miss these times.

To the Eskom Power Plant Engineering Institute for providing me with this opportunity and the funding required for this project.

Finally, to my shepherd, Lord Jesus Christ, who guides me, protects me and showers me with His blessings everyday. 


\section{Contents}

Declaration i

Abstract ii

Uittreksel iii

Acknowledgements iv

Contents

List of Figures vii

List of Tables $\quad$ xi

Nomenclature xiii

\begin{tabular}{lll}
\hline & Introduction & 1
\end{tabular}

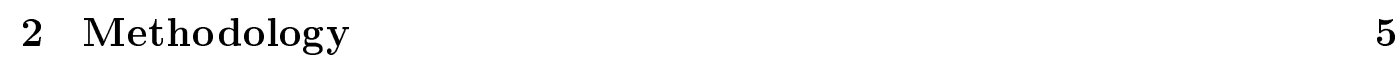

\begin{tabular}{lll}
\hline 3 & Literature review & 7 \\
\hline
\end{tabular}

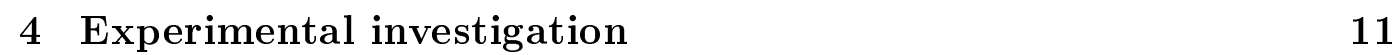

4.1 Introduction . . . . . . . . . . . . . . . . 11

4.2 Test facility . . . . . . . . . . . . . . . . . . . . . . . . . . . . . . . . . . . . 13

4.3 Experimental procedure . . . . . . . . . . . . . . . 14

4.4 Results and discussion . . . . . . . . . . . . . . . . 19

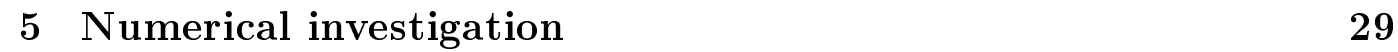

5.1 CFD theory . . . . . . . . . . . . . . . . . 29

5.2 Multiple fan facility . . . . . . . . . . . . . . . . . . . 32

5.3 Full scale ACSC . . . . . . . . . . . . . . . . . . 49

$\begin{array}{lll}6 & \text { Correlations } & 64\end{array}$

6.1 Expansion of Salta curve . . . . . . . . . . . . . . . . 64

6.2 Results and discussion ................. 65 
7 Conclusions and recommendations

74

7.1 Experimental evaluation of axial flow fan performance trends caused by platform height and fan configuration alterations . . . 74

7.2 Numerical simulation of experimental multiple fan, variable platform height facility . . . . . . . . . . . 76

7.3 Numerical evaluation of effects on ACSC performance caused

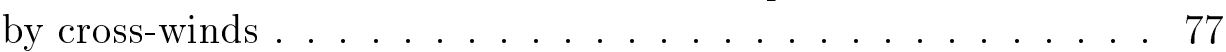

7.4 Correlation between platform height, cross-wind velocity and system volumetric effectiveness . . . . . . . . 78

7.5 Further work and recommendations . . . . . . . . . . . . . 80

\begin{tabular}{lr}
\hline Appendices & 81
\end{tabular}

\begin{tabular}{|lr}
\hline A Axial flow fans & 82 \\
\hline
\end{tabular}

A.1 N-fan . . . . . . . . . . . . . . . . . . 82

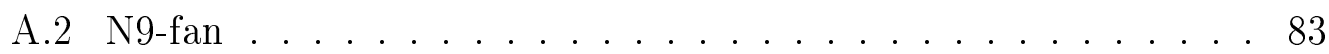

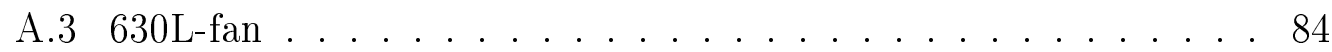

\begin{tabular}{lr}
\hline B Equipment calibration & 85
\end{tabular}

B.1 Reference anemometer . . . . . . . . . . . . . . 85

B.2 Multiple fan facility calibration . . . . . . . . . . . . 89

B.3 Hot film anemometers . . . . . . . . . . . . . . . . 996

\begin{tabular}{ll}
\hline C Fan tests & 101
\end{tabular}

C.1 Fan performance calculations . . . . . . . . . . . . . . 101

C.2 Flow velocity measurements . . . . . . . . . . . . . . . 104

\begin{tabular}{ll}
\hline D Numerical fan model & 108
\end{tabular}

\begin{tabular}{lll}
\hline ACHE numerical model & $\mathbf{1 1 1}$
\end{tabular}

E.1 Air and steam design point conditions . . . . . . . . . . . . 111

E.2 ACHE system resistance model . . . . . . . . . . . . . . . 111

E.3 ACHE heat transfer model . . . . . . . . . . . . . . . . . . . 113

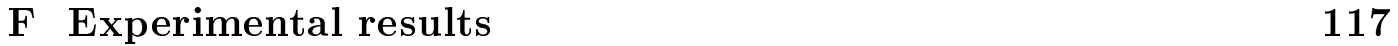

F.1 Individual fan performance results . . . . . . . . . . . . . . . 117

F.2 Multiple fan performance results . . . . . . . . . . . . . . . . . . . . . . . . . . . . . . . . . 122

F.3 $\quad$ Flow velocity measurement results. . . . . . . . . . . . . . 125

\begin{tabular}{ll}
\hline G CFD results & 127
\end{tabular}

G.1 Multiple fan performance CFD results . . . . . . . . . . . . . 127

G.2 ACSC CFD results . . . . . . . . . . . . . . . . . . . . . . . 129

\begin{tabular}{ll}
\hline List of References & 133
\end{tabular} 


\section{List of Figures}

1.1 Schematic of a steam power plant . . . . . . . . . . . . . . . . 1

1.2 Ideal Rankine cycle $\ldots . . \ldots \ldots . . \ldots . . \ldots 2$

1.3 Steam cycle with an ACSC cooling system . . . . . . . . . . . 4

2.1 Flow diagram of research procedure . . . . . . . . . . 5

4.1 Fan testing facility designed and built by $\operatorname{Visser}[(1990)]$. . . . . . 11

4.2 Layout of 3-fan unit in ACSC (van der Spuy [2011)] . . . . . . . . . 12

$4.3 \quad 3$-Fan experimental facility . . . . . . . . . . . . . 13

4.4 Schematic of the 3-fan variable platform height experimental facility 14

$4.5 \quad$ Individual fan performance experimental setup . . . . . . . . . . 15

4.6 Fan blade angle setting techniques $\ldots \ldots \ldots$. . . . . . . 16

4.7 Velocity measurement locations $\ldots \ldots \ldots . . \ldots . . \ldots 18$

$4.8 \quad$ Fan static pressure experimental results. . . . . . . . . . . . . . . . 19

4.9 Fan characteristic curve comparison . . . . . . . . . . . . . . 20

4.10 Fan power experimental results . . . . . . . . . . . . . . 21

4.11 Fan static efficiency experimental results . . . . . . . . . . . . 22

4.12 N-fan system variable platform height experimental results . . . . . 23

4.13 Effect of platform height on the system volumetric effectiveness of the N-, N9- and 630L-fan systems . . . . . . . . . . . . . . 24

4.14 Effect of platform height on the system volumetric effectiveness of the 630L-, N9- and 630L-N9-N9 fan systems . . . . . . . . 25

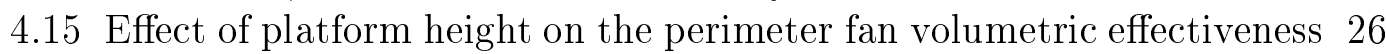
$4.16 \mathrm{~N}-\mathrm{N}-\mathrm{N}$ fan system velocity vectors for various platform heights . . . 26

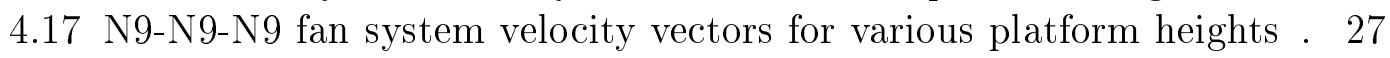
4.18 630L-630L-630L fan system velocity vectors for various platform

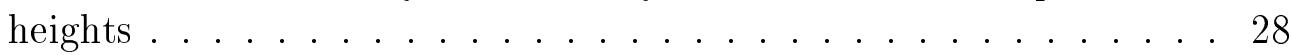

5.1 Single fan geometry and boundary conditions . . . . . . . . . . 33

5.2 Single fan unit mesh . . . . . . . . . . . . . . . . 34

5.3 Single fan CFD model mesh dependency results . . . . . . . . . . . . 34

5.4 N-fan static pressure CFD results comparison . . . . . . . . . . . . 37

5.5 N9-fan static pressure CFD results comparison . . . . . . . . . . . 37

$5.6 \quad 630 \mathrm{~L}-$ fan static pressure CFD results comparison . . . . . . . . . 38 
5.7 Multiple fan facility geometry and boundary conditions . . . . . . . 39

5.8 Multiple fan facility mesh . . . . . . . . . . . . . 40

5.9 N-fan system variable platform height CFD results comparison with experimental results ....................44

5.10 Perimeter N-fan variable platform height CFD results comparison with experimental results. . . . . . . . . . . . . 42

5.11 Comparison of CFD and experimental velocity vectors for the $\mathrm{N}-$

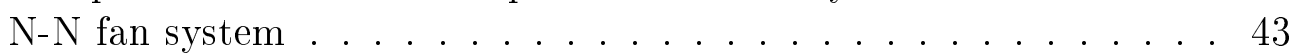

5.12 N9-fan system variable platform height CFD results comparison with experimental results. . . . . . . . . . . . . 44

5.13 Comparison of CFD and experimental velocity vectors for the N9N9-N9 fan system . . . . . . . . . . . . . . 45

5.14 630L-fan system variable platform height CFD results comparison with experimental results . . . . . . . . . . . . 46

5.15 Comparison of CFD and experimental velocity vectors for the 630L630L-630L fan system . . . . . . . . . . . . . . 47

5.16 Variable platform height CFD and experimental results . . . . . . . 47

5.17 Variable platform height perimeter fan CFD and experimental results 48

5.18 ACHE fan unit CFD model dimensions . . . . . . . . . . . . . . . 49

5.19 Single ACHE fan unit CFD validation model . . . . . . . . . . . 50

5.20 ACHE single unit mesh $\ldots \ldots \ldots \ldots \ldots$. . . . . . . . 51

5.21 ACHE convective heat transfer coefficient function . . . . . . . . 54

5.22 Analytical and CFD heat exchanger outlet temperature results . . . 56

5.23 ACSC numerical model domain . . . . . . . . . . . . . . 57

5.24 ACSC system mesh $\left(5.58 \times 10^{6}\right.$ cells $) \ldots \ldots \ldots$. . . . . . . 58

5.25 ACSC system mesh dependency investigation . . . . . . . . . 58

5.26 Temperature contours for N-fan ACSC street 1 . . . . . . . . . . 59

5.27 ACSC individual fan unit volumetric effectiveness results . . . . . . 60

5.28 ACSC system volumetric effectiveness results . . . . . . . . . . . 61

$5.29 \mathrm{~N}$-fan ACSC volumetric effectiveness results . . . . . . . . . . . . 61

$5.30 \mathrm{N9}$-fan ACSC volumetric effectiveness results. . . . . . . . . . . . 62

5.31 630L-fan ACSC volumetric effectiveness results . . . . . . . . . . 62

6.1 Wind- and cross-flow velocity definition. . . . . . . . . . . 65

6.2 Variable platform height and cross-wind velocity results . . . . . . . 66

6.3 Effect of non-dimensional wind number, $v_{w} / v_{x}$, on the wind factor,

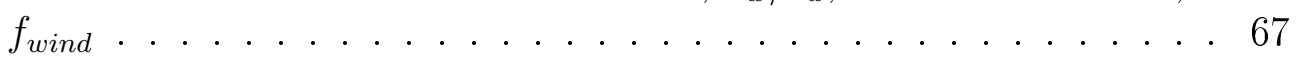

6.4 Perimeter fan flow field comparison of coinciding experimental and CFD data points at (a) in Figure $6.2 \ldots \ldots . \ldots 68$

6.5 Combined platform height and cross-wind velocity results for all

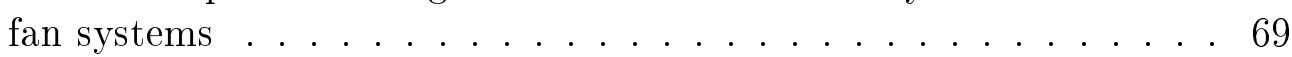

6.6 3D plot of volumetric effectiveness based on platform height and dimensionless wind velocity $\ldots \ldots \ldots \ldots 70$ 
6.7 Volumetric effectiveness curves at constant dimensionless wind velocities . . . . . . . . . . . . . . . . . 71

6.8 Volumetric effectiveness curves at constant dimensionless platform

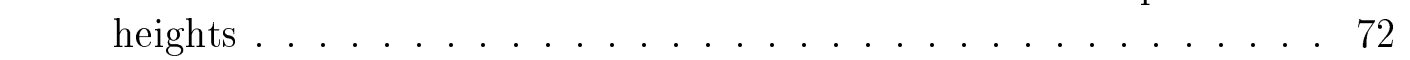

6.9 Dimensionless platform height curves at constant volumetric effectiveness values $\ldots \ldots \ldots \ldots . \ldots \ldots$

6.10 Correlation between dimensionless wind velocity and experimental dimensionless platform height producing the same volumetric effectiveness values . . . . . . . . . . . . . 73

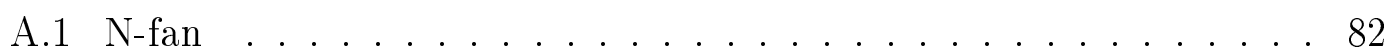

A.2 N9-fan . . . . . . . . . . . . . . . . . . . . . 83

A.3 630L-fan . . . . . . . . . . . . . . . . 84

B.1 Test wind tunnel (Kröger $[2004)$. . . . . . . . . . . . . . . . . . . . . . . 85

B.2 Anemometer clamped to wind tunnel . . . . . . . . . . . . . . 86

B.3 $\quad$ Pressure transducers $\ldots \ldots \ldots . \ldots . \ldots . \ldots 88$

B.4 Test wind tunnel pressure transducer calibration results . . . . . . . 88

B.5 $\quad$ Reference anemometer calibration results . . . . . . . . . . . . . . . . . 89

B.6 3 -Fan facility pressure transducers . . . . . . . . . . . . . . . 90

B.7 3 3-Fan experiment pressure transducer calibration results . . . . . . 91

B.8 3 3-Fan anemometer calibration set-up . . . . . . . . . . . . . 92

B.9 Anemometer calibration data . . . . . . . . . . . . . . . 93

B.10 Torque transducer calibration . . . . . . . . . . . . . . . . . 94

B.11 Moment $\mathrm{arm}$..................... . . 94

B.12 Torque transducer calibration data . . . . . . . . . . . . 95

B.13 Speed sensor calibration data . . . . . . . . . . . . . . 96

B.14 Hot film anemometer calibration coordinate systems . . . . . . . 97

B.15 Hot film anemometer King's law parameter calibration results for

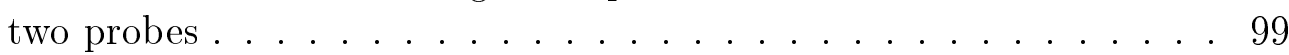

B.16 Hot film anemometer directional sensitivity calibration results for

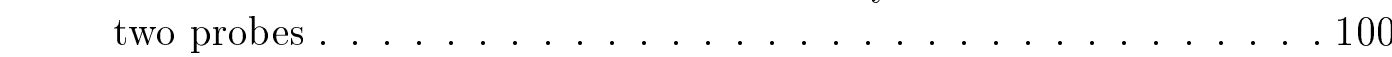

B.17 Determination of $K$ and $n^{\prime}$ parameters . . . . . . . . . . . 100

C.1 Hot film measurement technique. . . . . . . . . . . . . . . 105

C.2 Rotating single inclined hot film anemometer sample data, $\mathrm{H} / \mathrm{D}_{\text {fan }}$

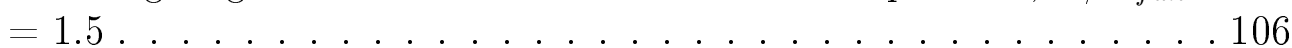

C.3 Hot film measurement data velocity angle determination . . . . . . 107

D.1 N-fan static pressure curve with polynomial curve fit . . . . . . . . 108

F.1 N-fan static pressure experimental results . . . . . . . . . . . 117

F.2 $\quad$ N-fan power experimental results . . . . . . . . . . . . . . 118

F.3 $\quad$ N-fan static efficiency experimental results . . . . . . . . . . . . . 118

F.4 $\quad$ N9-fan static pressure experimental results . . . . . . . . . . . . . 119 
F.5 N9-fan power experimental results . . . . . . . . . . . . . . 119

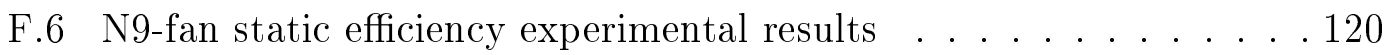

F.7 $630 \mathrm{~L}-$ fan static pressure experimental results . . . . . . . . . . . . 120

F.8 $630 \mathrm{~L}$-fan power experimental results $\ldots \ldots \ldots \ldots$. . . . . . . . 121

F.9 630L-fan static efficiency experimental results . . . . . . . . . . 121

G.1 Upstream average peripheral cross-flow velocity results . . . . . . 132 


\section{List of Tables}

4.1 List of fan experiments . . . . . . . . . . . . . . . . . . . . . . . . . . . . . . 14

4.2 Fan operating point . . . . . . . . . . . . . . . . . . . . . . . . . . . . . . . . .

4.3 Fan peak static efficiency values . . . . . . . . . . . . . . 22

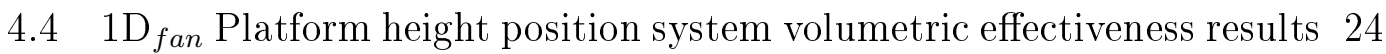

$5.1 \quad$ Pressure jump fan polynomials . . . . . . . . . . . . 35

5.2 Single fan model boundary and cell zone values . . . . . . . . . . . 36

5.3 Multiple fan facility model boundary and cell zone values . . . . . . 40

5.4 Outlet vent loss factor polynomial coefficients and corresponding volumetric flow rates . . . . . . . . . . . . . . 44

5.5 ACHE CFD model dimension values . . . . . . . . . . . . . . 50

5.6 ACHE pressure jump fan polynomials . . . . . . . . . . . . . . . 51

5.7 ACHE heat exchanger model porous zone parameters . . . . . . . . 52

5.8 Radiator piecewise-polynomial function coefficients . . . . . . . . . 55

5.9 Analytical and CFD ideal volumetric flow rate results . . . . . . . . 55

5.10 ACSC system domain dimensions . . . . . . . . . . . . . 56

6.1 Comparison of coincident experimental floor height and CFD wind

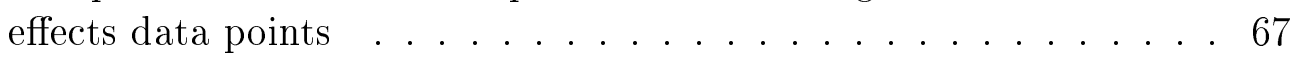

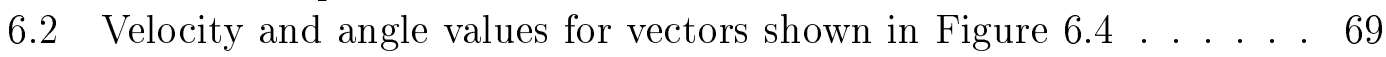

A.1 N-fan properties. . . . . . . . . . . . . . . . . 83

A.2 $\quad$ N9-fan properties . . . . . . . . . . . . . . . . . . . . . . . . . . . . 83

A.3 $630 \mathrm{~L}-$ fan properties . . . . . . . . . . . . . . . . . 84

C.1 Ambient conditions . . . . . . . . . . . . . . . . . . 101

C.2 Zero readings . . . . . . . . . . . . . . . . . 101

C.3 Mechanical friction torque readings . . . . . . . . . . . . . . . 102

C.4 Experimental measurements . . . . . . . . . . . . . . . . . . 102

C.5 Measured values . . . . . . . . . . . . . . . . . . . 102

C.6 Sample data results . . . . . . . . . . . . . . . . 107

E.1 Applicable air-cooled heat exchanger dimensions used in equation

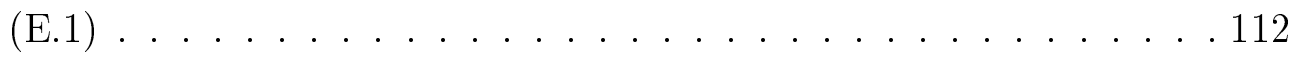

E.2 Air-cooled heat exchanger loss coefficients used in equation (E.1) 112 
E.3 $\quad$ Finned tube bundle specifications . . . . . . . . . . . . . . . 114

F.1 3-Fan volumetric flow rate results for N-fan system . . . . . . . . 122

F.2 $\quad$ N-fan system edge fan power consumption results . . . . . . . . . . . 122

F.3 3 -Fan volumetric flow rate results for N9-fan system . . . . . . . . . 123

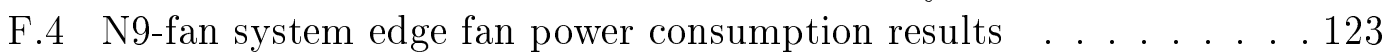

F.5 3 3-Fan volumetric flow rate results for 630L-fan system. . . . . . . . 123

F.6 630L-fan system edge fan power consumption results . . . . . . . . 124

F.7 3 3-Fan volumetric flow rate results for 630L-N9-N9 fan system . . . 124

F.8 630L-N9-N9 fan system edge fan power consumption results . . . . 124

F.9 $\quad$ N-N-N fans velocity measurement results . . . . . . . . . . . . . . . . 125

F.10 N9-N9-N9 fans velocity measurement results . . . . . . . . . . . . 126

F.11 630L-630L-630L fans velocity measurement results . . . . . . . . 126

G.1 3-Fan CFD volumetric flow rate results for N-fan system . . . . . . 127

G.2 3-Fan CFD volumetric flow rate results for N9-fan system . . . . 128

G.3 3-Fan CFD volumetric flow rate results for 630L-fan system . . . . 128

G.4 N-fans ACSC volumetric flow rate CFD results at cross-wind velocities of $0 \mathrm{~m} / \mathrm{s}, 3 \mathrm{~m} / \mathrm{s}, 6 \mathrm{~m} / \mathrm{s}$ and $9 \mathrm{~m} / \mathrm{s} \ldots \ldots . \ldots 129$

G.5 N-fans ACSC peripheral inlet average cross-flow velocity CFD results at cross-wind velocities of $0 \mathrm{~m} / \mathrm{s}, 3 \mathrm{~m} / \mathrm{s}, 6 \mathrm{~m} / \mathrm{s}$ and $9 \mathrm{~m} / \mathrm{s}$

G.6 N9-fans ACSC volumetric flow rate CFD results at cross-wind velocities of $0 \mathrm{~m} / \mathrm{s}, 3 \mathrm{~m} / \mathrm{s}, 6 \mathrm{~m} / \mathrm{s}$ and $9 \mathrm{~m} / \mathrm{s} \ldots \ldots . \ldots 130$

G.7 N9-fans ACSC peripheral inlet average cross-flow velocity CFD results at cross-wind velocities of $0 \mathrm{~m} / \mathrm{s}, 3 \mathrm{~m} / \mathrm{s}, 6 \mathrm{~m} / \mathrm{s}$ and $9 \mathrm{~m} / \mathrm{s}$. . 130

G.8 630L-fans ACSC volumetric flow rate CFD results at cross-wind velocities of $0 \mathrm{~m} / \mathrm{s}, 3 \mathrm{~m} / \mathrm{s}, 6 \mathrm{~m} / \mathrm{s}$ and $9 \mathrm{~m} / \mathrm{s} \ldots \ldots \ldots 131$

G.9 630L-fans ACSC peripheral inlet average cross-flow velocity CFD results at cross-wind velocities of $0 \mathrm{~m} / \mathrm{s}, 3 \mathrm{~m} / \mathrm{s}, 6 \mathrm{~m} / \mathrm{s}$ and $9 \mathrm{~m} / \mathrm{s} \ldots 131$ 


\title{
Nomenclature
}

\author{
Abbreviations \\ ACHE Air Cooled Heat Exchanger \\ ACSC Air Cooled Steam Condenser \\ ADM Actuator Disc Method \\ CAD Computer-aided Design \\ CFD Computational Fluid Dynamics \\ CNC Computer Numerical Control \\ DAQ Data Acquisition \\ EADM Extended Actuator Disc Method \\ PJM Pressure Jump Method \\ UDF User Defined Function
}

\section{Variables}

\begin{tabular}{|c|c|}
\hline$A$ & $\ldots \ldots \ldots\left[\mathrm{m}^{2}\right]$ \\
\hline$c_{p}$ & Specific heat at constant pressure . . . . . . . . \\
\hline$c_{v}$ & Specific heat at constant volume . . . . . . . . . [ J/kgK] \\
\hline$D$ & Diameter . . . . . . . . . . . . . . \\
\hline E & Voltage output \\
\hline$h$ & Convective heat transfer coefficient ... \\
\hline$H$ & Height . . . . . . . . . . . . . \\
\hline$i$ & Internal energy \\
\hline$k$ & Thermal conductivity . . . \\
\hline$L$ & Length .... . \\
\hline$m$ & {$[\mathrm{~kg}]$} \\
\hline$N$ & Rotational velocity \\
\hline$p$ & Pressure ...... \\
\hline$P$ & Power \\
\hline$Q$ & $\ldots \ldots$ \\
\hline$r$ & 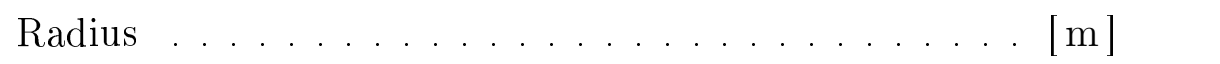 \\
\hline
\end{tabular}




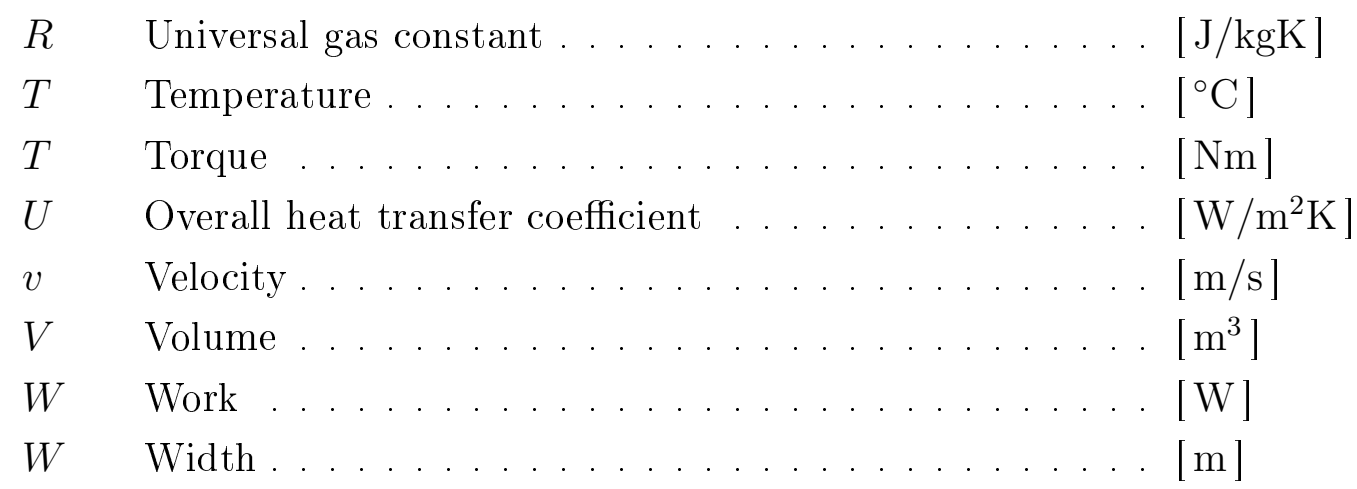

\section{Greek Symbols}

$\beta \quad$ Thermal expansion coefficient

$\eta \quad$ Efficiency

$\mu \quad$ Viscosity

$\rho \quad$ Density

$\varepsilon \quad$ Effectiveness

$\xi \quad$ Dimensionless platform height and wind effects number

\section{Subscripts}

$\begin{array}{ll}a & \text { Air } \\ a b s & \text { Absolute } \\ b & \text { Bundle } \\ a m b & \text { Ambient } \\ B & \text { Binormal } \\ d, d o & \text { Downstream } \\ d y n & \text { Dynamic } \\ e, e f f & \text { Effective } \\ \text { Exp } & \text { Experimental } \\ i d & \text { Ideal } \\ f & \text { Fan,Face } \\ h e & \text { Heat exchanger } \\ h e x & \text { Hex-core } \\ H & \text { High } \\ L & \text { Low } \\ n & \text { Nozzle } \\ N & \text { Normal } \\ O & \text { Operating } \\ p l & \text { Plenum }\end{array}$




$\begin{array}{ll}r e f & \text { Reference } \\ s & \text { Static,Steam } \\ s f & \text { Static fan } \\ \theta t & \text { Oblique total } \\ t & \text { Total } \\ t b & \text { Tube bundle } \\ t f r & \text { Total frontal } \\ t h & \text { Thermal } \\ t s & \text { Tower support } \\ t u s & \text { Tunnel Upstream } \\ T & \text { Tangential } \\ u p & \text { Upstream } \\ w & \text { Wind } \\ x & \text { x-direction,cross-flow } \\ x i & \text { x-direction inlet } \\ x o & \text { x-direction outlet } \\ z o & \text { z-direction outlet }\end{array}$




\section{Chapter 1}

\section{Introduction}

A steam power plant is a form of heat engine. Cengel and Boles (2007) define heat engines as devices with the following characteristics:

1. Heat is received from a high-temperature source (coal burners, solar energy etc.)

2. Part of the generated heat is converted to work.

3. The remaining waste heat is rejected to a low-temperature sink.

4. The operation of the engine can be represented by a thermodynamic cycle.

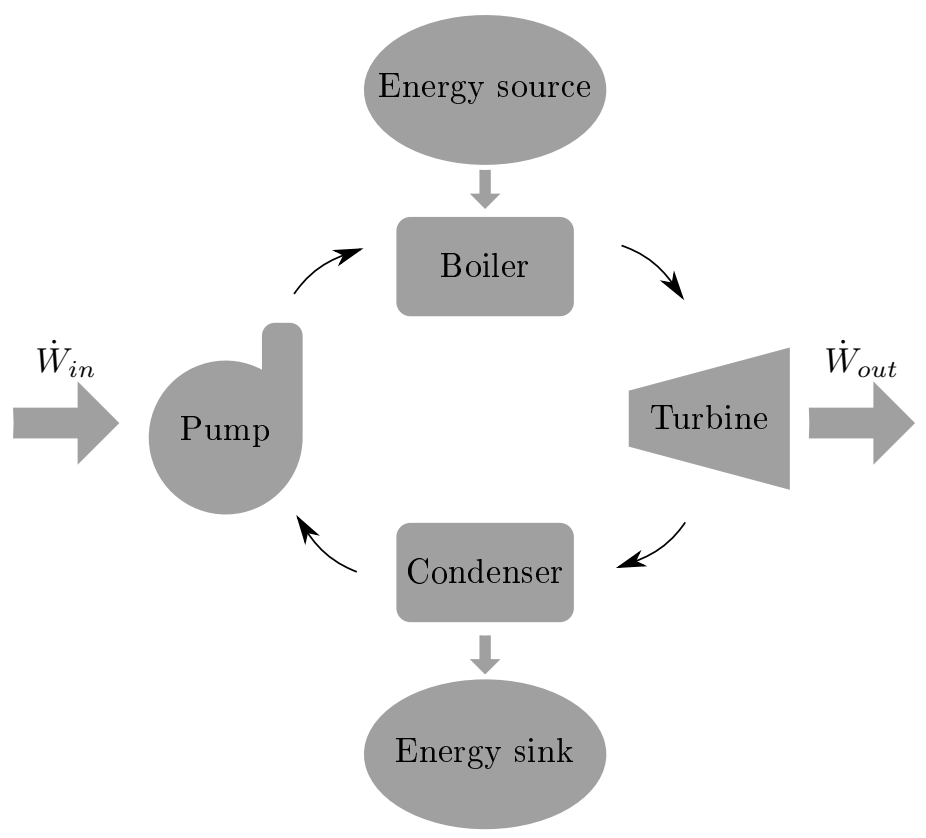

Figure 1.1: Schematic of a steam power plant 


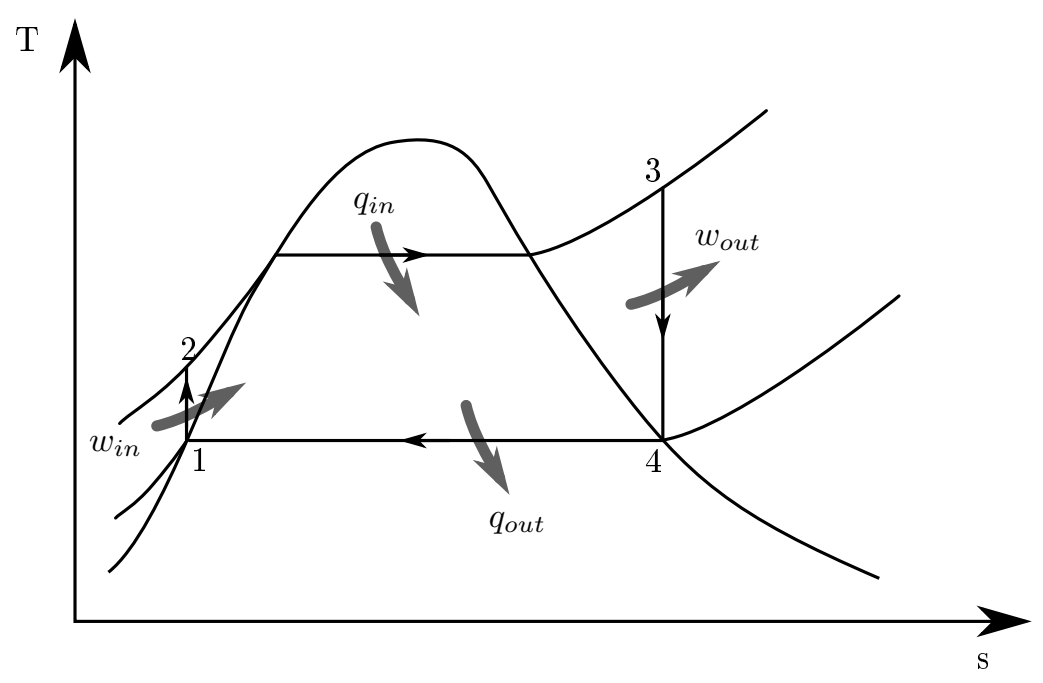

Figure 1.2: Ideal Rankine cycle

A simplified schematic of a steam power plant is shown in Figure 1.1. Fluid is pumped to the boiler where heat is transferred to the fluid from a fuel source (e.g. combustion of pulverised coal). The fluid leaves the boiler as superheated vapour. The superheated vapour then enters the turbine(s) where work is extracted by allowing the steam to expand. Finally the vapour is condensed in a condenser, rejecting the unused heat. This cycle is commonly known as the Rankine energy cycle and is shown on a T-s diagram in Figure 1.2 .

The highest thermodynamic efficiency that a reversible heat engine operating between two thermal energy reservoirs can obtain is referred to as the Carnot efficiency, given as

$$
\eta_{t h}=1-\frac{T_{L}}{T_{H}}
$$

Actual heat engines (such as the steam power plant) are however irreversible (due to irreversibilities in processes within the cycle) and cannot achieve the efficiency of a reversible heat engine. It is however obvious from equation (1.1) that the efficiency of a heat engine is increased as $T_{H}$ is increased, or $T_{L}$ is decreased. Some limitations however exist in the degree to which the heat source and heat sink temperatures can be altered. The degree to which one can increase $T_{H}$ is typically limited by material strength, whereas the degree to which one can decrease $T_{L}$ is limited by the ambient conditions as well as the cooling system. It is therefore clear that the cooling system performance in a steam power plant is an important factor when considering the generating capacity of the plant.

South-Africa's primary power utility, Eskom, uses two types cooling systems, wet-cooling and dry-cooling. Wet-cooling uses evaporative cooling to transfer heat from the condenser water. The warm water from the condenser 
is sprayed onto fill arrangements within the cooling tower which increases the surface area exposed to the air, enhancing the evaporating process. A natural draught is induced by a pressure differential caused by density differences of the air inside and outside the cooling tower (Kröger, 2004). Evaporation occurs at the air-water interface where the air is saturated with water. The saturated vapour subsequently diffuses into the free stream air which has a lower vapour concentration. This evaporation process cools the condenser water which drips down from the fill arrangement into a basin located at the bottom of the cooling tower. From here the water is pumped back to the condenser.

A considerable amount of make-up water is required in a wet-cooling system due to water lost during the evaporation process, as well as water lost during blowdown. Kröger (2004) quotes an average of between 1.6 and 2.5 liters of cooling water required per $\mathrm{kWh}(\mathrm{e})$ of net generation at a modern fossil-fuelled power plant, and the figure would be even greater for geothermal and nuclear power plants. The superior performance and cheaper installation cost of wet-cooling systems make it the preferred cooling system for power generating stations having access to sufficient water sources (Tawney et al., 2005). The decreasing availability of water sources and stringent environmental and water use regulations are however causing the use of wet-cooling systems to decrease due to the large amounts of water consumed by these systems. Power utilities and chemical process plants are being forced to consider converting to water conserving heat rejection systems such as dry-cooling systems which could reduce water consumption to around 0.17 liters per kWh(e) Goldschagg, 1993).

Dry-cooling systems are categorized as either direct dry-cooled or indirect dry-cooled (Heller). For this study only the direct dry-cooling system would be considered. In a direct dry-cooling system the exhaust steam is routed from the turbine to the finned-tube heat exchanger bundles where a heat exchange process takes place, allowing the steam to condense. An air draught flows over the heat exchanger bundles enhancing the heat exchange process and could be either 1) forced draught, 2) induced draught, or 3) natural draught (cooling tower). This research will specifically focus on the forced draught air-cooled heat exchanger (ACHE) as part of an ACSC system. In this system the finned tube bundles are arranged in an A-frame format with axial flow fans located beneath the bundles, forcing air through the bundles. Figure 1.3 shows a steam cycle with a forced draught ACSC.

The largest operating direct dry-cooled coal fired power plant, Matimba, is situated near Lephalale, Limpopo and consists of six $665 \mathrm{MW}(\mathrm{e})$ units. The decision to build the Matimba station was driven by the large coal deposits located in the area but the scarcity of water necessitated the use of a water conserving system, such as direct dry-cooling. Eskom's new build programme includes the current construction of two new direct dry-cooled power stations, Kusile and Medupi. When completed, Medupi would be the largest direct 
High pressure steam

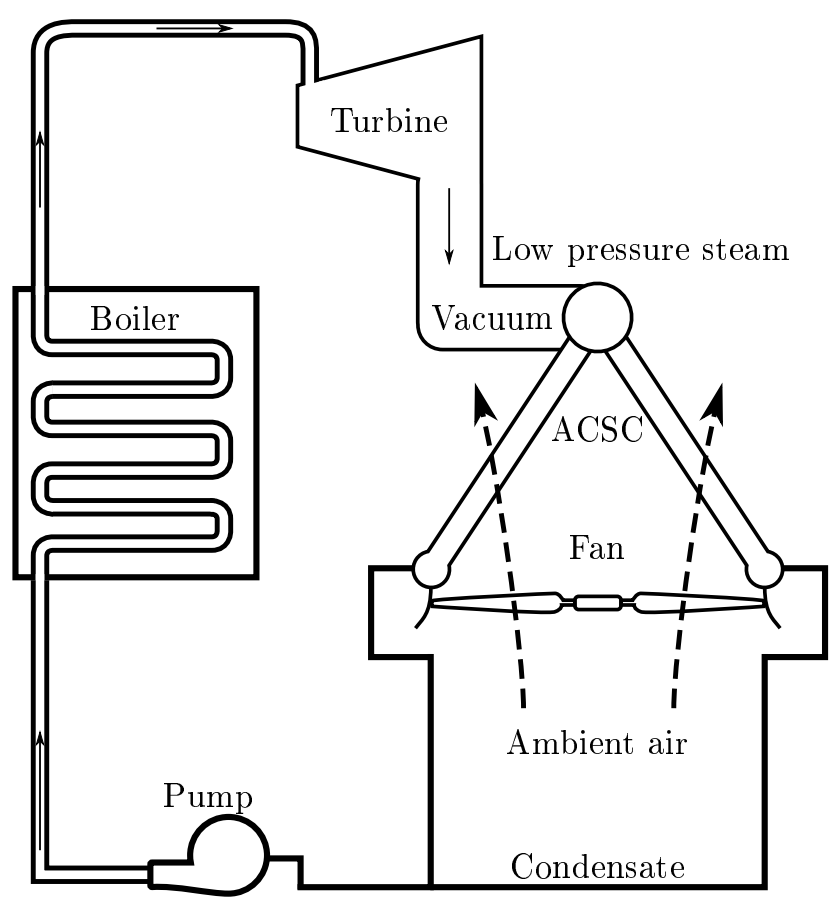

Figure 1.3: Steam cycle with an ACSC cooling system

dry-cooled coal fired power station. The increasing use of dry-cooling systems, and specifically forced draught ACSCs, emphasizes the importance of the understanding and improvement of the performance of these systems under all possible atmospheric conditions.

The performance of dry-cooling systems is greatly affected by atmospheric conditions. Gusts have been known to cause unit trips at Matimba with little or no warning. Goldschagg (1993) noted that the prevailing easterly winds at Matimba actually aids the performance of the ACSC due to the proximity of the boiler houses located on the western side of the ACSC (which causes a high pressure zone beneath the ACSC), but westerly winds as well as gusts cause distorted inflow conditions and hot plume recirculation.

Distorted inlet flow conditions have been simulated experimentally by conducting variable platform height investigations. By reducing the platform height of a model of an ACSC section, the inlet area is reduced, leading to an increase in the cross-flow velocity and distorted inlet flow conditions. These flow conditions are similar to flow conditions observed with full scale numerical investigations of ACSCs subjected to cross-winds. The similarity between the effect of ACSC platform height reduction and cross-winds have not been investigated explicitly. By further investigating into this similarity, the relevance of variable platform height experimental studies to the knowledge of axial flow fan performance in ACSC systems could be greatly improved. 


\section{Chapter 2}

\section{Methodology}

Previous studies have noted that the variation of platform height and the presence of winds have broadly similar effects on the performance of the axial flow fans in ACSCs. This study aims to formulate this correlation, within certain constraints.

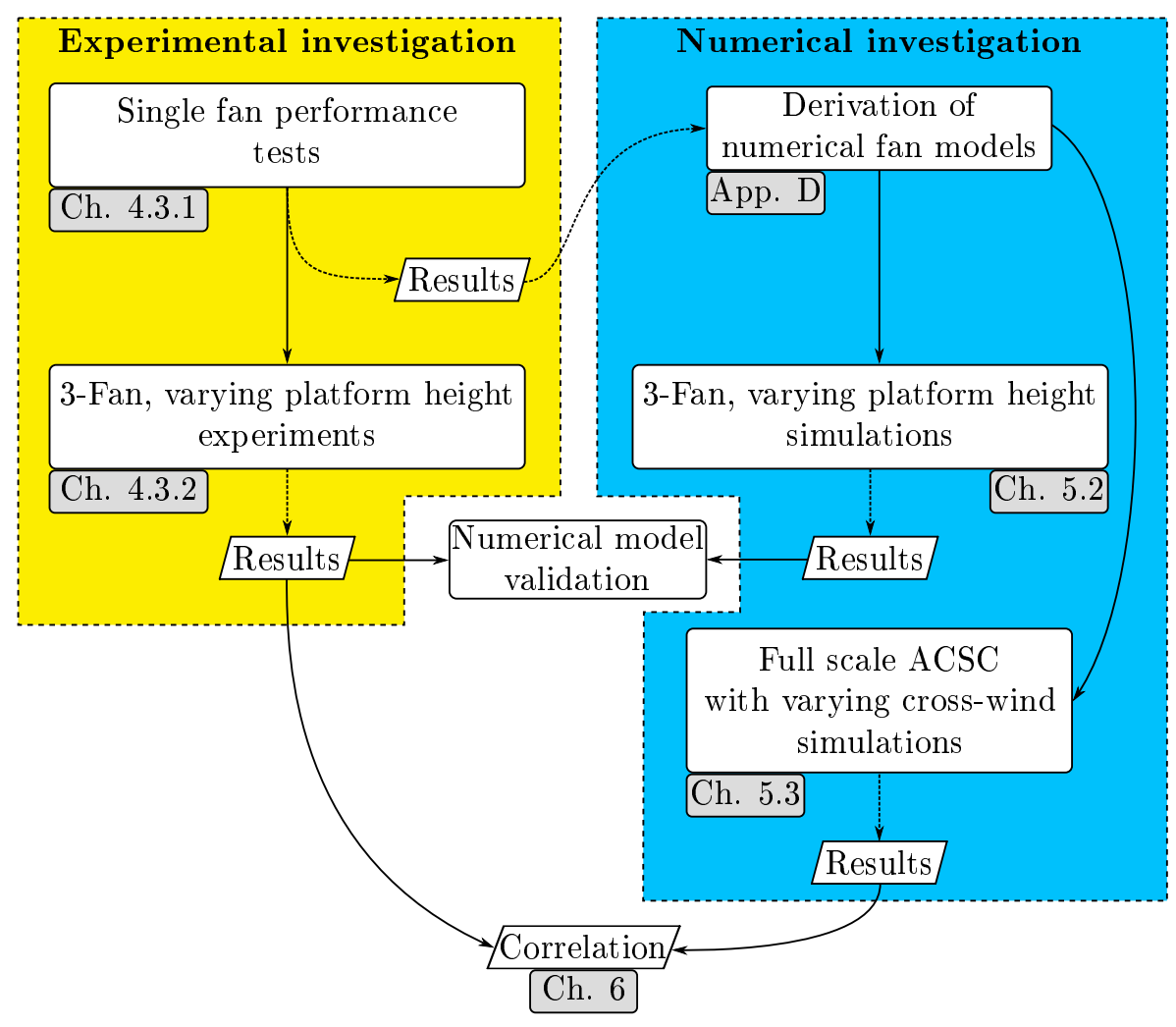

Figure 2.1: Flow diagram of research procedure

Figure 2.1 illustrates the research process through a flow diagram. The research process consists of various experimental and numerical investigations. 
Single fan performance tests are conducted first to determine the performance characteristics of the fans. Results from these tests are then used to create numerical fan models for use in the numerical investigation procedure.

Three-fan, varying floor height results are obtained experimentally as well as numerically by implementing the numerical fan models in a CFD model of the experimental facility. The numerical results are compared to the experimental results to validate and determine the accuracy of the CFD model.

The effects of cross-winds on ACSC are investigated by conducting numerical simulations with a full-scale ACSC system subjected to varying cross-winds. The experimental fan performance results are scaled using the fan scaling laws and then used to derive full-scale numerical fan models.

Finally the experimental variable platform height results and the numerical cross-wind simulation results are combined to obtain a correlation between the effects of wind speed and platform height on the performance of axial flow fans. 


\section{Chapter 3}

\section{Literature review}

The performance of ACHEs has been the subject of numerous studies. A overview of some of these studies now follows in chronological order.

Venter (1990) conducted experimental and analytical investigations into the effect of different system parameters and components on the performance of axial flow fans. A scale model of an industrial fan, referred to as the $\mathrm{V}$-fan, was used for testing. Various system parameters were identified and classified as either flow enhancing or flow restricting parameters. Fan specific flow enhancing techniques were investigated. These include the adjustment of fan tip clearance, inclusion of a hub disc on the downstream side of the fan and the variation of the number of fan blades. Flow reducing parameters were identified as inlet grids, walkways and their supporting structures, heat exchangers and windwalls. It was found that the performance of the investigated axial flow fan could be improved by reducing its tip clearance and installing a solid hub disc to the downstream side of the rotor. The addition of fan blades was found to only marginally increase fan performance. The removal or shifting of flow resisting components also showed improved system performance.

Goldschagg (1993) investigated the effects of wind on the performance of the ACSC at Matimba power station. It was found that the wind could be either beneficial or detrimental to the performance of the ACSC, depending on the wind direction. This was found to be caused by the proximity of the boiler house located on the western side of the ACSC. The circulation of hot plumes were identified, as well as reverse flow caused by a local inverse pressure gradient. Turbulent wind conditions were determined to be the biggest risk to ACSC performance as it causes sudden unit trips, with little or no warning. The effect of some modifications made to the ACSC were also investigated and proved to enhance performance.

Bruneau (1994) designed and tested two rotors for a relatively low volumetric flow design specification. The fans were termed the B1- and B2-fans. They were respectively based on the Clark-Y and NASA LS series aerofoil profiles and had the same hub-to-tip radius ratio value of 0.4 . The performance of the B-fans were compared to the results obtained during tests conducted by Venter 
(1990) on the $\mathrm{V}$-fan. Both fans showed improvements in static efficiency as well as static pressure rise at the design point.

Salta and Kröger (1995) conducted experimental investigations to determine the effect of inlet flow distortions on fan performance in ACSCs. The tests were conducted on a row of six fans with a variable platform height. An empirical correlation was developed for air flow vs. platform height. It was found that the edge fans were most affected by distorted inlet flow conditions. The inclusion of a periphery walkway was investigated and resulted in an increase in edge fan performance, particularly at low platform heights.

Duvenhage and Kröger (1996) investigated the effects of wind on fan performance and hot plume recirculation in an ACSC by means of numerical simulations. Longitudinal and cross-flow winds (winds parallel and perpendicular to the longest edge of the ACSC respectively) were considered. The rising hot plume and the ACSC structure is described as a flow obstruction 'seen' by the incoming wind. The wind is deflected by the obstructions and consequently accelerates underneath the fan platform and over the deflected plume. Longitudinal winds were found to cause a significant increase in hot plume circulation whereas cross-winds where more prone to induce distorted inlet flow conditions, reducing fan performance.

Flow distortions at the inlet of forced draught ACSC axial flow fans were numerically and experimentally investigated by Duvenhage et al. (1996). Again, the platform height was varied in experimental tests to simulate distorted inlet flow conditions. Three different inlet shrouds were investigated, cylindrical, conical and bell-mouth. The effect that the length of a cylindrical shroud as well as cylindrical sections within conical and bell-mouth shrouds have on fan performance were investigated. A critical cylindrical shroud length could be found and it was advised that no cylindrical section be included in conical and bell-mouth shrouds for the best fan performance.

Stinnes and von Backström (2002) investigated the effect of cross-flow on the performance of ACSC axial flow fans. Off-axis inflows were introduced to the axial flow fan by inserting inlet pipe sections between a standard test facility and the fan inlet. A decrement in the fan pressure rise was observed as the amount of cross-flow was increased. This decrement was found to be equal to the dynamic pressure based on the cross-flow component at the fan inlet. A model was created which accurately predicted the performance of a row of fans operating at off-axis inflow conditions (which is representative of fans operating in an ACSC). The model assumes that cross-flow is induced by fans further from the edge and in doing so predicts the cross-flow to inflow ratio for each fan.

Meyer (2005) did numerical investigations of the effect of inlet flow distortions on forced draught ACSC performance. Single and double banks of ACSCs were modelled. Four different cases were simulated, each case having a different configuration regarding fan inlet shroud and periphery walkway. Results of two of the four cases could be compared to experimental test re- 
sults obtained by Salta and Kröger (1995). Good correlation exists between the numerical and experimental results. It was found that an increase of up to $23 \%$ in the volumetric effectiveness of the edge fan could be obtained with the removal of the bell-mouth inlet shroud, especially at low platform heights. It could also be seen from vector plots and pressure contour plots that the inclusion of a periphery walkway shifted the zone of flow separation from the inlet of the edge fan to the walkway edge.

Bredell et al. (2006) investigated the effect of inlet flow distortions on the flow rate through forced draught ACSCs by numerical simulations of a section of an ACSC. This study focused on the performance of fans in an ACSC application under various degrees of distorted inlet flow conditions. Two different fans were considered, A-fan and B-fan (referring to the B2-fan in Bruneau (1994)) and featured the same diameter, number of blades and rotational speed, but different hub-to-tip ratios (0.153 and 0.4), solidities and blade designs. The effect of platform height on the fan performance was also investigated and although all the simulations were conducted under windless conditions Bredell et al. (2006) states that the effect of low platform height on the volumetric effectiveness may represent the effect of cross-winds on the fans located on the windward edge of the platform. Results showed superior performance by the B-fan which was attributed to the B-fan's steep static pressure rise curve. The steeper curve produces a smaller reduction in volumetric flow rate for a given change in pressure (caused by losses such as inlet flow distortions). The shaft power of the fans were however not investigated.

Joubert (2010) investigated the influence of geometric and environmental parameters on ACSC performance. A 30 fan ACSC was simulated and the effect of various parameters on ACSC performance was investigated. Parameters investigated include platform height, wind wall height, walkways, wind screens, fan inlet shrouds, fan types, fan power and wind directions. It was concluded that the most beneficial and practical modifications would be to add walkways to the periphery of the platform and porous wind screens below the platform. This modification produced a performance increase of $11.3 \%$ compared to the unmodified ACSC.

The performance of a 30-fan ACSC at El Dorado Power Plant in Nevada, USA, subjected to windy conditions was numerically investigated by Owen (2010). The ACSC was simulated using an iterative two-step modelling procedure consisting of a global flow field simulation and detailed ACSC simulation. The accuracy of the numerical model was also compared to test data collected during full-scale tests carried out at the actual operational ACSC and good correlation was found. It was found that distorted inlet flow conditions causing reduced fan performance had a far more significant effect on ACSC performance than hot plume recirculation.

Louw 2011) conducted a numerical investigation in an attempt to extend knowledge of the flow distribution in the vicinity of a large ACSC (consisting of 384 fans) during windy periods. The numerical model was subjected to 
longitudinal and cross winds with varying velocities. The flow was described as either two- or three-dimensional depending on the inflow location of the ACHE. It was found that perimeter fans subjected to two-dimensional flow conditions were the most affected and subsequently experienced significant reductions in performance. The study also showed that a significant reduction in ACSC effectiveness is caused by the presence of cross-winds (causing large areas of two-dimensional flow regions), whereas an overall effectiveness increase is seen for the case with longitudinal winds. Wind effect mitigation measures such as skirts and wind screens were also investigated. The performance enhancing effect of wind screens were confirmed with an improvement of $8-30 \%$.

The majority of studies into ACHE performance noted a significant decrease in perimeter fan performance when subjected to windy conditions. Extensive investigations into the performance of perimeter fans in a forced draught ACHE application were conducted by van der Spuy (2011). A 3fan, varying floor height, experimental investigation was conducted with six different perimeter fan configurations. The investigated fans were the B-fan (referring to the B2-fan designed by Bruneau (1994)), V-fan (referring to the fan initially tested by Venter (1990)) and various H-fan configurations (developed and tested by van der Spuy (1997)). An empirical method was derived in which the volumetric effectiveness of an edge fan having a certain floor height can be predicted. The results of the empirical formula compared well with experimental results. The test facility was also numerically simulated using three different analysis methods, the pressure jump method, the actuator disc method and the extended actuator disc method. It was found that the extended actuator disc method produced the most accurate results for the edge fan performance. High solidity and hub-tip ratio values showed the best volumetric effectiveness under distorted inflow conditions, although higher power consumption was recorded with high solidity fans. 


\section{Chapter 4}

\section{Experimental investigation}

This chapter details the experimental process of this investigation. The experimental test facility, test procedures and results are described. All related calibration data is included in Appendix B.

\section{$4.1 \quad$ Introduction}

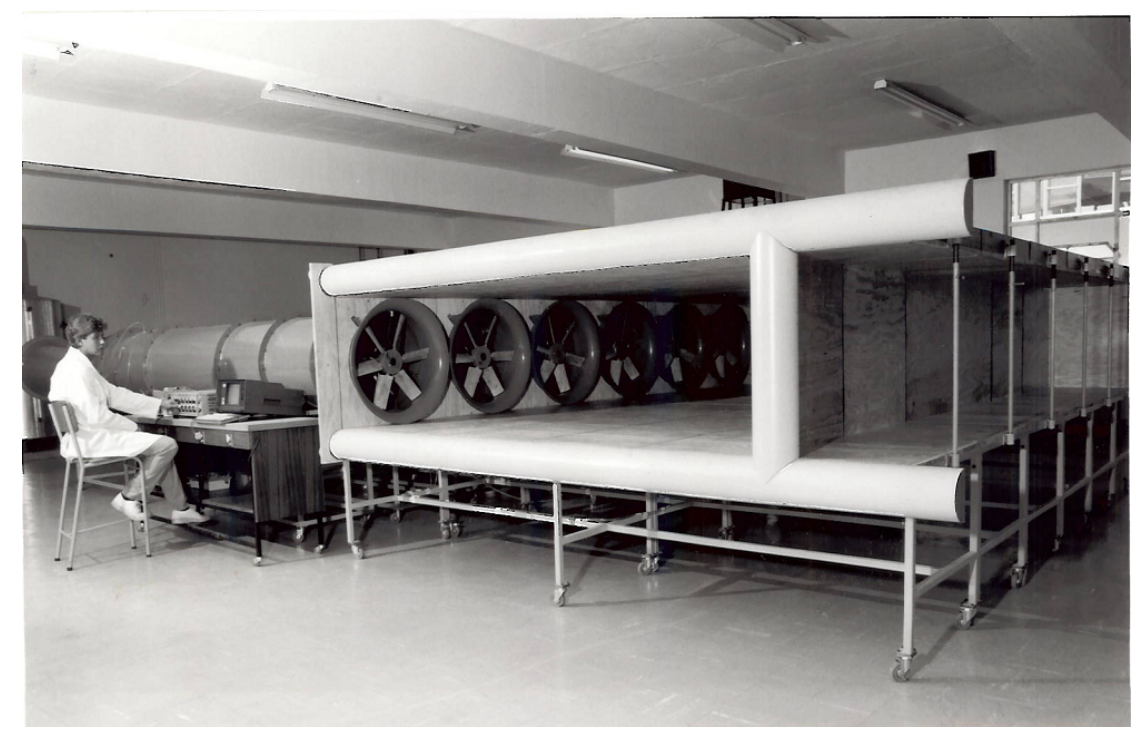

Figure 4.1: Fan testing facility designed and built by Visser (1990)

The axial flow fan experimental process consists of two investigations. Firstly the performance of the individual fans under ideal conditions needed to be measured by conducting single fan tests. Secondly, the performance of different axial flow fan configurations subjected to distorted inlet conditions were determined. These results were used to set-up and verify the CFD investigations. 


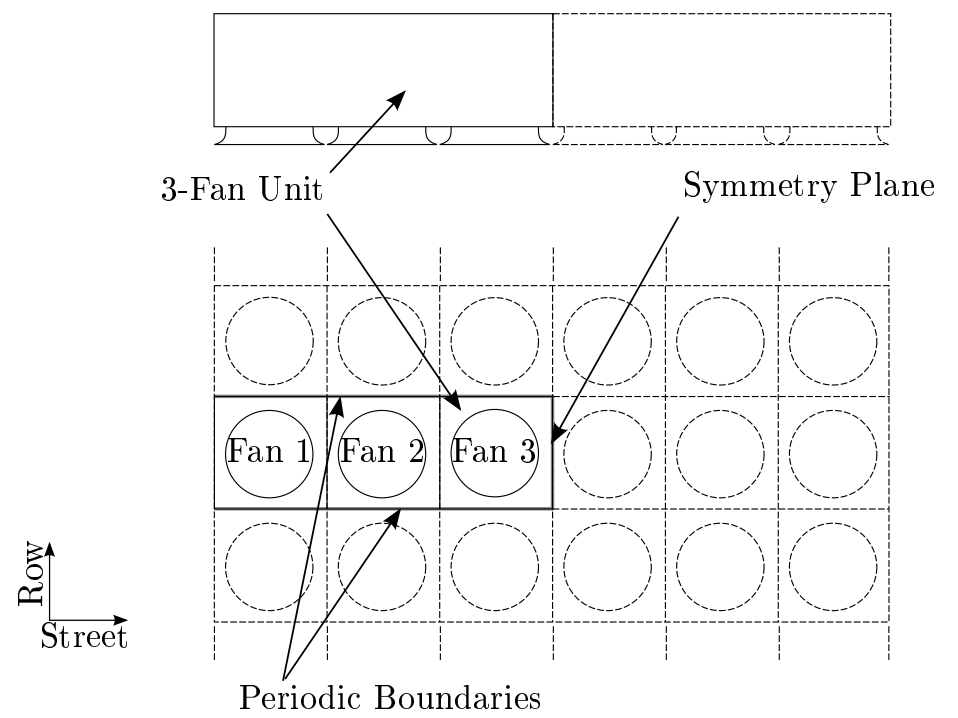

Figure 4.2: Layout of 3-fan unit in ACSC (van der Spuy, 2011)

Visser (1990) designed, built and tested a model of an ACSC fan street with an adjustable ground clearance (or platform height). The model, as shown in Figure 4.1, consisted of six $630 \mathrm{~mm}$ diameter axial flow fan test tunnels representing six fan rows, extracting air from a common inlet chamber. The top and bottom sides of the inlet chamber represent symmetry boundaries based on the assumption that no flow would cross the vertical planes between adjacent ACSC fan streets in a '2-D' flow condition. The platform height of the model is adjusted by means of removable wooden floor boards that can be inserted into grooves cut into the top and bottom inlet chamber boards.

Conradie (2010) adapted the facility designed by Visser and reduced the number of fan rows to three. Figure 4.2 shows the layout of the 3 -fan unit in an ACHE with the associated boundary condition assumptions. Conradie (2010) investigated the effect of fan configuration on the performance of a multiple fan installation. This facility was again used by van der Spuy (2011) to investigate the performance of the perimeter fan by comparing six different axial flow fans installed in the perimeter position and operating at varying platform height positions. These investigations all showed a reduction in system performance as the platform height is decreased. The perimeter fan is the most severely affected due to the presence of distorted inlet conditions.

The work done by Conradie (2010) and van der Spuy (2011) is extended in this investigation by including two additional axial flow fan configurations representing fans currently used in industry (refer to Appendix A for details of the fans used in the experiments). 


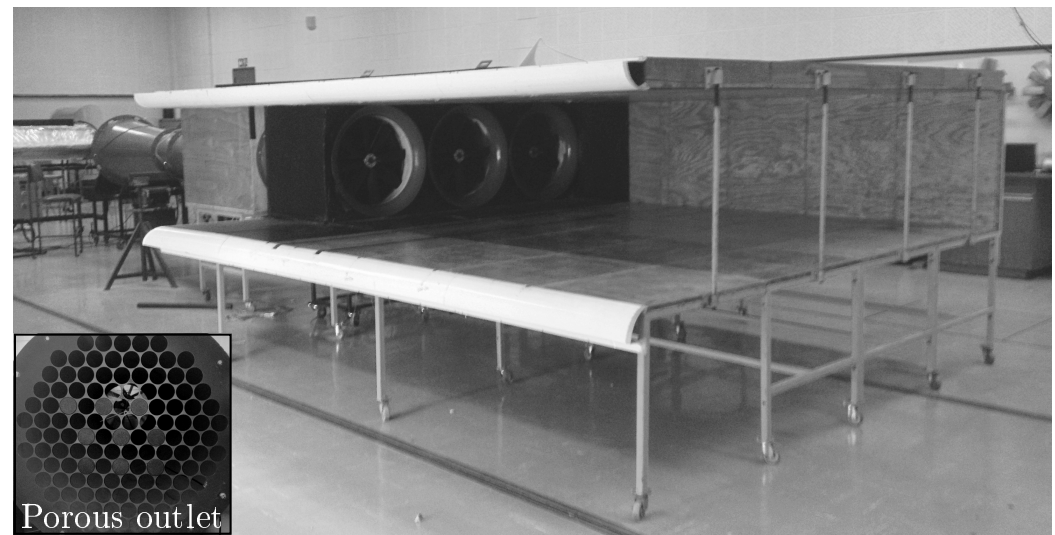

Figure 4.3: 3-Fan experimental facility

\subsection{Test facility}

A photo of the test facility, as used by van der Spuy (2011), is shown in Figure 4.3. The facility consists of three fan test tunnels which are based on a BS 848 Type B layout. The BS 848 part 1 standard (British Standards Institute, 2007) describes four different fan testing configurations:

1. Type A: Open inlet to open outlet

2. Type B: Open inlet to ducted outlet

3. Type C: Ducted inlet to open outlet

4. Type D: Ducted inlet to ducted outlet

The Type A facility is the best representation of the layout of the fans in a forced draught ACHE application since the plenum chamber into which the fan discharges can be regarded as an open outlet (van der Spuy, 2011). The reason for using type B test tunnels for the multiple fan tests was to enable the measurement of the flow rate of each fan separately. By installing anemometers in the three outlet ducts the flow rate of each fan could be measured independently. A schematic of the facility is shown in Figure 4.4.

The fan tunnels in the multiple fan test facility includes plenum chambers at the fan outlets, instead of ducted outlets as described in the BS 848 part 1. This modification was made to ensure that the test facility is a better representation of the actual installation.

A photo of one of the porous outlet sheets is shown as an insert in Figure 4.3. The porous outlet sheets allows the flow rate to be adjusted for each tunnel by adding or removing plugs. This ensures that the fan operating points correspond with the specified operating point. 
Top View

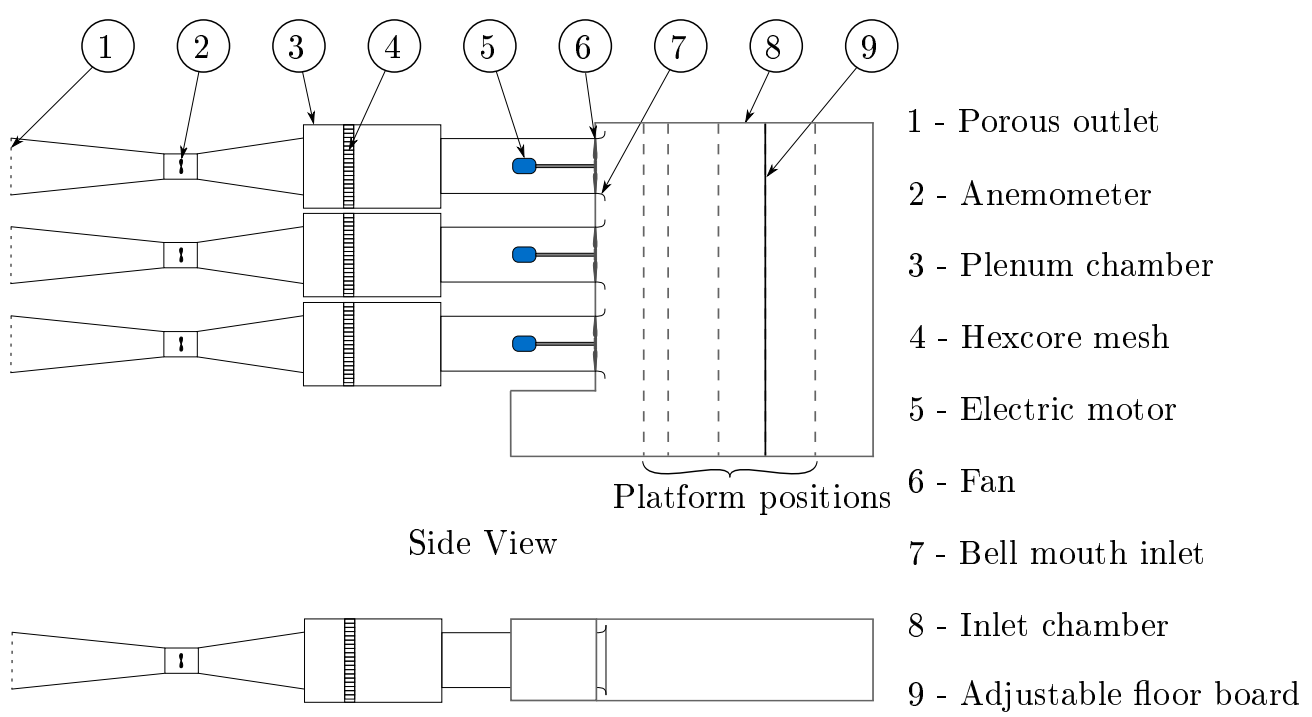

Figure 4.4: Schematic of the 3-fan variable platform height experimental facility

Table 4.1: List of fan experiments

\begin{tabular}{l|l|l|l}
\hline & $\begin{array}{l}\text { Individual fan } \\
\text { performance }\end{array}$ & $\begin{array}{l}\text { Multiple fan } \\
\text { performance }\end{array}$ & $\begin{array}{l}\text { Multiple fan } \\
\text { flow velocity } \\
\text { measurements }\end{array}$ \\
\hline \multirow{3}{*}{ Procedure details } & $\begin{array}{l}\text { Variable resis- } \\
\text { tance;various } \\
\text { blade angles }\end{array}$ & $\begin{array}{l}5 \text { platform } \\
\text { height positions }\end{array}$ & $\begin{array}{l}5 \\
\text { pre-determined } \\
\text { positions }\end{array}$ \\
\hline \multirow{5}{*}{ Fan configurations } & N & N-N-N & N-N-N \\
& $630 \mathrm{~L}$ & $\begin{array}{l}\text { N9-N9-N9 } \\
\text { 630L-630L-630L } \\
630 L-N 9-N 9\end{array}$ & $630 \mathrm{~L}-630 \mathrm{~L}-630 \mathrm{~L}$ \\
\hline
\end{tabular}

\subsection{Experimental procedure}

The performance of each individual fan described in Appendix A was first determined in a single test tunnel. These tests were performed with the inlet chamber removed and a flow throttle attached to the tunnel outlet. When the individual tests were completed the facility was reassembled and the multiple fan tests conducted. Table 4.1 gives an overview of all of the experiments that were performed. 


\subsubsection{Individual fan performance tests}

The goal of the individual fan performance tests was to determine the fan performance curves of each of the fans listed in Appendix A. During these tests the correct blade angle setting for each fan was set to ensure the fan performance curve intersects the chosen operating point, which was scaled from the design values used by Bruneau (1994). The operating point values are shown in Table 4.2 .

Table 4.2: Fan operating point

\begin{tabular}{l|rl}
\hline Static pressure & 62.3 & $\mathrm{~Pa}$ \\
Volumetric flow rate & 1.455 & $\mathrm{~m}^{3} / \mathrm{s}$ \\
\hline
\end{tabular}

Figure 4.5 shows a schematic of the individual fan performance test set-up, including all the measuring equipment used. The calibration of each device is described in Appendix B.

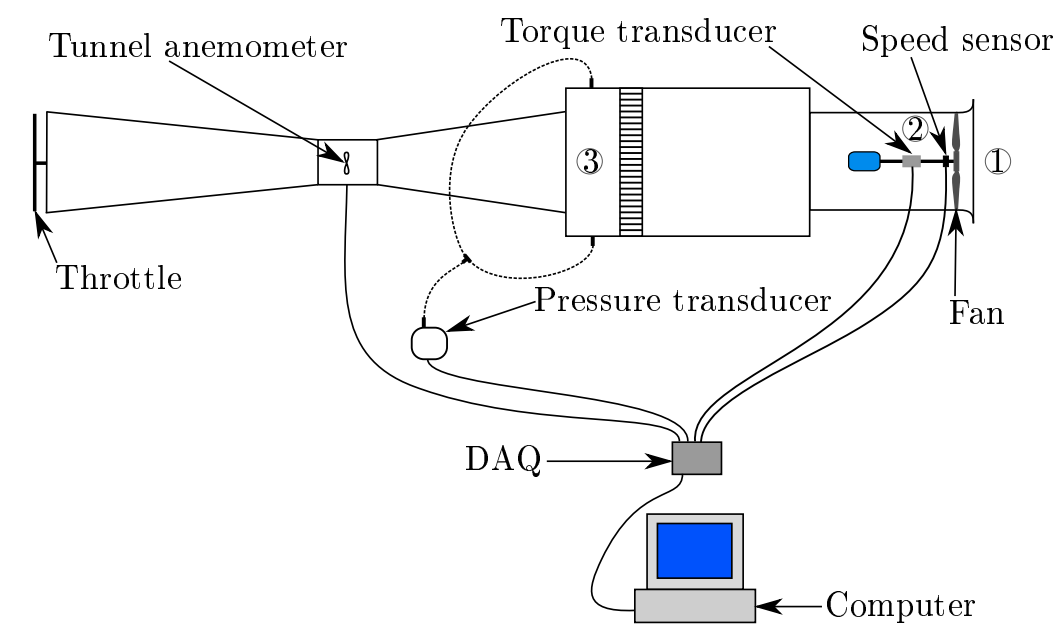

Figure 4.5: Individual fan performance experimental setup

Before testing a fan the blade angles were all set to within $0.2^{\circ}$ of a determined setting angle. The technique used for measuring the blade angles are shown in Figure 4.6. A jig was used to measure the angles for the N-blades, whereas the 630L-blade angles were measured by simply placing the protractor on the tip of the blade.

Once the blade angles had been set the fan was installed in the facility and the motor set to run at operating speed for ten minutes to allow all the bearings in the system to reach a steady state operating temperature. It was decided to test all the fans at $1000 \mathrm{RPM}$ in order to compare to the results of van der Spuy (2011). After the ten minutes had passed the motor was stopped and zero readings for all instrumentation recorded. Tests were then 


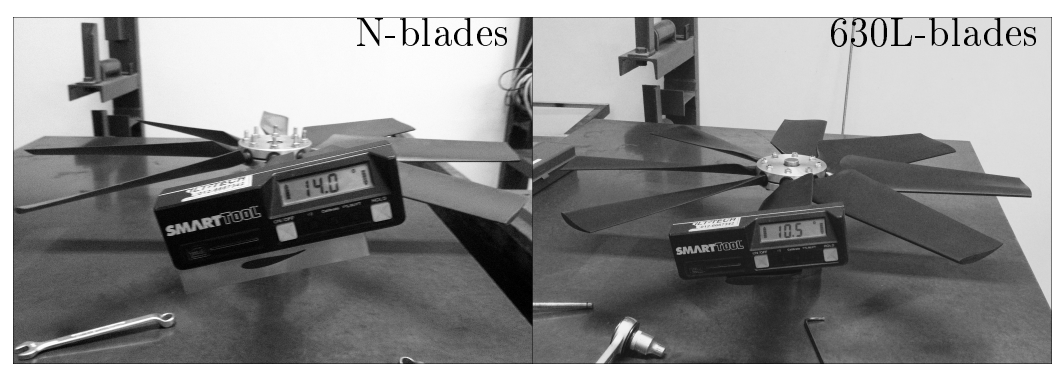

Figure 4.6: Fan blade angle setting techniques

conducted at various flow rates by adjusting the flow throttle at the tunnel outlet. At each throttle position the system was allowed to settle at the new steady state condition and readings were recorded. Once sufficient data points had been recorded a second set of zero readings were recorded. Finally the mechanical losses caused by friction in the bearings and couplings between the fan and the torque transducer were determined. This was achieved by measuring the torque with the fan removed and the motor running at the operating speed. This entire process was repeated at various blade angles until the fan performance curves intersected the operating point.

After the data was recorded the fan performance values could be determined by calculating the fan static pressure, power consumption and static efficiency values.

The fan static pressure is the total-to-static pressure rise between position 1 (atmospheric pressure) and position 2 in Figure 4.5. The static pressure is not measured at position 2 , however, but in the plenum chamber at position 3. The static pressure at position 2 is determined by taking into account the pressure loss between point 2 and 3 , as shown in the derivation below:

$$
\begin{aligned}
p_{\text {total } 3} & =p_{\text {total } 2}-\Delta p_{\text {loss }}-\Delta p_{\text {hex }} \\
\left(p_{s}+p_{\text {dyn }}\right)_{3} & =\left(p_{s}+p_{\text {dyn }}\right)_{2}-\Delta p_{\text {loss }}-\Delta p_{\text {hex }} \\
p_{s 2} & =p_{s 3}+p_{\text {dyn } 3}+\Delta p_{\text {loss }}+\Delta p_{\text {hex }}-p_{\text {dyn } 2}
\end{aligned}
$$

$\Delta p_{\text {loss }}$ is the pressure loss between position 2 and 3 and $\Delta p_{\text {hex }}$ is the pressure loss across the hexcore mesh. The fan static pressure would then be the pressure rise between position 1 and 2, and seeing as the total pressure at position 1 is atmospheric the fan static pressure is equal to the static gauge pressure at position 2:

$$
\begin{aligned}
p_{s f} & =p_{s 2(a b s)}-p_{t 1(a b s)} \\
& =p_{s 2(a b s)}-p_{a t m} \\
& =p_{s 2 \text { (gauge })}
\end{aligned}
$$

The power consumed by the fan is given by 


$$
P_{\text {fan }}=T_{\text {fan }} \omega=\left(T_{\text {measured }}-T_{\text {losses }}\right) \times\left(\frac{2 \pi}{60} N_{\text {fan }}\right)
$$

$T_{f a n}$ is the torque produced by the fan and is calculated by subtracting the measured losses (as described above), $T_{\text {losses }}$, from the measured torque, $T_{\text {measured. }} N_{\text {fan }}$ is the shaft speed measured by the speed sensor.

Finally the fan static efficiency is given by

$$
\eta=\frac{p_{s f} \times \dot{V}}{P_{f a n}}
$$

The final values are scaled to reference values of $1000 \mathrm{RPM}$ and $1.2 \mathrm{~kg} / \mathrm{m}^{3}$. A sample calculation which follows the procedure described above is shown in Appendix C.1.

\subsubsection{Multiple fan performance tests}

The multiple fan performance tests were conducted to determine the performance of a fan system when subjected to high cross-flow velocity conditions. Before the inlet chamber was attached for these tests it was necessary to first set the ideal operating point conditions.

The procedure started by varying the resistance of the outlet porous sheets (shown in Figure 4.3) by adding or removing plugs to ensure that the fans operate close to the operating point listed in Table 4.2. The flow rates were then recorded. Once the flow rates at the ideal operating point conditions had been recorded for each fan set, the inlet chamber was attached to the test tunnels and the system resistance kept constant to represent the actual ACSC system resistance. Tests were then performed at the infinite height position and the 5 different platform height positions by inserting the platform at the $4.5 \mathrm{D}_{\text {fan }}, 3.5 \mathrm{D}_{\text {fan }}, 2.5 \mathrm{D}_{\text {fan }}, 1.5 \mathrm{D}_{\text {fan }}$ and $1 \mathrm{D}_{\text {fan }}$ positions. Between platform adjustments the system was first allowed to settle before any data was recorded. As with the individual fan tests, zero readings as well as mechanical losses in the drive train were measured.

The calculation procedure shown in Appendix C.1 was followed to determine the flow rate of each fan at each platform height position. The system performance when subjected to increased cross-flow conditions is then expressed in terms of the volumetric effectiveness $\left(\dot{V} / \dot{V}_{i d}\right)$ as defined by Salta and Kröger (1995). The volumetric effectiveness $\left(\dot{V} / \dot{V}_{i d}\right)$ is the ratio between the system volumetric flow rate under certain operating conditions, compared to the system volumetric flow rate determined under ideal operating conditions (as described above). 


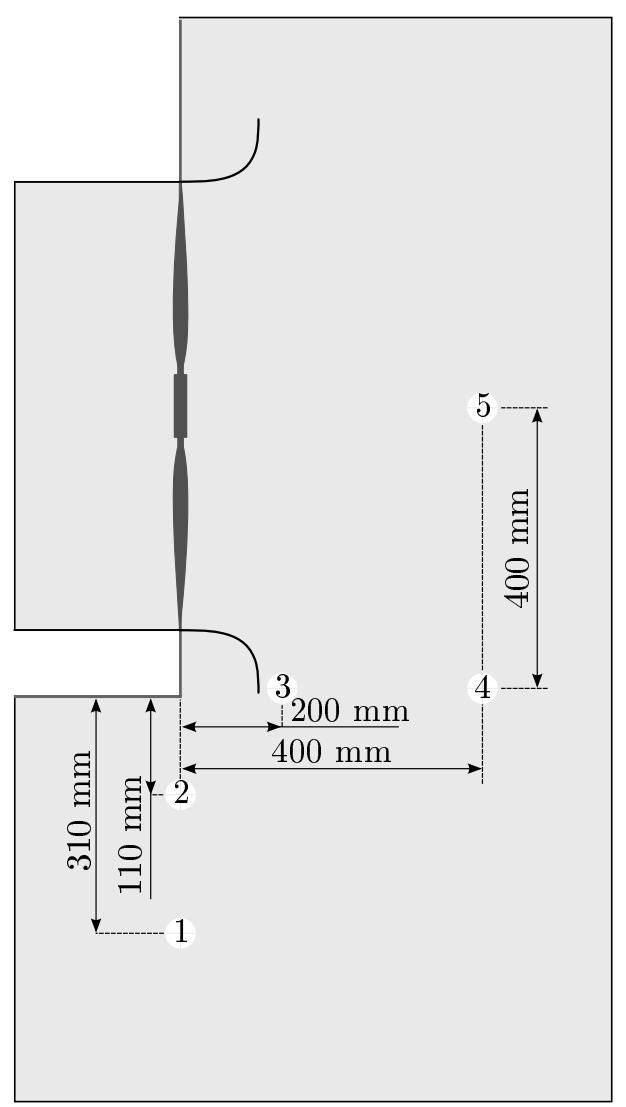

Figure 4.7: Velocity measurement locations

\subsubsection{Velocity measurements}

The flow conditions at the upstream side of the perimeter fan were determined by conducting velocity measurements at pre-determined locations. The resulting measured flow field vectors would provide insight into the effect of platform height on the behaviour of the flow upstream of the perimeter fan. The vectors would also be compared to vectors obtained by the numerical investigations to validate the numerical models and also investigate similarities between platform height positions and cross-wind conditions.

Five locations upstream of the perimeter fan were identified for flow velocity measurements. The locations are indicated in Figure 4.7. The velocity measurements were performed at three platform heights, including $3.5 \mathrm{D}_{\text {fan }}$, $2.5 \mathrm{D}_{\text {fan }}$, and $1.5 \mathrm{D}_{\text {fan }}$.

The velocity vectors were measured using a single $45^{\circ}$ inclined hot-film anemometer connected to a TSI IFA-100 flow analyser. The specifications and calibration procedure of the hot film anemometer are discussed in Appendix B.3.

At each location the anemometer was placed midway between the top and bottom sides of the inlet chamber and rotated through $180^{\circ}$ in $15^{\circ}$ intervals, 
and the output recorded at each orientation. The data was then used to determine the magnitude and direction of the velocity vector by employing a technique proposed by Menet et al. (1999). This technique is discussed in detail in Appendix B.3.

Substantial velocity measurements were also conducted by van der Spuy (2011) on three fan sets (including a N-N-N fan set-up) by employing particle image velocimetry (PIV) at three platform heights (infinite, $2.5 \mathrm{D}_{\text {fan }}$, and $\left.1 \mathrm{D}_{\text {fan }}\right)$. The results obtained by van der Spuy (2011) were used to verify the hot-film measurements obtained with the N-N-N fan system.

\subsection{Results and discussion}

\subsubsection{Individual fan performance}

The static pressure results of the experimental fans are shown in Figure 4.8 (Refer to Appendix F.1 for all the test results of each fan).

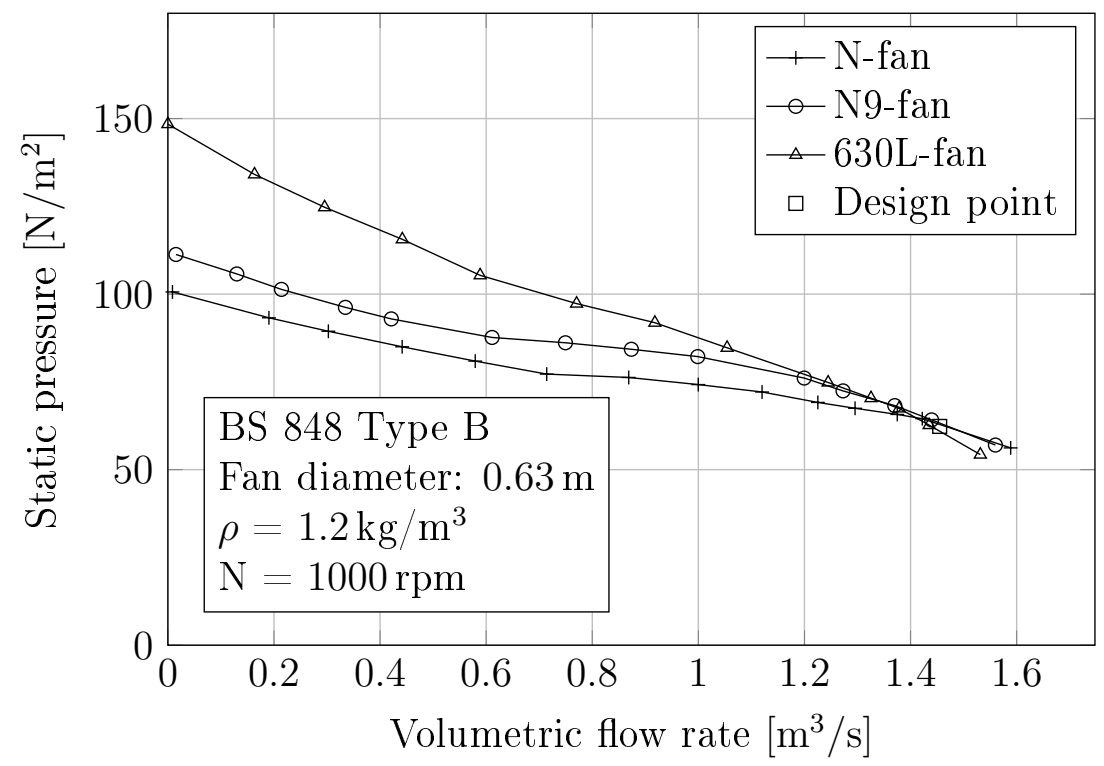

Figure 4.8: Fan static pressure experimental results

The blade angles of the three fans were all set to ensure that the fan performance curves pass through the chosen operating point. This can be seen in Figure 4.8. The system resistance of the test tunnel limited the flow rates that could be achieved by the experimental fans. Higher flow rates could, however, be produced by introducing a booster fan at the outlet of the test tunnel (which would then act as a negative system resistance). Since this investigation focuses on the reduction in flow rate due to distorted inlet flow, the use of a booster fan is not necessary. 
The difference in fan characteristics between the three fans can clearly be seen. The N- and N9-fans have relatively flat curves, with the N9-fan's pressure curve being slightly steeper than that of the N-fan. The 630L-fan however has a significantly steeper curve with higher fan static pressure values measured across the measured volumetric flow rate range. This result was expected due to the difference in solidity between the three fans. The 630L-fan has the highest solidity (calculated at mid-span) and would therefore exert a higher load on the fluid, which results in a higher static pressure rise over the fan when compared to the lower solidity $\mathrm{N}$ - and N9-fans. It should also be noted that whereas the $\mathrm{N}$ - and N9-fan share the same blade profile, the 630L-fan has a different blade profile (see Appendix A). This means that, although the difference in solidity has a definite effect on the fan characteristics, it would not be the only contributing factor.

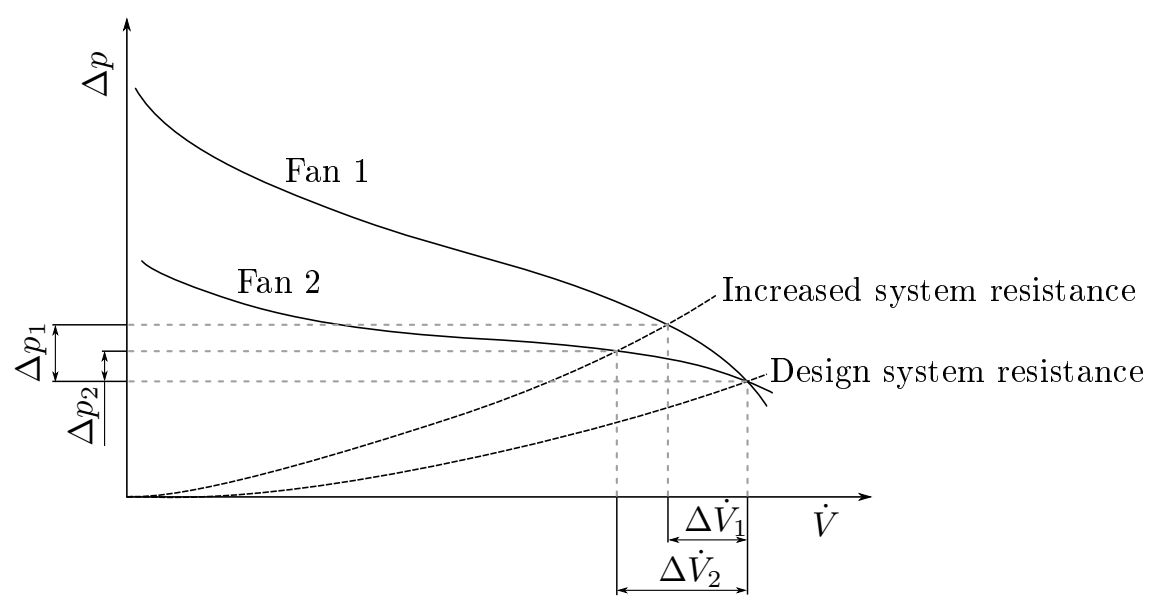

Figure 4.9: Fan characteristic curve comparison

The effect of the characteristic curve gradient becomes important when considering the operation of the fan in a dynamic system. As the system resistance is increased a fan with a steep characteristic curve would experience a smaller change in volumetric flow rate when compared to a fan with a relatively flat characteristic curve. This is illustrated in Figure 4.9 .

In an application where a stable operating volumetric flow rate is desired the fan with a steep characteristic curve would be more suitable. If, however the application requires less fluctuation in the operating pressure, a flatter characteristic curve would be beneficial.

The power consumption and static efficiency data of the three fans are shown in Figures 4.10 and 4.11 respectively. Again, a clear difference in static efficiency between the three fans can be seen across the tested range. The 630L-fan shows the highest static efficiency values across the measured range. The N9-fan again shows an improvement in static efficiency when compared 


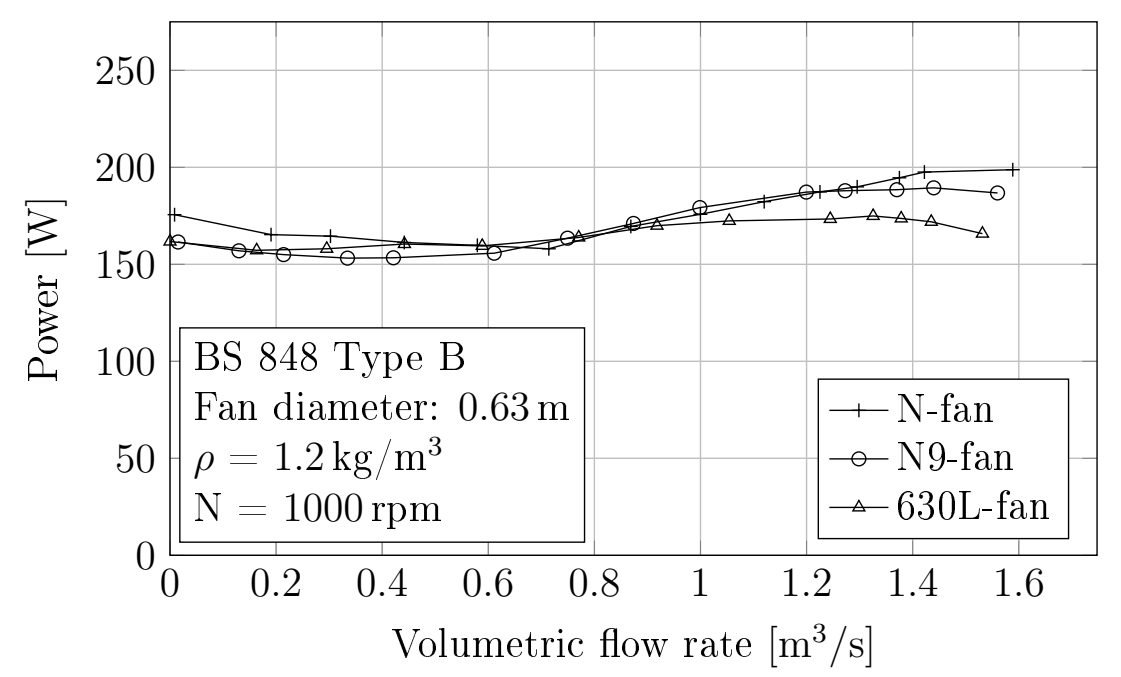

Figure 4.10: Fan power experimental results

with the $\mathrm{N}$-fan. The increase in efficiency is a result of a combination of higher static pressure values combined with smaller power consumption (as can be seen in Figure 4.10) shown by the N9-fan. The reduced power consumption shows that, although an extra blade has been added, the measured torque (which is used to determine the power consumption) has been reduced.

The differences in power consumption of the three fans are less pronounced when compared to the static pressure and efficiency differences. The 630Lfan power consumption data shows less fluctuation across the measured range when compared to the $\mathrm{N}$ - and N9-fans. At the higher measured flow rates the $\mathrm{N}$ - and N9-fan power consumption values increase and deviate from the values measured with the 630L-fan. When comparing the N- and N9-fans one would notice slightly higher power consumption values measured with the $\mathrm{N}$-fan at the lower and higher extremities of the measured flow range. In the middle part of the measured flow range between $0.6 \mathrm{~m}^{3} / \mathrm{s}$ and $1 \mathrm{~m}^{3} / \mathrm{s}$ the differences between the three fans are negligible.

At the operating point of $1.455 \mathrm{~m}^{3} / \mathrm{s}$ the difference in static efficiency between the N-fan and the 630L-fan is in the order of $7 \%$. At this point all of the variables used to calculate the static efficiency for the three fans have the same value, except for the torque values. This means that the difference in efficiency between the three fans are solely a result of the difference in torque measured. When considering the blade angles used for each fan the difference in the torque values measured makes sense. The setting angles for the $\mathrm{N}$-fan, $\mathrm{N} 9$-fan and $630 \mathrm{~L}$-fan are $14.2^{\circ}, 12.5^{\circ}$ and $10.5^{\circ}$ respectively. The larger setting angles (and consequently larger relative flow angles over the blades) cause higher drag forces experienced by the blades, which may result in higher torque values. Again it should be noted that the difference in the blade profiles and solidity also influences the drag forces and subsequently the measured torque. 


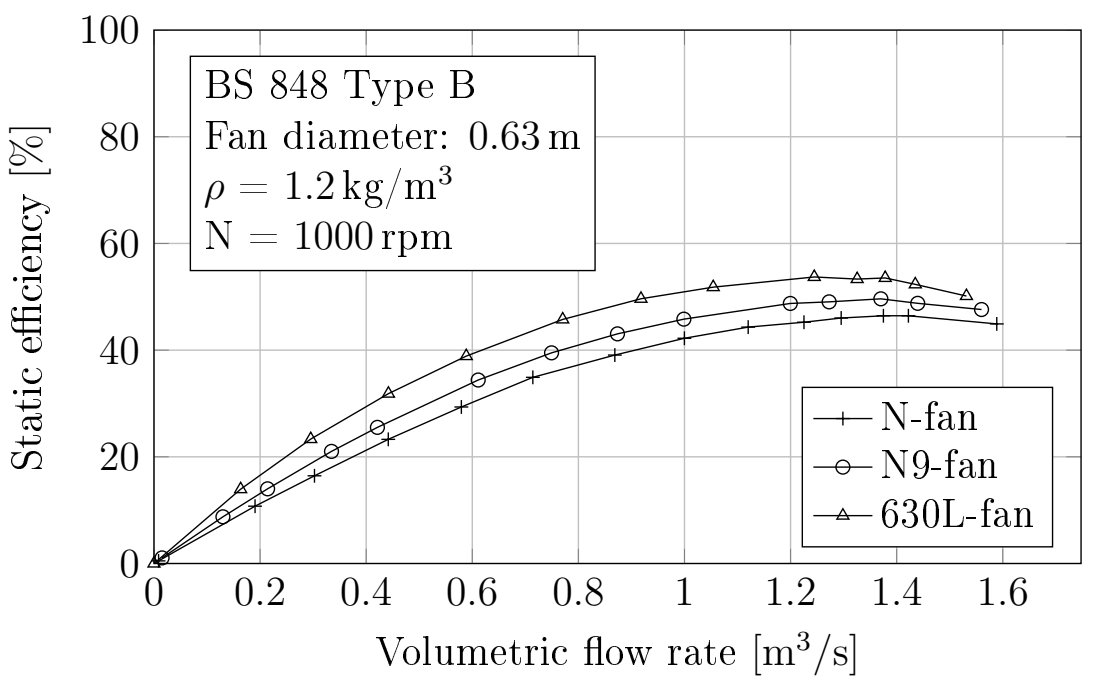

Figure 4.11: Fan static efficiency experimental results

The static efficiency peaks of the three fans appear at slightly different volumetric flow rate values. Table 4.3 lists the peak static efficiency values of the three fans. The N-fan's peak occurs closest to the operating flow rate, with the 630L-fan's peak furthest away. This shows that although the 630L-fan is operating at a higher static efficiency, it is not operating close to its peak static efficiency.

Table 4.3: Fan peak static efficiency values

\begin{tabular}{lrrr}
\hline Fan & N & N9 & 630L \\
\hline Peak static efficiency $(\%)$ & 46.4 & 49.6 & 53.9 \\
Volumetric flow rate $\left(\mathbf{m}^{3} / \mathbf{s}\right)$ & 1.42 & 1.37 & 1.24 \\
\hline
\end{tabular}

\subsubsection{Multiple fan performance}

Results of the variable platform experiments for the N-fan system are shown in Figure 4.12. The results are expressed in terms of the volumetric effectiveness and a dimensionless floor height number. The volumetric effectiveness of a fan unit is defined as the ratio of the actual flow through a fan unit installed in the test facility to the same free-standing unit operating with no inlet disturbances (Salta and Kröger, 1995). The dimensionless floor height number is defined as a ratio of the platform height to the fan diameter.

As the platform height is reduced the volumetric effectiveness of the fan system reduces. This reduction in volumetric effectiveness is caused by an increase in distorted inlet conditions, especially at the upstream periphery. 
The distorted inlet flow conditions are caused by an increase in cross flow which is induced by the inner fans. This effect is increased as the platform height is reduced, which reduces the inlet area.

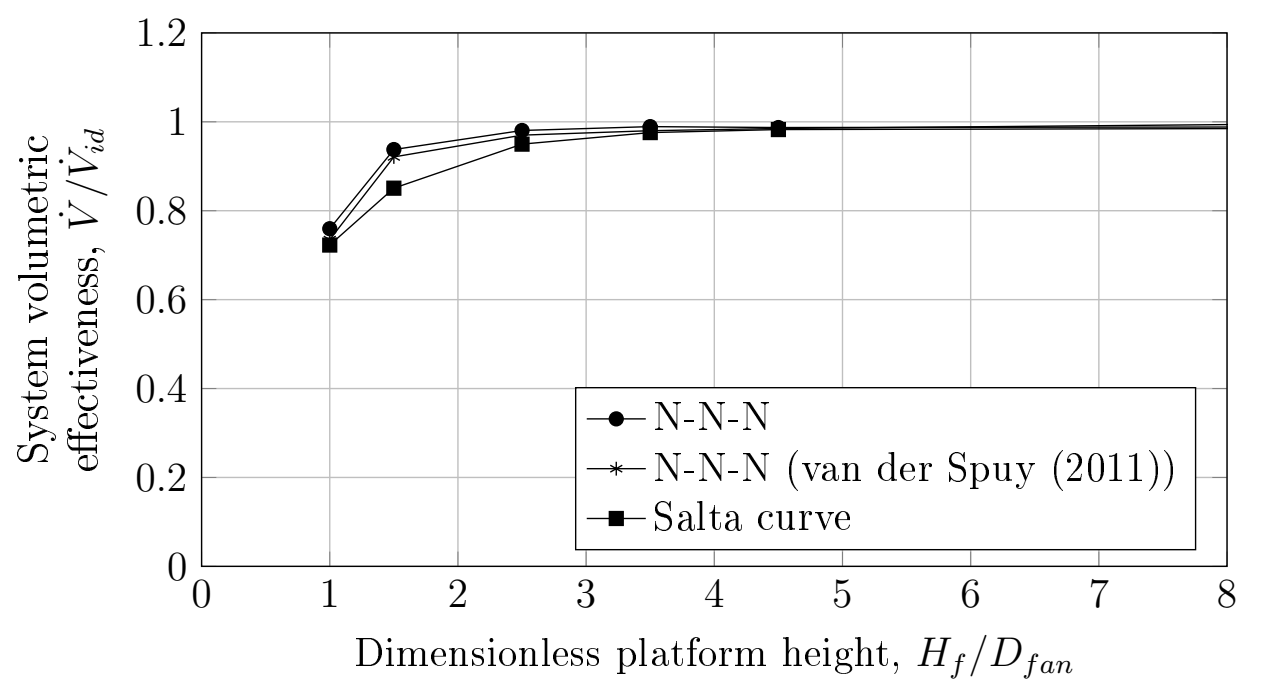

Figure 4.12: N-fan system variable platform height experimental results

Also included in Figure 4.12 are results of the $\mathrm{N}$-fan system as obtained by van der Spuy (2011) as well as the generic fan system curve published by Salta and Kröger (1995) (referred to as the Salta curve).

The results correlate well with the results obtained by van der Spuy (2011). The volumetric effectiveness as predicted by the Salta curve compares relatively well at most of the platform positions when compared to the results obtained with the N-fan system. A large discrepancy however exists at the $1.5 \mathrm{D}_{\text {fan }}$ platform height position with a difference in the order of $0.1 \mathrm{~m}^{3} / \mathrm{s}$. It should be noted that the results of Salta were obtained using an entirely different fan configuration.

Figure 4.13 shows the results of the variable platform height experiments for the N-, N9- and 630L-fan systems (refer to Appendix A for the properties of the fans used).

At the $4.5 \mathrm{D}_{\text {fan }}$ and $3.5 \mathrm{D}_{\text {fan }}$ platform height positions the three fan systems exhibit similar performance with only a slight drop in volumetric effectiveness shown by all three systems. At the lower platform height positions a distinctive difference can however be seen. The N9-fan system shows a slight improvement in volumetric effectiveness when compared to the N-fan system, especially at the lowest platform height position. The 630L-fan system shows the best performance at all platform heights, with a large improvement in volumetric effectiveness measured at the lowest platform height.

Table 4.4 shows the system volumetric effectiveness results at the lowest platform heights for the three fan systems. The N9- and 630L-fan systems 


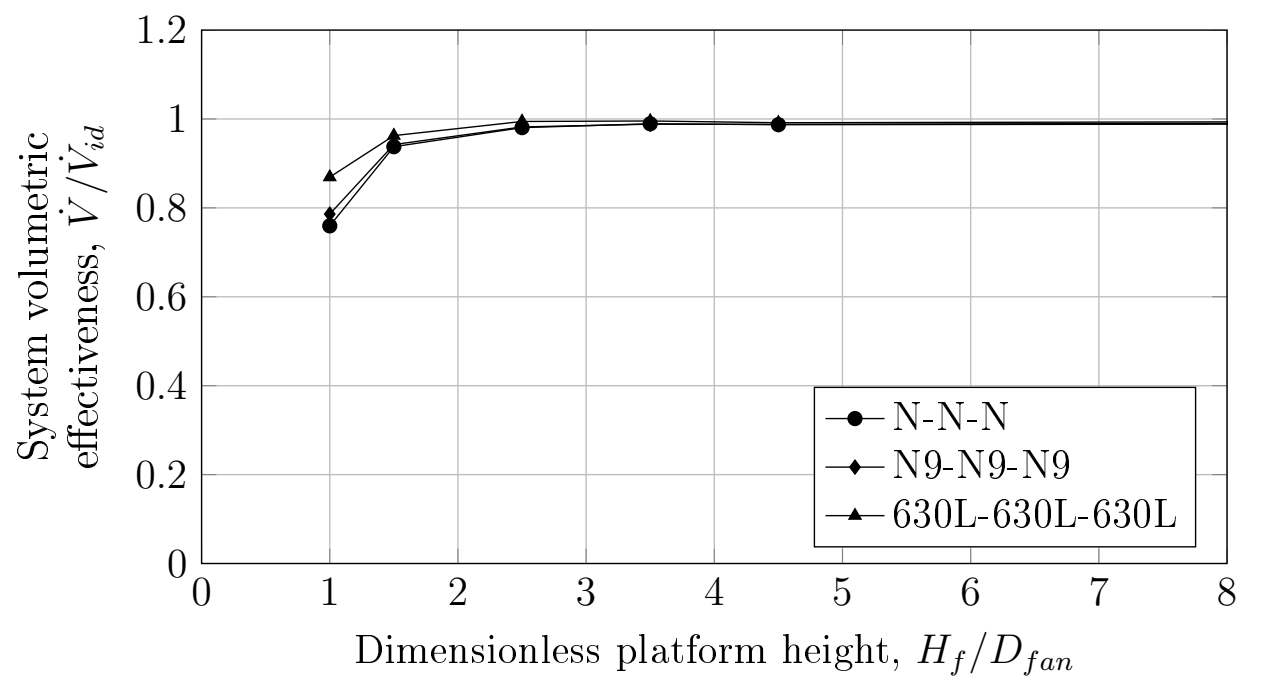

Figure 4.13: Effect of platform height on the system volumetric effectiveness of the N-, N9- and 630L-fan systems

show increases in volumetric effectiveness of $3.9 \%$ and $13.2 \%$, respectively, when compared to the $\mathrm{N}$-fan system. This shows that the higher solidity of the N9-fan and especially the 630L-fan results in smaller reductions in volumetric effectiveness under distorted inlet conditions.

Table 4.4: $1 \mathrm{D}_{\text {fan }}$ Platform height position system volumetric effectiveness results

\begin{tabular}{lrrr}
\hline Fan system & N & N9 & 630L \\
\hline Volumetric effectiveness & 0.76 & 0.79 & 0.86 \\
\hline
\end{tabular}

The effect of the edge fan performance on the overall system performance is shown in Figure 4.14 where the N9- and 630L-fan systems are compared to a 630L-N9-N9 fan configuration. The 630L-N9-N9 and 630L-fan systems show very similar performance with the 630L-fan system showing only slightly better volumetric effectiveness values than the 630L-N9-N9 fan system. A clear improvement in volumetric effectiveness of the N9-fan system (due to the 630Lfan installed in the edge fan position) is shown at the lowest platform height. This shows that the system performance is highly dependant on the edge fan's performance, especially at the lower platform height positions.

In Figure 4.15 the measured volumetric effectiveness of the edge fans are shown together with the volumetric effectiveness as calculated using empirical correlations derived by van der Spuy (2011). As with the system performance curves the largest difference occurs at the lowest platform height.

The N- and N9-fans show similar measured volumetric effectiveness values at all of the platform height positions except at the lowest position where 


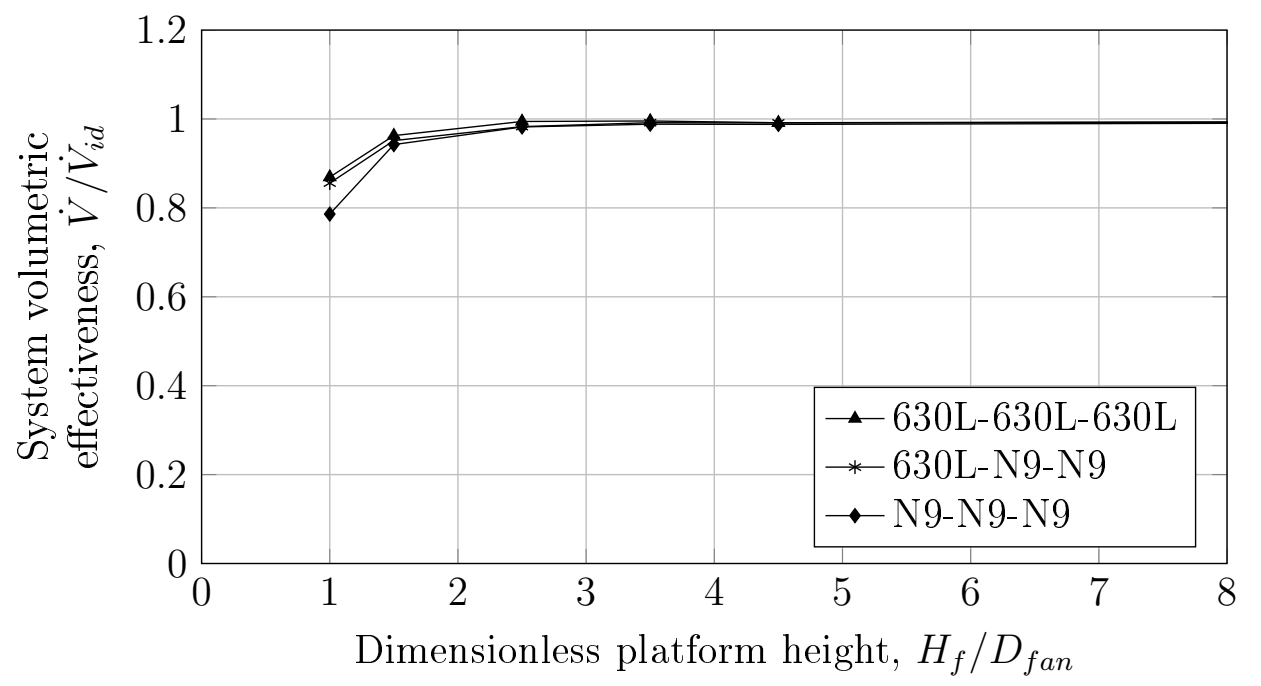

Figure 4.14: Effect of platform height on the system volumetric effectiveness of the 630L- ,N9- and 630L-N9-N9 fan systems

the N9-fan shows an improvement in volumetric effectiveness. The 630L-fan again shows the highest volumetric effectiveness values across the entire range and also shows a significant improvement in effectiveness at the lowest platform height position. This improvement at the lowest platform height explains how the system volumetric effectiveness can be improved by simply selecting a higher solidity edge fan, as shown in Figure 4.14. Results from the experimental investigations conducted by van der Spuy (2011) also showed an increase in system volumetric effectiveness where high solidity edge fans were implemented.

The empirical correlations derived by van der Spuy (2011) uses fan properties such as the hub-to-tip ratio and solidity together with the dimensionless platform height to calculate a loss factor which is then used to predict the fan volumetric flow rate. The predicted volumetric flow rate was divided by the ideal volumetric flow and plotted with the measured volumetric effectiveness values. The empirical correlations compare well with the N-and N9-fans, especially at the lowest platform height. The volumetric effectiveness of the 630L-fan is slightly underestimated by the correlations.

\subsubsection{Velocity measurements}

The results of the velocity measurements are shown in Figures 4.16, 4.17 and 4.18. The results are listed in Appendix F.3. The velocity vectors at each position are shown for each platform height.

The vectors at position 1 and 2 show very little change in flow angle between platform height positions. The main characteristic at these two positions are an increase of flow velocity at lower platform heights caused by a decrease in 


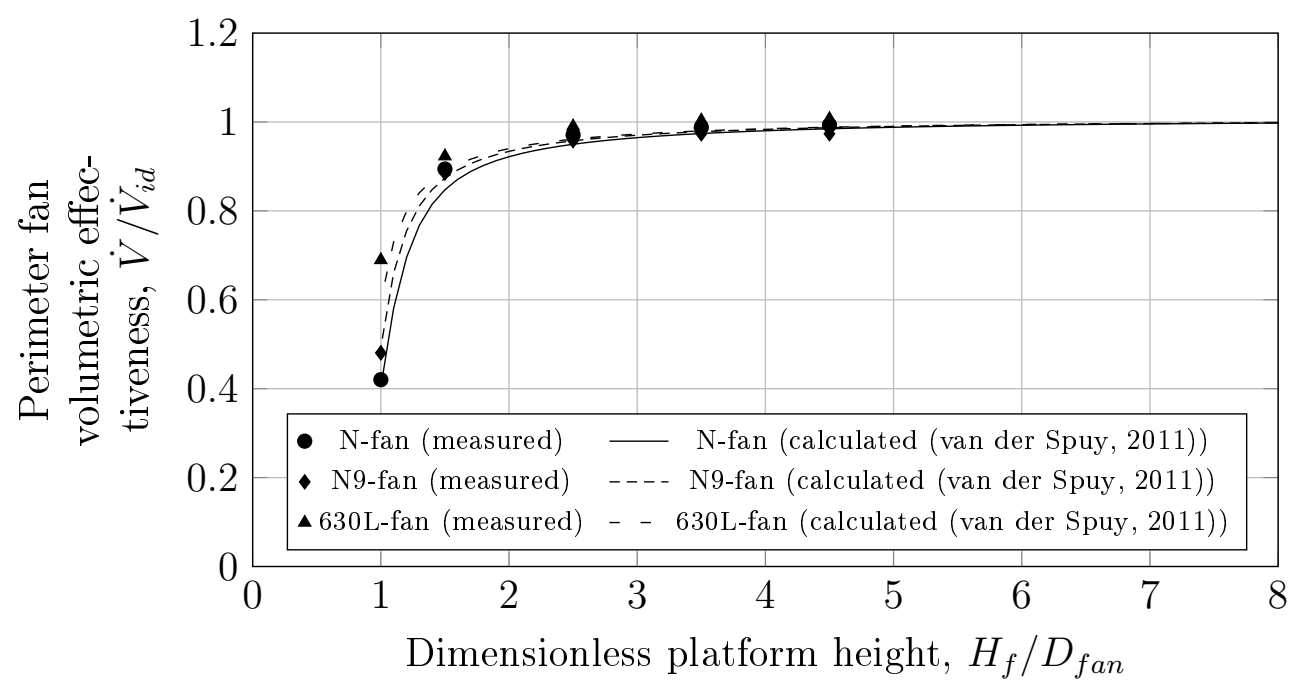

Figure 4.15: Effect of platform height on the perimeter fan volumetric effectiveness

the inlet flow area. A slight decrease in the flow angle (measured as indicated) at lower platform heights can be noticed in some of the cases. The decrease in the flow angle could be caused by the increase in the flow velocity of the flow coming from the outer area next to the perimeter fan (which is predominantly orientated in the positive $\mathrm{y}$-direction).

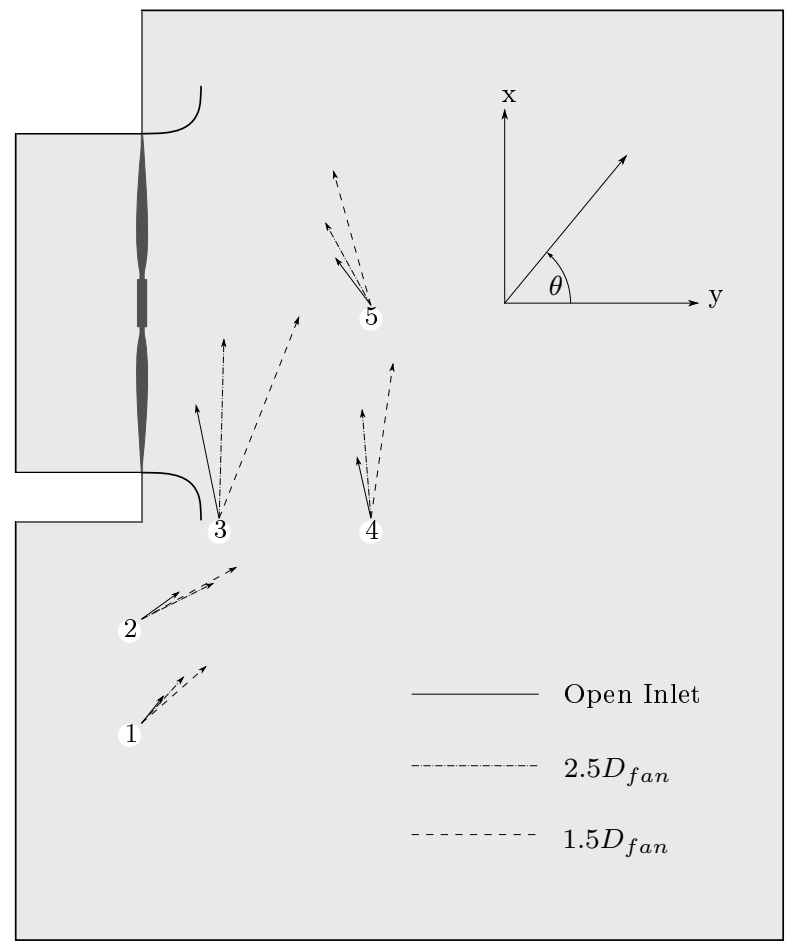

Figure 4.16: N-N-N fan system velocity vectors for various platform heights 
The close proximity of position 3 to the fan results in the largest velocity magnitudes being measured at that position at all platform heights. A definite trend in the flow angle can be seen between platform heights for all the fan systems. The flow angle significantly decreases (by as much as $43.7^{\circ}$ for the 630L-fan system) as the platform height is reduced. With an open inlet the flow direction at position 3 is already showing the presence of cross-flow at the perimeter fan caused by flow being drawn towards the two inner fans. At the $2.5 \mathrm{D}_{\text {fan }}$ platform height the flow angles are reduced to close to $90^{\circ}$ as the magnitude of the cross-flow velocity is increased. At the $1.5 \mathrm{D}_{\text {fan }}$ platform position the flow angle is reduced below $90^{\circ}$, with the flow trend moving away from the fan inlet. van der Spuy (2011) noticed that with the increased crossflow velocity the flow separates at the bell mouth edge causing recirculation and with it the flow is diverted away from the fan.

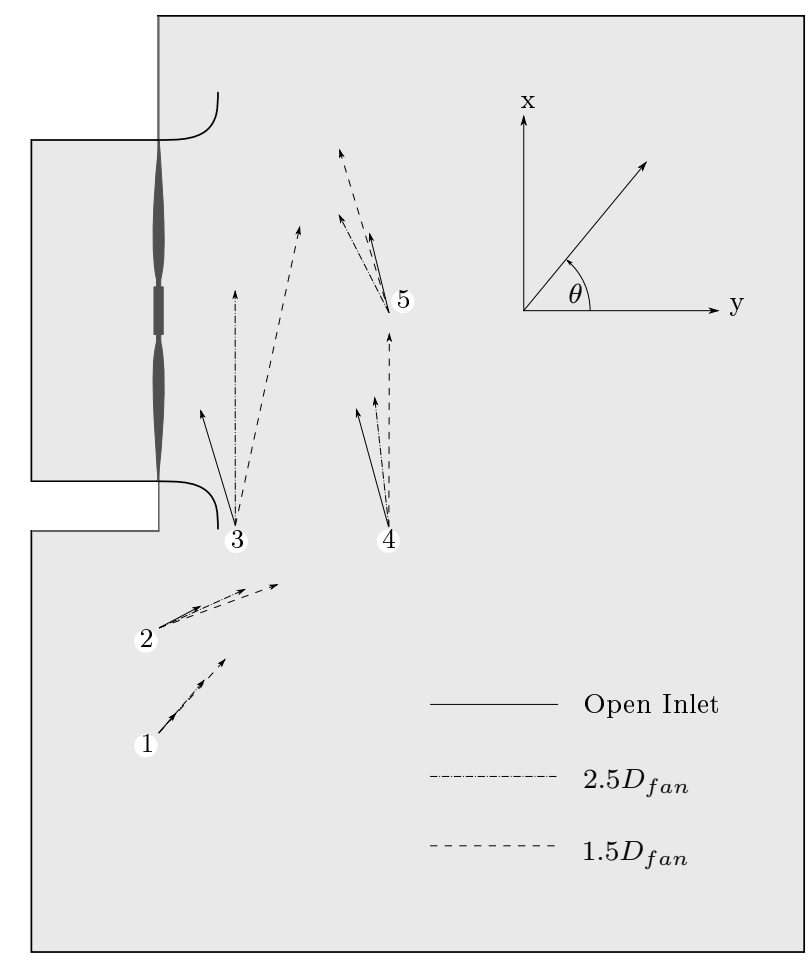

Figure 4.17: N9-N9-N9 fan system velocity vectors for various platform heights

The flow patterns measured at position 4 shows similar behaviour to that of position 3. Flow angles at the open inlet case are very similar to the angles measured at position 3, and again, as the platform height is reduced, the flow angle decreases, albeit to a lesser extent than at position 3. It would seem as if the recirculation zone at the inlet of the perimeter fan also influences the flow behaviour further upstream at position 4 .

The vectors at position 5 show that the flow changes direction and is moving towards the inner side of the perimeter fan after being diverted in the positive 


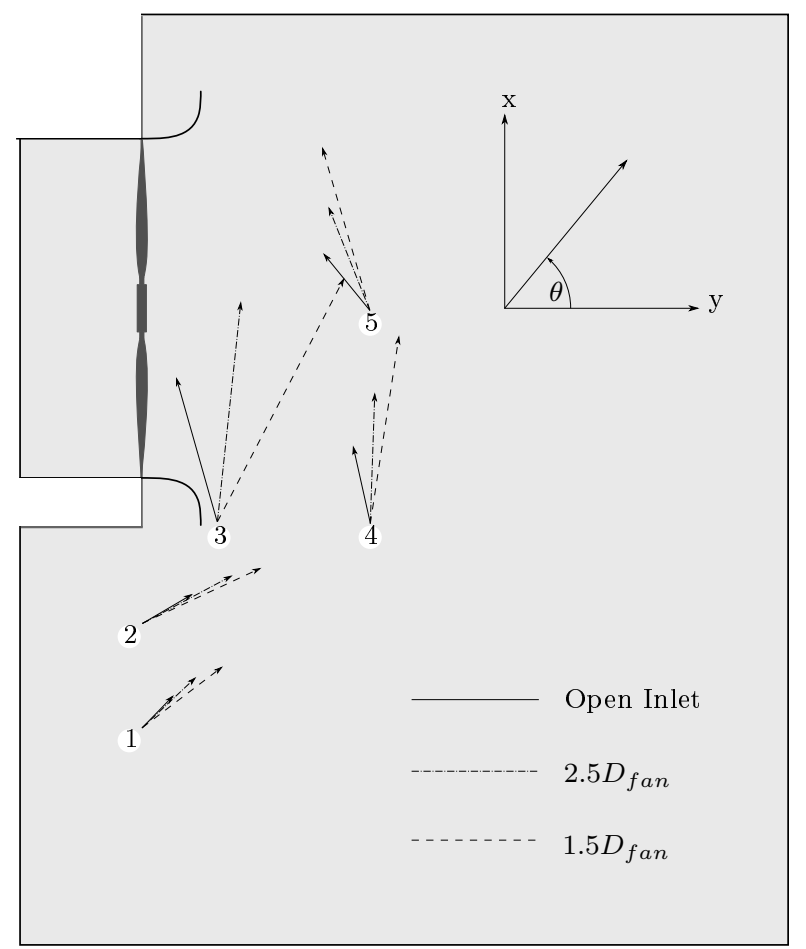

Figure 4.18: 630L-630L-630L fan system velocity vectors for various platform heights

y-direction at positions 3 and 4 . As with positions 3 and 4 the flow angles are reduced as the platform height is reduced indicating the presence of cross-flow conditions in front of the perimeter fan.

The velocity vector measured at position 5 for the open inlet case with the N9-fan system does not correlate well with the same vectors measured for the other fan systems. A difference of $\pm 25^{\circ}$ was calculated. This could have been caused by faulty sensor operation or measurement error. 


\section{Chapter 5}

\section{Numerical investigation}

For this study CFD models were created for the experimental test facility and for a simplified, full scale ACSC. This section will discuss the preparation and execution of these CFD simulations. The complete process will be discussed, including geometry layout, mesh information, boundary conditions, turbulence modelling, discretization and solver settings. Finally the results will be discussed and compared to, where available, experimental and analytical results.

\subsection{CFD theory}

\subsubsection{Governing equations}

For this study the computational fluid dynamics (CFD) simulations were performed using ANSYS Fluent version 14.0. Fluent incorporates a finite volume method to iteratively solve a set of discretised equations. The governing equations of fluid flow is based on the conservation of mass, momentum and energy.

The steady state, three dimensional governing equations can be listed as: Continuity Equation:

$$
\operatorname{div}(\rho \mathbf{u})=0
$$

Momentum Equation (expressed in tensor notation):

$$
\rho\left(u_{j} \frac{\partial u_{i}}{\partial x_{j}}\right)=-\frac{\partial p}{\partial x_{i}}+\mu \frac{\partial^{2} u_{i}}{\partial x_{j} \partial x_{j}}+S_{i}
$$

Energy-Equation:

$$
\operatorname{div}(\rho i \mathbf{u})=-p \operatorname{div} \mathbf{u}+\operatorname{div}(k \operatorname{grad} T)+\boldsymbol{\Phi}+S_{e}
$$

The velocity vector $\mathbf{u}$ in the equations above is expanded as $\mathbf{u}=u+v+w$, where $u, v$, and $w$ are the velocities in the $x, y$, and $z$ directions respectively.

$S_{i}$ and $S_{e}$ are source terms which are used as placeholders for external momentum or energy sources. Examples of elements for which such source terms 
are used include porous zones, pressure jump functions (for fan modelling), or heat exchangers.

\subsubsection{Discretization and solver settings}

The finite volume method used by Fluent divides the domain into discrete control volumes. The governing equations described above are converted to a set of discretised equations which could then be applied to each control volume.

Discretization yields:

$$
\sum_{f=1}^{N_{f a c e s}}\left(\rho_{f} \phi_{f} \mathbf{u}_{f}\right) \cdot A_{f}=\sum_{f=1}^{N_{f a c e s}}\left(\Gamma_{f} \operatorname{grad} \phi_{f}\right) \cdot A_{f}+S_{\phi} V
$$

where $f$ represents a CV face index. The parameters in equation (5.4) therefore hold the values at the faces of the CV.

Several schemes exist which describe processes for calculating $\phi$ based on the value of this parameter at surrounding nodes. For this study first- and second-order upwind differencing schemes were chosen due to its stability and ability to provide realistic results. These schemes take into account the flow direction when determining the value at a cell face.

The first-order upwind differencing scheme is more stable than the secondorder upwind differencing scheme and performs better when working with lower grid resolution. It is however less accurate, thus where a high resolution grid could be afforded, the second-order upwind differencing scheme was used.

Previous numerical investigations of full-scale ACSCs conducted by van Rooyen (2007), Owen (2010) and Louw (2011) utilised the first-order upwind differencing scheme.

\subsubsection{Turbulence modelling}

The occurrence of random velocity fluctuation in a flow field is known as turbulence. Turbulence occurs in most flows encountered in engineering. These fluctuations can be of very small scale and high frequency, which makes them too computationally expensive to simulative directly.

To account for turbulence the governing equations are modified to contain additional unknown variables. Various turbulence models exist, which are used to calculate these added unknown variables based on known values. The choice of which turbulence model to use is dependent on the physics associated with the problem, the established practice for a specific class of problem, the level of accuracy required, the available computational resources and time constraints (Fluent, 2009).

For this study the realizable $\mathrm{k}-\varepsilon$ turbulence model is used. The realizable $\mathrm{k}-\varepsilon$ model is based on the standard $\mathrm{k}-\varepsilon$ model which is known for its robustness, 
economy and reasonable accuracy. The realizable $\mathrm{k}-\varepsilon$ turbulence model however has shown substantial improvements over the standard model. Studies have shown that the realizable model provides superior performance in flows characterised by complex secondary flow features and flow separation (Shih et al., 1995).

Louw (2011), Owen (2010) and van Rooyen (2007) also used the realizable $\mathrm{k}-\varepsilon$ turbulence model for modelling turbulence when investigating the flow surrounding ACSCs.

\subsubsection{Boundary conditions}

To solve the set of governing equations it is necessary to specify boundary conditions. It is important to specify the correct combination of boundary conditions to ensure a realistic solution. The types of boundary conditions used in this study is discussed below:

\section{Wall}

A wall represents a solid surface in the flow domain. Wall boundary conditions are characterised by the no-slip condition, but Fluent also allows the user to specify the shear stresses at the surface. By specifying zero shear stress in all directions it is thus possible to specify a 'slip wall' boundary condition.

\section{Velocity}

A flow velocity and direction is specified at a boundary of the domain. Other parameters such as temperature, initial static pressure and turbulence should also be specified. The velocity profile could also be specified (such as a wind profile). The static pressure at the boundary is adapted throughout the simulation to comply with the specified flow velocity.

\section{Pressure}

A pressure boundary condition specifies the total or static pressure at a boundary and is used when the flow velocity at that boundary is unknown. It could also be used to define a 'free' boundary in external or unconfined flows (Fluent, 2009). Pressure boundaries can be located at either the inlet (total pressure) or outlet (static pressure) of the flow domain. An inlet pressure boundary condition should specify additional values such as the flow direction, temperature and turbulence parameters. An outflow pressure boundary condition uses a static pressure value at the outlet and extrapolates all other flow quantities from the interior flow. 'Backflow' parameters should also be specified in case the flow direction is reversed at the outlet.

\section{Interior}

Interior boundaries are surfaces/faces inside the flow domain which has 
no effect on the flow. Interior faces are used by the user as a monitoring surface.

Fan

Fluent's fan boundary condition requires the user to provide a fan staticto-static pressure jump function. This function is used to calculate a discontinuous static pressure rise across the fan surface based on the normal component of the flow velocity immediately upstream of the fan surface. The static pressure increase is obtained by introducing an appropriate source term into the momentum equation.

\section{Radiator}

The radiator boundary condition simulates a heat exchanger by allowing the user to specify a pressure drop and/or heat transfer coefficient function based on the normal flow velocity.

\section{Porous Zone}

A porous zone boundary condition incorporates an empirically determined flow resistance in the assigned region. The resistance is modelled by adding a momentum sink term to the governing momentum equations.

\section{Outlet Vent}

An outlet vent boundary condition represents an outlet with a flow resistance. It is similar to a regular pressure outlet boundary condition, with the addition of a non-dimensional loss coefficient which should be specified. The pressure loss is proportional to the dynamic head of the fluid.

\section{Symmetry}

Symmetry boundaries are used where the physical geometry, as well as the expected flow/thermal patterns are symmetrical around a specific plane. Symmetry boundaries are mainly used to reduce the size of a computational model. Fluent assumes a zero flux of all quantities across a symmetry boundary (Fluent, 2009).

\subsection{Multiple fan facility}

This section will discuss the CFD models used for the multiple fan test facility simulations. The geometry, mesh, boundary conditions and numerical models used will be discussed. Finally the results will be presented and compared to experimental multiple fan test results. 


\subsubsection{Single fan unit}

A single fan CFD model was created to simulate the single fan tests as performed in the experimental procedure. The model also served to determine the accuracy of the numerical fan models used in the CFD simulations.

\subsubsection{Geometry and mesh}

A three dimensional model of the single fan test tunnel, as shown in Figure 4.5. was created. Figure 5.1 shows a sketch of the model geometry.

The same geometry could be used for all three fans since the hub diameters and lengths are all the same (see Appendix A). A $3 \mathrm{~m}$ cubic inlet zone was added in front of the test tunnel with an inlet face on one side and frictionless walls on the other sides. The bell mouth inlet was created by revolving a profile sketch as a thin wall inside the inlet zone. The fan is represented by a surface at the inlet of the tunnel. The fan hub and motor were also included in the domain by subtracting the solid bodies from the geometry. Inside the plenum chamber the hex-core mesh was modelled by isolating a section in the geometry which could then be modelled in Fluent as a porous zone.

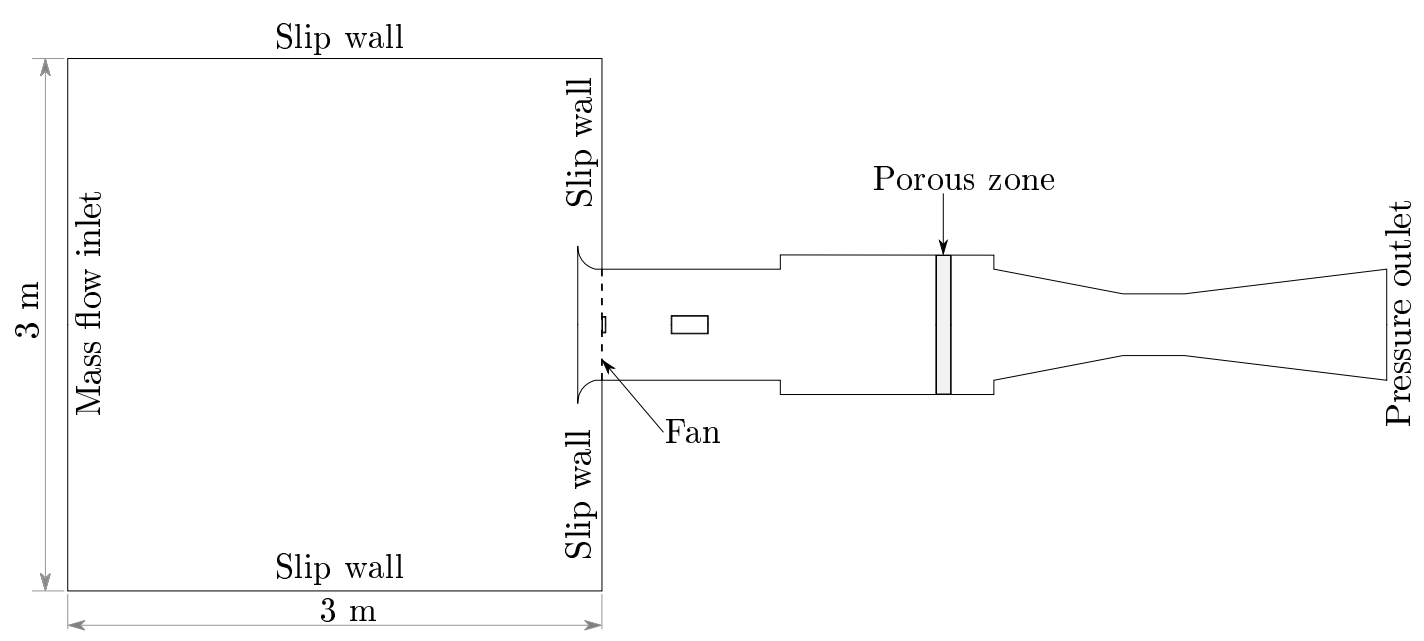

Figure 5.1: Single fan geometry and boundary conditions

The meshing process was performed using the tetrahedral elements available in the ANSYS Meshing interface. An advanced size function was used to refine the mesh near curved surfaces and walls subjected to control parameters such as minimum and maximum element size, maximum face size, growth rate and proximity accuracy. This ensured that the mesh resolution conformed to complexities and walls in the flow domain. Additional mesh sizing settings were specified in regions where complex flow patterns were expected. Figure 5.2 shows the computational mesh. 


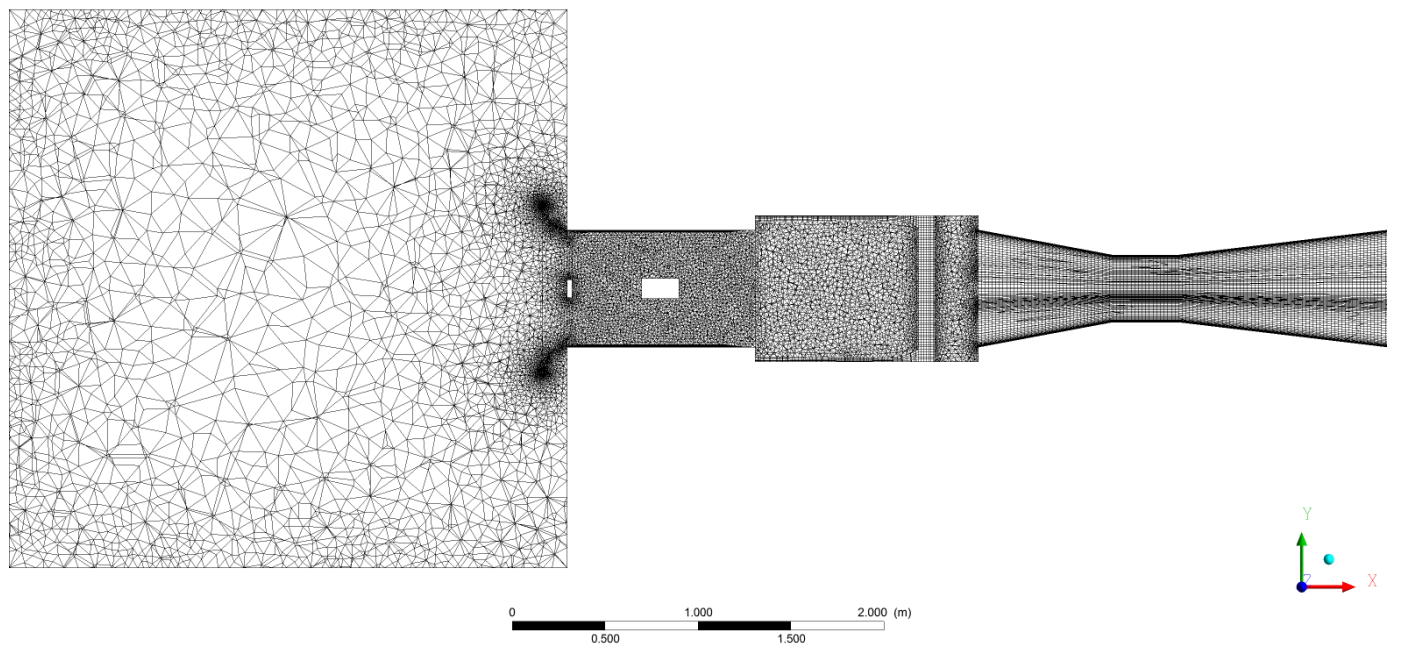

Figure 5.2: Single fan unit mesh

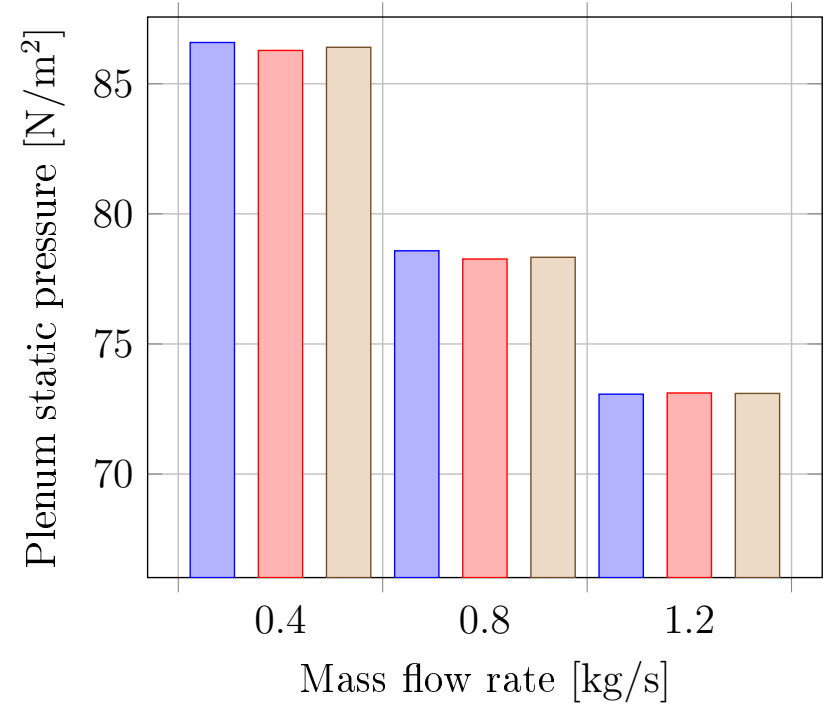

$\square \square$ Coarse $\left(0.423 \times 10^{6}\right.$ cells $) \square \square$ Medium $\left(1.563 \times 10^{6}\right.$ cells $)$ प Fine $\left(3.1 \times 10^{6}\right.$ cells $)$

Figure 5.3: Single fan CFD model mesh dependency results

The original mesh consisted of $1.563 \times 10^{6}$ cells. To investigate the effect of mesh resolution on simulation results two additional mesh resolutions were created. The mesh sizing settings were reduced and increased to create fine and coarse mesh resolutions respectively. A coarse mesh consisting of $0.423 \times 10^{6}$ cells and a fine mesh consisting of $3.1 \times 10^{6}$ cells were created. Three different flow rates were simulated with each mesh. The plenum static pressure was used to compare the simulation results. Figure 5.3 shows the results of the mesh dependency study. The difference in results obtained when using the 
three mesh resolutions are negligible. The medium and fine mesh results are almost identical with a maximum difference of $0.12 \mathrm{~N} / \mathrm{m}^{2}$ obtained at a mass flow rate of $0.4 \mathrm{~kg} / \mathrm{s}$. Despite the good results obtained by the coarse mesh, the original (medium) mesh was chosen due to its superior resolution at critical zones in the domain. Finally, to reduce the number of cells, the mesh was converted to a polyhedra structure in Fluent. The results obtained by using the polyhedra mesh were within $2 \%$ of the results obtained with the original mesh with a reduced cell count of $0.858 \times 10^{6}$ cells.

\subsubsection{Fan models}

Fluent's pressure jump boundary condition was used to model the fans. This method was favoured due to its simplicity and relatively low mesh resolution requirement(when compared to other fan modelling methods) which is especially significant when modelling the full-scale ACSC facility. It is also the model used by previous investigations (Louw, 2011).

The pressure jump model (PJM) is a simplified fan model that applies a discontinuous static pressure rise across the fan surface by means of a momentum source term in the main flow direction. The value for the pressure rise is provided by a static-to-static pressure function which is derived from experimental data. The fan static pressure obtained from the experimental procedure is actually a total-to-static pressure value and should be converted to a static-to-static pressure value by adding the dynamic pressure at the inlet of the fan. Appendix $\mathrm{D}$ details this procedure.

The fan static pressure results obtained from the experimental data were used to derive third order static-to-static pressure polynomial functions for the PJM. Table 5.1 lists these polynomials for the three fans listed in Appendix A.

Table 5.1: Pressure jump fan polynomials

\begin{tabular}{ll}
\hline N-fan & $-0.527 v^{3}+4.993 v^{2}-16.982 v+101.3$ \\
N9-fan & $-0.846 v^{3}+6.995 v^{2}-21.471 v+113.1$ \\
630L-fan & $-0.762 v^{3}+7.072 v^{2}-31.649 v+151.6$ \\
\hline
\end{tabular}

\subsubsection{Boundary and cell zone conditions}

The boundary conditions used in the numerical model is listed in Table 5.2 .

A mass flow inlet condition was selected since it provides a way to control the flow rate through the system. An alternative method of controlling the flow rate would be to induce a pressure inlet condition with an outlet vent boundary condition, and then vary the flow rate by adjusting the outlet vent resistance. The turbulence intensity and length scale values are the same 
Table 5.2: Single fan model boundary and cell zone values

\begin{tabular}{lll}
\hline $\begin{array}{l}\text { Boundary/Zone } \\
\text { name }\end{array}$ & Condition & Value(s) \\
\hline Inlet & Mass flow inlet & $\begin{array}{l}\text { Mass flow range }=0 \mathrm{~kg} / \mathrm{s} \rightarrow 1.8 \mathrm{~kg} / \mathrm{s} \\
\text { Turbulence intensity }=3 \% \\
\text { Turbulence length scale }=0.02 \mathrm{~m}\end{array}$ \\
\hline Inlet chamber & Wall (Zero-slip) & Wall shear $=0 \mathrm{~N} / \mathrm{m}^{2}$ \\
walls & & See Table 5.1 \\
\hline Fan face & Fan & Rotational speed $=104.72 \mathrm{rad} / \mathrm{s}$ \\
\hline Fan hub wall & Wall (Rotating) & Inertial resistance factor, $C_{x}=2.442 \mathrm{~m}^{-1}$ \\
\hline Hex-core mesh & Porous zone & Viscous resistance factor, $1 / \alpha_{x}=$ \\
& & $1173168 \mathrm{~m}^{-2}$ \\
& & $C_{y}, C_{z}, 1 / \alpha_{y}$, and $1 / \alpha_{z} \quad \mathrm{multiplied} \mathrm{by}$ \\
& & $1 \times 10^{3}$ \\
\hline Outlet & & Static pressure $=0 \mathrm{~N} / \mathrm{m}^{2}$ \\
\hline
\end{tabular}

as used by van der Spuy (2011). van der Spuy (2011) verified the value for turbulence intensity by conducting hot-film measurements upstream of the fan.

The hex-core mesh located in the plenum chamber was modelled using Fluent's porous zone cell condition. van der Spuy (2011) measured the pressure loss over the hex-core mesh at various flow rates and could then fit a second order polynomial to the data. The inertial and viscous resistance values could then be calculated by applying the following equation (Fluent, 2009)

$$
\Delta p=\left(\frac{\mu}{\alpha_{i}} \Delta n_{i}\right) v+\left(\frac{1}{2} C_{i} \rho \Delta n_{i}\right) v^{2}
$$

The inertial $\left(C_{i}\right)$ and viscous $\left(1 / \alpha_{i}\right)$ resistance factors were determined from the coefficients of the second order pressure loss polynomial function.

\subsubsection{Simulation results}

Simulations were conducted with each fan model at various flow rates, as listed in Table 5.2. The air properties were specified with a density of $1.2 \mathrm{~kg} / \mathrm{m}^{3}$ and viscosity of $1.789 \times 10^{-5} \mathrm{~kg} / \mathrm{ms}$.

The results of the simulations were compared to experimental results by comparing the fan static pressure vs. volumetric flow rate curves. A surface plane was created in Fluent from which the plenum static pressure values were extracted. The location of this plane coincides with the location of the plenum pressure ports in the experimental facility (see Figure 4.5). As with the experimental procedure, equation (4.1) was used to calculate the fan static pressure using the simulation plenum static pressure and volumetric flow values (following the procedure shown in Appendix C.1). 
The fan static pressure CFD simulation results are shown for each fan. The experimental static pressure results are also plotted for comparison with the CFD results. The simulation results of the N-, N9-, and 630L-fan are shown in Figures 5.4, 5.5, and 5.6 respectively.

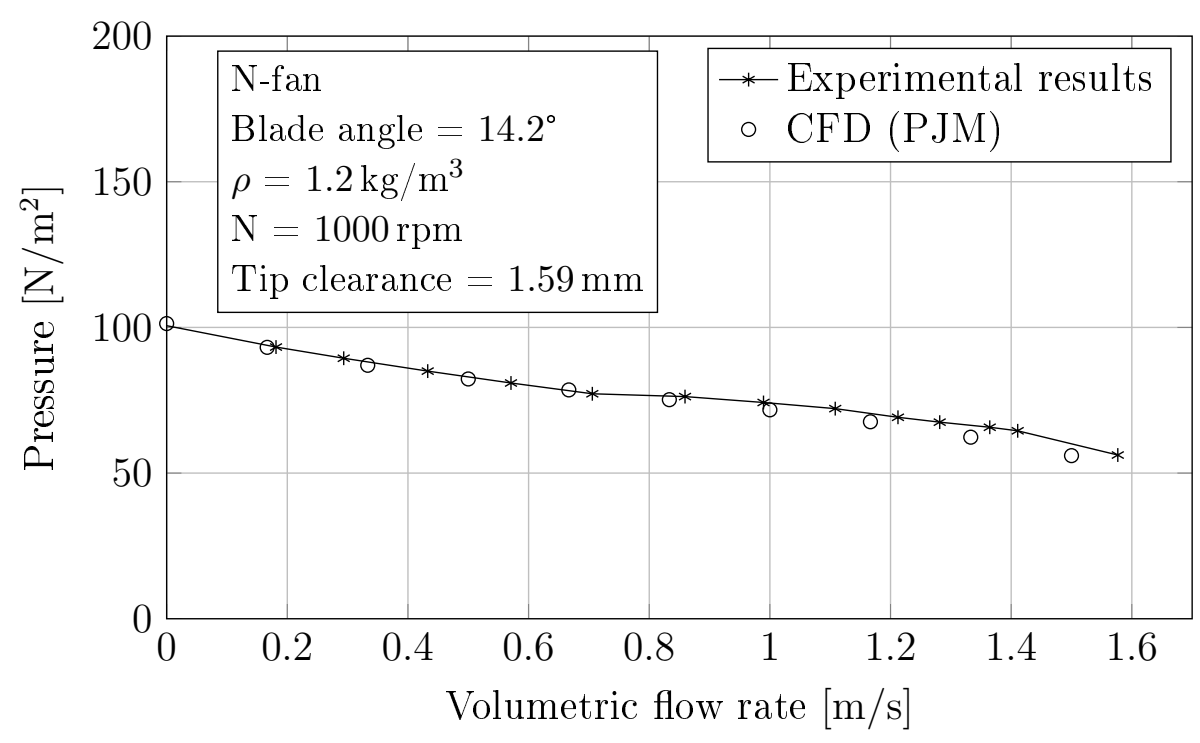

Figure 5.4: N-fan static pressure CFD results comparison

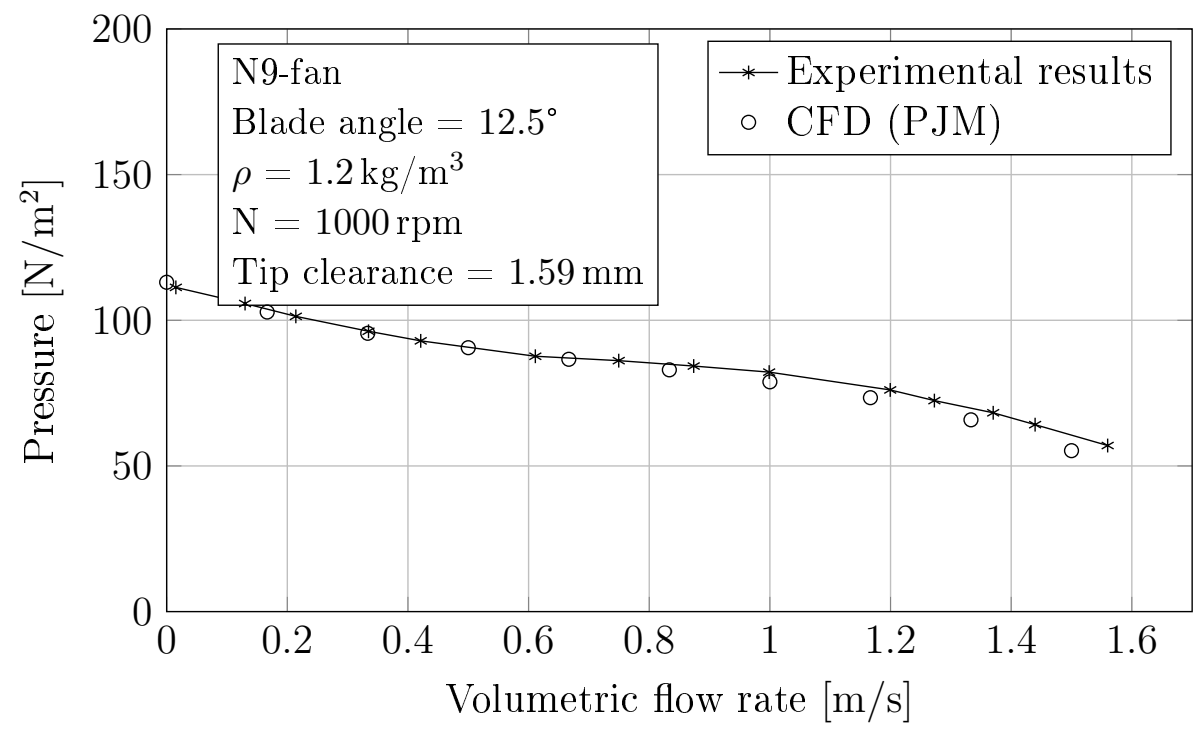

Figure 5.5: N9-fan static pressure CFD results comparison

The simulation results show close correlation with the experimental results. The simplistic PJM, which applies a static-to-static pressure increase based 


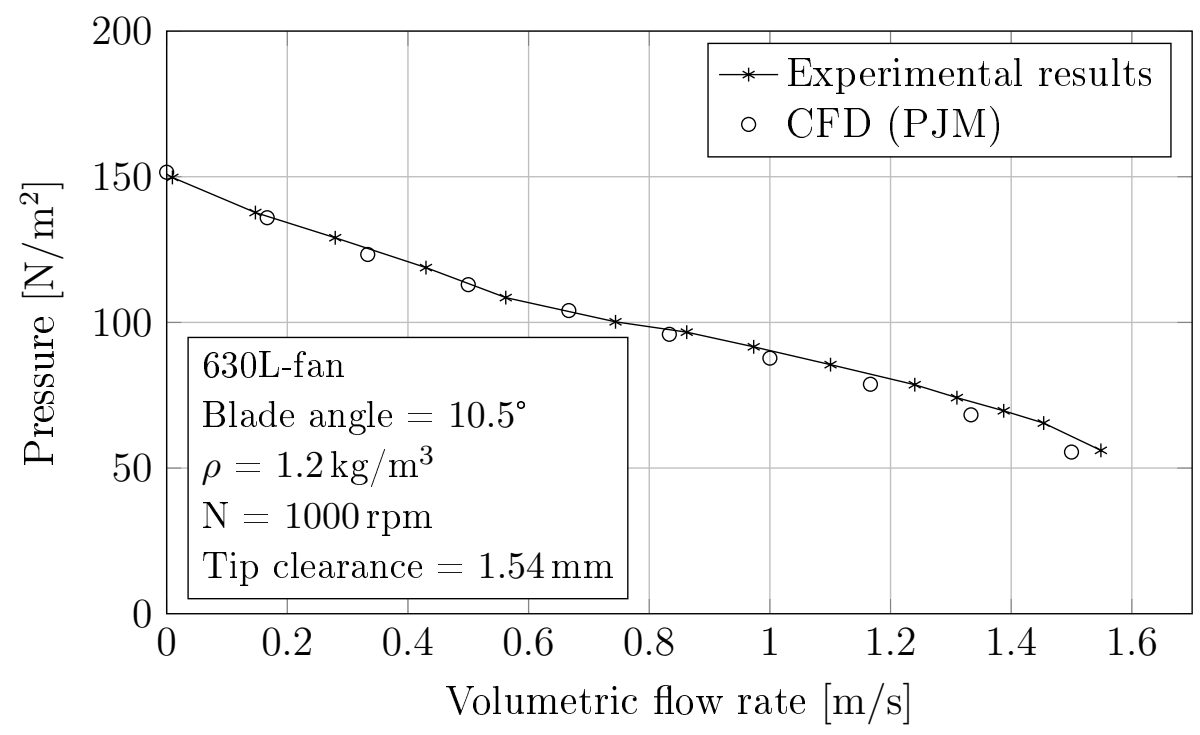

Figure 5.6: 630L-fan static pressure CFD results comparison

on the average velocity on the fan face, performs well in ideal flow conditions (which is characterised by a relatively uniform velocity distribution across the fan surface area). Only slight deviations from the experimental results can be seen at higher flow rates. This could be a result of differences in the system pressure losses determined through the CFD simulation and the values used in the analytical equations.

\subsubsection{Multiple fan facility model}

The multiple fan experimental facility was modelled as part of the numerical investigation. The fan configurations that were simulated are N-N-N, N9-N9N9, and 630L-630L-630L. This section discusses the various processes in the preparation and execution of the CFD model. The results of the simulations are compared to the experimental results obtained.

\subsubsection{Geometry and mesh}

A three dimensional model of the multiple fan facility shown in Figure 4.4 was created. The three fan tunnels are duplicates of the tunnel geometry used in Chapter 5.2.1. An open air inlet zone and inlet chamber were also added to the model, as shown in Figure 5.7.

The inlet chamber includes five surfaces representing the five platform height positions in the experimental facility. These surfaces could be specified as either a wall or an interior face, depending on the desired platform height. 
The outlets of the three fan tunnels are specified as outlet vent boundaries to simulate the porous outlet sheets used during the experimental investigations. The outlet vent boundary condition includes a loss coefficient parameter which can be adjusted to reduce or increase the pressure loss at the outlet.

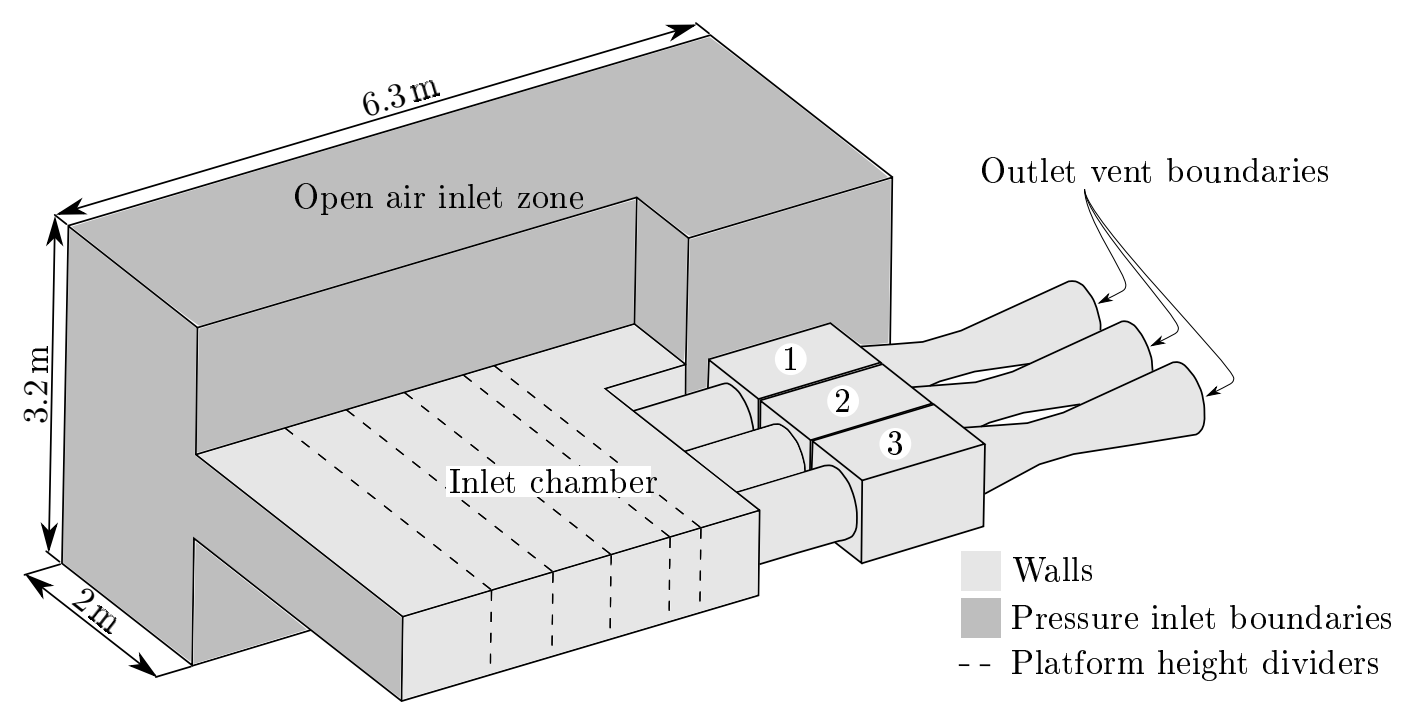

Figure 5.7: Multiple fan facility geometry and boundary conditions

The mesh of the multiple fan facility model is shown in Figure 5.8. The mesh of the three fan tunnels were duplicated from the single fan tunnel mesh. For the inlet chamber a combination of structured hexahedral and unstructured tetrahedral mesh structures were used. Structured zones were used where feasible to reduce the number of cells while maintaining a relatively fine structure. The mesh consists of $3.05 \times 10^{6}$ cells which was reduced to $2.14 \times 10^{6}$ cells by converting to polyhedra cells in Fluent.

\subsubsection{Boundary and cell zone conditions}

Table 5.3 lists the boundary and cell zone conditions applied in the multiple fan facility CFD model.

The outlet vent loss coefficients were determined by conducting simulations with the single fan model and specifying a static pressure inlet boundary together with an outlet vent boundary at the tunnel outlet. The outlet loss coefficient was adjusted for each fan until the flow rate was within $0.05 \%$ of the design flow rate.

The loss coefficient is applied as follows:

$$
\Delta p=k_{\text {outlet }} \frac{1}{2} \rho v^{2}
$$

and $k_{\text {outlet }}$ is a function of the flow velocity: 


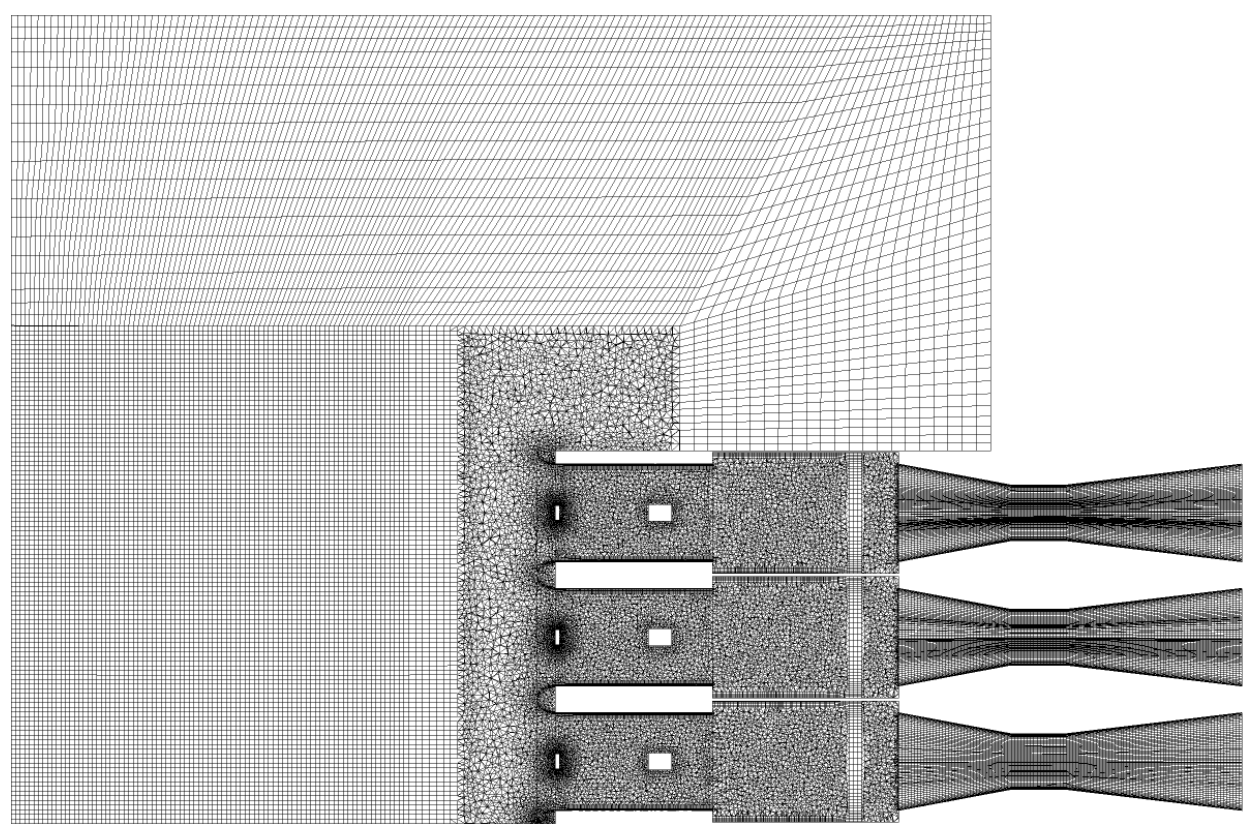

Figure 5.8: Multiple fan facility mesh

Table 5.3: Multiple fan facility model boundary and cell zone values

\begin{tabular}{|c|c|c|}
\hline $\begin{array}{l}\text { Boundary/Zone } \\
\text { name }\end{array}$ & Condition & Value(s) \\
\hline Open air inlet & Pressure inlet & $\begin{array}{l}\text { Static pressure }=0 \mathrm{~N} / \mathrm{m}^{2} \\
\text { Turbulence intensity }=3 \% \\
\text { Turbulence length scale }=0.02 \mathrm{~m}\end{array}$ \\
\hline Fan face & Fan & \begin{tabular}{l|l|l|} 
See Table 5.1 & \\
\end{tabular} \\
\hline Fan hub wall & Wall (Rotating) & Rotational speed $=104.72 \mathrm{rad} / \mathrm{s}$ \\
\hline Hex-core mesh & Porous zone & $\begin{array}{l}\text { Inertial resistance factor, } C_{x}= \\
2.442 \mathrm{~m}^{-1} \\
\text { Viscous resistance factor, } 1 / \alpha_{x}= \\
1173168 \mathrm{~m}^{-2} \\
C_{y}, C_{z}, 1 / \alpha_{y} \text {, and } 1 / \alpha_{z} \text { multiplied by } \\
1 \times 10^{3}\end{array}$ \\
\hline Outlet & Outlet vent & $\begin{array}{l}\text { Static pressure }=0 \mathrm{~N} / \mathrm{m}^{2} \\
\text { Loss coefficients: see Table } 5.4\end{array}$ \\
\hline
\end{tabular}

$$
k_{\text {outlet }}=C_{1}+C_{2} v+C_{3} v^{2}+\ldots
$$

A linear loss coefficient function was used by specifying zero values for all of the polynomial coefficients except $C_{2}$. The values of $C_{2}$, together with the corresponding volumetric flow rates are listed in Table 5.4 . 
Table 5.4: Outlet vent loss factor polynomial coefficients and corresponding volumetric flow rates

\begin{tabular}{lcccc}
\hline & & N-fan & N9-fan & 630L-fan \\
\hline Outlet loss coefficient & $C_{2}$ & 0.645 & 0.660 & 0.675 \\
\hline Volumetric flow rate & {$\left[\mathrm{m}^{3} / \mathrm{s}\right]$} & 1.45504 & 1.45515 & 1.45475 \\
\hline
\end{tabular}

\subsubsection{Simulation results}

Simulations were executed at five platform heights $\left(1 \mathrm{D}_{f a n}, 1.5 \mathrm{D}_{f a n}, 2.5 \mathrm{D}_{f a n}\right.$, $3.5 \mathrm{D}_{\text {fan }}$ and $\left.4.5 \mathrm{D}_{\text {fan }}\right)$ as well as with an open platform inlet. The results are evaluated by comparing the simulation and measured values of the system volumetric effectiveness and by comparing the velocity vectors measured by hot-film anemometry to the velocity vectors at the same positions obtained by the simulation results.

\subsubsection{N-N-N fan facility results}

The volumetric effectiveness simulation results of the multiple N-fan system is plotted in Figure 5.9 together with simulation results obtained for the same fans by van der Spuy (2011) and the experimental results obtained in Chapter 4.

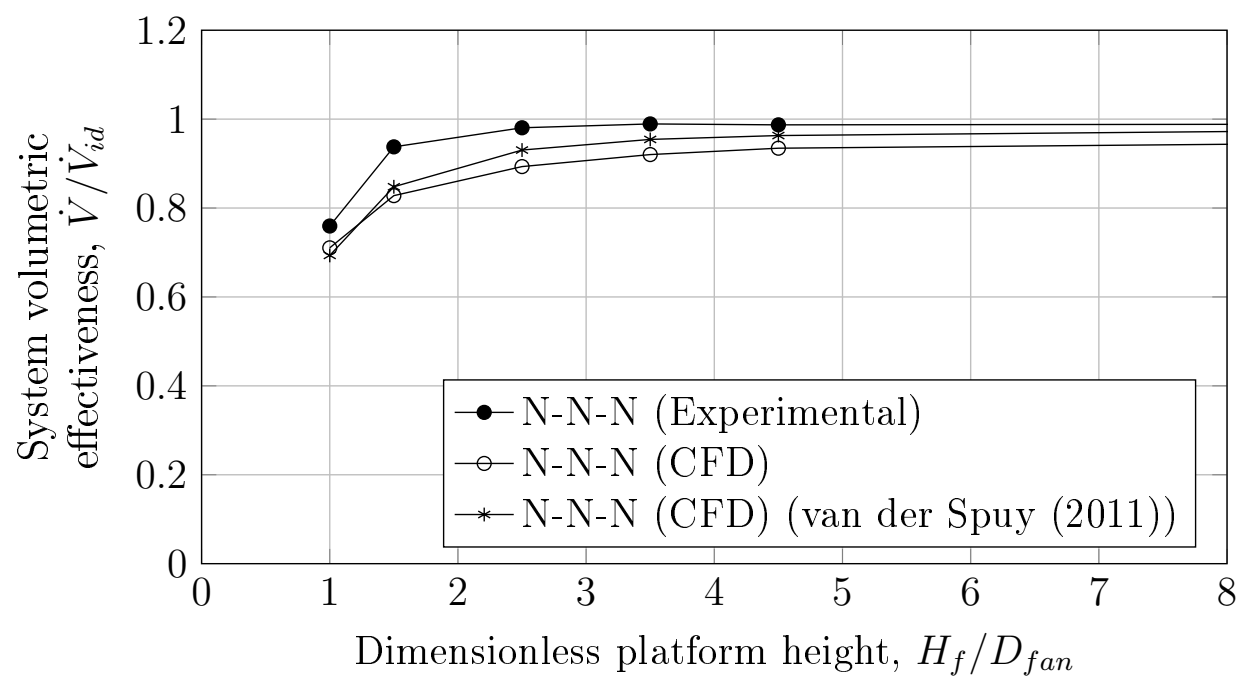

Figure 5.9: N-fan system variable platform height CFD results comparison with experimental results

Figure 5.9 shows that the volumetric effectiveness results obtained by the CFD simulations are consistently lower than the experimental results. The 
difference is most notable at the $1.5 \mathrm{D}_{\text {fan }}$ and $2.5 \mathrm{D}_{\text {fan }}$ platform height positions. The results correlate well at the $1 \mathrm{D}_{\text {fan }}$ platform position. The CFD results obtained by van der Spuy (2011) show the same behaviour, but discrepancies with the current study CFD results are noticeable at the $2.5 \mathrm{D}_{\text {fan }}$, $3.5 \mathrm{D}_{\text {fan }}$ and $4.5 \mathrm{D}_{\text {fan }}$ platform height positions. These discrepancies could be a result of differences in the fan model pressure jump functions used, outlet loss coefficients applied, or the reference volumetric flow rate used to calculate the volumetric effectiveness values (the reference flow rate used by van der Spuy (2011) was $1.450 \mathrm{~m}^{3} / \mathrm{s}$ ).

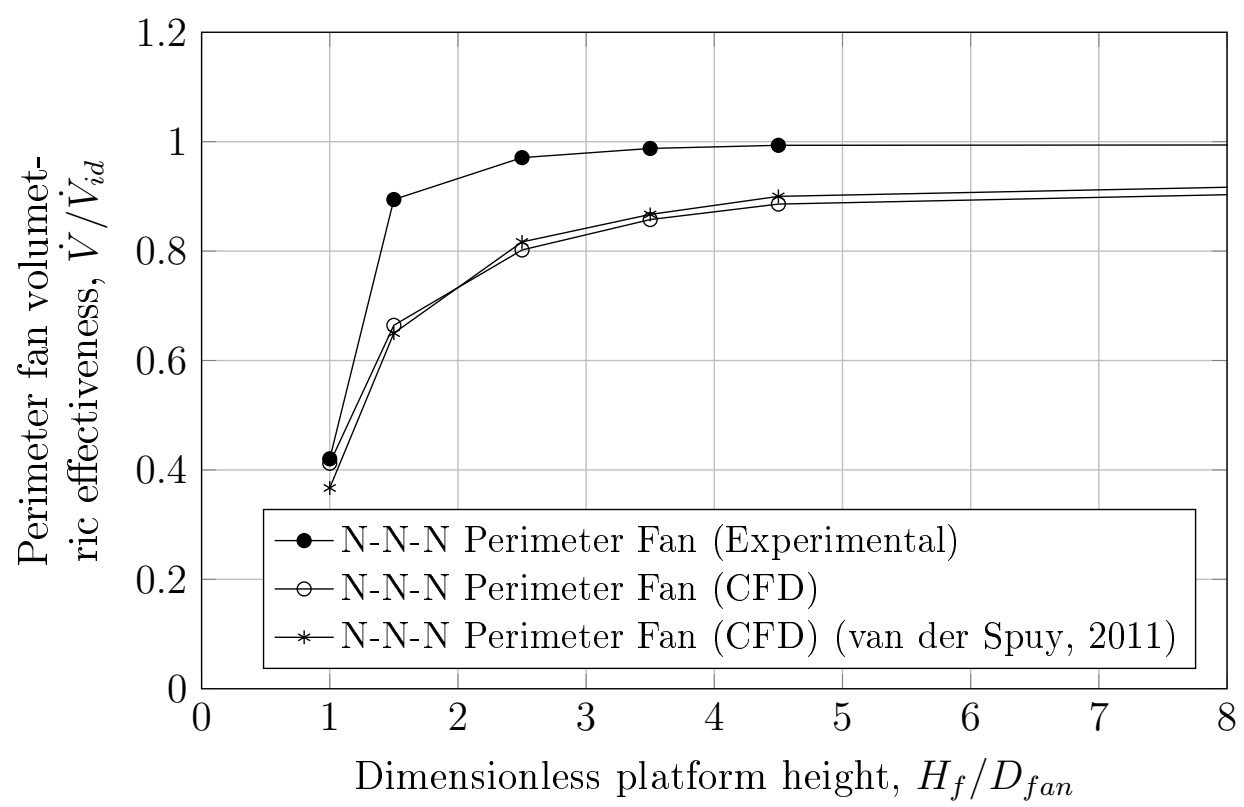

Figure 5.10: Perimeter N-fan variable platform height CFD results comparison with experimental results

The perimeter fan is most affected by the reduction of the platform height due to the increase in distorted inlet flow conditions at the periphery. The CFD and experimental volumetric effectiveness results of the perimeter fan are plotted in Figure 5.10. The effectiveness at the lowest platform height is well predicted by the CFD simulation. A large discrepancy however exists between the CFD and experimental volumetric effectiveness results at the other higher platform heights. CFD results obtained by van der Spuy (2011) show the same trend. This shows that the presence of cross-flow conditions affect the ability of the PJM to simulate the fans in the CFD model accurately. The large difference in volumetric effectiveness at the perimeter fan translates into the differences in the results of the overall system volumetric effectiveness.

Figure 5.11 shows experimental and CFD velocity vectors at three platform heights. Velocity vectors were extracted from the CFD results at the 


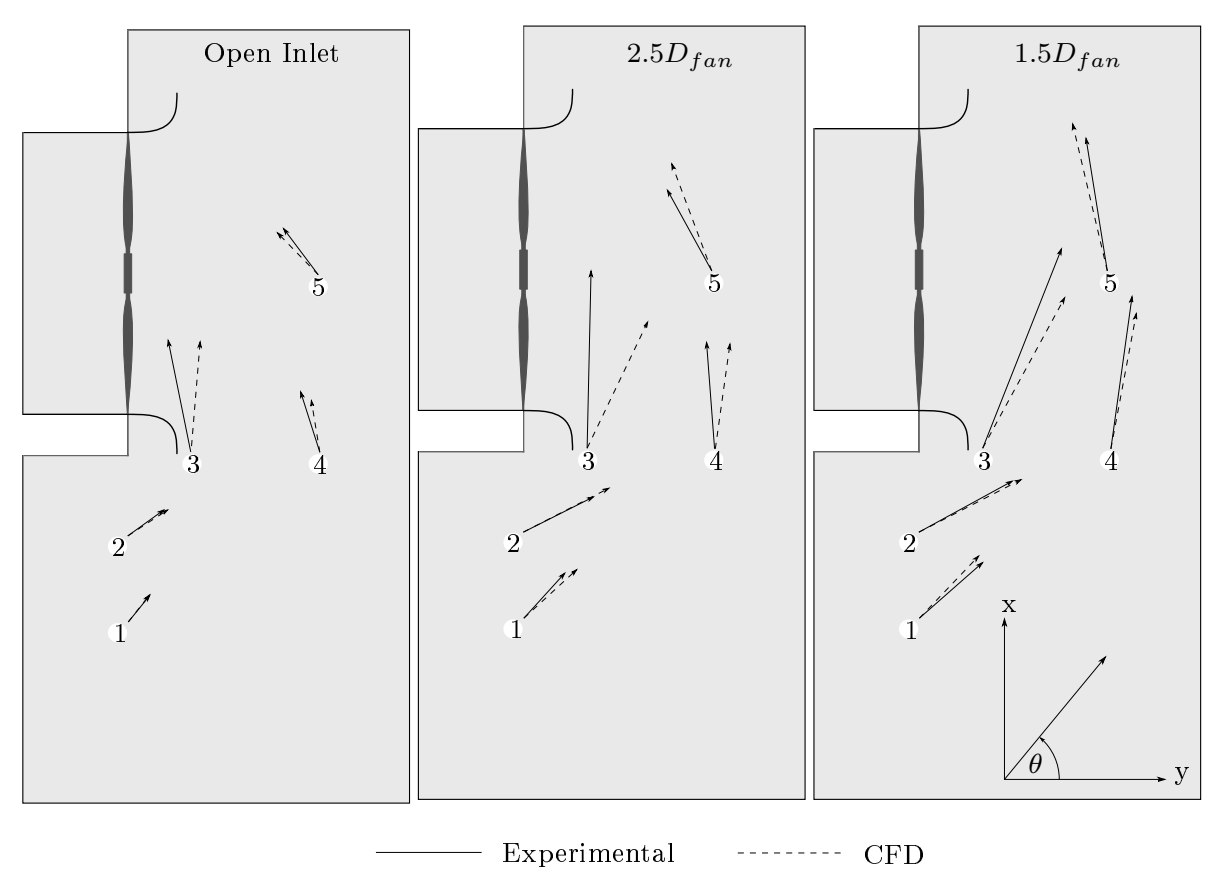

Figure 5.11: Comparison of CFD and experimental velocity vectors for the N-N-N fan system

same measurement locations used during the hot film velocity measurement procedure (see Figure 4.7).

The vectors at position 1 and 2 correlate well. Both the velocity angles and magnitudes are well predicted by the CFD model.

At position 3 large errors in the velocity angle obtained by the CFD simulations can be observed at the open and $2.5 \mathrm{D}_{\text {fan }}$ platform height positions. At the $1.5 \mathrm{D}_{\text {fan }}$ platform height position the results correlate better. The CFD velocity vector angles are consistently smaller than the experimental vector angles, pointing away from the fans. They also show little change in direction between platform height positions when compared to the experimental vectors.

The CFD velocity vectors at position 4 correlate well with the experimental results. The velocity angle obtained by $\mathrm{CFD}$ at a platform height of $2.5 \mathrm{D}_{\text {fan }}$ shows a noticeable difference from the experimental velocity angle.

The vectors at position 5 show good correlation between the CFD and experimental results.

\subsubsection{N9-N9-N9 fan facility results}

Figure 5.12 shows the variable platform height CFD and experimental system volumetric effectiveness results. The CFD results follow the same general trend as seen with the experimental results. Good correlation between the CFD and experimental volumetric effectiveness results can be seen at the $1 \mathrm{D}_{\text {fan }}, 3.5 \mathrm{D}_{\text {fan }}$ and $4.5 \mathrm{D}_{\text {fan }}$ platform heights. As with the $\mathrm{N}$-fan system, the CFD results show 
the biggest deviation from the experimental values at the $1.5 \mathrm{D}_{\text {fan }}$ and $2.5 \mathrm{D}_{\text {fan }}$ platform heights.

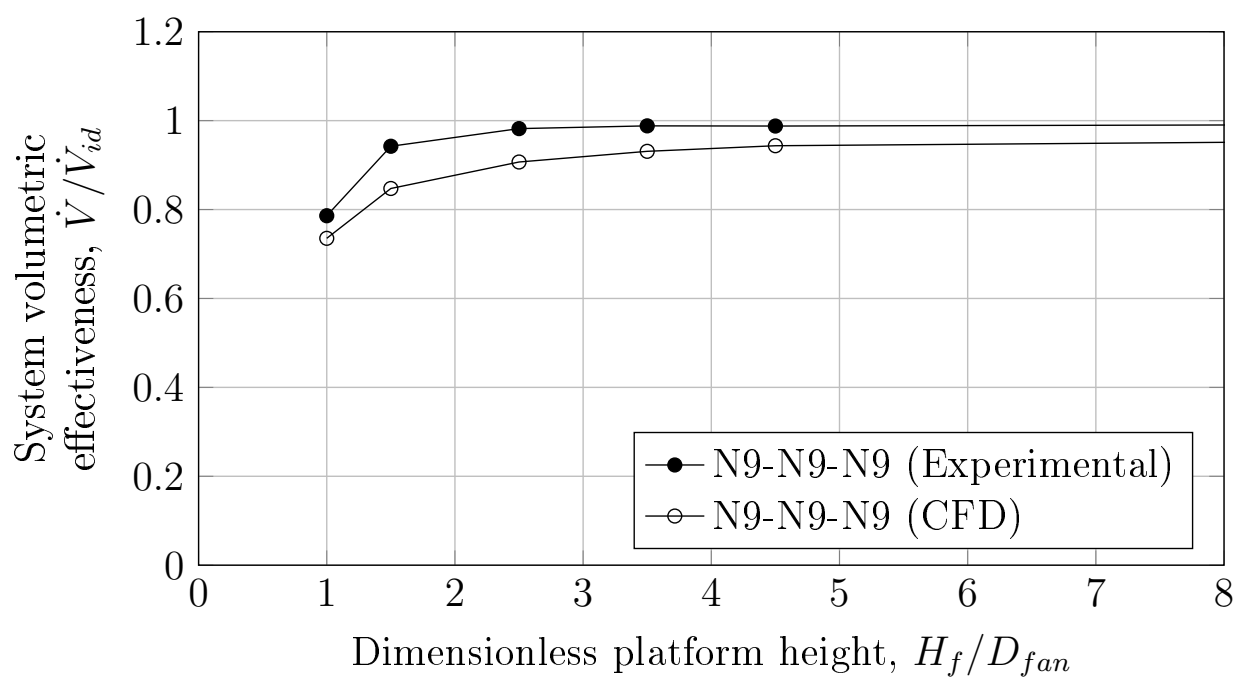

Figure 5.12: N9-fan system variable platform height CFD results comparison with experimental results

The velocity vectors obtained by CFD and experimental investigations are shown in Figure 5.13 .

The vectors at positions 1 and 2 correlate well, with only the vectors at position 2 at a platform height of $1.5 \mathrm{D}_{\text {fan }}$ showing a relatively large difference.

At position 3 the vectors show a large difference in velocity and, especially, angle. The CFD vector angles are similar to the vectors of the $\mathrm{N}$-fan system. As with the N-fan CFD vectors, the vector angles are consistently smaller than the measured vector angles. The reduction in the flow angles between platform heights are also less than what was measured.

The vectors at position 4 show similar angular differences than what is observed with the N-fan results. The experimental velocity magnitude measured at the open platform height seems incorrect, however. The velocity appears to be too large when compared to other vectors measured with an open inlet as well as the same position's velocity magnitude obtained from the N-fan system measurements. The vector magnitude and angle values at the $2.5 \mathrm{D}_{\text {fan }}$ and $1.5 \mathrm{D}_{\text {fan }}$ platform positions correlate fairly well.

With an exception to the open inlet vectors, the other vector results at position 5 show excellent correlation. It seems as if a faulty hot-film anemometer angle measurement was made at the open inlet. The CFD vector angle seems to be in agreement with simulation and measurement results obtained with the N-fan system. 


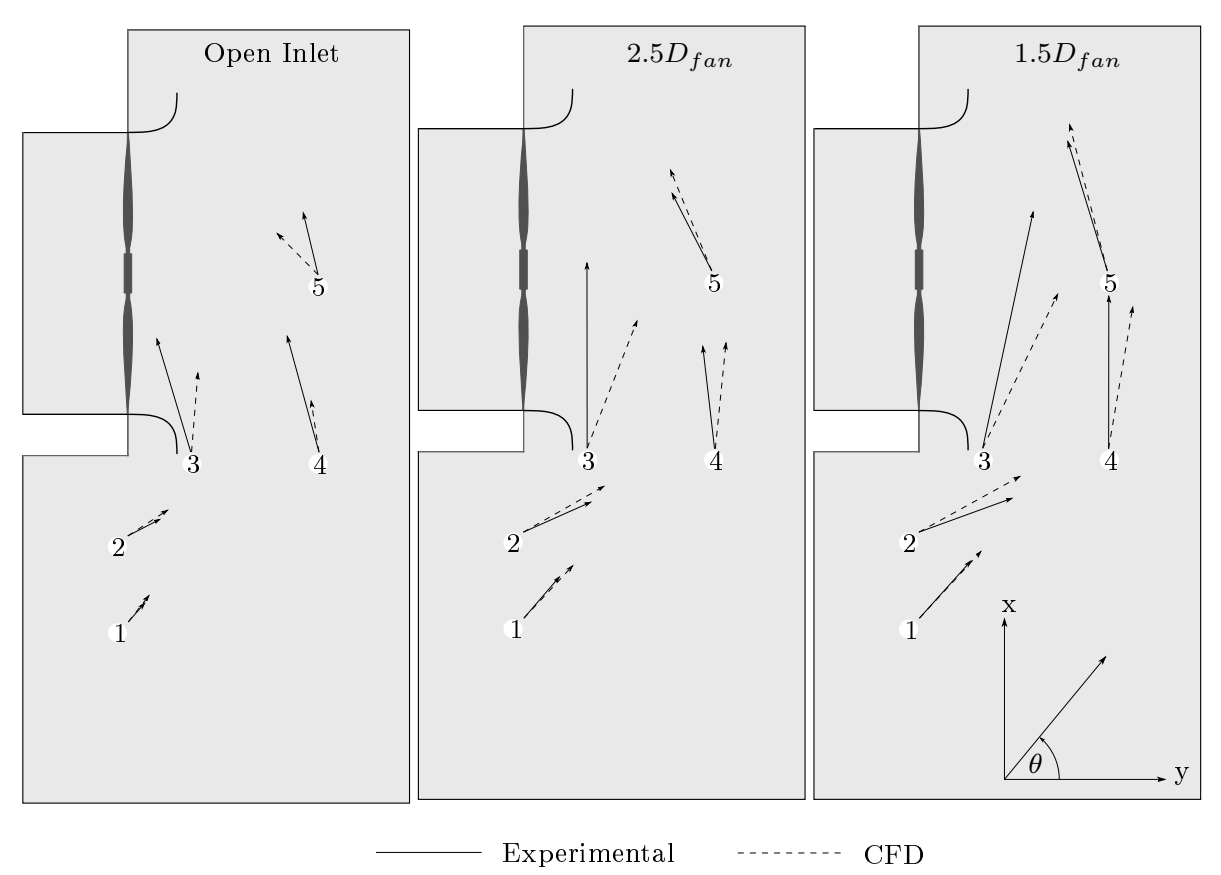

Figure 5.13: Comparison of CFD and experimental velocity vectors for the N9-N9N9 fan system

\subsubsection{630L-630L-630L fan facility results}

Figure 5.14 shows the CFD and experimental volumetric effectiveness results of the multiple 630L-fan system. The multiple fan performance tests conducted in Chapter 4 showed that the 630L-fan system achieved the highest volumetric effectiveness at all platform height positions, and also showed an increase of $13.2 \%$ over the N-fan system at the lowest platform height position (see Figure 4.13). The CFD simulations however fail to predict this substantial increase in volumetric effectiveness at the lowest platform height. An increase is observed, but not to the extent shown by the experimental results. As with the N- and N9-fan CFD results, the volumetric effectiveness is under-predicted at the $1.5 \mathrm{D}_{\text {fan }}$ and $2.5 \mathrm{D}_{\text {fan }}$ platform height positions, and improves as the platform height increases.

Figure 5.15 shows the CFD and experimental velocity vectors for the 630Lfan system. The CFD results correlate well with the experimental results at all the positions except at position 3 with the open inlet and $2.5 \mathrm{D}_{\text {fan }}$ platform height.

\subsubsection{Summary}

Simulations were executed at five platform heights as well as with an open platform inlet. The results were evaluated by comparing the system volumetric effectiveness and velocity vectors to experimental results. 


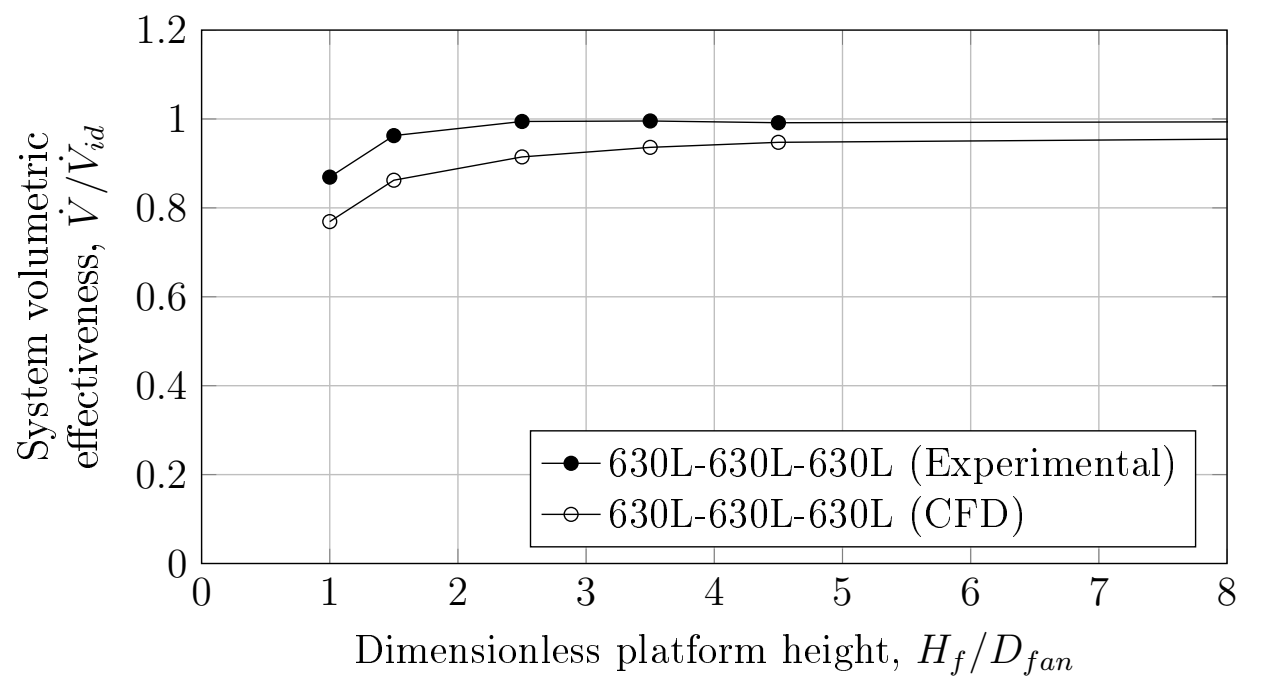

Figure 5.14: 630L-fan system variable platform height CFD results comparison with experimental results

Figure 5.16 summarises the results by plotting the variable platform height volumetric effectiveness results obtained by CFD and experimental investigations of all three fan systems.

The most notable difference between the CFD and experimental results is the reduced volumetric effectiveness values shown by the CFD results. The largest differences are observed at the $1.5 \mathrm{D}_{\text {fan }}$ and $2.5 \mathrm{D}_{\text {fan }}$ platform height positions.

The experimental volumetric effectiveness values remain relatively constant with a reduction of the platform height down to $2.5 \mathrm{D}_{\text {fan }}$. It then drops slightly at $1.5 \mathrm{D}_{\text {fan }}$ followed by a large drop in effectiveness at $1 \mathrm{D}_{\text {fan }}$ (with the exception of the 630L-fan). The CFD volumetric effectiveness values show a more gradual reduction as the platform height is decreased. This implies that the relatively simple PJM used in the CFD models is more sensitive to a reduction in platform height (or increase in distorted inlet flow conditions). In reality, the fans are more resilient to changes in inlet flow conditions with regard to volumetric effectiveness.

Another notable difference between the CFD and experimental results is the volumetric effectiveness values of the 630L-fan system at the lowest platform height. The CFD under-predicts the volumetric effectiveness by $12.7 \%$. Due to the relatively large solidity of the 630L-fan, it performs better than the lower solidity N- and N9-fans when subjected to distorted inlet flow conditions. The PJM used in the CFD model clearly fails to effectively reflect the influence of fan solidity on the performance of fans subjected to distorted inlet flow conditions.

Figure 5.17 shows the volumetric effectiveness results for the perimeter fan obtained by CFD and experiments. The same trend observed with the perime- 


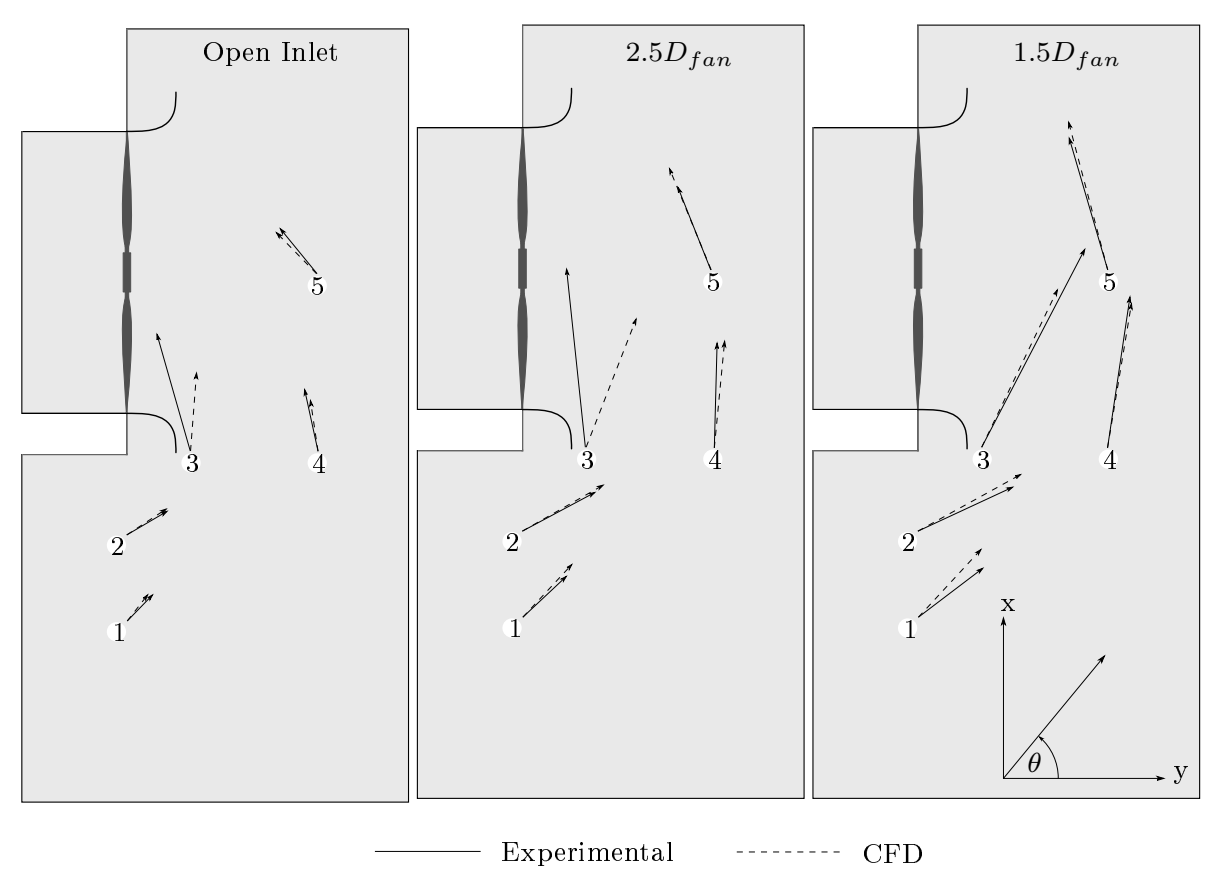

Figure 5.15: Comparison of CFD and experimental velocity vectors for the 630L630L-630L fan system

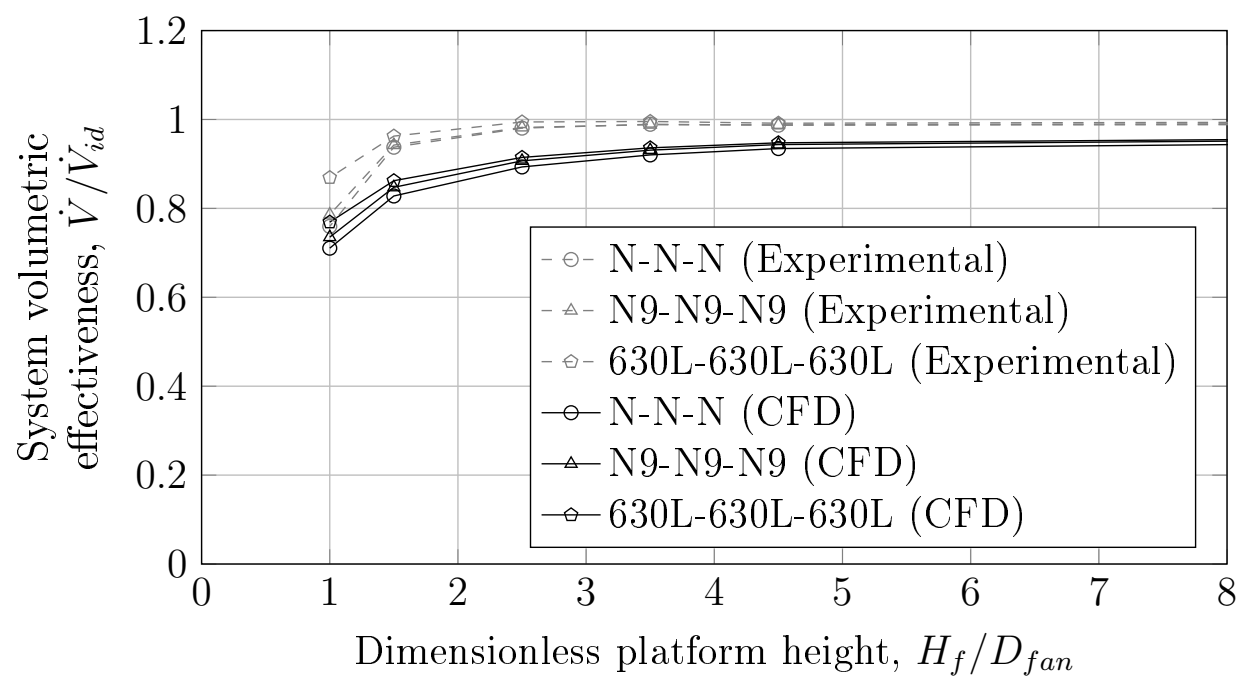

Figure 5.16: Variable platform height CFD and experimental results

ter $\mathrm{N}$-fan is seen with the other two fans. Large differences are observed at the $1.5 \mathrm{D}_{\text {fan }}, 2.5 \mathrm{D}_{\text {fan }}$ and $3.5 \mathrm{D}_{\text {fan }}$ platform heights. The $\mathrm{N}$ - and N9-fans show good correlation with the experimental results at the lowest platform height, with the 630L-fan CFD results failing to predict the improved volumetric effectiveness shown by experimental results. These results show that the complex flow patterns located at the perimeter of the multiple fan facility reduces the 
accuracy of the CFD models. The large differences observed at the perimeter fan also translates into differences in the total system volumetric effectiveness value, which explains the discrepancies observed in the system volumetric effectiveness results, especially at the $1.5 \mathrm{D}_{\text {fan }}$ and $2.5 \mathrm{D}_{\text {fan }}$ platform height positions.

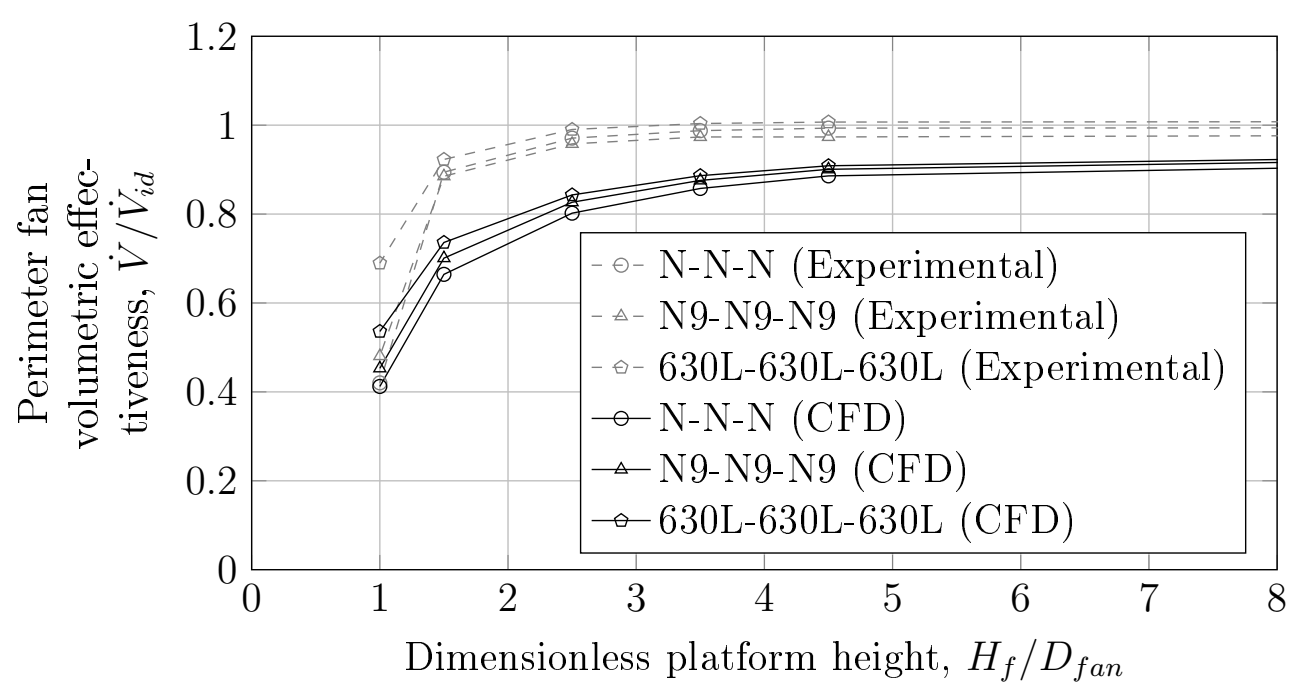

Figure 5.17: Variable platform height perimeter fan CFD and experimental results

The PJM used to simulate the fans in the CFD models assumes a constant fan static pressure function which is obtained from the single fan experimental tests. The static pressure function is thus based on ideal operating conditions, and does not change as the operating conditions vary (as with a reduction in platform height). In reality, however, the fan characteristics change with a change in inlet flow conditions. This explains why a large difference is observed between the CFD and experimental results with the perimeter fan at low platform height positions where the operating conditions differ substantially from ideal test conditions.

The velocity vector comparisons have shown that the CFD models give an accurate prediction of the general flow patterns around the perimeter fan. Velocity vectors at position 3 , which is nearest to the fan, did not correlate well except at the lowest platform height position. This is justifiable due to the lack of physical fan characteristics included in the CFD model. The change in the general flow patterns with a reduction in platform height is well predicted by the CFD models. 


\subsection{Full scale ACSC}

In this section the CFD simulation procedure of the full scale ACSC will be discussed. The ACSC consists of an arrangement of individual air-cooled heat exchanger (ACHE) fan units. The geometry and boundary conditions of a single ACHE fan unit is first discussed and validated by comparing the simulation results with analytical results. The geometry, mesh and boundary conditions of the ACSC system is then discussed. Finally the results from the ACSC system CFD model is presented and discussed for each fan system.

\subsubsection{Single ACHE unit}

The ACSC system consists of a collection of individual ACHE fan units. These units consist of the fan, plenum chamber and heat exchanger, as shown in Figure 5.18(i). This section will discuss the single ACHE numerical fan unit in detail, including model dimensions, mesh and boundary conditions. The simulation results are then compared to analytical results.

\subsubsection{Geometry and mesh}

The single ACHE fan unit CFD model is shown together with a representation of a conventional A-frame ACHE fan unit in Figure 5.18. The A-frame fan unit was simplified for the CFD model by excluding detail such as the inlet screen, fan bridge, fan motor, finned tubes, etc. The mesh required to simulated the A-frame unit with all these intricate details would require a very large mesh size which would be too computationally expensive when used in simulations, especially for a complete ACSC system. The same rationale was applied by Bredell (2005), van Rooyen (2007), Owen (2010) and Louw (2011).

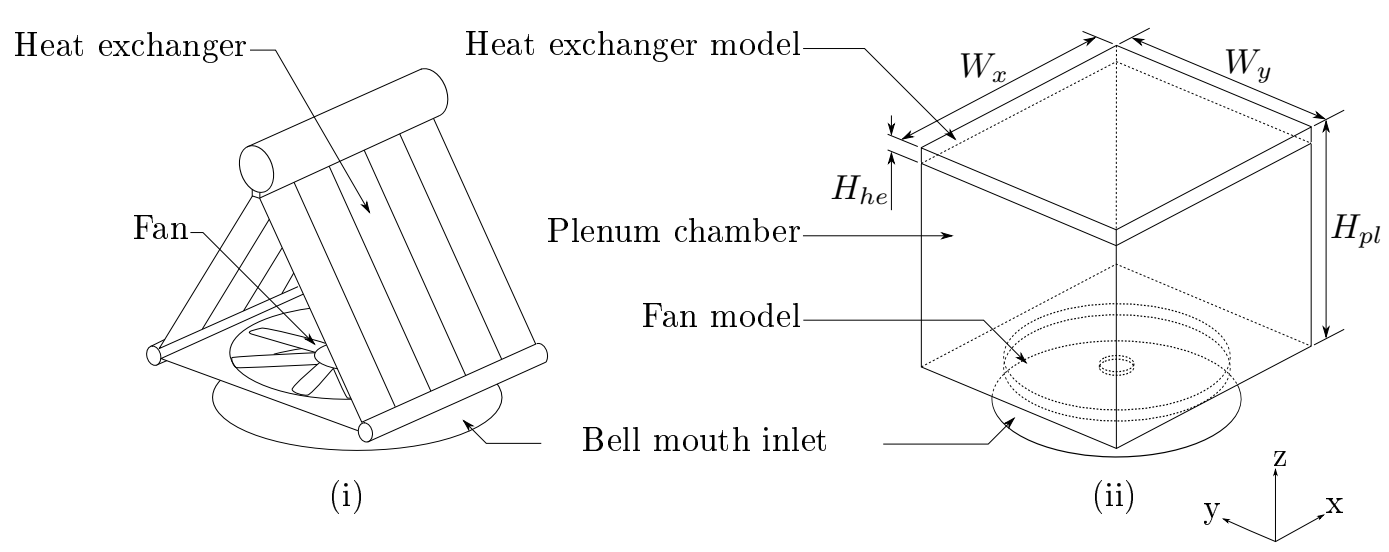

Figure 5.18: ACHE fan unit CFD model dimensions

The simplified CFD fan unit is shown in Figure 5.18(ii). The A-frame unit is simplified as a cubic unit with a bell mouth inlet. The fan is modelled using 
the PJM, applied to a face located in the plane of rotation of the fan. The cube consists of a plenum chamber and a heat exchanger model. The dimensions of the simplified CFD fan unit are listed in Table 5.5 .

\begin{tabular}{llr}
\hline$W_{x}$ & $(\mathrm{~m})$ & 11.8 \\
$W_{y}$ & $(\mathrm{~m})$ & 10.56 \\
$H_{p l}$ & $(\mathrm{~m})$ & 10 \\
$H_{h e}$ & $(\mathrm{~m})$ & 0.2 \\
\hline
\end{tabular}

Table 5.5: ACHE CFD model dimension values

To validate the single CFD fan unit, a computational domain was created which simulated ideal operating conditions. The domain with its dimensions are shown in Figure 5.19. The domain consists of the fan unit located within a cylinder. The bottom face of the cylinder is modelled as a wall, with the side and top walls modelled as pressure inlet and outlet boundary conditions respectively. The fan unit is located at the platform height that would be used in the ACHE system simulations.

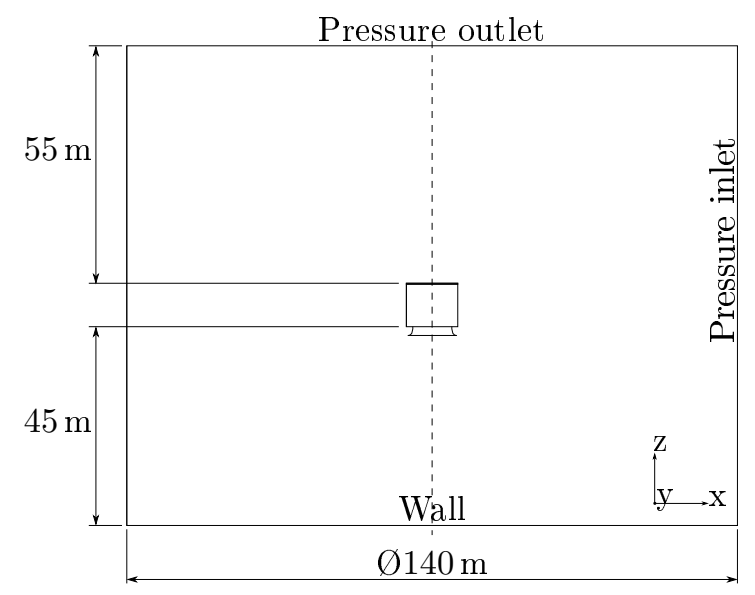

Figure 5.19: Single ACHE fan unit CFD validation model

The fan unit mesh is shown in Figure 5.20. Fluent's advanced size function was used (as with the multiple fan facility mesh) with suitable control parameters to ensure that the mesh conforms to complex geometries and wall surfaces. The bell mouth inlet was modelled as a wall surface with mesh inflation applied to the fan side surface. The plenum chamber walls were modelled as slip walls (zero friction) since it is not part of the actual fan unit and should not contribute to mechanical flow losses.

The modelling of the fan and heat exchanger is discussed in the following sections. 

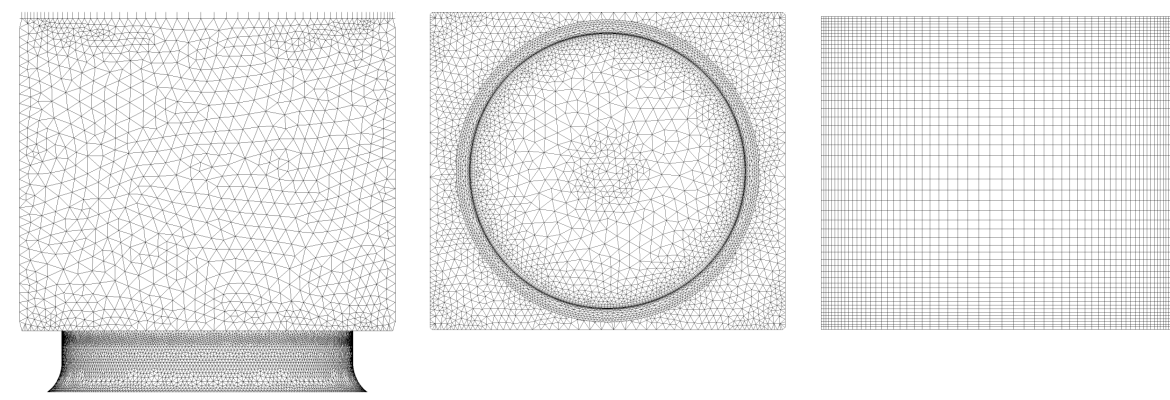

Figure 5.20: ACHE single unit mesh

\subsubsection{Fan models}

The ACSC fans were modelled using Fluent's fan model, which uses the PJM. As discussed in chapter 5.2.1.2, this method was chosen due to its simplicity, relatively low computational resource requirements and popularity in the ACSC modelling research field.

Results from the single fan performance tests were used to derive pressure jump functions for the ACHE CFD fan models. The fan static pressure results were scaled to the ACHE operating conditions (refer to Appendix E), using the fan scaling laws. Static-to-static pressure functions were then obtained by following the procedure detailed in Appendix D using the ACHE fan specifications and operating conditions. The ACHE fan PJM polynomials are listed in Table 5.6.

Table 5.6: ACHE pressure jump fan polynomials

\begin{tabular}{ll}
\hline N-fan & $-0.262 v^{3}+4.517 v^{2}-28.287 v+303.35$ \\
N9-fan & $-0.423 v^{3}+6.321 v^{2}-35.274 v+336.76$ \\
630L-fan & $-0.372 v^{3}+6.167 v^{2}-50.989 v+443.57$ \\
\hline
\end{tabular}

\subsubsection{Heat exchanger model}

The CFD heat exchanger model accounts for the momentum and energy effects associated with the actual heat exchanger. This is achieved by defining the heat exchanger zone as a porous medium (to account for the ACHE system resistance) and the heat exchanger outlet face as a radiator boundary condition (to account for the heat transfer).

The porous zone parameters are derived from the one-dimensional draft equation presented by Kröger (2004) which provides a method for calculating the effective system resistance, $\Delta p_{h e}$ of a single fan unit: 


$$
\begin{aligned}
& \Delta p_{h e}=K_{t s} \frac{\left(\dot{m}_{a} / A_{t f r}\right)^{2}}{2 \rho_{t s}}+K_{u p} \frac{\left(\dot{m}_{a} / A_{e}\right)^{2}}{2 \rho_{u p}}+K_{d o} \frac{\left(\dot{m}_{a} / A_{e}\right)^{2}}{2 \rho_{d o}} \\
&+K_{\theta t} \frac{\left(\dot{m}_{a} / A_{t f r}\right)^{2}}{2 \rho_{t}}
\end{aligned}
$$

The K-coefficients listed in equation (5.8) are loss coefficients, defined in general as:

$$
K=2 \Delta p / \rho v^{2}
$$

The four loss-coefficients in equation (5.8) account for the physical properties of the A-frame fan unit. $K_{t s}$ accounts for the ACHE platform support structure. $K_{u p}$ and $K_{d o}$ represent flow losses caused by obstacles in close proximity upstream and downstream of the fan. $K_{\theta t}$ accounts for losses across the heat exchanger, as well as kinetic energy losses at the heat exchanger outlet.

The loss coefficients are calculated using equations and guidelines provided by Kröger (2004). By substituting the loss coefficients, density and area values and expressing the flow rate in terms of flow velocity, a pressure loss function is obtained. From this function the porous zone inertial and viscous resistance factors, as shown in equation (5.5), are determined (see results listed in Table 5.7). This procedure is detailed in Appendix E.

Table 5.7: ACHE heat exchanger model porous zone parameters

\begin{tabular}{llr}
\hline Inertial resistance factor, $C_{z}$ & $\left(\mathrm{~m}^{-1}\right)$ & 55.787 \\
Viscous resistance factor, $1 / \alpha_{z}$ & $\left(\mathrm{~m}^{-2}\right)$ & $2.046 \times 10^{6}$ \\
\hline
\end{tabular}

Fluent's radiator boundary condition is applied to the heat exchanger zone outlet face to model the heat transferred at the A-frame fan unit finned tube bundles. The finned tube specifications are based on the specifications used by Bredell (2005) (see Appendix E) and consists of two staggered rows of finned tubes.

The radiator boundary condition assumes a purely convective heat transfer condition, with the resulting heat flux equation expressed as:

$$
q=\dot{m} c_{p}\left(T_{\text {air }, u p}-T_{a i r, d}\right)=h A\left(T_{a i r, d}-T_{s}\right)
$$

where $c_{p}$ is the specific heat capacity of air, $T_{a i r, u p}$ and $T_{a i r, d}$ are the air temperatures upstream and downstream of the heat exchanger, $T_{s}$ is the steam temperature in the heat exchanger and $h$ is the convective heat transfer coefficient.

By rearranging equation 5.10 the outlet air temperature, $T_{a i r, d}$, is calculated by assuming a constant steam temperature: 


$$
T_{a i r, d}=\frac{h A T_{s}+\dot{m} c_{p} T_{a i r, u p}}{h A+\dot{m} c_{p}}
$$

Fluent requires the specification of the convective heat transfer coefficient either as a constant, polynomial function, piecewise linear function, or piecewise polynomial function. For a polynomial function, the relationship takes the form

$$
h=\sum_{n=0}^{N} h_{n} v^{n}, \quad 0 \leq N \leq 7
$$

By using the $\varepsilon$-NTU method, the heat transfer rate between the condensing steam and the cooling air surrounding a heat exchanger having $n_{r}$ finned tube rows is given by the following equation:

$$
Q=\sum_{i=1}^{n_{r}} \dot{m} c_{p}\left(T_{a i r, d(i)}-T_{a i r, u p(i)}\right)=\sum_{i=1}^{n_{r}} \varepsilon_{i} \dot{m} c_{p}\left(T_{s}-T_{a i r, u p(i)}\right)
$$

with the effectiveness, $\varepsilon_{i}$, of each row given by

$$
\varepsilon_{i}=1-e^{-U A_{i} / \dot{m} c_{p}}
$$

where $U A_{i}$ being the overall heat transfer coefficient, which in this case is approximated as equal to the air-side convection heat transfer coefficient, $h A_{i}$, since the thermal resistance of the condensate layer inside the finned tube is very small in comparison to the overall resistance (Louw, 2011).

The convective heat transfer coefficient function was determined analytically in Appendix E by using the $\varepsilon$-NTU method with heat transfer characteristics obtained from the finned tube bundle specifications. The function was specified as a piecewise-polynomial in Fluent consisting of 3 flow velocity ranges. The function is shown in Figure 5.21 and the coefficients of equation (5.12) are listed in Table 5.8 for the 3 velocity ranges.

\subsubsection{Buoyancy modelling}

Buoyancy effects, which are caused by a reduction in density of heated air, were modelled using the Boussinesq model. The Boussinesq model is an alternative method of modelling buoyancy effects, as opposed to solving the density in each cell based on the temperature. Instead, the Boussinesq model treats density as a constant in all equations except for the buoyancy term in the momentum equations. The buoyancy term is approximated as follows:

$$
\left(\rho-\rho_{0}\right) g \approx-\rho_{0} \beta\left(T-T_{0}\right) g
$$




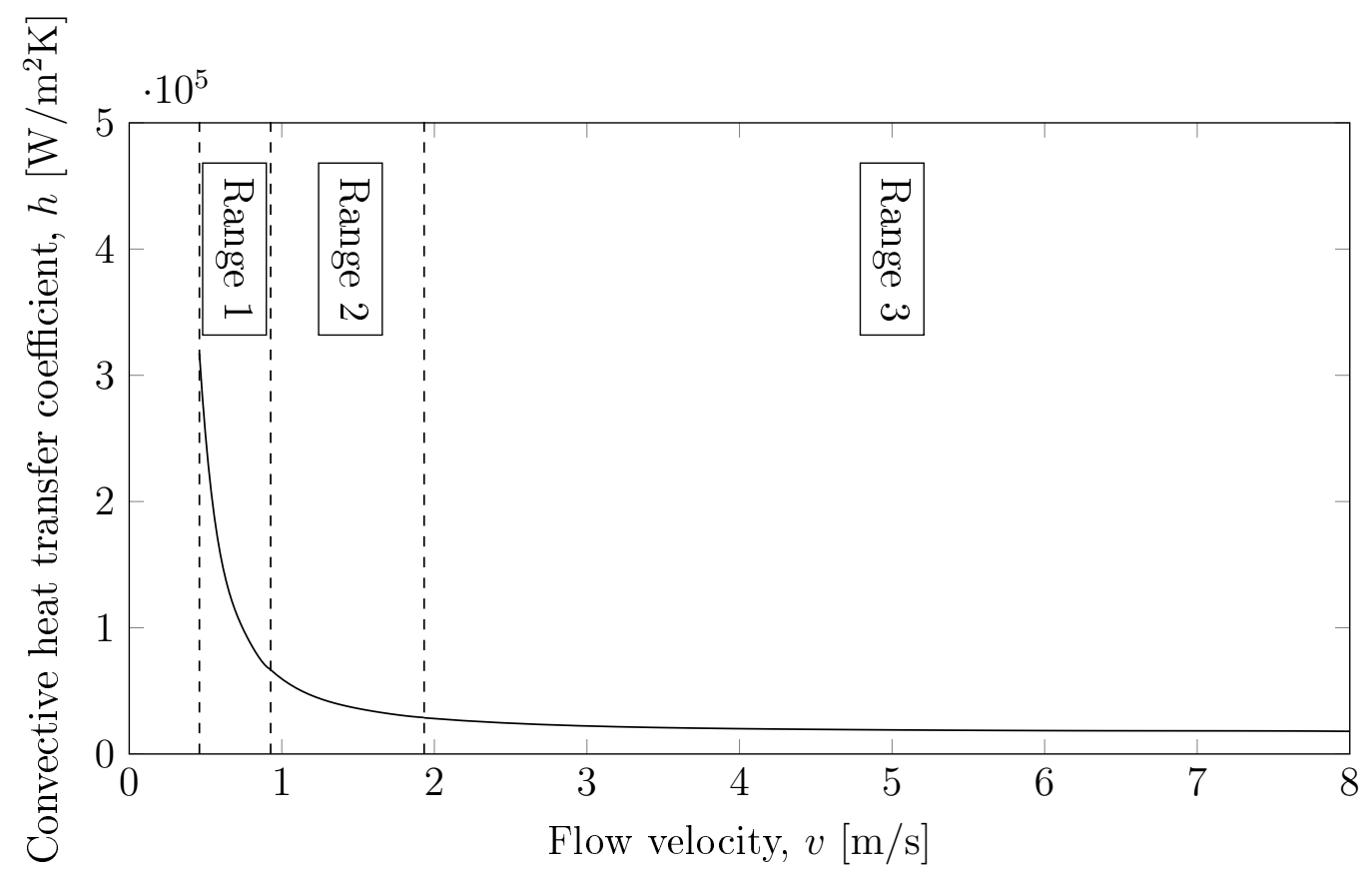

Figure 5.21: ACHE convective heat transfer coefficient function

where $\rho_{0}$ is a constant density of the fluid, $T_{0}$ is the operating temperature, and $\beta$ is the thermal expansion coefficient.

The use of the Boussinesq model instead of a density-temperature coupling reduces the convergence time of simulations (Fluent, 2009).

\subsubsection{Simulation results}

The single fan unit CFD simulations consisted of two processes. Firstly, the ideal volumetric flow rate for each fan was determined by specifying the heat exchanger model properties as discussed above. Secondly, the accuracy of the heat transfer modelling technique was investigated by adjusting the flow rate passing through the ACHE unit (by varying the porous zone resistance parameters) and recording the outlet temperatures. The volumetric flow rates and outlet temperature results were then compared to the corresponding analytical results.

The ideal volumetric flow rate is analytically solved by finding a volumetric flow rate value which solves the system resistance equation:

$$
\begin{aligned}
\Delta p_{h e}-\Delta p_{f a n}=K_{t s} & \frac{\left(\dot{m}_{a} / A_{t f r}\right)^{2}}{2 \rho_{t s}}+K_{u p} \frac{\left(\dot{m}_{a} / A_{e}\right)^{2}}{2 \rho_{u p}} \\
& +K_{d o} \frac{\left(\dot{m}_{a} / A_{e}\right)^{2}}{2 \rho_{d o}}+K_{\theta t} \frac{\left(\dot{m}_{a} / A_{t f r}\right)^{2}}{2 \rho_{t}}-\Delta p_{f a n} \approx 0
\end{aligned}
$$


Table 5.8: Radiator piecewise-polynomial function coefficients

\begin{tabular}{l|r|r}
\hline Velocity range $(\mathrm{m} / \mathrm{s})$ & $n$ & $h_{n}$ \\
\hline \multirow{3}{*}{0.46 to 0.927} & 0 & $4.212 \times 10^{6}$ \\
& 1 & $-1.951 \times 10^{7}$ \\
& 2 & $3.562 \times 10^{7}$ \\
& 3 & $-2.948 \times 10^{7}$ \\
& 4 & $9.231 \times 10^{6}$ \\
\hline 0.927 to 1.933 & 0 & $436 \times 10^{3}$ \\
& 1 & $-866 \times 10^{3}$ \\
& 2 & $732 \times 10^{3}$ \\
& 3 & $-286 \times 10^{3}$ \\
1.933 to 8 & 4 & $42.7 \times 10^{3}$ \\
\hline & 0 & $77 \times 10^{3}$ \\
& 1 & $-47.9 \times 10^{3}$ \\
& 2 & $16.7 \times 10^{3}$ \\
& 3 & $-2.99 \times 10^{3}$ \\
& 4 & 270 \\
& 5 & -9.67 \\
\hline
\end{tabular}

This is achieved by iteratively solving equation (5.16) until the solution converges. Table 5.9 shows the analytical and CFD ideal volumetric flow rate results. The CFD results show excellent correlation with the analytical results.

Table 5.9: Analytical and CFD ideal volumetric flow rate results

\begin{tabular}{lll}
\hline & \multicolumn{2}{l}{ Ideal volumetric } \\
Fan & Analytical & CFD \\
\hline N & 594 & $\dot{V}_{i d}\left(\mathrm{~m}^{3} / \mathrm{s}\right)$ \\
N9 & 591 & 596 \\
$630 \mathrm{~L}$ & 587 & 592 \\
\hline
\end{tabular}

Figure 5.22 shows the ACHE fan unit outlet temperatures obtained analytically and through CFD simulations. The outlet temperature is accurately predicted by the CFD model. Slight deviations from the analytical results can be seen at lower flow rates, and at the highest simulated flow rate. These differences are still very small however (within $1 \%$ of analytical results) and would be acceptable for this study. 


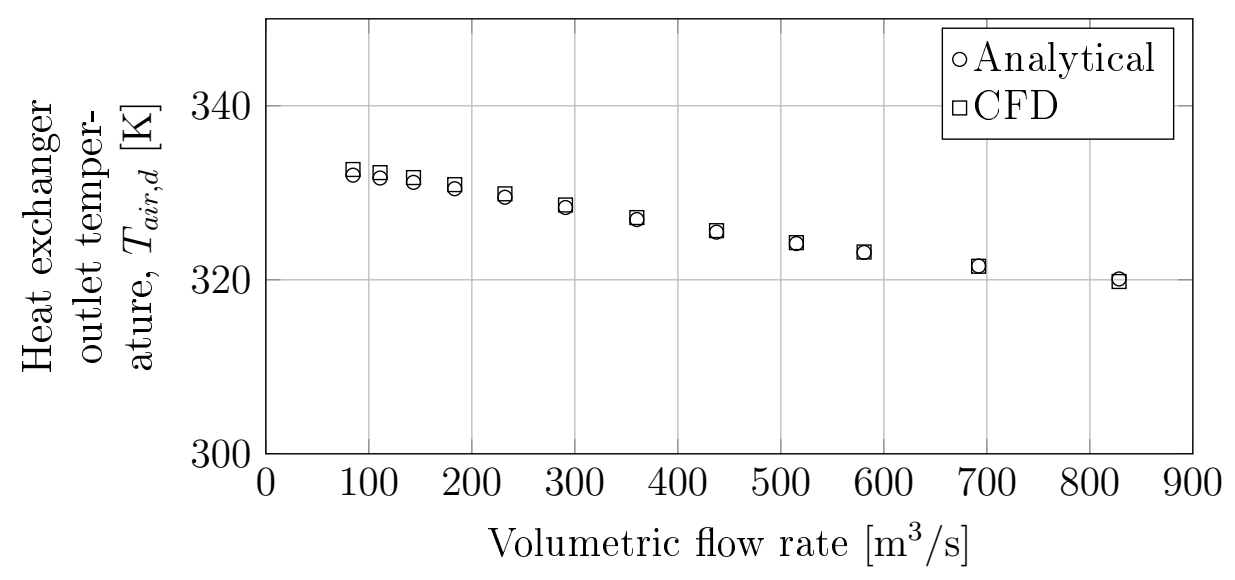

Figure 5.22: Analytical and CFD heat exchanger outlet temperature results

Table 5.10: ACSC system domain dimensions

\begin{tabular}{ccccc}
\hline$L_{x i}(\mathrm{~m})$ & $L_{x o}(\mathrm{~m})$ & $L_{y}(\mathrm{~m})$ & $L_{z o}(\mathrm{~m})$ & $H_{f}(\mathrm{~m})$ \\
\hline 200 & 600 & 400 & 600 & 45 \\
\hline
\end{tabular}

\subsubsection{Geometry and mesh}

A general ACSC system consisting of a total of 36 fan units (6 rows and 6 streets) were simulated. Symmetry could be used to reduce the computational effort required to solve the grid since only ' $2-\mathrm{D}$ ' wind conditions were investigated (with the wind direction perpendicular to the ACSC rows). The ACSC computational domain is shown in Figure 5.23 and the dimensions listed in Table 5.10 .

The inlet boundary was specified as a velocity inlet with a wind profile defined by a user defined function (UDF) (described in chapter 5.3.3). Slip wall (zero shear) conditions were applied to the top and far-side longitudinal walls. This is justified due to the flow adjacent to these walls being orientated in the $\mathrm{x}$-direction and the location of the walls being sufficiently far from the ACSC where the flow is more complex. The top wall was however also specified as an outlet pressure boundary (with atmospheric pressure) for the zero wind velocity simulations.

Figure 5.24 shows the mesh used for the simulations. The mesh consists of $5.58 \times 10^{6}$ tetrahedral cells. The mesh resolution is fine near the ACSC system and gradually decreases towards the outer regions of the domain. A mesh sizing bias was applied to the z-direction edge of the inlet which refines the mesh near the ground surface. This ensures that the velocity gradient of the wind profile would be accurately represented.

The dependency of simulation results on the mesh resolution was investigated. Three mesh sizes were created and simulations performed with a $3 \mathrm{~m} / \mathrm{s}$ wind velocity inlet. Figure 5.25 shows the results of this study. The mesh de- 

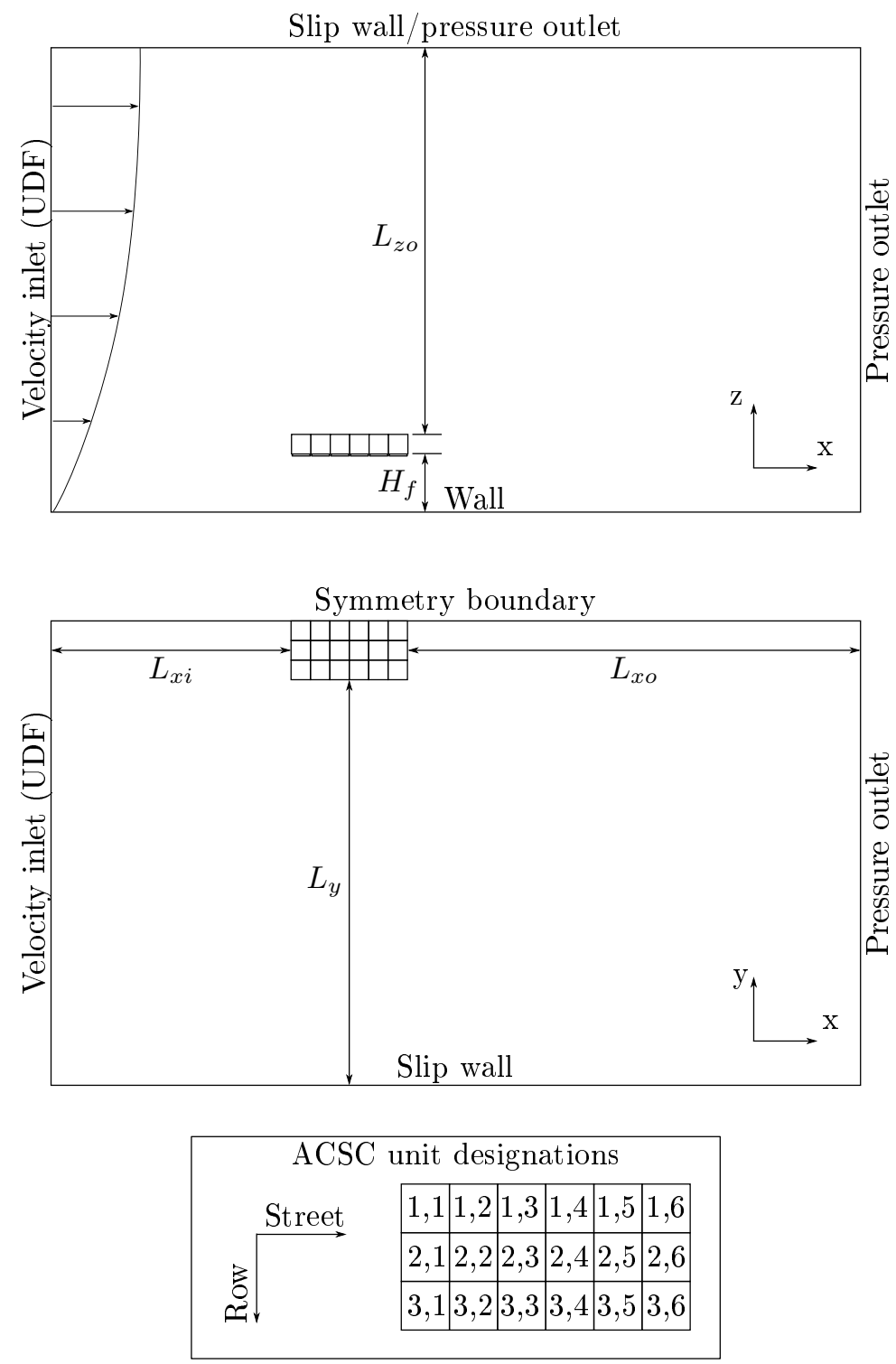

Figure 5.23: ACSC numerical model domain

pendency was investigated based on the volumetric effectiveness results of the whole system, as well as the three upstream peripheral fans. The volumetric effectiveness results show little change as the mesh size is changed. It should be stated that, although the three mesh sizes differ considerably, the mesh resolution surrounding the ACSC does not differ substantially between the three meshes. By increasing the cell sizes at the outer regions of the domain while keeping the cells surrounding the ACSC small, the mesh size could thus be reduced without compromising accuracy. 


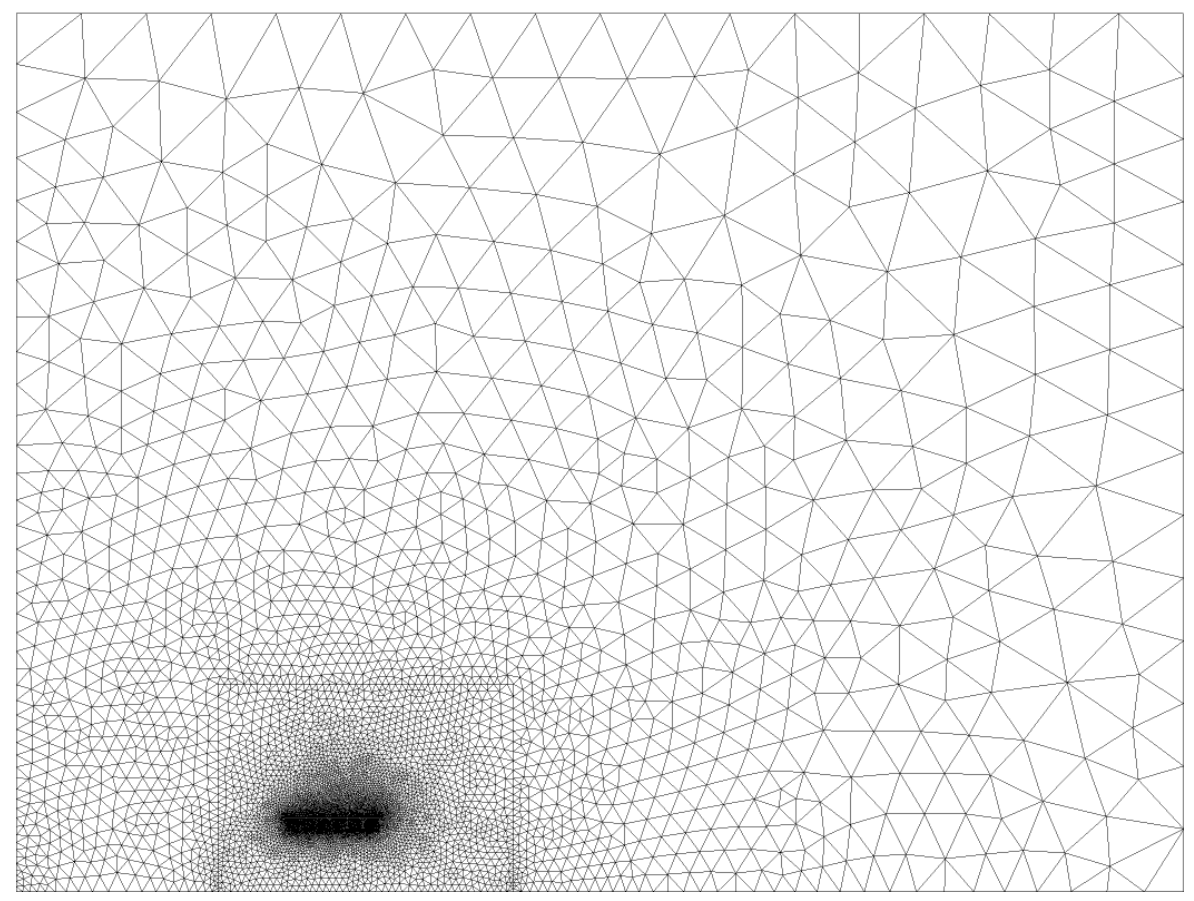

Figure 5.24: ACSC system mesh $\left(5.58 \times 10^{6}\right.$ cells $)$

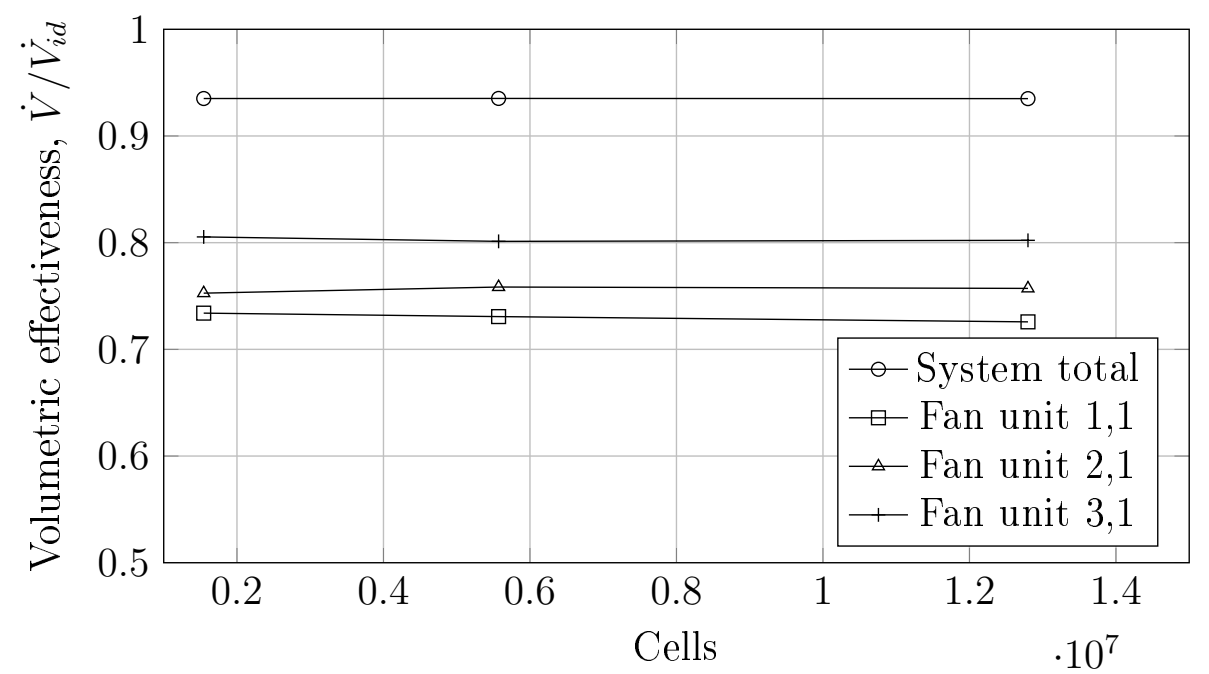

Figure 5.25: ACSC system mesh dependency investigation

\subsubsection{Modelling of wind}

The cross-winds were simulated using a user defined function (UDF) which specifies a wind velocity profile. The wind velocity profile is given by:

$$
v_{z}=v_{r e f}\left(\frac{z}{z_{r e f}}\right)^{b}
$$



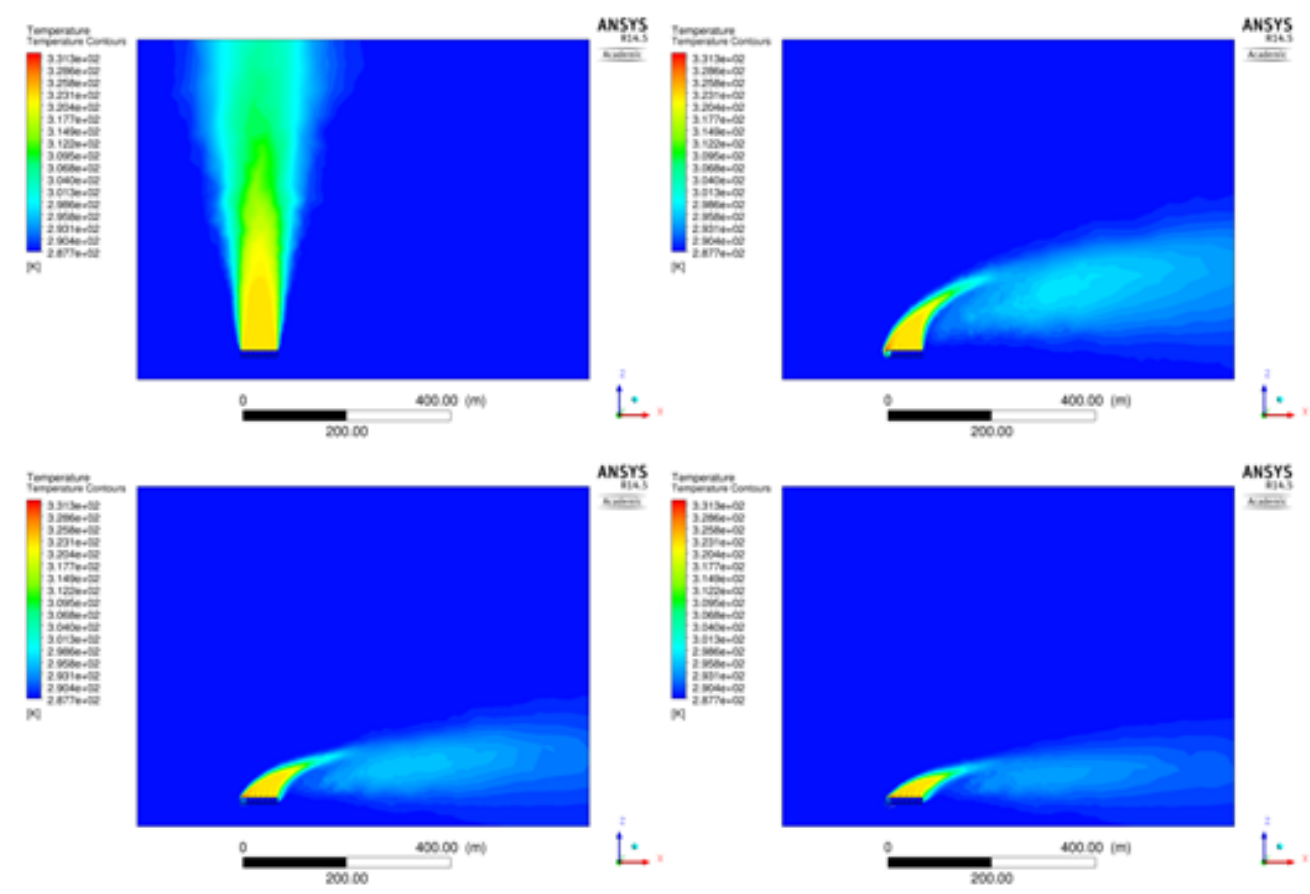

Figure 5.26: Temperature contours for N-fan ACSC street 1

where $v_{z}$ is the horizontal velocity at an elevation $z$, and $v_{\text {ref }}$ is the reference velocity at an elevation of $z_{\text {ref }}$. For this study the reference elevation is equal to the platform height, i.e., $z_{r e f}=H_{f}$. The coefficient, $b$, defines the shape of the wind profile at the inlet boundary. For this study a value of $1 / 5$ was chosen for the $b$-coefficient, as recommended by VDI (1978).

\subsubsection{Simulation results}

The full scale ACSC cross-wind simulations were conducted for each fan system with wind speeds of $0 \mathrm{~m} / \mathrm{s}, 3 \mathrm{~m} / \mathrm{s}, 6 \mathrm{~m} / \mathrm{s}$ and $9 \mathrm{~m} / \mathrm{s}$. Figure 5.26 shows temperature contours for street 1 of the $\mathrm{N}$-fan ACHE. The plume above the ACSC is deflected as the wind velocity is increased.

The volumetric effectiveness of each individual fan unit in the ACSC is displayed in Figure 5.27. With the $0 \mathrm{~m} / \mathrm{s}$ wind velocity condition a reduction in volumetric effectiveness can be seen at the perimeter fan units. As the wind velocity increases a trend in the volumetric effectiveness distribution in the ACSC can be seen. The first ACSC row shows a substantial reduction in effectiveness and the effectiveness gradually improves in the downstream rows to such an extent that the downstream perimeter units show a higher volumetric effectiveness at the $3 \mathrm{~m} / \mathrm{s}, 6 \mathrm{~m} / \mathrm{s}$ and $9 \mathrm{~m} / \mathrm{s}$ wind velocity conditions when compared to the zero wind condition.

Figure 5.28 shows plots of the volumetric effectiveness results for the ACSC system, as well as the first row units. As expected, a decrease in volumetric 


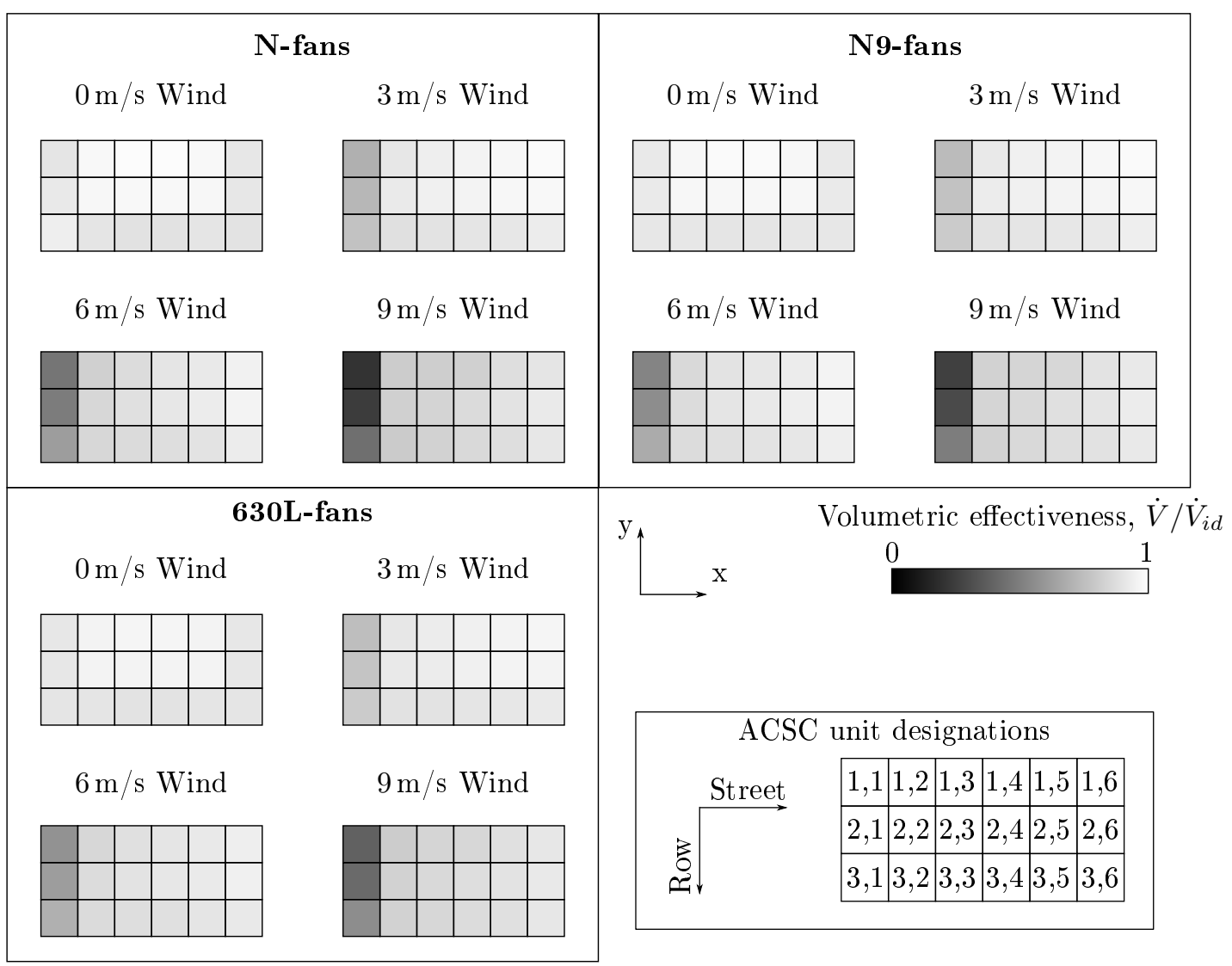

Figure 5.27: ACSC individual fan unit volumetric effectiveness results

effectiveness is seen with an increase in the cross-wind velocity. The system volumetric effectiveness shows a gradual decrease towards a value of \pm 0.8 at a wind velocity of $9 \mathrm{~m} / \mathrm{s}$. As with the multiple fan variable platform height CFD results, the three fan system volumetric effectiveness results for the different fans show little differences. The gradual volumetric effectiveness reduction trend is also similar to the variable platform height CFD results.

The first row volumetric effectiveness results show a steeper reduction trend with the differences between the fans more accentuated. As expected, the 630L-fans show the highest volumetric effectiveness values. An increase of $48.2 \%$ above the $\mathrm{N}$-fans volumetric effectiveness results are seen at the $9 \mathrm{~m} / \mathrm{s}$ wind velocity.

Figures 5.29, 5.30 and 5.31 show volumetric effectiveness results of the three ACSC streets and upstream perimeter fans of the N-, N9-, and 630L-fan systems respectively.

The volumetric effectiveness results of the ACSC streets show the same trend for the three fan systems. Streets 1 and 2 show very similar results, except at the highest wind velocity where the volumetric effectiveness of street 2 is slightly better than street 1 . The results for street 3 show a different 


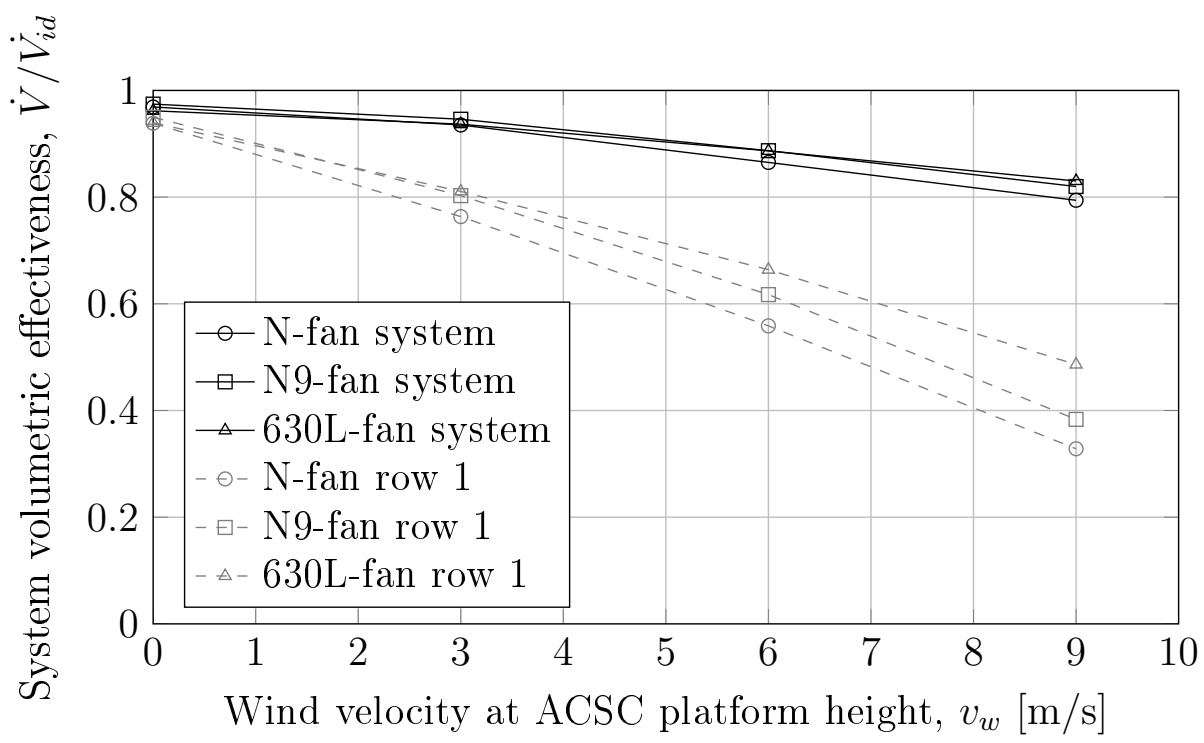

Figure 5.28: ACSC system volumetric effectiveness results

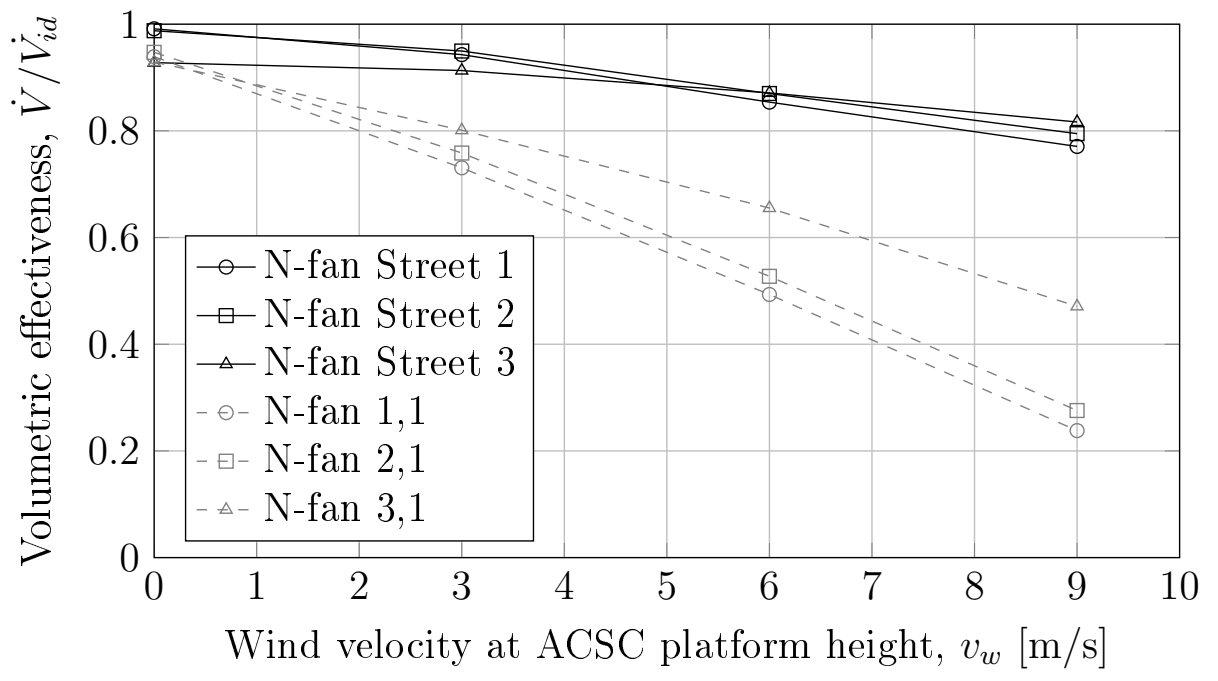

Figure 5.29: N-fan ACSC volumetric effectiveness results

trend however. A flatter trend-line is observed showing the lowest volumetric effectiveness values at the $0 \mathrm{~m} / \mathrm{s}$ and $3 \mathrm{~m} / \mathrm{s}$ wind velocities, but the highest values at the $9 \mathrm{~m} / \mathrm{s}$ wind velocity when compared to the other ACSC streets. Street 3 is thus less affected by the presence of wind which can also be seen in Figure 5.27 where the change in volumetric effectiveness of the units in this street is less apparent than the units in the other two streets. Street 3 is located at the outer edge of the ACSC and is entirely comprised of perimeter fan units. This explains the lower effectiveness results seen at the zero wind condition, which is a result of the distorted inlet flow conditions affecting the 


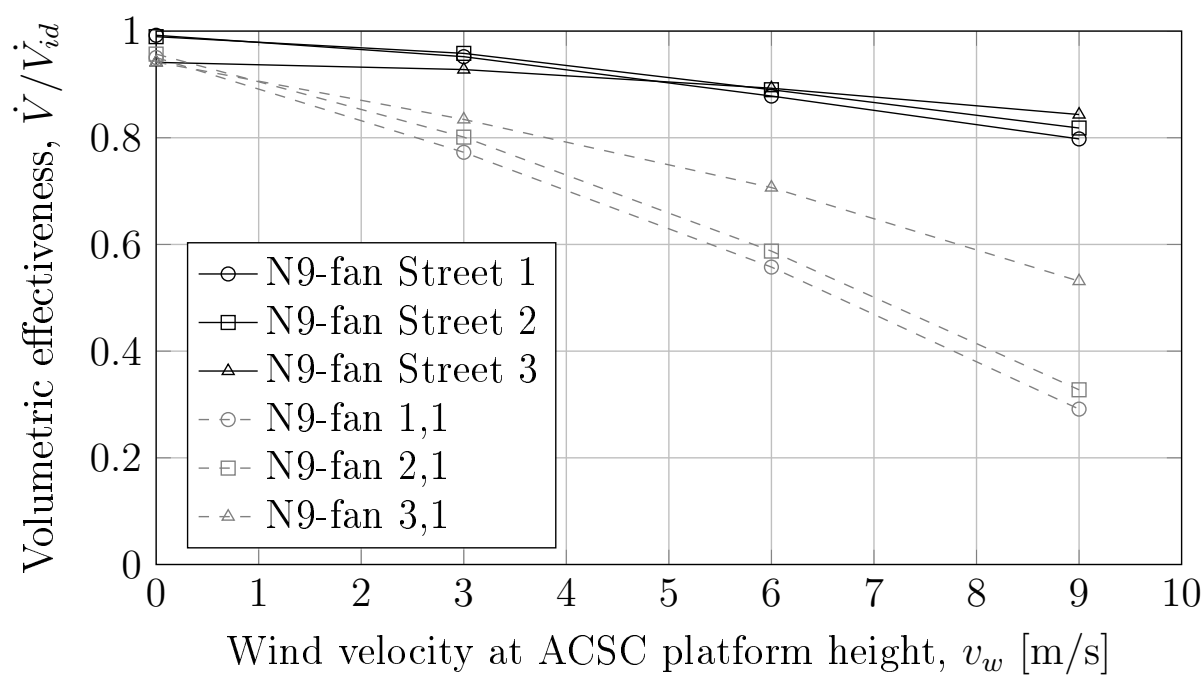

Figure 5.30: N9-fan ACSC volumetric effectiveness results

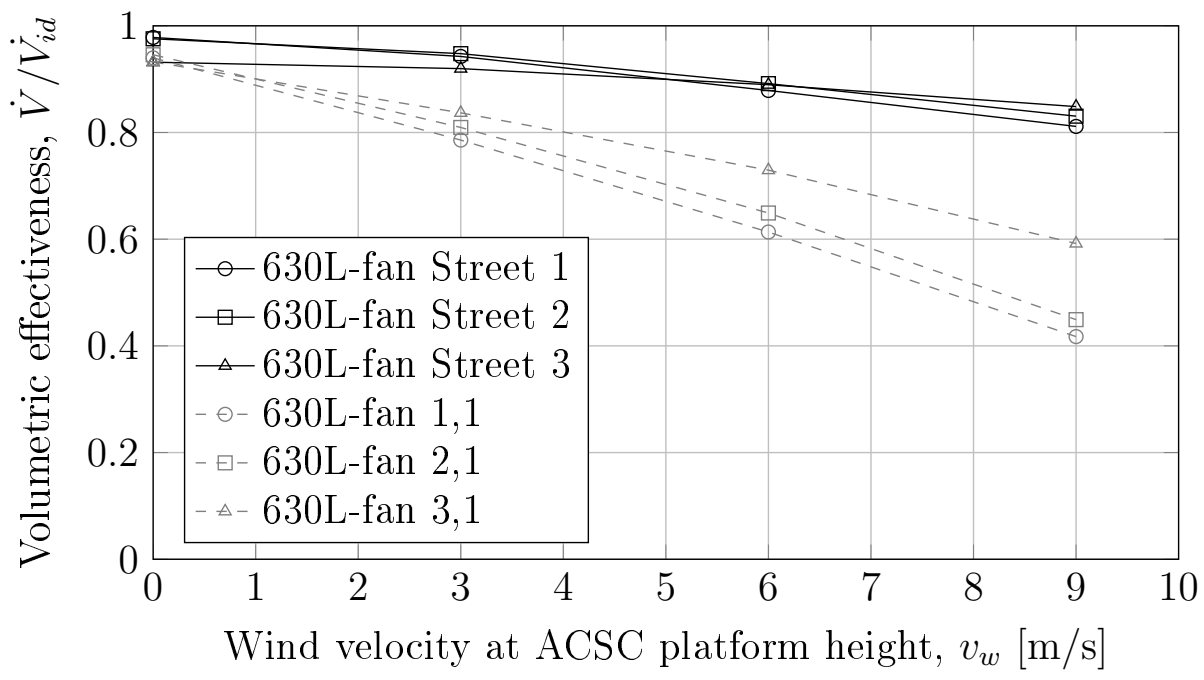

Figure 5.31: 630L-fan ACSC volumetric effectiveness results

effectiveness of the perimeter units.

The upstream perimeter unit's volumetric effectiveness results show much steeper gradients and shows reductions of up to $74.6 \%$ in the worst case occurring at the $\mathrm{N}$-fan unit 1,1 . Units 2,1 and 3,1 show better effectiveness values than unit 1,1 with unit 3,1 showing the best effectiveness of the three. This is ascribed to the fact that unit 3,1 is able to draw air in from the $\mathrm{x}$ - or $\mathrm{y}$ directions leading to less restrictions than experienced by the other two units, which mainly draws air from the x-direction. Differences between the three fans are evident at these three units. The 630L-fan units show substantially better volumetric effectiveness results, and also less variation between the three 
units. This again shows how the high solidity of the 630L-fan is beneficial in situations where distorted inlet flow conditions are present.

The simulation results obtained by Louw (2011) showed similar trends in the volumetric effectiveness of the fan units. From Louw's (2011) results it can be seen that the reduction in volumetric effectiveness seen at the upstream perimeter units (with $\mathrm{x}$-direction winds) increases as the number of ACSC streets is increased. As the upstream peripheral edge becomes larger the fans near the symmetry plane experiences increased '2-D' wind conditions, drawing in air purely from the $\mathrm{x}$-direction which is also drawn in from a higher elevation in an attempt to maintain the same volumetric flow rate. 


\section{Chapter 6}

\section{Correlations}

The results obtained by the experimental variable platform height and numerical ACSC investigation are used to derive a correlation between the system volumetric effectiveness, dimensionless platform height and wind speed. The procedure followed to derive this correlation is detailed in this section.

\subsection{Expansion of Salta curve}

To obtain a correlation for volumetric effectiveness which takes into account the effect of the platform height as well as wind speed it was decided to expand the Salta curve, which already provides a correlation between the volumetric effectiveness and platform height. The Salta curve is given by:

$$
\dot{V} / \dot{V}_{i d}=0.985-e^{-X}
$$

with $X$ given by:

$$
X=\left(\frac{1+45 / n_{f}}{6.35}\right)\left(\frac{H_{f}}{D_{f a n}}\right)
$$

where $n_{f}$ is the number of fans.

To expand the Salta curve, the dimensionless number $X$ is adjusted to account for wind effects. A new dimensionless number, $\xi$, is introduced:

$$
\xi=K X f_{\text {wind }}
$$

where $\mathrm{K}$ is a constant which accounts for the different fan models and $f_{\text {wind }}$ is the wind factor, defined as:

$$
f_{\text {wind }}=\left(1+\frac{v_{w}}{v_{x}}\right)^{c}
$$

where $c$ is a constant and $v_{w}$ and $v_{x}$ are the wind velocity measured at the ACSC platform height and upstream average cross-flow velocity measured at 
the peripheral inlet area to the ACSC street, respectively. Figure 6.1 illustrates the definition of the wind- and cross-flow velocities.

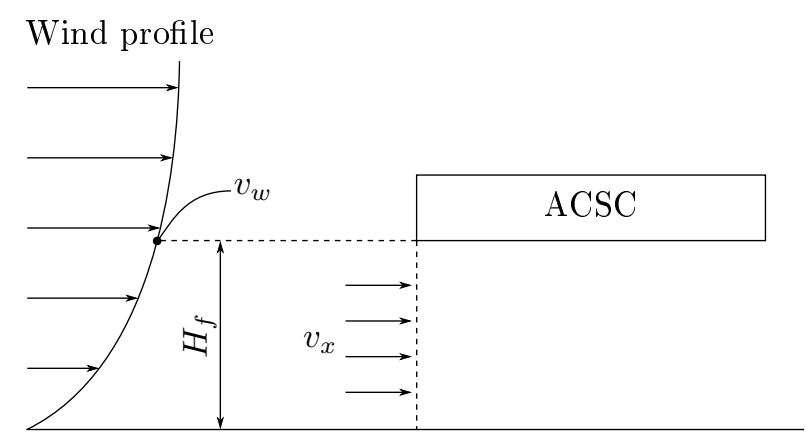

Figure 6.1: Wind- and cross-flow velocity definition

The cross-flow velocity, $v_{x}$, has some significance in the study of the effect of cross-flow on the performance of axial flow fans. Stinnes and von Backström (2002) investigated the effect of cross-flow on the performance of axial flow fans and managed to accurately predict the reduction in volumetric effectiveness of a fan system due to a reduction in platform height by applying a theoretical model which predicts the ratio of cross-flow to in-flow.

Substituting equation (6.4) into equation (6.3) gives:

$$
\xi=K X f_{\text {wind }}=K\left(\frac{1+45 / n_{f}}{6.35}\right)\left(\frac{H_{f}}{D_{\text {fan }}}\right)\left(1+\frac{v_{w}}{v_{x}}\right)^{c}
$$

The Salta curve is then adapted by replacing $X$ with the new dimensionless number, $\xi$ :

$$
\dot{V} / \dot{V}_{i d}=0.985-e^{-\xi}=0.985-e^{-K X f_{\text {wind }}}
$$

\subsection{Results and discussion}

The constants in equation (6.5) are obtained by fitting the numerical and experimental volumetric effectiveness results to the expanded Salta curve given by equation (6.6). The results for the three fan systems are shown in Figure 6.2 . The constants of equation (6.5) as well as the coefficient of determination are also shown for each set of results.

The resulting $c$ constants can be used to plot the wind factor function given by equation $(6.4)$. Figure 6.3 shows the wind factor function for the three fans as a function of the dimensionless wind velocity, $v_{w} / v_{x}$. A reduction in the wind factor is shown as the dimensionless wind velocity increases. From equation 6.6 it can be seen that the volumetric effectiveness reduces as the wind factor, $f_{\text {wind }}$, is reduced. Little difference can be seen between the results 

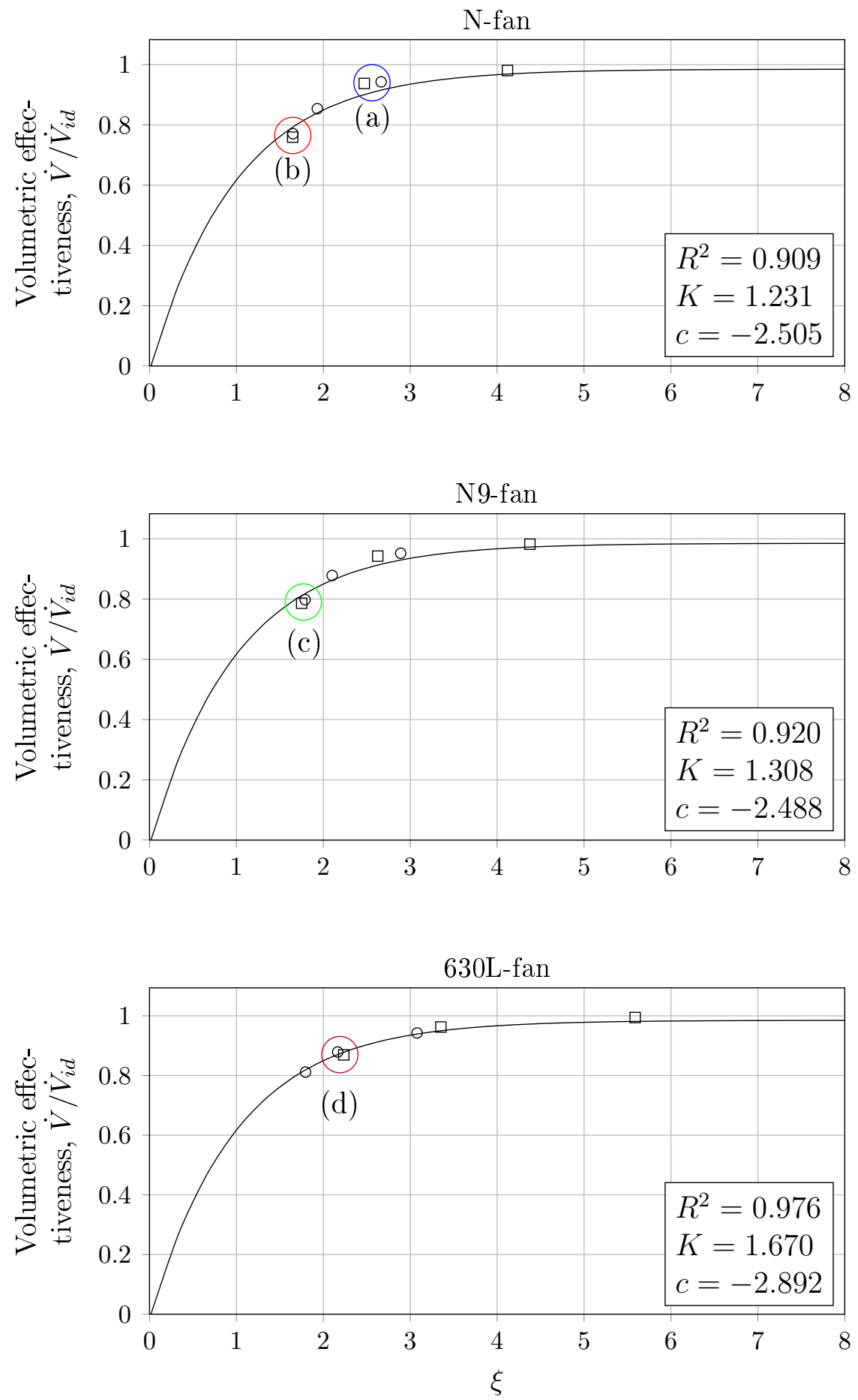

Equation 6.6

$\square$ Experimental variable platform height results

$\circ$ CFD ACSC wind speed simulation results (Street \#1)

Figure 6.2: Variable platform height and cross-wind velocity results 
for the three fans with the 630L-fan showing slightly lower values than the other two fans.

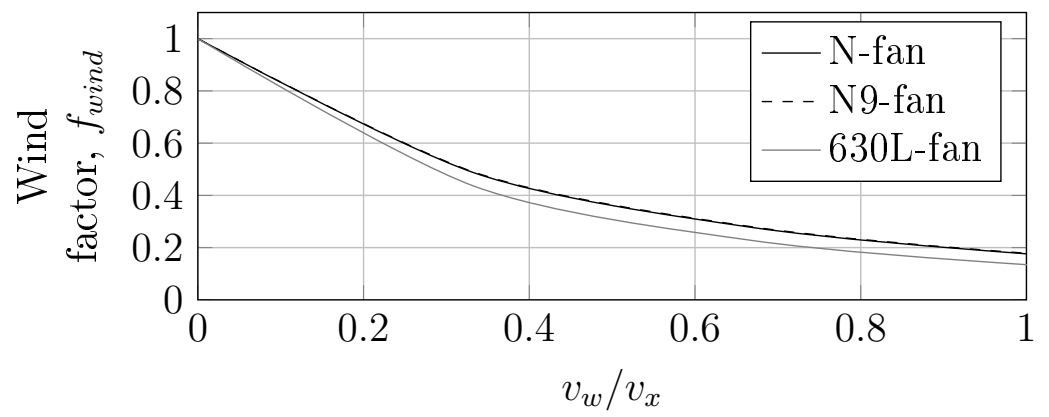

Figure 6.3: Effect of non-dimensional wind number, $v_{w} / v_{x}$, on the wind factor, $f_{\text {wind }}$

The results shown in Figure 6.2 shows some numerical wind effects and experimental floor height data points lying close together. These points are listed in Table 6.1. The similarity of the results at the coinciding data points provides insight into the relationship between the effects of platform height and cross-wind effects on the volumetric effectiveness of a fan system. For example, for the $\mathrm{N}$-fan system, platform heights of $1.5 \mathrm{D}_{\text {fan }}$ and $1 \mathrm{D}_{\text {fan }}$ produce the same volumetric effectiveness results (due to similar operating conditions) as cross-wind speeds of $3 \mathrm{~m} / \mathrm{s}$ and $9 \mathrm{~m} / \mathrm{s}$ respectively. This trend is fan specific however, as the N9- and 630L-fans are less sensitive to changes in the platform height (and wind velocity), leading to different distributions in the data points.

Table 6.1: Comparison of coincident experimental floor height and CFD wind effects data points

\begin{tabular}{ll|ccc|ccc}
\hline & & \multicolumn{3}{|c|}{ Experimental } & \multicolumn{3}{c}{ CFD } \\
Point & Fan & $H_{f} / D_{\text {fan }}$ & $\xi$ & $\dot{V} / \dot{V}_{i d}$ & $v_{w}(\mathrm{~m} / \mathrm{s})$ & $\xi$ & $\dot{V} / \dot{V}_{i d}$ \\
\hline (a) & $\mathrm{N}$ & 1.5 & 2.471 & 0.938 & 3 & 2.665 & 0.943 \\
(b) & $\mathrm{N}$ & 1.0 & 1.648 & 0.760 & 9 & 1.650 & 0.771 \\
(c) & N9 & 1.0 & 1.751 & 0.786 & 9 & 1.790 & 0.798 \\
(d) & 630L & 1.0 & 2.235 & 0.869 & 6 & 2.165 & 0.879 \\
\hline
\end{tabular}

The similarity of the coinciding points listed in Table 6.1 are further investigated by comparing the flow field surrounding the perimeter fan of the experimental and CFD investigations. No flow field velocity measurements were made at the $1 \mathrm{D}_{\text {fan }}$ platform height position which means only point (a) can be used for this comparison. 
Due to the dimensional differences of the experimental and CFD facilities the velocity vectors had to be converted to non-dimensional values for comparison. This was achieved by dividing the vector velocity value with the fan tip velocity $\left(v_{t i p}\right)$ value. Figure 6.4 shows the non-dimensional vectors of the experimental and CFD investigations for point (a) in Figure 6.2.

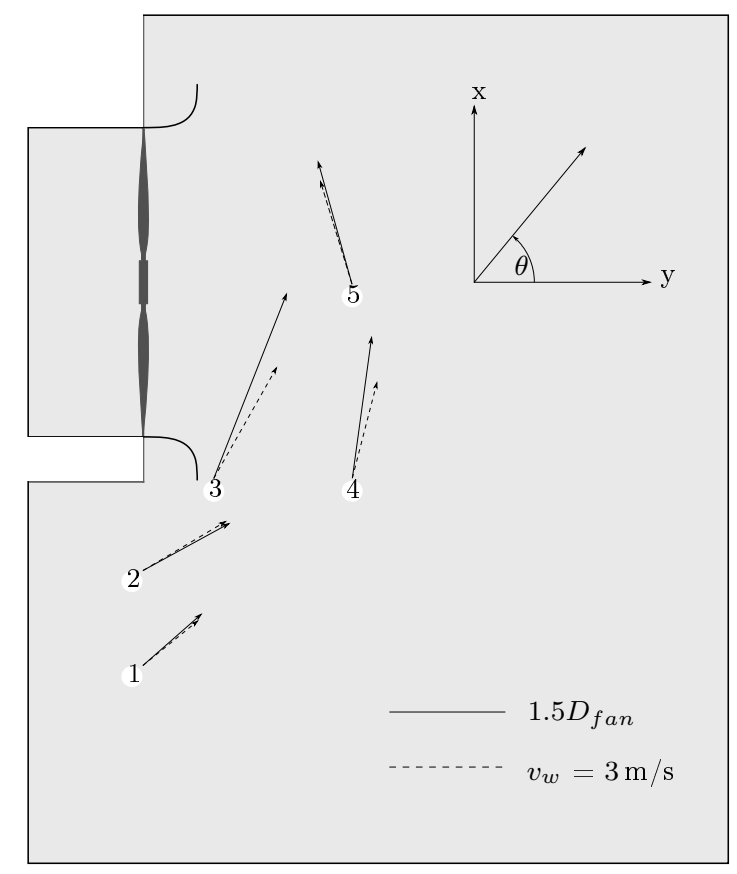

Figure 6.4: Perimeter fan flow field comparison of coinciding experimental and CFD data points at (a) in Figure 6.2

The vectors in Figure 6.4 are indeed very similar. This supports the claim made earlier that the operating conditions of the coinciding data points in Figure 6.2 are similar.

The non-dimensional velocity and flow angle values for the vectors in Figure 6.4 are listed in Table 6.2. The experimental and CFD vectors at positions 1,2 and 5 are very similar, with position 5 showing a notable deviation only in the vector dimensionless velocity value. Positions 3 and 4 show differences in the flow velocity and angle. The vector comparison made in Figure 5.11 in chapter 5.2.3.1 showed similar differences at these positions, which were ascribed to the proximity of these positions to the fan and the lack of actual fan geometrical properties included in the PJM CFD fan model.

The constants of equation (6.5) were also optimised for the combined data set of all the wind velocity and platform height results. In doing so, a general solution to equation (6.6) is obtained. The combined results are shown together with the optimised constants in Figure 6.5. The amount of scatter in the data 
Table 6.2: Velocity and angle values for vectors shown in Figure 6.4

\begin{tabular}{|l|c|c|c|c|}
\cline { 2 - 5 } \multicolumn{1}{c|}{} & \multicolumn{2}{c|}{ Dimensionless velocity, $v^{*}=v / v_{\text {tip }}$} & \multicolumn{2}{c|}{ Flow angle $\left({ }^{\circ}\right)$} \\
\hline Position & Experimental & CFD & Experimental & CFD \\
\hline 1 & 0.113 & 0.103 & 39.2 & 41.3 \\
2 & 0.143 & 0.140 & 30.8 & 28.8 \\
3 & 0.287 & 0.184 & 60.4 & 68.4 \\
4 & 0.206 & 0.143 & 75.3 & 81.7 \\
5 & 0.184 & 0.156 & 107.3 & 105.7 \\
\hline
\end{tabular}

results in a lower coefficient of determination value, but the solution would be sufficient for an investigation into general performance trends.

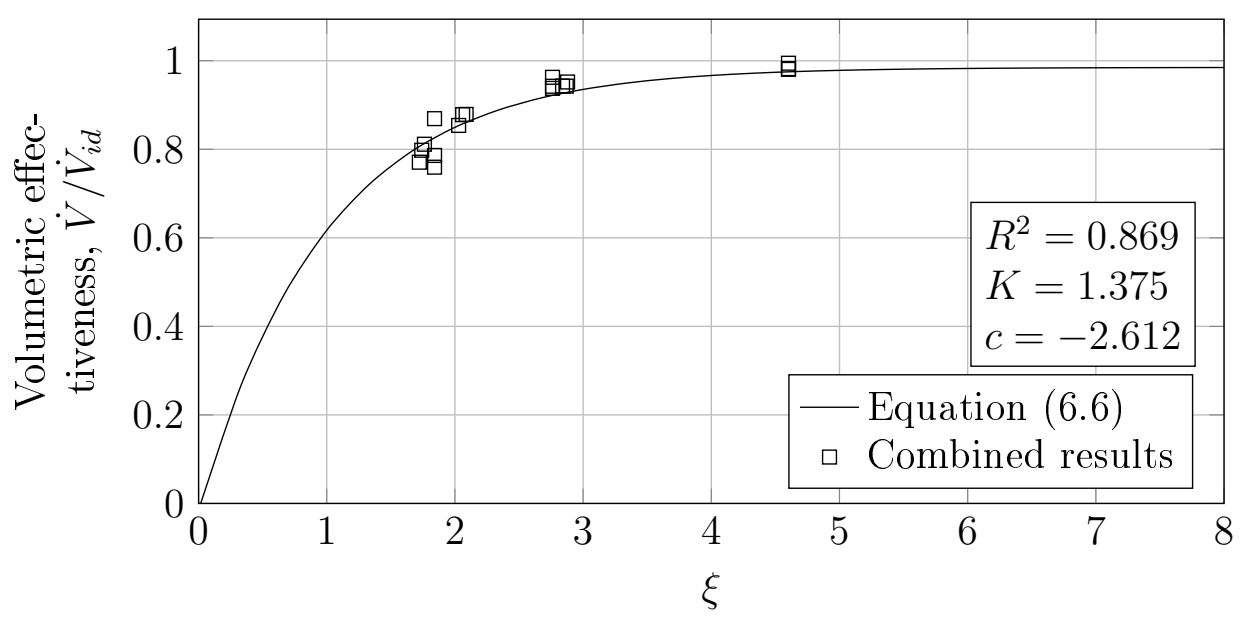

Figure 6.5: Combined platform height and cross-wind velocity results for all fan systems

The constants shown in Figure 6.5 can now be used to obtain a general solution for the volumetric effectiveness by substituting it into equation (6.5) and then substituting equation (6.5) into (6.6):

$$
\begin{array}{r}
\dot{V} / \dot{V}_{\text {id }}=0.985 \\
\quad-\exp \left[-1.375\left(\frac{1+45 / n_{f}}{6.35}\right)\left(\frac{H_{f}}{D_{\text {fan }}}\right)\left(1+\frac{v_{w}}{v_{x}}\right)^{-2.612}\right]
\end{array}
$$

Equation 6.7) provides a general solution to the volumetric effectiveness of a fan street with a set number of fans $\left(n_{f}\right)$. Figure 6.6 shows a threedimensional plot of equation (6.7). The reduction of volumetric effectiveness can be seen as the platform height is reduced and dimensionless cross-wind velocity increased, creating a downward slope towards the lower corner of the graph where the lowest platform height and highest wind velocity coincide. 


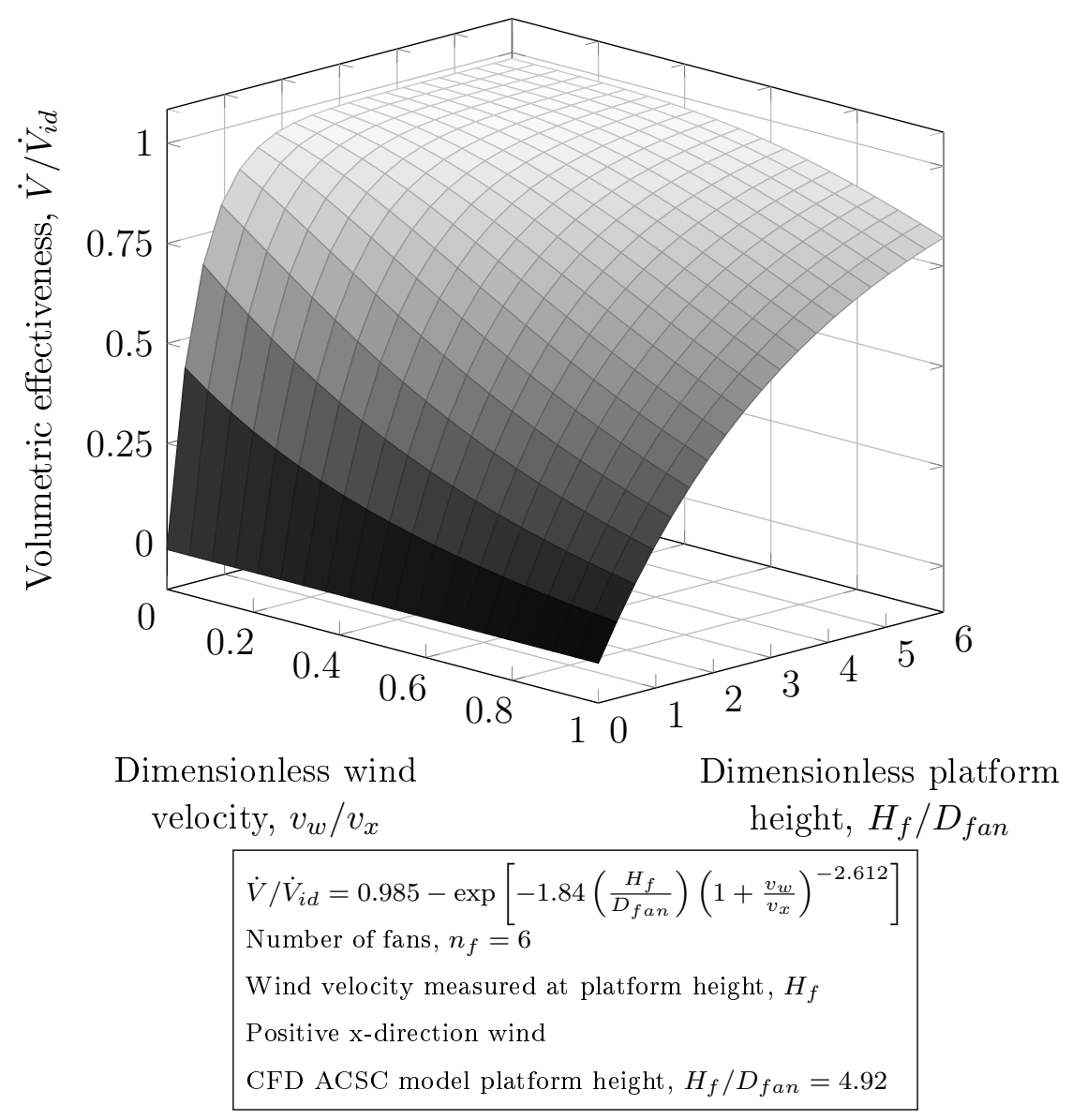

Figure 6.6: $3 \mathrm{D}$ plot of volumetric effectiveness based on platform height and dimensionless wind velocity

The effect of the cross-wind velocity on the volumetric effectiveness is illustrated in Figure 6.7 by plotting a range of constant dimensionless wind velocity contours. The zero dimensionless wind velocity condition produces the Salta curve, and as the velocity increases the curve shape changes and assumes a more gradual slope. This implies that with high cross-wind velocity conditions a significantly higher platform height is required to maintain the same volumetric effectiveness value. It also shows how the volumetric effectiveness is reduced as the cross-wind velocity increases for a given platform height. At the lower platform heights, the volumetric effectiveness is very sensitive to a change in cross-wind velocity, whereas at high platform heights, the volumetric effectiveness is much less sensitive to a change in the cross-wind velocity.

Figure 6.8 shows constant dimensionless platform height contours. The high platform height contours remain relatively unchanged as the dimensionless wind velocity increases up to a value of \pm 0.3 where after it shows a gradual reduction as the dimensionless wind velocity is further increased. In contrast the low platform height contours show a drastic reduction in volumetric effec- 


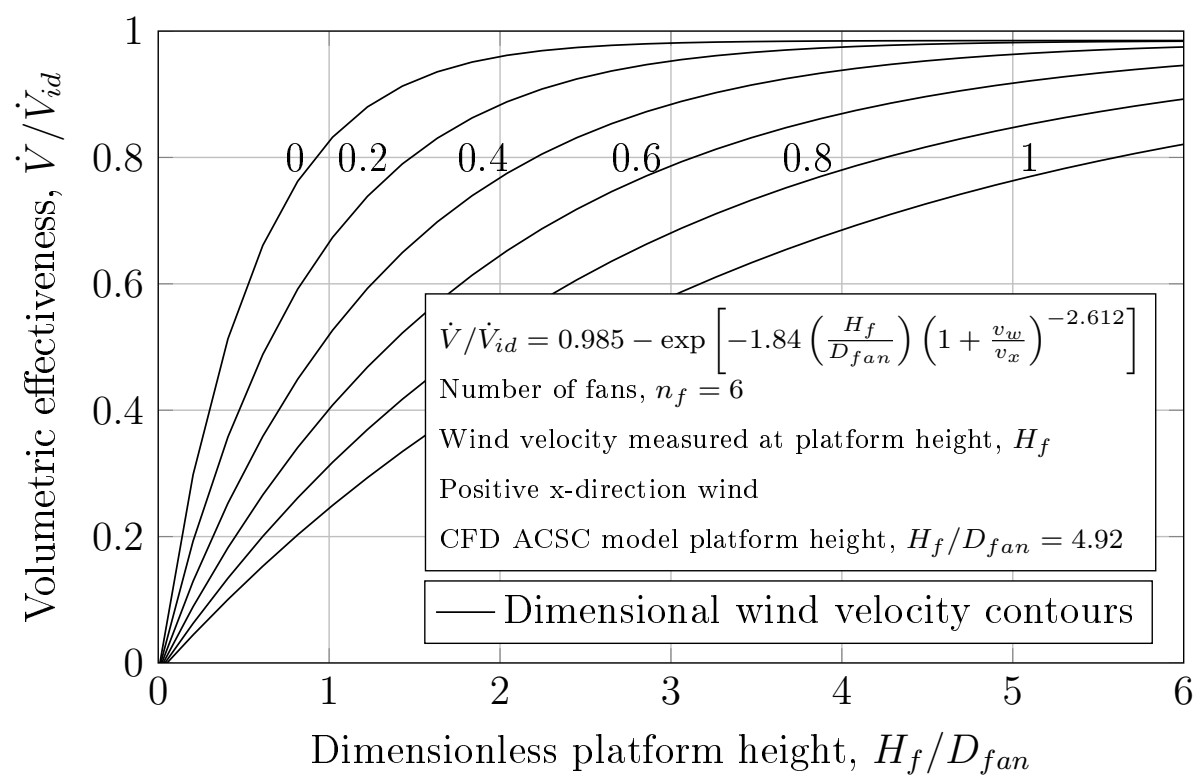

Figure 6.7: Volumetric effectiveness curves at constant dimensionless wind velocities

tiveness, which occurs immediately from the zero wind condition. This again shows that the volumetric effectiveness of a system becomes less sensitive to cross-wind velocity as the platform height is increased.

To illustrate the relationship between platform height and cross-wind velocity, volumetric effectiveness contour plots are shown in Figure 6.9. This shows to what extent the platform height should be increased to maintain a certain volumetric effectiveness value as the cross-wind velocity increases. The steep gradients shown by the high volumetric effectiveness contour lines shows that the presence of cross-winds requires a substantial increase in platform height in order to maintain a high volumetric effectiveness. From an ACSC design perspective this emphasizes the significance of specifying a platform height that will ensure effective operation of the ACSC when subjected to cross-winds.

From a practical perspective it would be beneficial to show the relationship between the dimensionless platform height (or floor height) of the experimental facility and a dimensionless wind velocity which would produce the same volumetric effectiveness value. Such a correlation can be obtained by putting the volumetric effectiveness of the experimental facility and the CFD ACSC model equal to each other, i.e.

$$
\left(\dot{V} / \dot{V}_{i d}\right)_{E x p}=\left(\dot{V} / \dot{V}_{i d}\right)_{A C S C}
$$

Substituting the volumetric effectiveness equations with equation (6.6) and substituting the following values, 


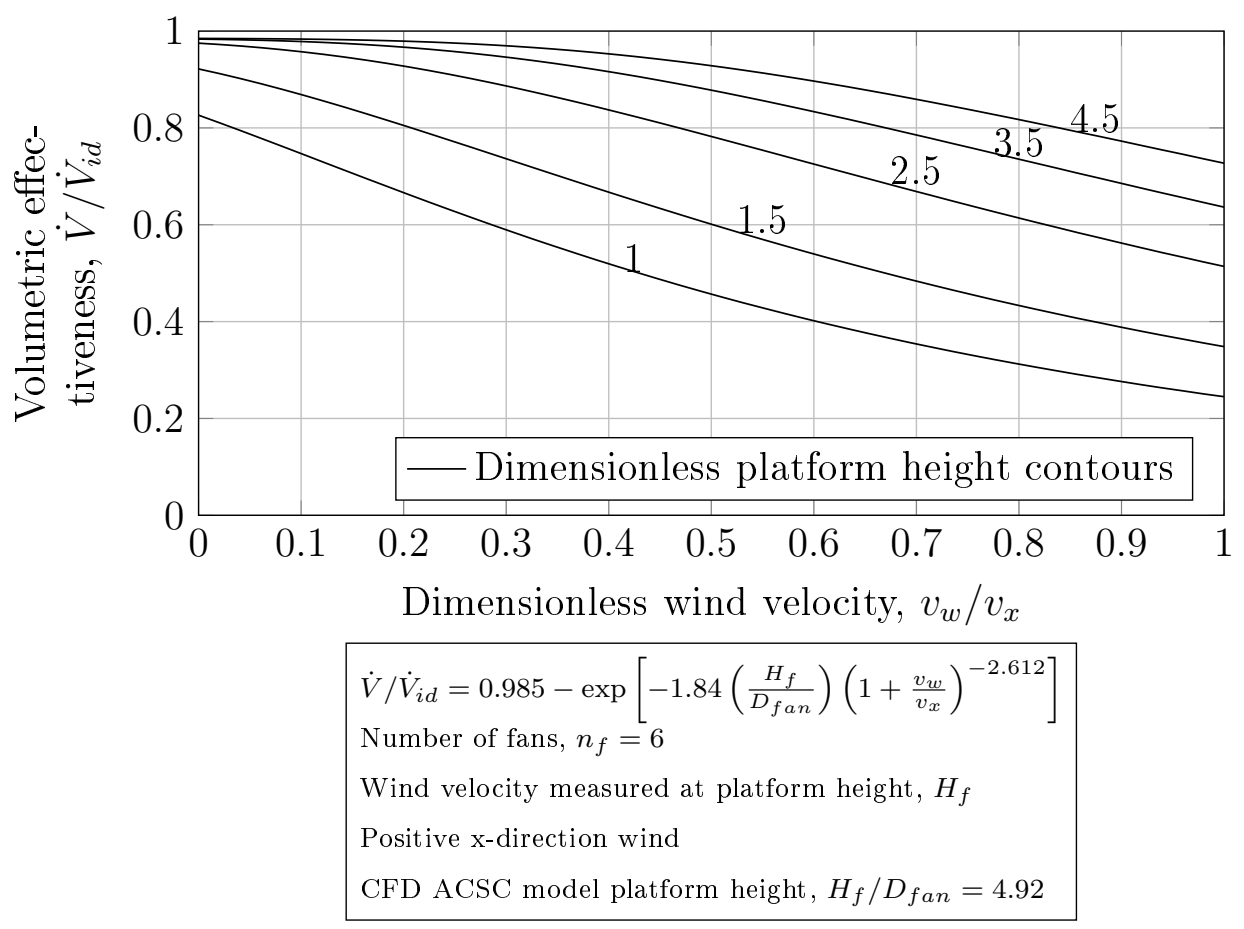

Figure 6.8: Volumetric effectiveness curves at constant dimensionless platform heights

Experimental facility wind velocity

CFD ACSC platform height

$$
\begin{aligned}
\left(v_{w} / v_{x}\right)_{E x p} & =0 \\
\left(H_{f} / D_{f a n}\right)_{A C S C} & =4.92
\end{aligned}
$$

yields the following equation

$$
\left(\frac{v_{w}}{v_{x}}\right)_{A C S C}=\left[\frac{\left(H_{f} / D_{f a n}\right)_{\text {Exp }}}{4.92}\right]^{1 / c}-1
$$

Equation (6.8) allows one to determine a dimensionless wind condition that is simulated in the experimental facility by adjusting the platform height to a certain position. Figure 6.10 shows equation (6.8) for the three fans used in the investigation.

The $\mathrm{N}$ - and N9-fan curves are almost indistinguishable and the 630L-fan curve lie slightly lower than the other two. This means that when conducting experiments with the 630L-fan (which has the highest solidity of the three fans) and a certain dimensionless wind velocity needs to be simulated, the floor height would have to be set at a lower height than what would be required for the same dimensionless wind velocity with the other two fans. This is plausible since the volumetric effectiveness values produced by the 630L-fans with the variable platform height experimental investigation were in all cases higher than the other two fans. 


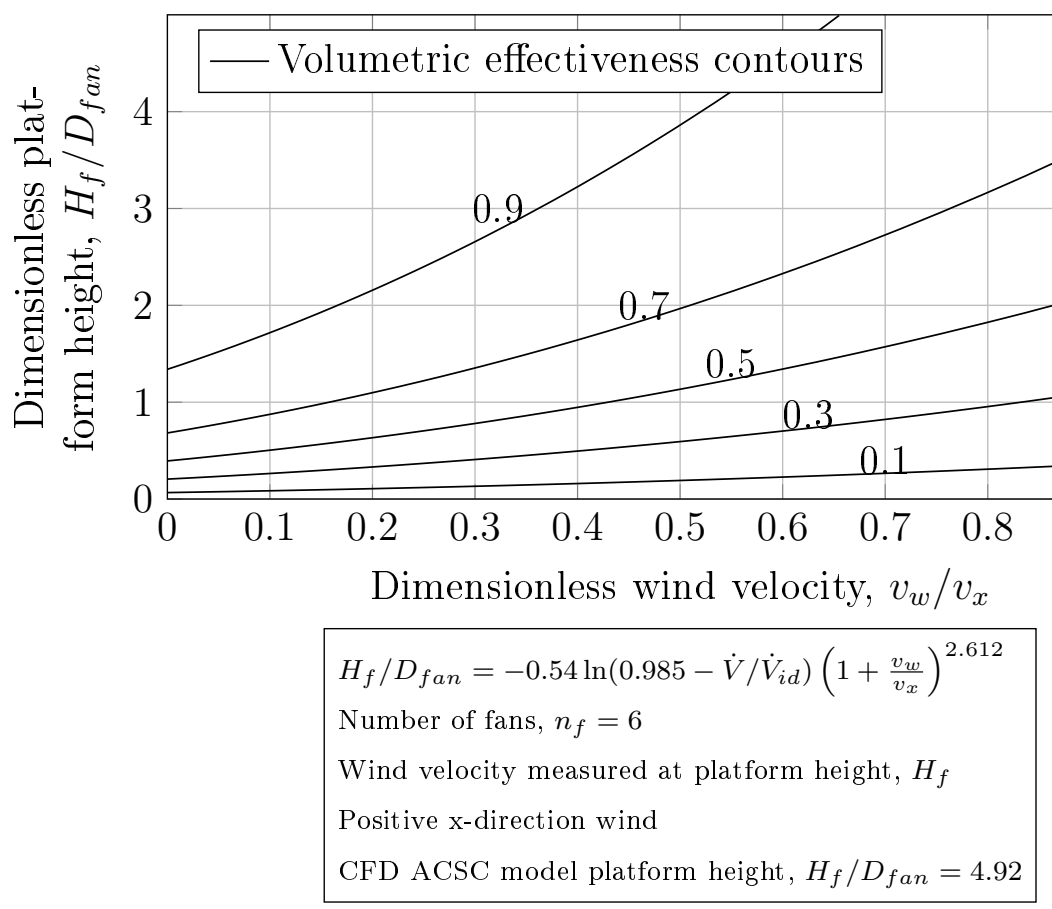

Figure 6.9: Dimensionless platform height curves at constant volumetric effectiveness values

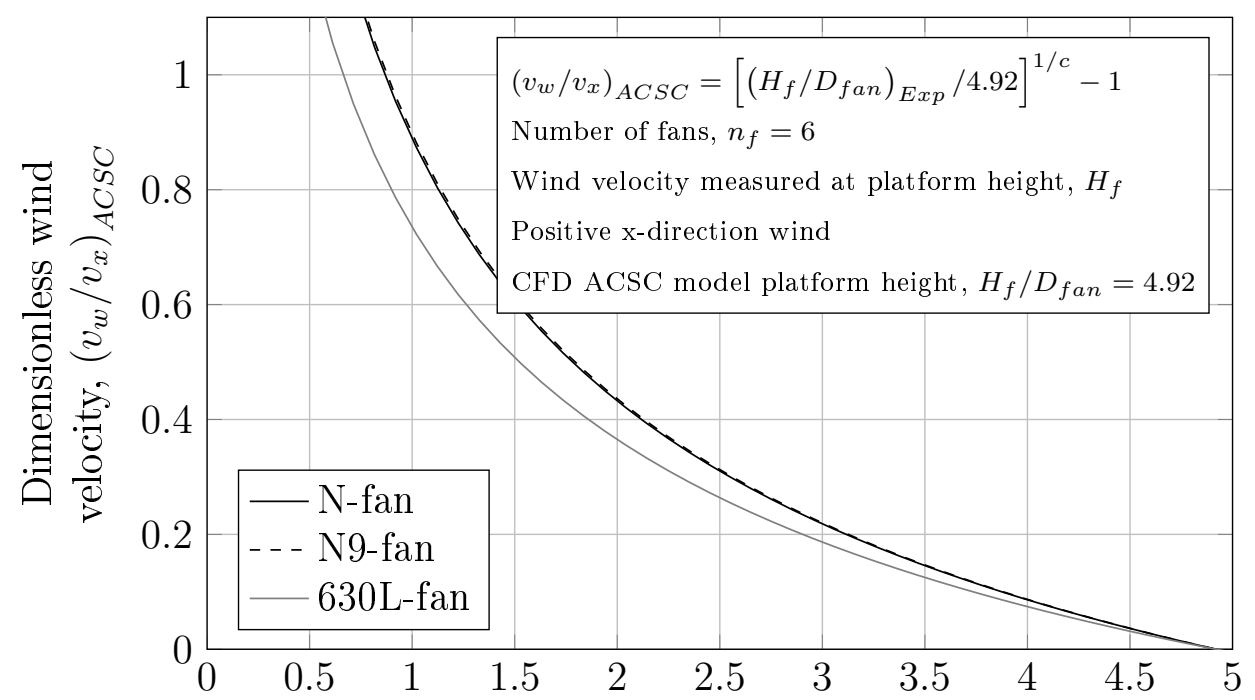

Experimental facility dimensionless platform height, $\left(H_{f} / D_{f a n}\right)_{E x p}$

Figure 6.10: Correlation between dimensionless wind velocity and experimental dimensionless platform height producing the same volumetric effectiveness values 


\section{Chapter 7}

\section{Conclusions and recommendations}

The goal of the present study was to further investigate the effects of distorted inlet flow conditions on the performance of axial flow fans in forced draught ACSC applications. An additional goal was to obtain a correlation between the effects of cross-winds and experimental platform height.

The experimental and numerical investigation processes followed to succeed in the goals of this study is discussed along with important results and findings.

\subsection{Experimental evaluation of axial flow fan performance trends caused by platform height and fan configuration alterations}

The variable platform height experimental investigation was preceded by measuring the performance characteristics of the three experimental axial flow fans (as listed in Appendix A). This was achieved by performing single fan performance tests where the static pressure, power consumption and efficiency of the three fans were determined. The fan setting angles were adjusted to ensure that the performance curves pass through an operating point which was based on the design point of Bruneau (1994).

The three axial flow fans (N-, N9- and 630L-fan) are distinguished by a difference in the solidity values with the $\mathrm{N}$-fan having the smallest solidity value and the 630L-fan the largest. The effect of the fan solidities could clearly be seen in the fan performance characteristic results.

The static pressure curves obtained showed that the high solidity 630L-fan has the steepest gradient and the highest static pressure values measured in the test volumetric flow rate range. When comparing the static pressure curves of the N-fan and N9-fan an increase in static pressure values is shown by the N9-fan, but the curve gradients show little difference.

The fan static pressure characteristic curve gradient is significant when considering a dynamic system where the system resistance is able to change 
(resulting in a new operating point). A steep characteristic curve gradient would result in smaller changes in the operating flow rate when compared to flatter curves. In an ACSC application a stable flow rate is desirable to prevent a loss in heat transfer capacity.

The effects of platform height on the performance of axial flow fans were determined by measuring the individual flow rates of the fans in a 3 -fan variable platform height test facility (as also used by van der Spuy (2011)). The facility consists of three fan tunnels and an inlet chamber with a variable floor, allowing one to vary the fan platform height. The three fans represent a symmetrical section of an ACSC fan street consisting of six fan units.

Results from the variable platform tests showed a decrease in volumetric effectiveness with decreasing platform height. The reduction in effectiveness is a result of increased distorted inlet flow conditions, especially at the upstream periphery. The distorted inlet flow conditions are caused by an increase in cross flow which is induced by the inner fans. This effect increases as the platform height is reduced due to the reduced inlet flow area.

When comparing the three fan systems the results showed that the 630Lfan system had a higher volumetric effectiveness at all platform heights. The largest difference is seen at the lowest platform height of $1 \mathrm{D}_{f a n}$, where the $630 \mathrm{~L}-$ fan system showed an increase in volumetric effectiveness $\left(\dot{V} / \dot{V}_{i d}=0.86\right)$ of $13.2 \%$ over the $\mathrm{N}$-fan volumetric effectiveness $\left(\dot{V} / \dot{V}_{i d}=0.76\right)$. The N9-fan system volumetric effectiveness values were less distinguishable from the N-fan system volumetric effectiveness values, but were nonetheless higher, especially at the lowest platform height position $\left(\dot{V} / \dot{V}_{i d}=0.79\right)$. The results showed that the higher solidity of the N9-fan and especially the 630L-fan results in smaller reductions in volumetric effectiveness with a reduction of fan platform height (or increase in distorted inlet flow conditions).

The effect of the edge fan performance on the total system performance was also investigated by comparing the system volumetric effectiveness of three different fan configurations, i.e. 630L-630L-630L, 630L-N9-N9 and N9-N9-N9. The results showed almost negligible differences between the 630L-630L-630L and 630L-N9-N9 fan configurations. This result highlights the significance of the performance of the edge fan, and shows how the system volumetric effectiveness can be improved by simply replacing the edge fan with a higher solidity fan.

The flow field near the perimeter fan was investigated by measuring velocity vectors at five positions upstream of the perimeter fan at three platform height positions including $3.5 \mathrm{D}_{\text {fan }}, 2.5 \mathrm{D}_{\text {fan }}$ and $1.5 \mathrm{D}_{\text {fan }}$. The orientation and magnitude of the measured velocity vectors confirmed the increase in crossflow velocity at lower platform height positions. The results also suggested the presence of flow separation at the upstream bell mouth edge of the edge fan, especially at the lower platform height positions which are associated with higher cross-flow velocities. van der Spuy (2011) noticed flow separation occurring at the bell mouth edge, with an increase in cross-flow velocity. 


\subsection{Numerical simulation of experimental multiple fan, variable platform height facility}

A CFD model of the experimental three fan, variable platform height facility was created. The model was used to analyse and validate results obtained by the numerical fan models. Although more accurate models exist it was decided to use the pressure jump model (PJM) to model the fans due to its simplicity, low mesh resolution requirement and also its popularity in the ACSC facility modelling research field ((Louw, 2011), (Owen, 2010)).

The numerical fan models were first applied in a single fan test facility CFD model for the N-, N9- and 630L-fan. The static pressure curves of the fans were obtained by simulating at varying flow rates. The static pressure results were then compared to their corresponding experimental results. The results showed very good correlation with experimental results. This was expected due to the fact that the PJM applies a static-to-static pressure rise function which is based on a curve fit to the experimental fan static pressure results.

Simulations of the multiple fan, varying platform height experiments were executed with three fan configurations, i.e. N-N-N, N9-N9-N9 and 630L-630L630L. Reference volumetric flow rates obtained with the single fan simulations were used to determine the volumetric effectiveness values. Velocity vectors were compared to measurements made during the experimental investigations by extracting the velocity magnitude and direction results from the CFD solutions at the same positions in the CFD model.

The CFD volumetric effectiveness results for the N-fan system showed lower values at each platform height. The largest discrepancies were noticed at the $1.5 \mathrm{D}_{\text {fan }}$ and $2.5 \mathrm{D}_{\text {fan }}$ platform height positions. Interestingly, the CFD results showed good correlation at the $1 \mathrm{D}_{\text {fan }}$ platform height position. The perimeter fan volumetric effectiveness results also show a close correlation between the CFD and experimental results at the $1 \mathrm{D}_{\text {fan }}$ platform height position. At all of the other platform heights the CFD model significantly underestimates the edge fan volumetric effectiveness. The velocity vectors obtained by CFD for the $\mathrm{N}$-fan system showed very good correlation with experimental results except at the measurement position nearest to the fan. The increase in the level of cross flow upstream of the fan is well predicted by the CFD model.

Comparison of the volumetric effectiveness CFD and experimental results for the N9-fan system showed similar trends than what was observed with the $\mathrm{N}$-fan system. The largest discrepancies were again noticed at the $1.5 \mathrm{D}_{\text {fan }}$ and $2.5 \mathrm{D}_{\text {fan }}$ platform height positions with a fairly accurate prediction shown by the CFD volumetric effectiveness result at the $1 \mathrm{D}_{\text {fan }}$ platform height position. The velocity vector comparison also shows good correlation between the CFD and experimental results.

The CFD volumetric effectiveness results of the 630L-fan system failed to 
predict the substantial increase shown by the experimental results when compared to the other fans. This is especially evident at the lowest platform height position where the CFD model shows a significant underestimation of the volumetric effectiveness. When compared to the CFD volumetric effectiveness results of the other fans at the lowest platform height position, only a slight increase is shown by the 630L-fan system. This is very different to the experimental results where the 630L-fan shows a significant increase in volumetric effectiveness at the lowest platform height position. The velocity vectors however again shows good correlation with the experimental results, with accurate predictions of the change in the flow field as the platform height is decreased.

The comparison between the CFD and experimental volumetric effectiveness results has highlighted some important shortcomings of the PJM. In all cases the CFD volumetric effectiveness values showed a more gradual reduction in volumetric effectiveness when compared to the experimental results. This shows that the PJM is more sensitive to a reduction in the platform height, or an increase in the level of distortion in the inlet flow conditions. In reality, however, the fans are more resilient to such changes with regard to volumetric effectiveness. Another observed shortcoming of the PJM is its inability to predict the improved volumetric effectiveness shown by the 630L-fan at low platform height positions. The PJM fails to predict the influence of fan solidity on the performance of fans subjected to distorted inlet flow conditions.

The PJM applies a static-to-static pressure function which is derived from experimental values obtained by conducting single fan tests under ideal operating conditions. The PJM is therefore based on ideal operating conditions and does not change as the operating conditions vary (as is the case when the fan platform height is changed). This is not the case in reality, however, where the fan characteristics are dependant on the upstream operating conditions. The differences between the CFD and experimental volumetric effectiveness results at low platform height positions can therefore be explained by the fact that the operating conditions at these platform heights differ substantially from ideal operating conditions.

\subsection{Numerical evaluation of effects on ACSC performance caused by cross-winds}

A simplified CFD ACHE fan unit was created that excluded physical details of the actual ACHE fan unit. Instead, the effects of these physical ACHE characteristics were accounted for by a numerical ACHE model which models the momentum and energy effects of the actual ACHE. The accuracy of the CFD ACHE model was verified by conducting simulations with a single ACHE unit and comparing the results with analytical results. The operating volumetric flow rate values of the three fans, as well as the outlet temperatures 
at various flow rates correlated well with the analytical results, with all CFD results being within $1 \%$ of the analytical results.

A general ACSC system consisting of 36 (6 rows and 6 streets) ACHE fan units, as simulated by van Rooyen (2007) and Louw (2011), were chosen for this investigation. To reduce the computational effort required to solve the simulations, symmetry was applied to the domain which means that only 18 ACHE fan units (6 rows and 3 streets) were included in the computational domain. The use of symmetry is valid since this investigation only simulated $\mathrm{x}$-directional winds which flows perpendicular to the ACSC rows (see Figure 5.23). The wind was modelled using a user defined function (UDF) which specifies a velocity profile at the domain inlet boundary. Three wind velocities were simulated, $3 \mathrm{~m} / \mathrm{s}, 6 \mathrm{~m} / \mathrm{s}$ and $9 \mathrm{~m} / \mathrm{s}$ which were specified at the ACSC platform height. Simulations were also performed without the presence of wind.

The total system volumetric effectiveness results showed similar trends for the three fan systems. A gradual reduction in the system volumetric effectiveness were seen as the wind velocity is increased. The observed trend showed similar behaviour than what was observed with the numerical three-fan facility investigation volumetric effectiveness results. The system volumetric effectiveness results did not display any large differences between the three fan systems. Large improvements were however shown by the 630L-fan system at individual ACHE fan units located on the upstream periphery of the ACSC.

When comparing volumetric effectiveness results of the three ACSC streets it was found that street 1 is worst affected by an increase in cross-wind velocity. The reason for this was found to be the large reduction in volumetric effectiveness shown by the upstream peripheral ACHE fan unit of street 1 which experiences '2-D' flow conditions. This unit is only able to draw air in from the $\mathrm{x}$-direction, whereas the upstream peripheral ACHE fan unit of street 3 is able to draw in air from either the $\mathrm{x}$ - or $\mathrm{y}$-direction. Street 3 is however comprised entirely of perimeter fan units, which means at zero wind conditions it showed the lowest volumetric effectiveness values, which stayed relatively unchanged as the wind velocity was increased when compared to the other ACSC streets.

\subsection{Correlation between platform height, cross-wind velocity and system volumetric effectiveness}

The Salta curve which predicts the volumetric effectiveness of a fan system subjected to a reduction in platform height was expanded to include wind effects. The dimensionless platform height number, $X$, used by Salta and Kröger (1995) was adjusted and the new number, $\xi$, includes a dimensionless wind number, $v_{w} / v_{x}$, which is the ratio of the wind velocity $\left(v_{w}\right)$ measured at 
the ACSC platform height $\left(H_{f}\right)$ to the average upstream peripheral cross-flow velocity $\left(v_{x}\right)$. Figure 6.1 shows an illustration of the definition of these two velocities. The expanded Salta equation was given as

$$
\dot{V} / \dot{V}_{i d}=0.985-\exp \left[-K\left(\frac{1+45 / n_{f}}{6.35}\right)\left(\frac{H_{f}}{D_{f a n}}\right)\left(1+\frac{v_{w}}{v_{x}}\right)^{c}\right]
$$

The constants ( $c$ and $K$ ) of the expanded Salta equation were obtained by fitting the volumetric effectiveness data obtained by the experimental and numerical investigations to the Salta curve. This was done for each fan system individually. The results showed some experimental and numerical data points lying in close proximity (listed in Table 6.1). The flow fields near the perimeter fan of these coinciding data points were investigated by comparing dimensionless velocity vectors at positions where measurements were made as part of the experimental investigation. The comparison showed very similar flow behaviour near the perimeter fan which implies that the operating conditions at these coinciding experimental and numerical data points are indeed similar.

A general solution to the expanded Salta curve was also obtained by optimising the constants for a combined data set including experimental and numerical results of all the fan systems. Although the solution showed a larger amount of data scatter (with a coefficient of determination value of $R^{2}=0.869$ ) it is still sufficient for an investigation into general performance trends. The general volumetric effectiveness solution was given by the following equation

$$
\dot{V} / \dot{V}_{i d}=0.985-\exp \left[-1.375\left(\frac{1+45 / n_{f}}{6.35}\right)\left(\frac{H_{f}}{D_{f a n}}\right)\left(1+\frac{v_{w}}{v_{x}}\right)^{-2.612}\right]
$$

This general volumetric effectiveness equation was used to illustrate various performance trends by plotting a three-dimensional function as well as contour lines of constant dimensionless wind velocity, dimensionless platform height and volumetric effectiveness values (as shown by Figures 6.6 to 6.9).

Several performance characteristics could be identified from the general volumetric effectiveness solution plots. The plots show that the system volumetric effectiveness sensitivity to cross-winds can be greatly reduced by increasing the platform height. For example, at a cross-wind velocity of $9 \mathrm{~m} / \mathrm{s}$ a system volumetric effectiveness increase of $42 \%$ is predicted by increasing the dimensionless platform height from $2.5 \mathrm{D}_{\text {fan }}$ to $5 \mathrm{D}_{\text {fan }}$. This highlights the significance of specifying a platform height that would ensure high volumetric effectiveness values in cross-wind operating conditions in the design process of an ACSC system.

A correlation between the experimental facility platform height and dimensionless cross-wind velocity was also obtained. This was achieved by putting 
the volumetric effectiveness equation for the experimental facility equal to the ACSC volumetric effectiveness equation, i.e. $\left(\dot{V} / \dot{V}_{i d}\right)_{E x p}=\left(\dot{V} / \dot{V}_{i d}\right)_{A C S C}$. By specifying zero wind for the experimental facility $\left(\left(v_{w} / v_{x}\right)_{E x p}=0\right)$ and the platform height used in the ACSC simulations $\left(\left(H_{f} / D_{\text {fan }}\right)_{A C S C}=4.92\right)$ the following correlation was obtained

$$
\left(\frac{v_{w}}{v_{x}}\right)_{A C S C}=\left[\frac{\left(H_{f} / D_{f a n}\right)_{E x p}}{4.92}\right]^{1 / c}-1
$$

which gives a relation between the dimensionless wind velocity and experimental dimensionless platform height that would produce the same system volumetric effectiveness. This is a useful correlation for practical application in experimental variable platform height investigations where it is desirable to know how the platform height relates to cross-wind conditions.

\subsection{Further work and recommendations}

A number of recommendations for future work can be made based on the results form the present study:

1. Further work should include other numerical fan models such as the actuator disc method (ADM) or the extended actuator disk method (EADM), as developed by van der Spuy (2011), which could improve the accuracy of the numerical models.

2. The Salta curve should be adapted by introducing effects of fan solidity and hub-to-tip ratio on the system volumetric effectiveness. This could be achieved by conducting experimental and numerical investigations with a range of fan models which should have different properties.

3. The volumetric effectiveness correlation obtained in this study should be verified by conducting additional experimental and/or numerical investigations with varying properties.

4. Additional wind velocity conditions should be investigated to extend the knowledge of the effect of cross-winds on ACSC volumetric effectiveness. 


\section{Appendices}




\section{Appendix A}

\section{Axial flow fans}

Specifications of the fans referred to in the main text are discussed here. The three fans selected for this investigation are referred to as the N-fan, N9-fan and 630L-fan.

\section{A.1 N-fan}

The N-fan is a $630 \mathrm{~mm}$ scale model of a $9.216 \mathrm{~m}$ diameter industrial cooling fan. The full scale fan is used in large ACHEs in the South-African power industry and is therefore the best representation of large diameter fans currently in operation. Figure A.1 shows an illustration of the N-fan.

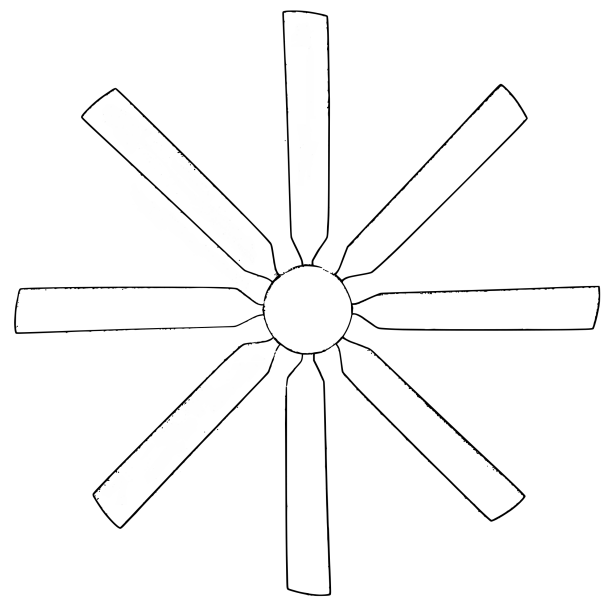

Figure A.1: N-fan

Table A.1 lists the overall properties of the N-fan. Conradie (2010) describes the manufacturing and geometry of the N-fan in detail. 
Table A.1: N-fan properties

\begin{tabular}{ll}
\hline Nominal diameter & $630 \mathrm{~mm}$ \\
Blades & 8 \\
Tip clearance & $1.59 \mathrm{~mm}$ \\
Hub-to-tip ratio & 0.15 \\
Solidity (at mid-span) & 0.350 \\
\hline
\end{tabular}

\section{A.2 N9-fan}

The N9-fan is a variation of the N-fan with nine blades. The blade geometry is exactly the same as used with the N-fan. The N9-fan is also intended to be a scale model of an industrial cooling fan to be used in the South-African power industry. Figure A.2 shows an illustration of the N9-fan.

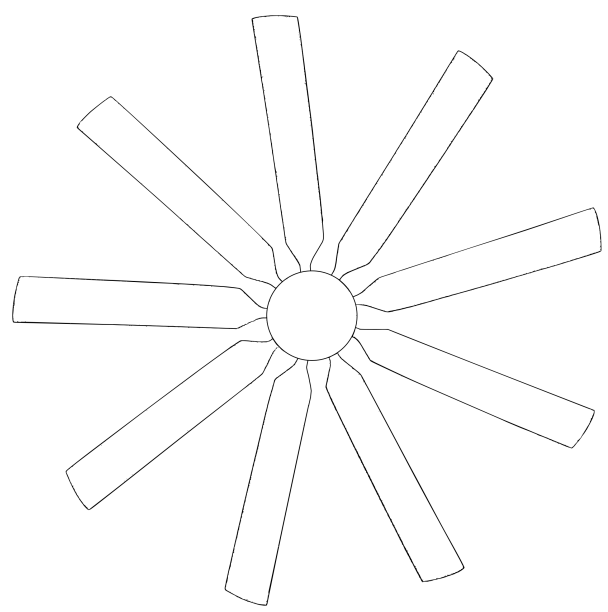

Figure A.2: N9-fan

The properties of the N9-fan is listed in Table A.2. Note the effect the additional blade has on the solidity compared to the N-fan solidity.

Table A.2: N9-fan properties

\begin{tabular}{ll}
\hline Nominal diameter & $630 \mathrm{~mm}$ \\
Blades & 9 \\
Tip clearance & $1.59 \mathrm{~mm}$ \\
Hub-to-tip ratio & 0.15 \\
Solidity (at mid-span) & 0.394 \\
\hline
\end{tabular}




\section{A.3 630L-fan}

The 630L-fan is a scaled down $630 \mathrm{~mm}$ diameter version of the L2-fan, which was tested by Augustyn (2013). The L2-fan is a $1.24 \mathrm{~m}$ diameter scaled version of an industrial cooling fan also intended for use in the power industry in South-Africa.

Augustyn (2013) conducted full 3D CFD simulations of the L2-fan, and could therefore provide a CAD model of the L-fan blade. The CAD model was scaled down for the $630 \mathrm{~mm}$ fan and then used to create computer numerical control (CNC) code for the manufacturing of a physical model. A three-axis CNC milling machine was then programmed to cut the blade from 6082 aluminium stock. The final part of the manufacturing process was outsourced to SKEG Product Development ${ }^{\circledR}$ where the aluminium blade was used as a master part for creating silicone moulds. The silicone moulds were then used in a vacuum casting process to produce the final set of blades. Figure A.3 shows an illustration of the assembled 630L-fan.

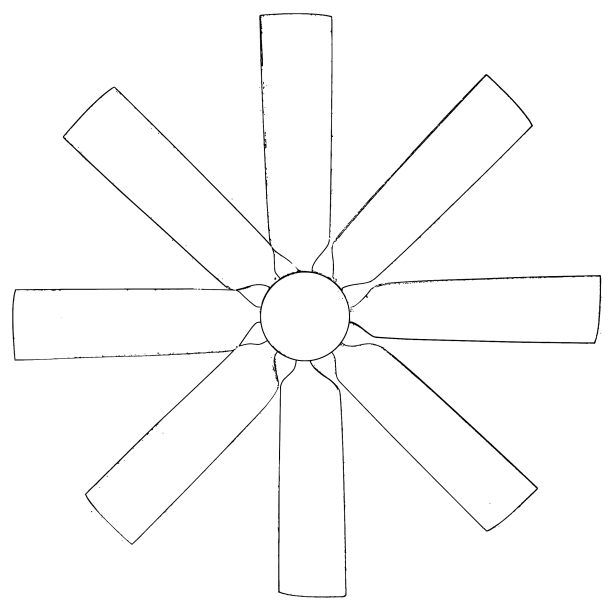

Figure A.3: 630L-fan

The properties of the 630L-fan is listed in Table A.3. Note that the hubto-tip ratio is the same as the $\mathrm{N}$ - and N9-fans, but the solidity is greater than that of the other fans.

Table A.3: 630L-fan properties

\begin{tabular}{ll}
\hline Nominal diameter & $630 \mathrm{~mm}$ \\
Blades & 8 \\
Tip clearance & $1.54 \mathrm{~mm}$ \\
Hub-to-tip ratio & 0.15 \\
Solidity (at mid-span) & 0.532 \\
\hline
\end{tabular}




\section{Appendix B}

\section{Equipment calibration}

The measuring instrumentation used in the experimental procedures all needed to be calibrated to ensure reliable and accurate data capturing.

\section{B.1 Reference anemometer}

In order to calibrate the anemometers in the 3-fan experiment setup it is required to acquire a reliable volumetric flow rate reference. A reference anemometer was calibrated at an atmospheric open-loop induced draught wind tunnel as shown in Figure B.1.

The anemometer along with its own bell mouth inlet section is clamped onto the front of the wind tunnel. Figure B.2 shows the anemometer clamped to the front of the wind tunnel.

The objective of the reference anemometer calibration is to obtain a calibration curve relating the anemometer voltage output to the volumetric flow rate. In order to calculate the volumetric flow rate through the wind tunnel the pressure drop over one or more elliptical nozzles mounted in position 7 , as

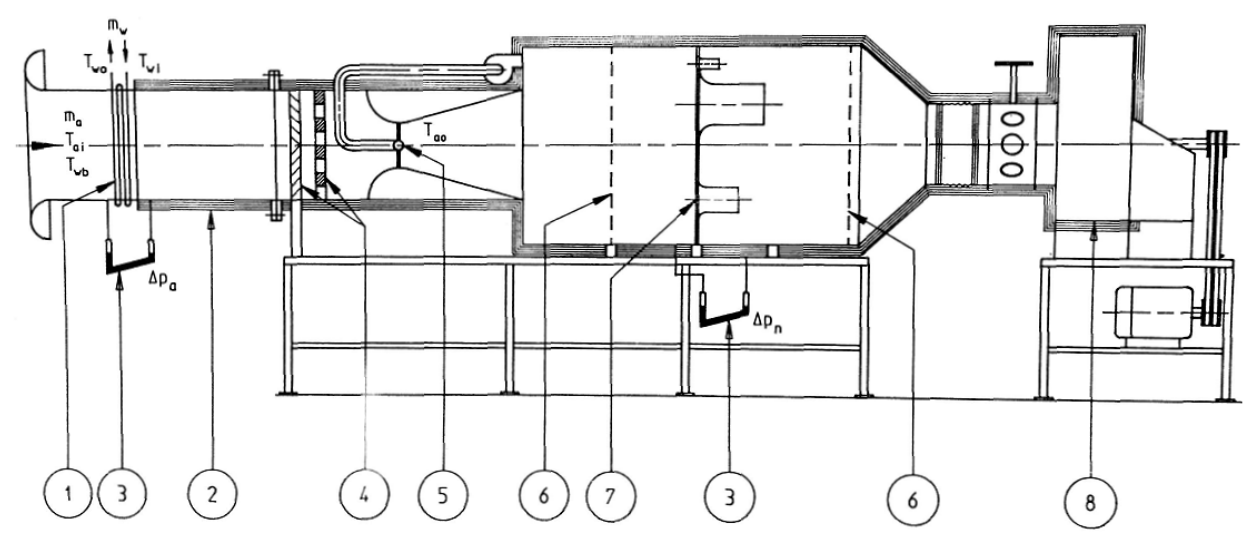

Figure B.1: Test wind tunnel Kröger, 2004 


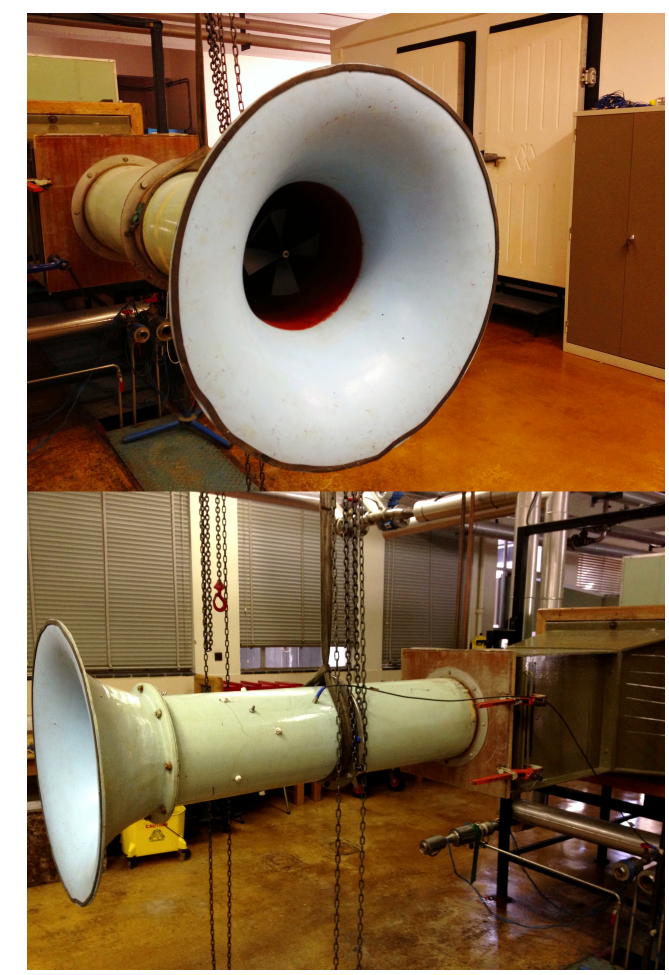

Figure B.2: Anemometer clamped to wind tunnel

indicated in Figure B.1, is measured. There are a total of five nozzles, each one having a different diameter. The volumetric flow rate is varied by adjusting the speed of a radial fan located at position 8 .

The mass flow rate through the wind tunnel is given by

$$
\dot{m}=C_{n} \Phi_{g} Y A_{n} \sqrt{2 \rho_{n} \Delta p_{n}}
$$

where $C_{n}$ is the nozzle discharge coefficient, $\Phi_{g}$ is the gas expansion factor, and $Y$ is the approach velocity factor (Kröger, 2004). The nozzle discharge coefficient is a function of the Reynolds number. For $30000<R e_{n}<100000$,

$$
C_{n}=0.954803+6.37817 \cdot 10^{-7} R e_{n}-4.65394 \cdot 10^{-12} \operatorname{Re}_{n}{ }^{2}+1.33514 \cdot 10^{-17} \operatorname{Re}_{n}{ }^{3}
$$

For $100000<R e_{n}<350000$

$$
C_{n}=0.9758+1.08 \cdot 10^{-7} R e_{n}-1.6 \cdot 10^{-13} \operatorname{Re}_{n}{ }^{2}
$$

and for $R e_{n}>350000, C_{n}=0.994$.

The gas expansion factor is approximated by the following relation:

$$
\Phi_{g}=1-\frac{3 \Delta p_{n}}{4 p_{u p} c_{p} / c_{v}}
$$

where $p_{u p}$ is the upstream pressure and $c_{p} / c_{v}=1.4$ for air. 
The approach velocity factor for a compressible fluid can be approximated as

$$
Y=1+0.5\left(A_{n} / A_{t u s}\right)^{2}+\frac{2\left(A_{n} / A_{t u s}\right)^{2} \Delta p_{n}}{p_{u p} c_{p} / c_{v}}
$$

where $A_{\text {tus }}$ is the wind tunnel upstream cross sectional area.

Note that a cyclic dependency in the above equations exist. The nozzle coefficient equations are dependent on the Reynolds number but in order to calculate the Reynolds number the mass flow rate should be known. It is thus necessary to guess an initial Reynolds number and then iterate the calculation procedure until the solution has converged.

Two pressure transducers were used to measure the upstream tunnel pressure, $p_{u p}$, as well as the pressure difference across the nozzles, $\Delta p_{n}$. The pressure transducers were connected through tubes and pressure taps to the upstream and downstream side of the nozzles. $p_{u p}$ was measured by connecting the suction side of the pressure transducer to the upstream pressure tap and leaving the positive pressure side open to the atmosphere. $\Delta p_{n}$ was measured by connecting the suction side of the pressure transducer to the downstream pressure tap and the positive pressure side to the upstream pressure tap, which would then give a positive pressure difference.

The two pressure transducers, anemometer output, as well as five type$\mathrm{T}$ thermocouples were connected to a Schlumberger data logger which was connected to a computer.

The speed of the radial fan was varied with a variable speed drive at intervals of $10 \mathrm{~Hz}$ between $0 \mathrm{~Hz}$ and a maximum of $50 \mathrm{~Hz}$. At each fan speed the system was allowed to settle before the data was logged. Nozzle diameters of $150 \mathrm{~mm}$ and $200 \mathrm{~mm}$ were chosen for the calibration to achieve flow rates that would be in the expected region in which the experiments would be conducted.

\section{B.1.1 Pressure transducer calibration}

The pressure transducers used for the pressure measurements had to be calibrated to ensure accurate mass flow rate calculations. Figure B.3 shows the two pressure transducers (right hand side) that were used for the calibrations. The operating range of the pressure transducers lies between $-10 \mathrm{kPa}-10 \mathrm{kPa}$.

The pressure transducers were calibrated using a Betz manometer. A tube was connected to the negative side of the manometer and a suction induced by sucking on the open end of the tube. The tube was then clamped and then connected to the negative side of the pressure transducer. The manometer and pressure transducer were allowed to settle and then the voltage output from the transducer and the pressure reading on the manometer were recorded. This process was repeated at various pressures.

The resulting calibration data is plotted in Figure B.4 and the linear calibration equations were found to be: 


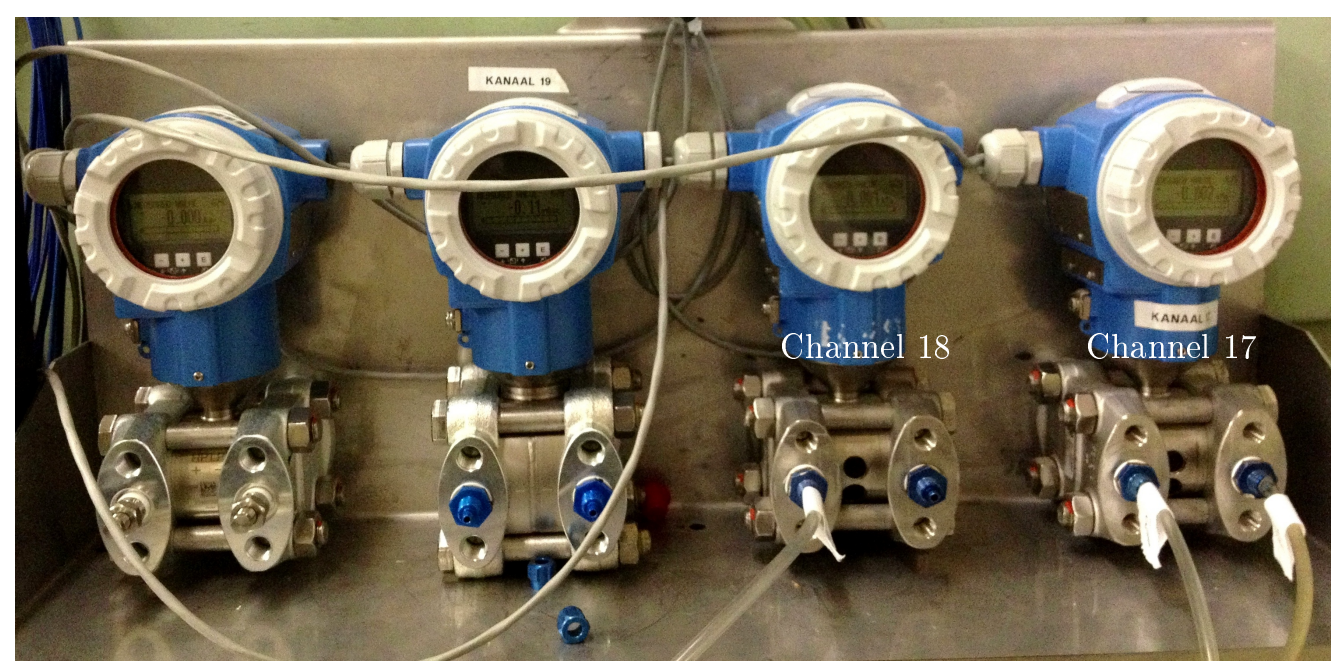

Figure B.3: Pressure transducers

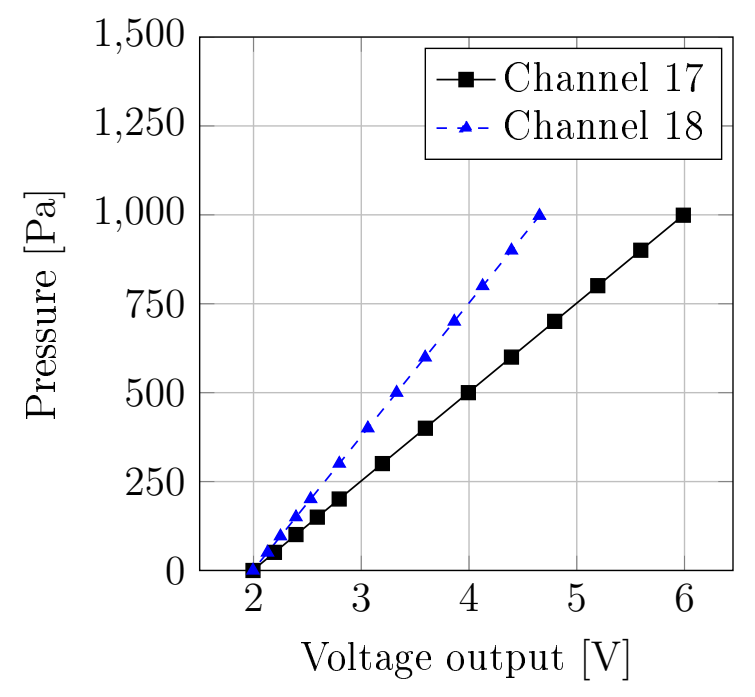

Figure B.4: Test wind tunnel pressure transducer calibration results 


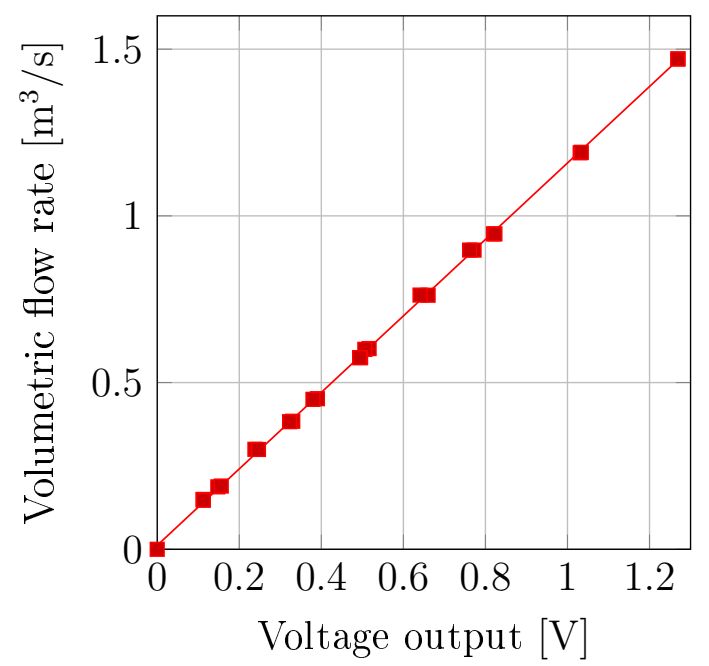

Figure B.5: Reference anemometer calibration results

$$
\begin{aligned}
& p_{17}=249.94 v_{17}-497.95 \\
& p_{18}=375.04 v_{18}-748.02
\end{aligned}
$$

\section{B.1.2 Calibration results}

The anemometer calibration procedure was repeated twice for each nozzle opening. The results are shown in Figure B.5 together with a linear regression.

The reference anemometer calibration equation was found to be:

$$
\dot{V}_{\text {ref }}=1.1468 v+0.0118
$$

\section{B.2 Multiple fan facility calibration}

\section{B.2.1 Pressure transducers}

The pressure transducers used in the 3-fan experimental facility needed to be calibrated. The same procedure as described for the test wind tunnel pressure transducer calibration was followed.

Five pressure transducers were used, as shown in Figure B.6. The pressure operating range is $0 / 1000 \mathrm{~Pa}$ with an output of $1-10 \mathrm{VDC}$. The output range is adjustable by means of an offset adjusting screw.

The data logging was done by a National Instruments NI-6218 DAQ unit which connects via USB to a computer. LabView software was used for data recording. 


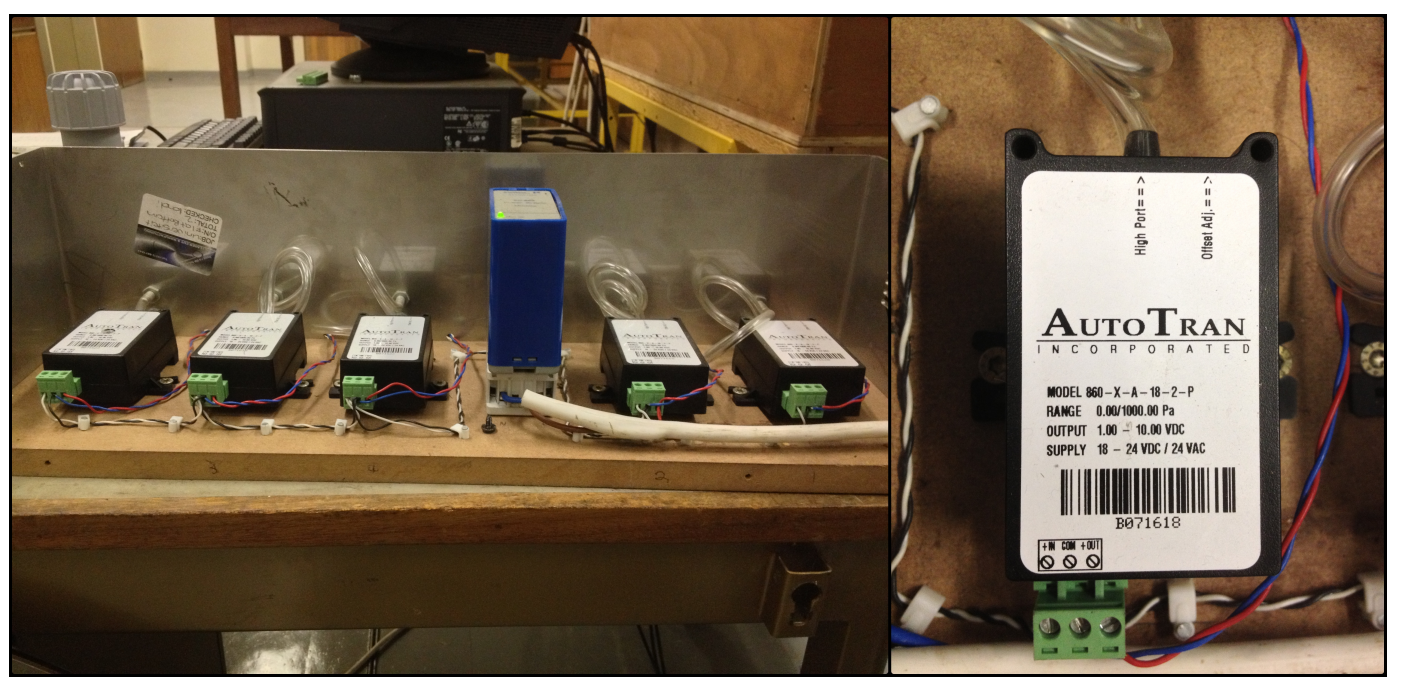

Figure B.6: 3-Fan facility pressure transducers

The calibration was done using a Betz manometer as a reference. A suction was applied to the manometer by sucking on a tube that is connected to the negative side. The tube was then clamped and connected to the negative side of the pressure transducer. The manometer and pressure transducer were allowed to settle, and the output voltage and Betz manometer pressure readings were then recorded.

The calibration equations for the pressure transducers were found to be:

$$
\begin{gathered}
p_{1}=111.32 v_{1}-87.640 \\
p_{2}=111.81 v_{2}+11.300 \\
p_{3}=111.47 v_{3}-80.295 \\
p_{4}=112.07 v_{4}-8.800 \\
p_{5}=112.15 v_{5}-76.920
\end{gathered}
$$

The calibration data is shown in Figure B.7. 

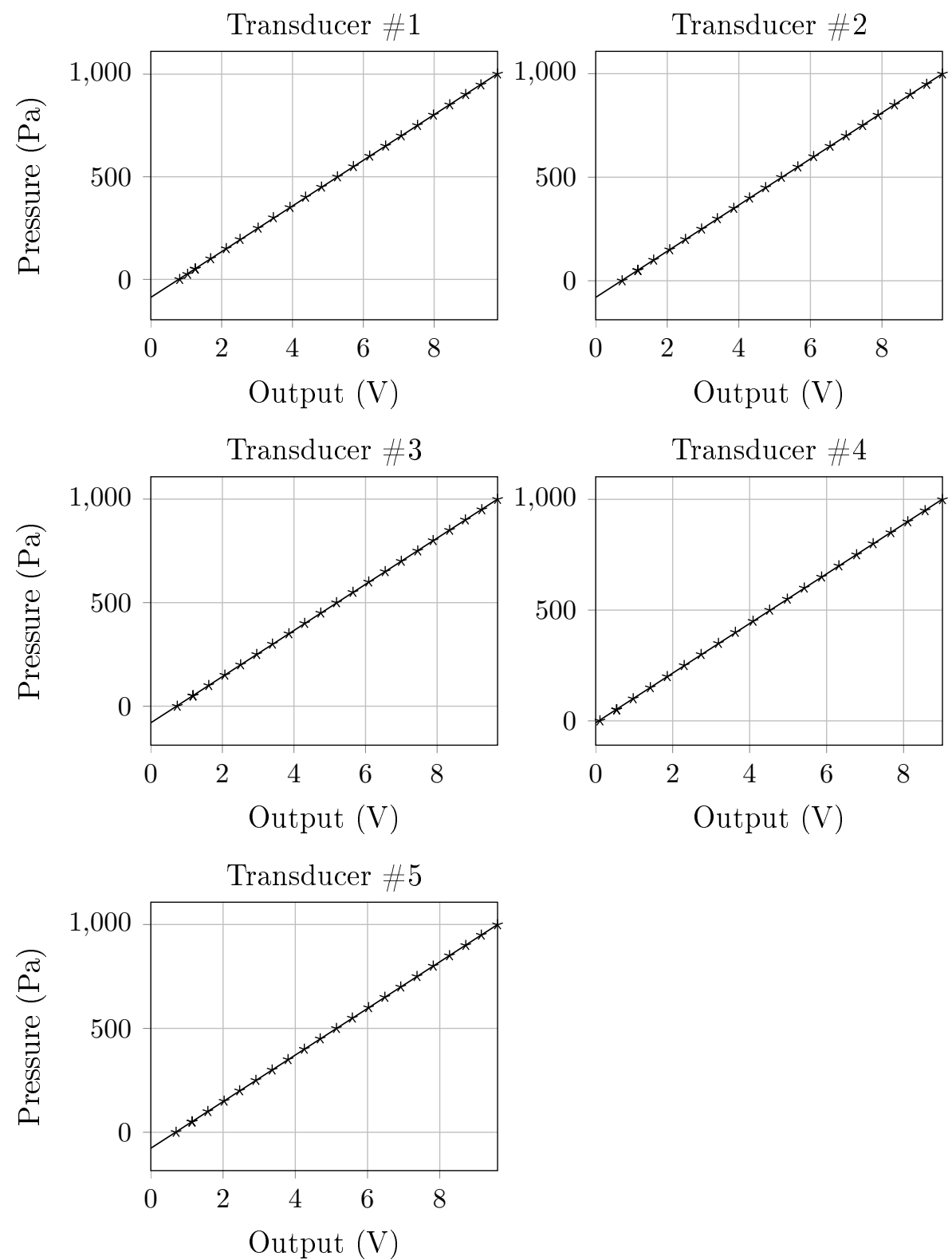

Figure B.7: 3-Fan experiment pressure transducer calibration results 


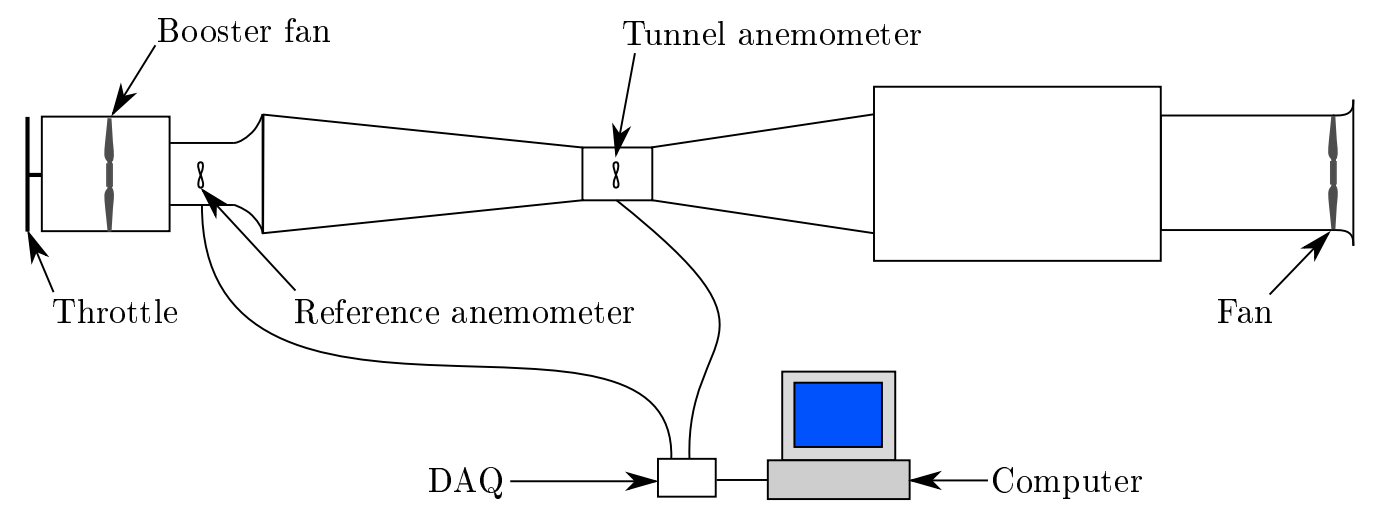

Figure B.8: 3-Fan anemometer calibration set-up

\section{B.2.2 Anemometers}

The flow rate in the 3 -fan experimental facility is measured by 3 anemometers located in the venturi section of each tunnel. Accurate calibration of these anemometers was necessary to ensure reliable flow rate measurements during experiments.

The reference anemometer described in section B.1 was used to calibrate the three tunnel anemometers. To calibrate the tunnel anemometers it is necessary to measure the flow rate with both anemometers simultaneously. The reference anemometer was therefore clamped to the outlet of the test tunnels, as shown in Figure B.8. Also shown in Figure B.8 is a booster fan, attached to the outlet of the reference anemometer housing. Due to the system resistances it was necessary to use a booster fan to achieve flow rates of up to $1.9 \mathrm{~m}^{3} / \mathrm{s}$.

The volumetric flow rate was adjusted by means of a throttle located at the outlet of the booster fan. After each adjustment the system was allowed to stabilize and then the voltage output from the tunnel anemometer and reference anemometer was recorded. This was repeated at various flow rates for each tunnel anemometer.

Figure B.9 shows the calibration results. The results shows good linear characteristics with a very small offset, as was expected. The coefficient of determination of each linear regression is equal to 1.

The resulting equations obtained from the linear regressions are:

$$
\begin{aligned}
& v_{a n 1}=0.8282 v_{r e f}+0.0017 \\
& v_{a n 2}=0.8380 v_{r e f}+0.0013 \\
& v_{a n 3}=0.8513 v_{r e f}+0.0018
\end{aligned}
$$



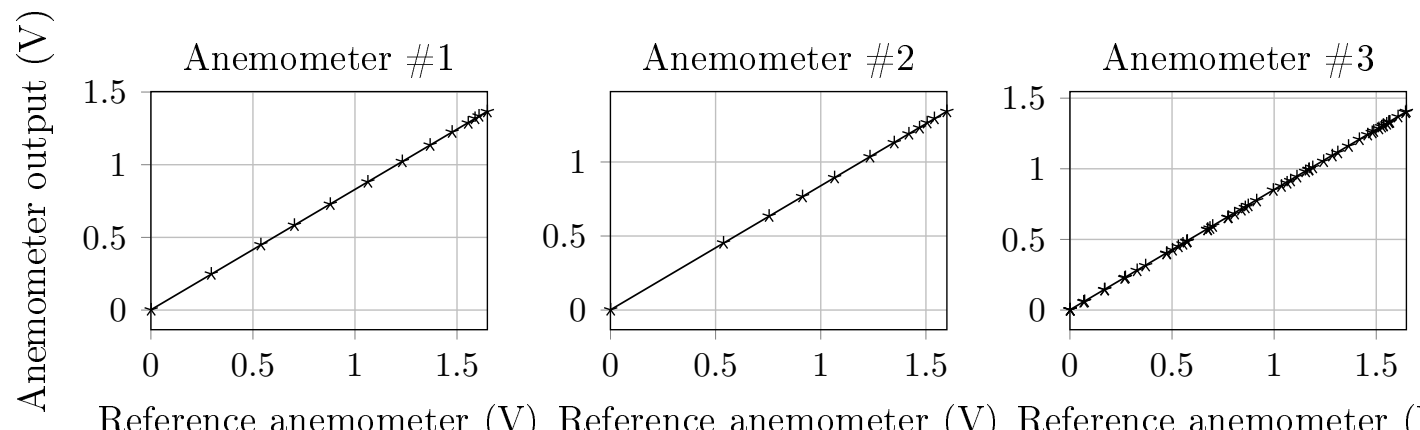

Figure B.9: Anemometer calibration data

To obtain equations relating the volumetric flow rate to output voltage of each tunnel anemometer equations (B.14), B.15) and (B.16) are reaaranged and substituted into the reference anemometer calibration equation (B.8). The resulting calibration equations for the tunnel anemometers are:

$$
\begin{aligned}
& \dot{V}_{1}=1.38471 v_{a n 1}+0.00945 \\
& \dot{V}_{2}=1.36851 v_{a n 2}+0.01000 \\
& \dot{V}_{3}=1.34710 v_{a n 3}+0.01422
\end{aligned}
$$

\section{B.2.3 Torque transducer}

The perimeter fan in the 3-fan experimental facility was fitted with a torque transducer, which was used to calculate the power consumed during experiments.

To calibrate the torque transducer a known load is applied to the transducer and the output measured. The output can then be related to the actual applied torque.

To apply a known torque a moment arm with a known mass suspended on the edge was used. The moment arm was fixed to the fan shaft. Figure B.10 shows the moment arm connected to the front of the fan shaft.

Figure B.11 shows a sketch of the moment arm. A weight with mass $m$ is suspended at a length, $x$, from the middle of the moment arm. As the mass was increased the mechanism that held the shaft stationary flexed somewhat, causing the moment arm to lie at an angle, $\alpha$, relative to the horizontal. The torque applied by the moment arm can then be expressed as

$$
T=(m g) \cdot(x \cos (\alpha))
$$

The weights and the tray on which it was placed were weighed with a laboratory scale which is accurate to $1 \mathrm{~g}$. The length of the moment arm was 


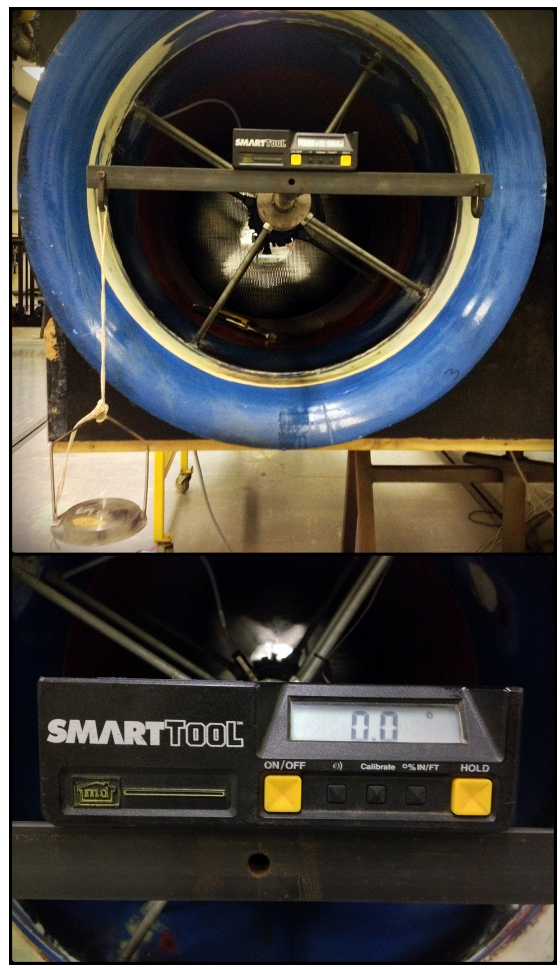

Figure B.10: Torque transducer calibration

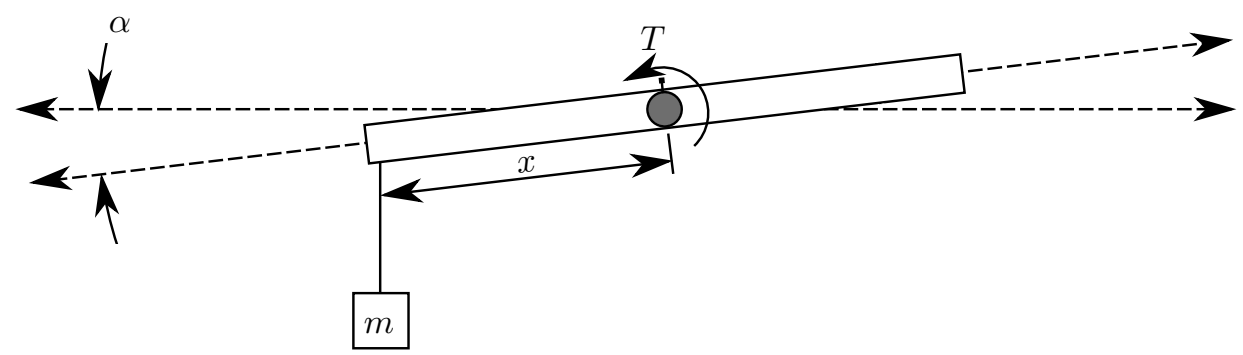

Figure B.11: Moment arm

measured as $250 \mathrm{~mm}$. As extra weights were stacked on the tray the angle at which the moment arm settled increased. The exact angle was measured with a digital protractor, as shown in Figure B.10.

The torque transducer is a HBM T5 $20 \mathrm{Nm}$ full bridge strain-gauge transducer. The signal from the torque transducer is amplified by an external HBM Spider8 DAQ system. The DAQ connects to a computer via USB and the data is viewed and edited with catman Easy DAQ software. The software includes a database of measurement devices which can be assigned to the channels. After selecting the correct device the signal is converted to the appropriate units, in this case the signal is converted to a $\mathrm{Nm}$ value. This value is henceforth 
referred to as the indicated torque value.

Before applying any force on the moment arm a zero reading was recorded. Thereafter the weight on the tray was incrementally increased by $\pm 100 \mathrm{~g}$. With each extra weight added the moment arm was allowed to settle, and then the angle was measured. The applied torque was then calculated and the indicated torque recorded. The process was repeated at the opposite end of the moment arm to reverse the torque direction.

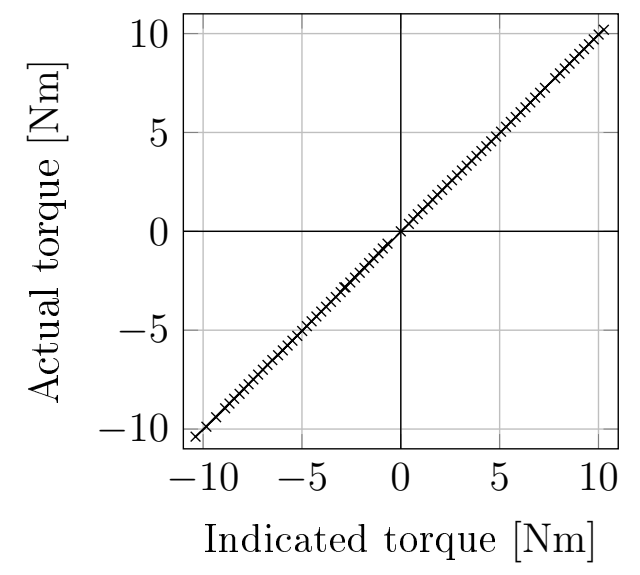

Figure B.12: Torque transducer calibration data

The recorded data is shown in Figure B.12. The linear characteristic of the torque transducer can clearly be seen. The linear regression line has a coefficient of determination of 1 , and a very small offset.

The calibration equation was found to be:

$$
T=0.9995 T_{\text {Indicated }}-0.0287
$$

\section{B.2.4 Speed sensors}

The three fans in the experimental facility are each fitted with a magnetic pick-up speed measuring device. The device consists of a ferrous gear that is attached to the fan shaft and a stationary magnetic pickup that is located at the circumference of the gear. As the gear turns the pickup generates a voltage as the gear teeth enters its magnetic field. By calibration this voltage can be related to the shaft angular velocity.

The calibration was conducted by running the motor at a range of frequencies and then measuring the actual angular velocity with a tachometer while also recording the voltage output from the speed sensors at each frequency setting. Zero readings were also recorded to determine the offset. 

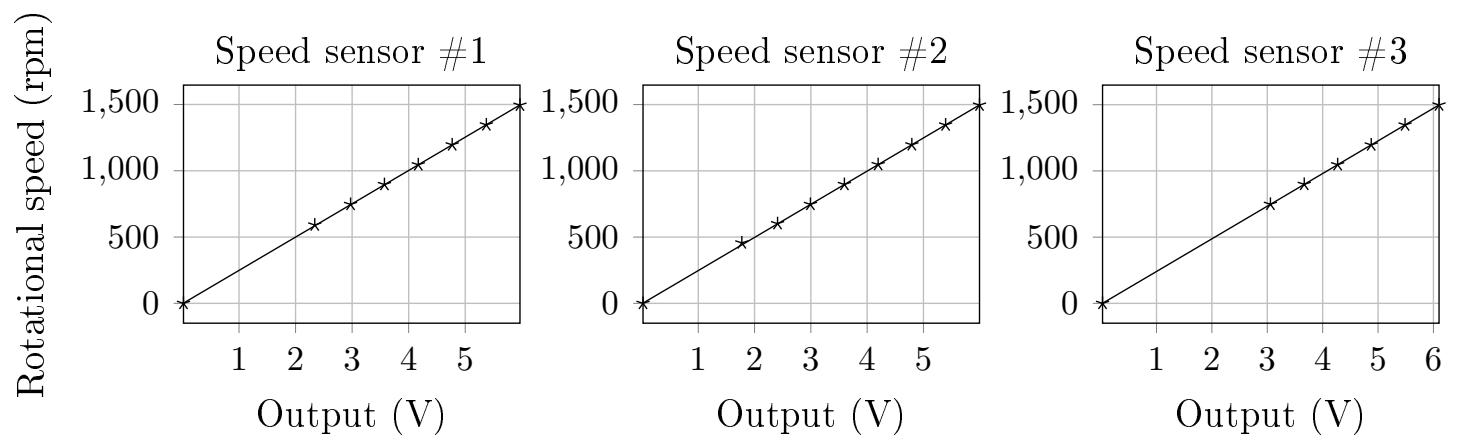

Figure B.13: Speed sensor calibration data

The speed sensors are connected to a National Instruments NI-6218 DAQ unit which connects via USB to a computer. The LabView software package was used to record the voltage output from the sensors.

The recorded data is shown in Figure B.13. Note that no readings were taken between $0 \mathrm{rpm}$ and $\pm 500 \mathrm{rpm}$. This was due to a large amount of scatter present in the voltage output data at these low speeds. The speed at which the fans would be tested is $1000 \mathrm{rpm}$ however, so the range in which the scatter occurs falls well outside the testing speed.

The data shows good linear characteristics with very small offset values. The equations for the linear regressions were obtained as:

$$
\begin{aligned}
& N_{1}=251.23 v_{1}-2.7506 \\
& N_{2}=250.19 v_{2}-2.8021 \\
& N_{3}=246.56 v_{3}-5.9609
\end{aligned}
$$

\section{B.3 Hot film anemometers}

In this section the calibration of the hot film anemometers used for the flow field velocity measurements are discussed.

\section{B.3.1 Theory}

To be able to employ the rotating single inclined hot film anemometer measurement technique the characteristics of the anemometer should be determined through two calibration procedures. Firstly the relationship between the effective cooling velocity, $\bar{U}_{e}$, and the voltage output at the prongs, $\bar{E}$, need to be determined. Secondly the directional sensitivity of the anemometer needs to be quantified. 


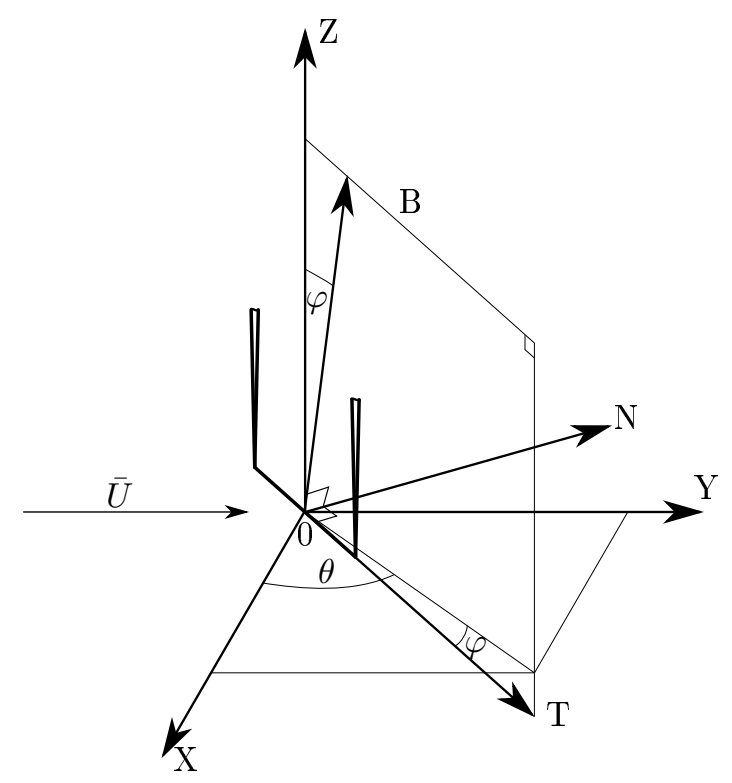

Figure B.14: Hot film anemometer calibration coordinate systems

Figure B.14 illustrates the coordinate systems used with the calibration procedure. The global coordinate system is represented by the $\mathrm{X}-, \mathrm{Y}-$ and Zaxes. The anemometer coordinate system is represented by the T-,N- and B-axes.

The relationship between the cooling velocity and the probe voltage output at a specific orientation is commonly expressed by the King's Law (King, 1914):

$$
\bar{E}^{2}=E_{0}^{2}+B \bar{U}_{e}^{n}
$$

Where $E_{0}$ is the voltage measured at zero velocity. The factors $\mathrm{B}$ and $\mathrm{n}$ are determined through the calibration procedure by varying the flow and taking the voltage readings at each flow velocity with the anemometer orientated perpendicular to the flow $\left(\theta=0^{\circ}\right)$.

The directional sensitivity of the anemometer is expressed by the Jørgensen formula (Jorgensen, 1971):

$$
\bar{U}_{e}^{2}=\bar{U}_{N}^{2}+k^{2} \bar{U}_{T}^{2}+l^{2} \bar{U}_{B}^{2}
$$

$\bar{U}_{N}, \bar{U}_{T}$ and $\bar{U}_{B}$ refers to the normal, tangential and bi-normal velocity components. The $\mathrm{k}$ and $\mathrm{l}$ parameters are the yaw and pitch factors and describe the influence that the probe yaw and pitch orientation has on the effective cooling velocity.

The velocity components in equation (B.26) can be expressed in terms of the mean velocity modulus, $\bar{U}$ : 


$$
\begin{array}{r}
\bar{U}_{N}=\cos \theta|\bar{U}|, \\
\bar{U}_{T}=\sin \theta \cos \varphi|\bar{U}|, \\
\bar{U}_{B}=\sin \theta \sin \varphi|\bar{U}|,
\end{array}
$$

Menet et al. (1999) derived the following formula by combining equations (B.25) and (B.26) and expanding the velocity components as shown in equation B.27):

$$
\bar{E}^{2}-\bar{E}_{0}^{2}=B \bar{U}^{n}\left\{1-\left[1-\left(k^{2} \cos ^{2} \varphi+l^{2} \sin ^{2} \varphi\right)\right] \sin ^{2} \theta\right\}^{n^{\prime} / 2}
$$

Note that the factor $n^{\prime}$ in equation (B.28) has no relation to the factor $n$ in equation (B.25). Menet et al. $(1999)$ then eliminates the factor $B \bar{U}^{n}$ by dividing the value of the quantity $\bar{E}^{2}-\bar{E}_{0}^{2}$ measured at the current position $\theta$, by the value at $\theta=90^{\circ}$ where $\bar{E}^{2}-\bar{E}_{0}^{2}$ is a minimum. A non-dimensional value, $\Phi$, is then introduced:

$$
\Phi=\frac{\left(\bar{E}^{2}-E_{0}^{2}\right)_{\theta}}{\left(\bar{E}^{2}-E_{0}^{2}\right)_{90^{\circ}}}
$$

A quantity, $\Psi$, is introduced that is defined as:

$$
\Psi=1+K \cos ^{2} \theta
$$

with $\mathrm{K}$ defined as

$$
K=\frac{1}{A}-1=\frac{1}{k^{2} \cos ^{2} \varphi+l^{2} \sin ^{2} \varphi}-1
$$

Equation $(\mathrm{B} .28)$ can then be rewritten as:

$$
\ln \Phi=\frac{n^{\prime}}{2} \ln \Psi
$$

The values of $K$ and $n^{\prime}$ are determined using data obtained from calibration procedures. The non-dimensional value, $\Phi$, is calculated at each value of $\theta$ by substituting the values of $\bar{E}$ measured. For a range of values of the parameter $K$, values of $\ln \Psi$ are calculated using equation (B.30). The value of $K$ should be such that the plotted values in the plane $(2 \ln \Phi, \ln \Psi)$ lie in a straight line, in order to comply with the linear nature of the relation in equation (B.31). The gradient of that line would then be equal to $1 / n^{\prime}$.

\section{B.3.2 Calibration procedures and results}

The first step in the calibration procedure was to determine the King's Law parameters, $E_{0}, B$ and $n$. This was achieved by positioning the probe in a wind tunnel and then recording the probe output at various flow velocities. 
The probe(TSI 1213) was positioned in a wind tunnel test section with the yaw- and pitch-angles set at $\theta=90^{\circ}$ and $\varphi=45^{\circ}$. At this position the incoming flow would approach the probe perpendicularly and without any disturbances upstream of the probe. The probe was connected to a TSI IFA-100 flow analyser that provided the required voltage source and signal amplification.

The flow velocity was measured using a pitot tube and a manometer. The flow velocity was varied by controlling the wind tunnel fan speed.

At each fan speed the probe output voltage and the flow velocity was recorded.
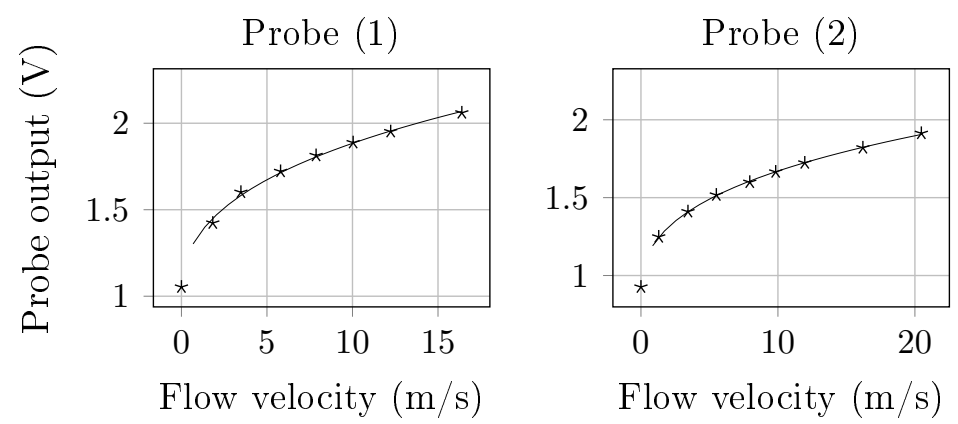

Figure B.15: Hot film anemometer King's law parameter calibration results for two probes

Figure B.15 shows the results of the King's Law parameter calibration for two probes (both TSI 1213 models). The King's Law parameters were then optimised to find a best fit for the calibration data. The following equations were derived:

$$
\begin{aligned}
& \bar{E}_{1}^{2}=1.0499^{2}+0.7265 \bar{U}_{e}^{0.5274}, \\
& \bar{E}_{2}^{2}=0.9270^{2}+0.6052 \bar{U}_{e}^{0.5043},
\end{aligned}
$$

The next step was to determine the directional sensitivity of the probe. For this calibration the flow velocity was held constant at an expected average test flow velocity value. The probe yaw-angle was then rotated through $180^{\circ}$ at intervals of $15^{\circ}$ starting at $0^{\circ}$ (see Figure B.14). The pitch angle was held constant at $45^{\circ}$.

At each yaw angle position the probe output voltage was recorded.

Figure B.16 shows the measured results for the $\Phi$ parameter at the calibration yaw angles. Also shown is the calculated values of $\Phi$ based on the $K$ and $n^{\prime}$ parameters. The $K$ and $n^{\prime}$ parameters were determined as described in section B.3.1 (see Figure B.17. The values of the $n^{\prime}$-parameter for probe 1 and 2 were determined as 1.0049 and 0.9497 , respectively. 

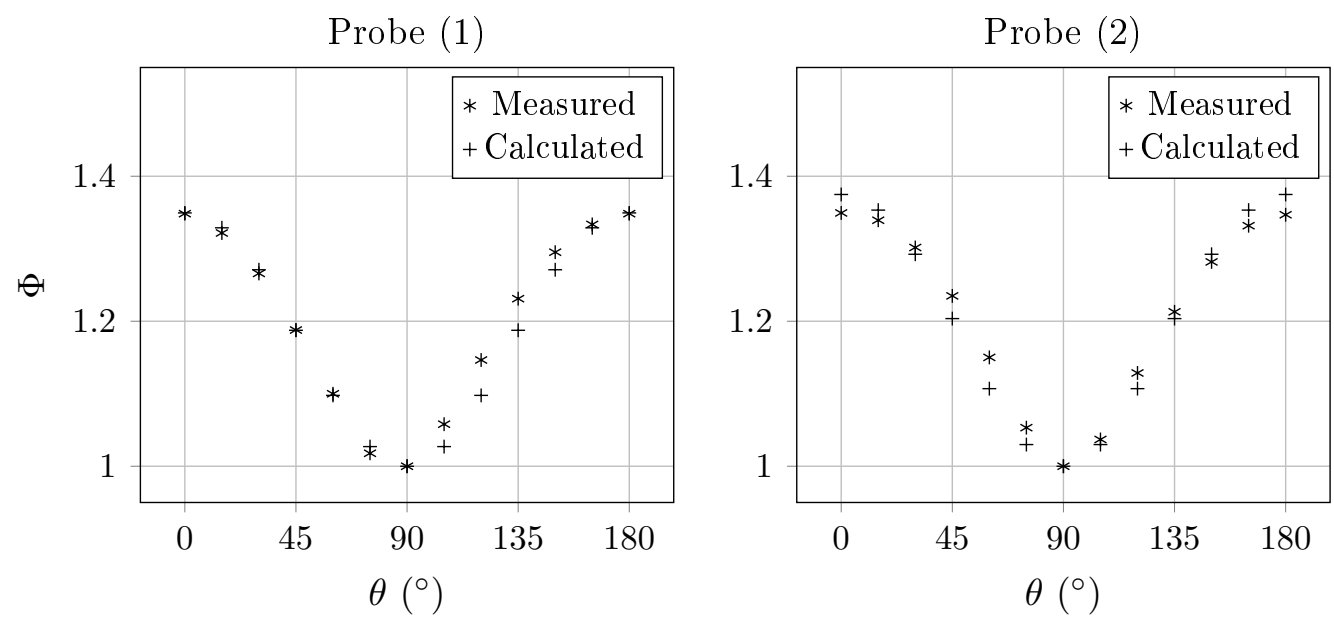

Figure B.16: Hot film anemometer directional sensitivity calibration results for two probes
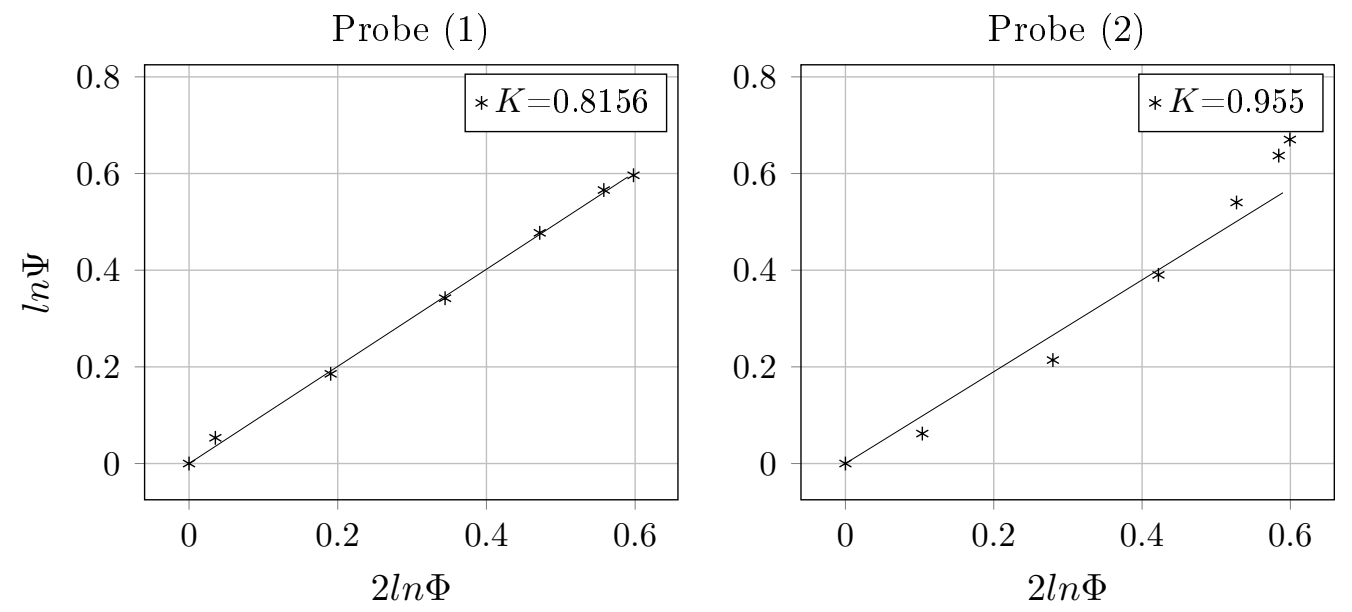

Figure B.17: Determination of $K$ and $n^{\prime}$ parameters 


\section{Appendix C}

\section{Fan tests}

\section{C.1 Fan performance calculations}

This section shows the calculations done to determine the static pressure measured during testing. The sample data for the calculations were recorded during tests done with the $\mathrm{N}$-fan at a blade angle of $14.2^{\circ}$.

The ambient conditions during this particular test is shown in Table C.1.

Table C.1: Ambient conditions

\begin{tabular}{lr}
\hline Ambient temperature & $15.3^{\circ} \mathrm{C}$ \\
Atmospheric pressure & $99300 \mathrm{~Pa}$ \\
\hline
\end{tabular}

Before and after the tests zero readings were recorded. The zero readings are given in Table C.2.

Table C.2: Zero readings

\begin{tabular}{lrrr}
\hline Channel name & Zero reading 1 & Zero reading 2 & Average zero reading \\
\hline Flow Rate & $0.000781 \mathrm{~V}$ & $0.000729 \mathrm{~V}$ & $0.000755 \mathrm{~V}$ \\
Pressure & $0.7167 \mathrm{~V}$ & $0.7168 \mathrm{~V}$ & $0.71675 \mathrm{~V}$ \\
Speed & $0.0172 \mathrm{~V}$ & $0.0175 \mathrm{~V}$ & $0.01735 \mathrm{~V}$ \\
Torque indicated & $-0.0300 \mathrm{Nm}$ & $-0.0384 \mathrm{Nm}$ & $-0.0342 \mathrm{Nm}$ \\
\hline
\end{tabular}

The mechanical friction caused by the bearings were also measured before and after the tests by removing the edge fan and running the motor at the test speed. Table C.3 shows the recorded data.

Table C.4 is a sample of measurements recorded during testing.

The recorded readings were then substituted into the various calibration equations and the zero values deducted to obtain the values listed in Table C.5. 
Table C.3: Mechanical friction torque readings

\begin{tabular}{rrr}
\hline Reading 1 & Reading 2 & Average reading \\
\hline $0.18044 \mathrm{Nm}$ & $0.19183 \mathrm{Nm}$ & $0.18614 \mathrm{Nm}$ \\
\hline
\end{tabular}

Table C.4: Experimental measurements

\begin{tabular}{lr}
\hline Channel name & Output \\
\hline Flow rate & $0.8012 \mathrm{~V}$ \\
Pressure & $1.3776 \mathrm{~V}$ \\
Speed & $3.9832 \mathrm{~V}$ \\
Torque indicated & $1.8853 \mathrm{Nm}$ \\
\hline
\end{tabular}

Table C.5: Measured values

\begin{tabular}{lr}
\hline Property & Value \\
\hline Flow rate & $1.118 \mathrm{~m}^{3} / \mathrm{s}$ \\
Pressure & $73.67 \mathrm{~Pa}$ \\
Speed & $997.96 \mathrm{rpm}$ \\
Torque & $1.732 \mathrm{Nm}$ \\
\hline
\end{tabular}

The ambient condition values are used to calculate the air density:

$$
\rho_{a m b}=\frac{p_{a m b}}{R T_{a m b}}=\frac{99300}{287.08 \times 288.45}=1.199 \mathrm{~kg} / \mathrm{m}^{3}
$$

The average velocity in the duct in which the fan is located is calculated as follows:

$$
v_{2}=\frac{\dot{V}}{A_{2}}=\frac{1.118}{0.25 \times \pi \times 0.63^{2}}=3.586 \mathrm{~m} / \mathrm{s}
$$

The dynamic pressure based on this velocity is then calculated as follows:

$$
p_{\text {dyn } 2}=\frac{1}{2} \rho_{a m b} v_{2}^{2}=\frac{1}{2} \times 1.199 \times 3.586^{2}=7.709 \mathrm{~N} / \mathrm{m}^{2}
$$

The Reynolds number for this section is calculated as follows using a viscosity of $1.7934 \times 10^{-5} \mathrm{Ns} / \mathrm{m}$ :

$$
R e_{2}=\frac{\rho_{a m b} v_{2} D_{2}}{\mu}=\frac{1.199 \times 3.586 \times 0.63}{1.7934 \times 10^{-5}}=151040
$$

The average velocity in the plenum is determined by using a hydraulic diameter of $0.79 \mathrm{~m}$ : 


$$
v_{3}=\frac{\dot{V}}{A_{3}}=\frac{1.118}{0.79^{2}}=1.791 \mathrm{~m} / \mathrm{s}
$$

Now the dynamic pressure based on the average plenum velocity can be calculated as follows:

$$
p_{\text {dyn } 3}=\frac{1}{2} \rho_{a m b} v_{3}^{2}=\frac{1}{2} \times 1.199 \times 1.791^{2}=1.923 \mathrm{~N} / \mathrm{m}^{2}
$$

The Reynolds number in the plenum chamber is given as:

$$
R e_{3}=\frac{\rho_{a m b} v_{3} D_{h 3}}{\mu}=\frac{1.199 \times 1.791 \times 0.79}{1.7934 \times 10^{-5}}=94594
$$

The correlations given in the BS 848 for the pressure loss between the fan exit plane and the pressure measuring plane are implemented as follows:

$$
\begin{aligned}
\Delta p_{\text {loss }}= & \left(0.1+0.005+0.42 R e_{2}^{-0.3}\right) p_{\text {dyn } 2}+\left(0.005+0.42 R e_{3}^{-0.3}\right) p_{\text {dyn } 3} \\
= & \left(0.1+0.005+0.42 \cdot 151040^{-0.3}\right) \cdot 7.709 \\
& +\left(0.005+0.42 \cdot 94594^{-0.3}\right) \cdot 1.923 \\
= & 0.9355 \mathrm{~N} / \mathrm{m}^{2}
\end{aligned}
$$

Using the pressure loss equation obtained by van der Spuy (2011) for the hexcore mesh and the average plenum chamber velocity, the pressure loss is obtained as:

$$
p_{\text {hex }}=0.0981 v_{3}^{2}+1.4782 v_{3}=0.0981 \times 1.791^{2}+1.4782 \times 1.791=2.962 \mathrm{~N} / \mathrm{m}^{2}
$$

The fan static pressure as defined by BS 848 is the difference between the outlet static pressure and the inlet total pressure. The inlet total pressure is atmospheric, so the fan static pressure is calculated as follows:

$$
\begin{aligned}
p_{s f} & =p_{s 3}+\Delta p_{\text {loss }}+p_{\text {hex }}+p_{\text {dyn } 3}-p_{\text {dyn } 2} \\
& =73.67+0.9355+2.962+1.923-7.709 \\
& =71.78 \mathrm{~N} / \mathrm{m}^{2}
\end{aligned}
$$

The fan shaft power is determined by using the measured torque and fan angular velocity:

$$
P_{\text {fan }}=\frac{2 \pi}{60} N_{\text {fan }} T_{\text {fan }}=\frac{2 \pi}{60} \times 997.96 \times 1.732=181 \mathrm{~W}
$$

Finally the measured values are scaled to fixed reference values of 1000 RPM and $1.2 \mathrm{~kg} / \mathrm{m}^{3}$.

$$
\dot{V}^{\prime}=\dot{V} \frac{N^{\prime}}{N}=1.118 \times \frac{1000}{997.96}=1.120 \mathrm{~m}^{3} / \mathrm{s}
$$




$$
\begin{gathered}
p_{s f}^{\prime}=p_{s f}\left(\frac{N^{\prime}}{N}\right)^{2}\left(\frac{\rho^{\prime}}{\rho_{a m b}}\right)=71.78\left(\frac{1000}{997.96}\right)^{2}\left(\frac{1.2}{1.199}\right)=72.13 \mathrm{~N} / \mathrm{m}^{2} \\
P_{\text {fan }}^{\prime}=P_{\text {fan }}\left(\frac{N^{\prime}}{N}\right)^{3}\left(\frac{\rho^{\prime}}{\rho_{a m b}}\right)=181\left(\frac{1000}{997.96}\right)^{3}\left(\frac{1.2}{1.199}\right)=182.3 \mathrm{~W}
\end{gathered}
$$

\section{C.2 Flow velocity measurements}

This section explains the velocity measurement process. A sample data set will be used from measurements made at position 3 with the $\mathrm{N}$-fan at a platform height of $1.5 \mathrm{D}_{\text {fan }}$.

Figure C.1 shows an illustration of the set-up used for the hot film measurements. A angle measurement jig consisting of a protractor and a rotatable angle indicator was used to position the hot film probe. A grub screw secures the probe at the correct height and angle relative to the indicator's pointer.

The hot film probe was connected to a TSI IFA-100 flow analyser which provided the excitation voltage and signal amplification. The TSI IFA-100 was connected to a National Instruments NI-6218 DAQ unit which connected via USB to a computer. National Instruments data logging software was used to record the hot film voltage output.

Before any measurements were made the flow analyser was set-up by measuring and entering transducer parameters (such as cable resistance and operating resistance) and then tuning the frequency response. The TSI IFA-100 user manual provides instructions for these processes.

The rotating single inclined hot film anemometer measurement technique requires taking measurements at multiple angles to be able to determine the flow direction. For this investigation it was decided to take measurements at $15^{\circ}$ intervals through $180^{\circ}$.

The measurement process is described below:

1. The protractor is placed in a hole in the bottom platform located at the chosen position and aligned with the global axis system as indicated in Figure C.1.

2. The probe support is inserted through the protractor and fixed at a height that ensures the hot film probe would measure at the mid plane between the top and bottom platforms of the inlet chamber.

3. The probe is inserted into the probe support and the probe assembly aligned with the protractor angle indicator with the longer probe prong on the same side as the angle indicator. The probe assembly is then 


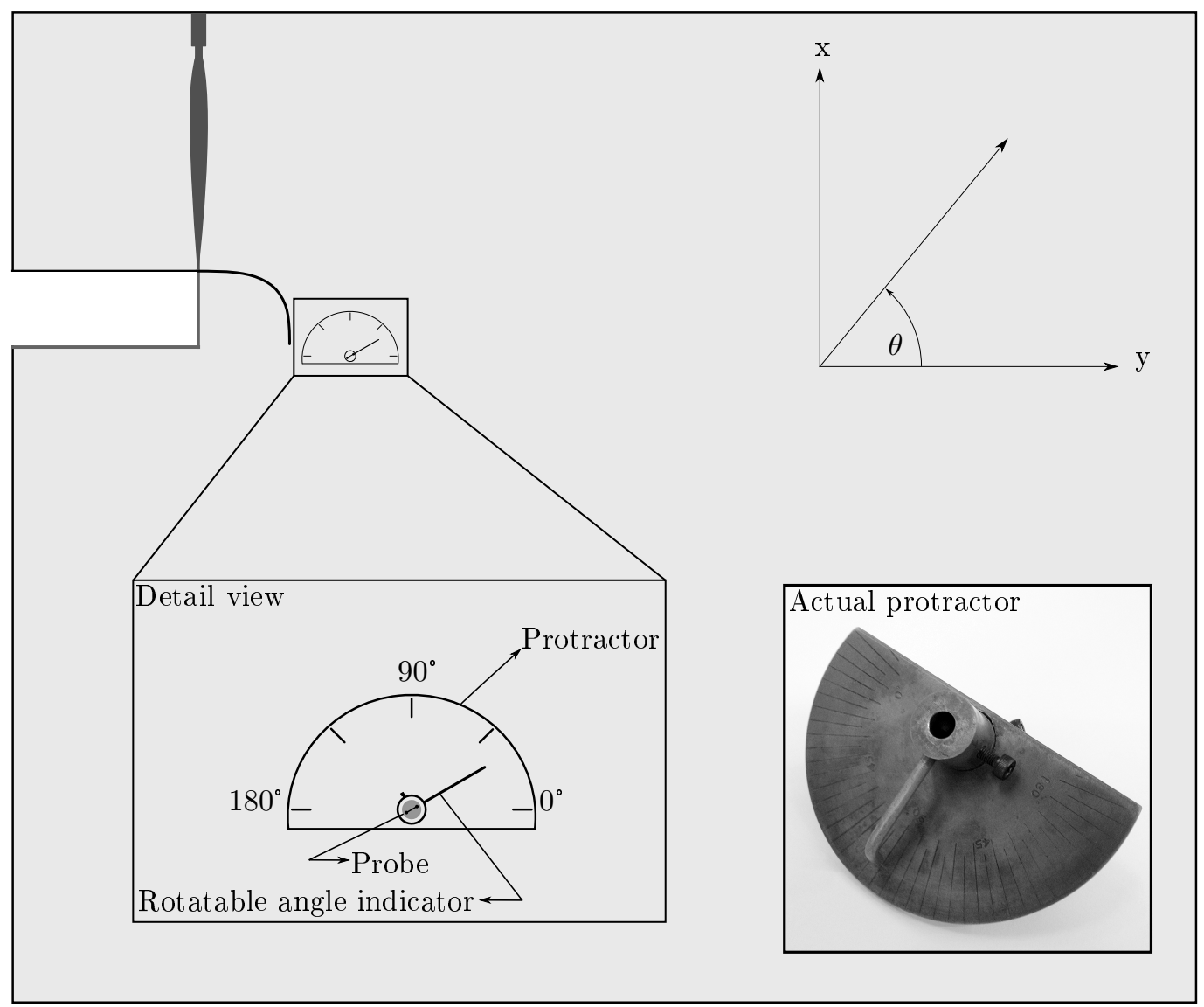

Figure C.1: Hot film measurement technique

secured at this position by tightening a grub screw located on the side of the angle indicator.

4. The protractor angle indicator is aligned with the $0^{\circ}$ position and then secured by tightening another grub screw.

5. The voltage output from the probe is now recorded over a period of two minutes to ensure that an accurate average can be calculated.

6. The angle indicator is rotated counter clockwise through $15^{\circ}$ to the next position.

7. Steps 5 and 6 are repeated until the last recording at $180^{\circ}$ is made.

8. The probe is removed from the probe support and the probe support removed from the protractor.

9. Steps 1 to 8 are repeated at all the five measurement positions (as shown in Figure 4.7) and platform height positions. 
Figure C.2 shows the voltage output averages recorded with the N-fan system at position 2 with a platform height of $1.5 \mathrm{D}_{\text {fan }}$.

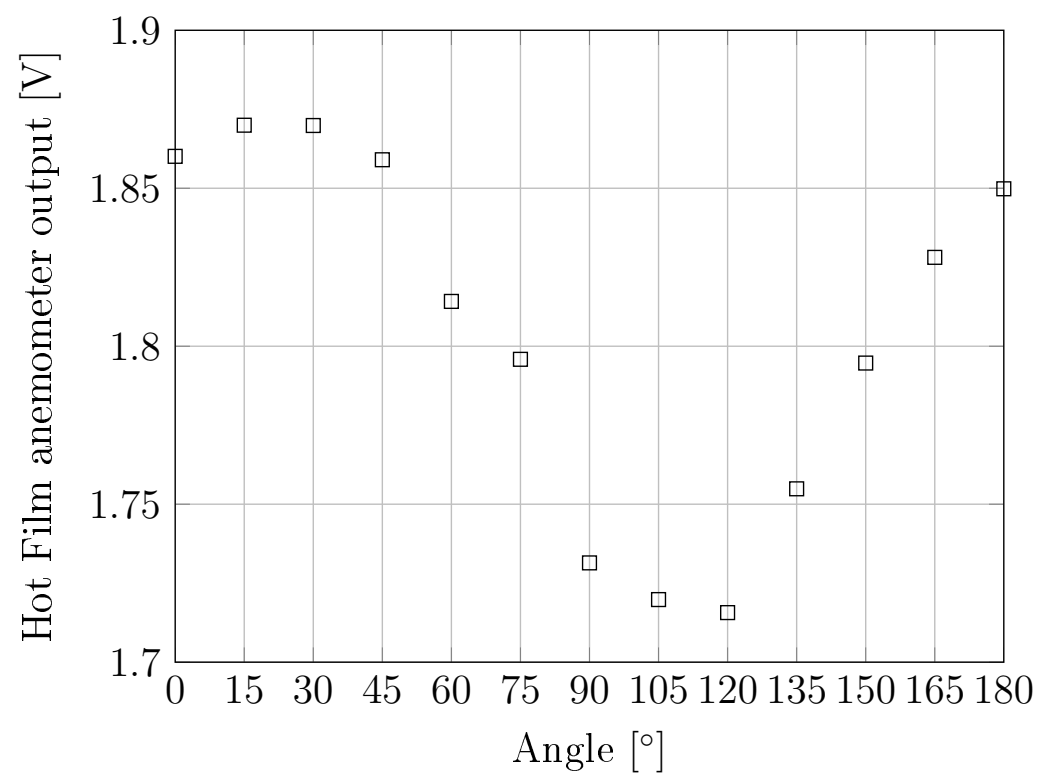

Figure C.2: Rotating single inclined hot film anemometer sample data, $\mathrm{H} / \mathrm{D}_{\text {fan }}=$ 1.5

The parameters obtained from the probe calibration procedures discussed in section B.3.2 are now used to determine the flow magnitude and direction. The voltage output values are used to calculate a non-dimensional value, $\Phi$, which is defined by equation (B.29). Equations $(\mathrm{B} .30)$ and $(\mathrm{B} .31)$ are then used together with the probe $n^{\prime}$ - and $K$-parameters to also calculate $\Phi$. A least squares fit is done between the measured and calculated $\Phi$-values by changing an angle offset value included in equation (B.30). The value of the offset angle value which gives the best fit is then used to determine the flow angle. Figure C.3 shows the measured and calculated values of $\Phi$ before and after angle offset correction.

Finally the King's Law equation $(B .25)$ is employed to calculate the velocity magnitude. The velocity magnitude corresponds to the peak voltage output measured. This voltage is used in equation (B.25) together with the calibration constants determined in section B.3.2. For this data set probe \#1 was used. The velocity calculation is shown below:

$$
\bar{U}_{e}=\left(\frac{\bar{E}^{2}-E_{0}^{2}}{B}\right)^{1 / n_{e}}=\left(\frac{1.87^{2}-1.0499^{2}}{0.7265}\right)^{1 / 0.5274}=9.6 \mathrm{~m} / \mathrm{s}
$$

The final result is summarised in Table C.6. 

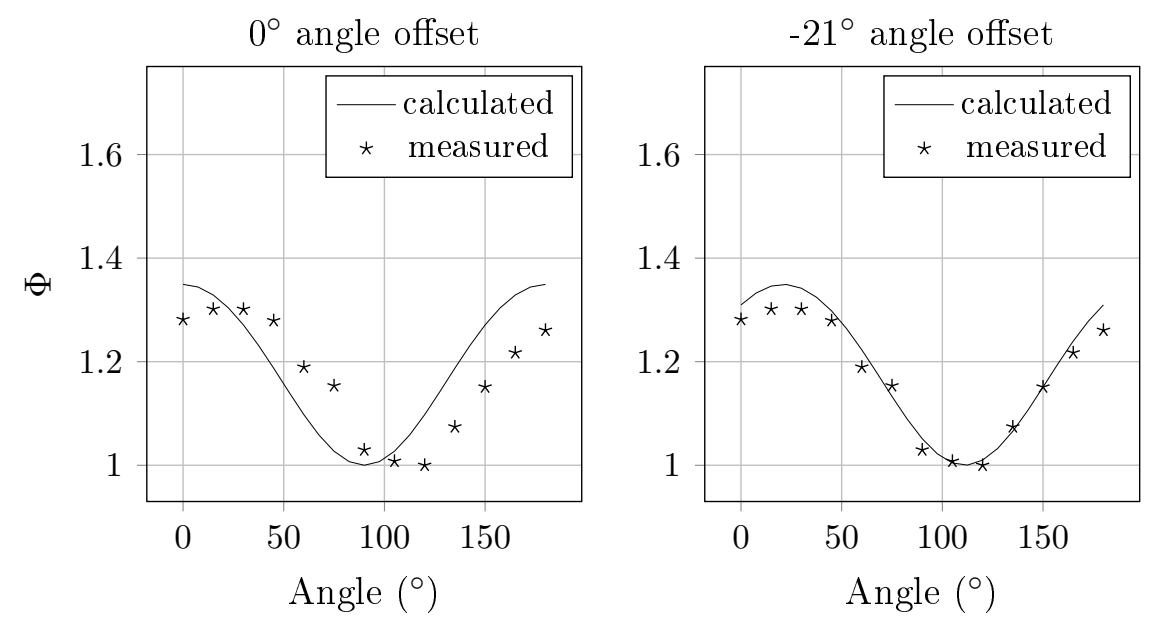

Figure C.3: Hot film measurement data velocity angle determination

Table C.6: Sample data results

\begin{tabular}{lr}
\hline Velocity & $9.6 \mathrm{~m} / \mathrm{s}$ \\
Angle & $68.4^{\circ}$ \\
\hline
\end{tabular}




\section{Appendix D}

\section{Numerical fan model}

Fluent's pressure jump method (PJM) was implemented as the numerical fan model used in the CFD simulations. This section shows the application of the PJM using the N-fan (see Appendix A) performance results.

A $3^{\text {rd }}$ order polynomial is fitted to the fan static pressure curve, as shown in Figure D.1. The equation is expressed as:

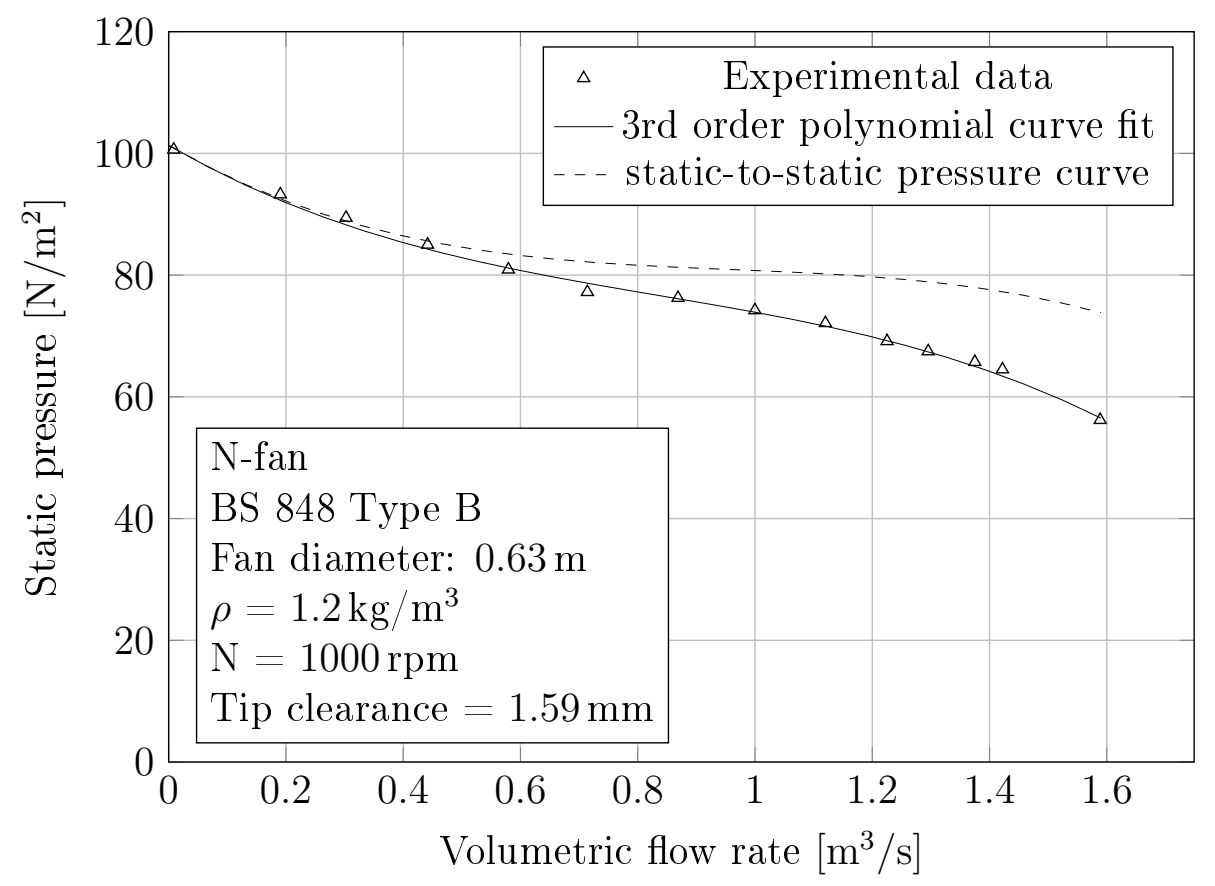

Figure D.1: N-fan static pressure curve with polynomial curve fit

$$
p_{s f}=-18.649 \dot{V}^{3}+47.004 \dot{V}^{2}-55.771 \dot{V}+101.32
$$

The pressure jump function in Fluent is specified as a function of the velocity normal to the pressure jump plane. In this case the fan static pressure 
function should be expressed in terms of the fan axial velocity. The volumetric flow rate can be expressed in terms of the cross sectional area and axial velocity as

$$
\dot{V}=A v
$$

Substituting equation D.2 in the static pressure equation (D.1).

$$
p_{s f}=-18.649 A^{3} v^{3}+47.004 A^{2} v^{2}-55.771 A v+101.32
$$

The fan cross sectional is

$$
A=\pi\left(r_{\text {shroud }}^{2}-r_{\text {hub }}^{2}\right)=\pi\left(0.315^{2}-0.048^{2}\right)=0.3045 \mathrm{~m}^{2}
$$

which gives

$$
p_{s f}=-0.5265 v^{3}+4.3582 v^{2}-16.9823 v+101.32
$$

Equation (D.5) represents the difference in pressure between the total (atmospheric) pressure upstream of the fan and the static pressure immediately downstream of the fan. It can also be expressed as

$$
\left(p_{\text {static }}\right)_{2}-\left(p_{\text {total }}\right)_{1}=p_{s f}
$$

Fluent requires the user to specify a static-to-static pressure function for the PJM. Expanding and rearranging equation (D.6) gives

$$
\begin{aligned}
\left(p_{\text {static }}\right)_{2}-\left(p_{\text {static }}+p_{\text {dynamic }}\right)_{1} & =p_{\text {sf }} \\
\left(p_{\text {static }}\right)_{2}-\left(p_{\text {static }}\right)_{1} & =p_{\text {sf }}+\left(p_{\text {dynamic }}\right)_{1} \\
p_{\text {static-static }} & =p_{s f}+\left(p_{\text {dynamic }}\right)_{1}
\end{aligned}
$$

The losses at the bell mouth inlet of the fan could also be included in the static-to-static pressure function

$$
p_{\text {static-static }}=p_{\text {sf }}+\left(p_{\text {dynamic }}\right)_{1}+p_{\text {inlet losses }}
$$

substituting equation (D.5) and the dynamic pressure and inlet loss terms

$$
\begin{aligned}
p_{\text {static-static }}=-0.5265 v^{3}+4.3582 v^{2}-16.9823 v & +101.32 \\
& +\frac{1}{2} \rho v^{2}+\frac{1}{2} \rho v^{2} K_{\text {inlet }}
\end{aligned}
$$

The inlet loss coefficient is defined in terms of the shroud flow area van der Spuy, 2011)

$$
K_{\text {inlet } O D}=0.06
$$

This value is then converted to the the actual flow area: 


$$
K_{\text {inlet }}=K_{\text {inletOD }} \frac{A}{\pi r_{\text {shroud }}^{2}}=0.06 \frac{0.3045}{0.312}=0.0586
$$

Substituting equation (D.10) into equation (D.9) and using a density value of $1.2 \mathrm{~kg} / \mathrm{m}^{3}$ gives the static to static pressure equation

$$
p_{\text {static-static }}=-0.5265 v^{3}+4.9933 v^{2}-16.9823 v+101.32
$$

Equation (D.11) (converted to be a function of volumetric flow rate) is also shown in Figure D.1. Equation (D.11) can be used in Fluent to specify the N-fan PJM. This process was repeated for each fan described in Appendix A. 


\section{Appendix E}

\section{ACHE numerical model}

This section will describe the process followed to derive a numerical model of the ACHE for use in the CFD simulations. The ACHE system modelled in this study is based on a general ACHE system as modelled by van Rooyen (2007) and Louw (2011).

\section{E.1 Air and steam design point conditions}

Atmospheric conditions

$$
\begin{array}{ll}
\text { Atmospheric dry bulb air temperature } & \mathrm{T}_{\mathrm{a}}=15.6^{\circ} \mathrm{C}(288.75 \mathrm{~K}) \\
\text { Atmospheric pressure } & \mathrm{p}_{\mathrm{a}}=90000 \mathrm{~N} / \mathrm{m}^{2}
\end{array}
$$

Steam design point condition

$$
\text { Steam temperature } \quad \mathrm{T}_{\mathrm{s}}=60^{\circ} \mathrm{C}(333.15 \mathrm{~K})
$$

Air thermo-physical properties at design conditions

\section{Air density}

Air thermal conductivity

Air specific heat

Air molecular viscosity

Air Prandtl number

$$
\begin{aligned}
\rho_{\mathrm{a}} & =1.0857 \mathrm{~kg} / \mathrm{m}^{3} \\
\mathrm{k}_{\mathrm{a}} & =0.02535 \mathrm{~W} / \mathrm{mK} \\
\mathrm{c}_{\mathrm{pa}} & =1006.609 \mathrm{~J} / \mathrm{kgK} \\
\mu_{\mathrm{a}} & =1.7948 \times 10^{-5} \mathrm{~kg} / \mathrm{ms} \\
\operatorname{Pr}_{\mathrm{a}} & =0.713
\end{aligned}
$$

\section{E.2 ACHE system resistance model}

The system resistance of the ACHE is given by the one-dimensional draft equation as provided by Kröger (2004): 


$$
\begin{aligned}
\Delta p_{h e}=-\left(K_{t s} \frac{\left(\dot{m}_{a} / A_{t f r}\right)^{2}}{2 \rho_{t s}}+K_{u p}\right. & \frac{\left(\dot{m}_{a} / A_{e}\right)^{2}}{2 \rho_{u p}} \\
& \left.+K_{d o} \frac{\left(\dot{m}_{a} / A_{e}\right)^{2}}{2 \rho_{d o}}+K_{\theta t} \frac{\left(\dot{m}_{a} / A_{t f r}\right)^{2}}{2 \rho_{t}}\right)
\end{aligned}
$$

Table E.1 lists the ACHE dimensions applicable to equation (E.1). The values were calculated using the ACHE dimensions and specifications given by Louw (2011).

Table E.1: Applicable air-cooled heat exchanger dimensions used in equation (E.1)

Frontal area of a single finned tube bundle $A_{f r}=27.434 \mathrm{~m}^{2}$

Total frontal area of finned tube bundles $\quad A_{t f r}=219.472 \mathrm{~m}^{2}$

Fan annulus area

$$
A_{e}=64.126 \mathrm{~m}^{2}
$$

Table E.2 lists the values of the loss coefficients in equation (E.1). The coefficients were calculated using the empirical correlations provided by Kröger (2004) along with dimensions and specification provided by Louw (2011).

Table E.2: Air-cooled heat exchanger loss coefficients used in equation E.1

Tower support structure loss coefficient Upstream objects loss coefficient Downstream objects loss coefficient Heat exchanger loss coefficient

$$
\begin{aligned}
K_{t s} & =1.6 \\
K_{u p} & =0.28 \\
K_{d o} & =0.35 \\
K_{\theta t} & =392.213 \dot{m}^{-0.439}+11.810
\end{aligned}
$$

Substituting the values in Table E.1 and E.2 into equation (E.1), and expressing the resulting equation in terms of volumetric flow rate gives

$$
\Delta p_{h e}=-\left(2.3429\left(10^{-4}\right) \dot{V}^{2}+4.2634\left(10^{-3}\right) \dot{V}^{1.561}\right)
$$

Equation E.2 can be approximated by a second order polynomial expressed as

$$
\Delta p_{h e} \approx-\left(3.9008\left(10^{-4}\right) \dot{V}^{2}+5.8943\left(10^{-2}\right) \dot{V}\right)
$$

To model the pressure loss in a porous zone Fluent (2009) adds a momentum source term defined as (for the z-direction)

$$
S_{z}=-\left(\frac{\mu}{\alpha_{z}} v_{z}+\frac{1}{2} C_{z} \rho|v| v_{z}\right)
$$


Equation (E.4), which represents a body force, can be converted to a zdirection pressure equation by multiplying with the porous zone z-direction length $\left(L_{z}\right)$

$$
S_{z} L_{z}=\Delta p_{z}=-\left(L_{z} \frac{\mu}{\alpha_{z}} v_{z}+L_{z} \frac{1}{2} C_{z} \rho|v| v_{z}\right)
$$

The volumetric flow rate $(\dot{V})$ in equation E.3 can be expressed in terms of the z-direction velocity $\left(v_{z}\right)$ and $\mathrm{x}$ - and y-direction lengths $\left(L_{x}\right.$ and $\left.L_{y}\right)$ as

$$
\dot{V}=\left(L_{x} L_{y}\right)\left|v_{z}\right|
$$

Equation (E.3) can be converted to a z-directional pressure loss function based on the z-directional velocity by substituting the volumetric flow rate with equation (E.6)

$$
\Delta p_{z}=\left[3.9008\left(10^{-4}\right)\left(L_{x} L_{y}\right)^{2}\right]\left|v_{z}\right| v_{z}+\left[5.8943\left(10^{-2}\right)\left(L_{x} L_{y}\right)\right] v_{z}
$$

The velocity magnitude value, $|v|$, in equation (E.5) can be assumed to be equal to the z-direction velocity, $v_{z}$, since the flow in the numerical heat exchanger is forced to being orientated in the z-direction. In doing so equation (E.7) can be substituted into equation $($ E.5) and the inertial and viscous loss coefficients $\left(C_{z}\right.$ and $1 / \alpha_{z}$ respectively) determined as follows

$$
\begin{gathered}
C_{z}=\frac{2 \cdot 3.9008\left(10^{-4}\right)\left(L_{x} L_{y}\right)^{2}}{L_{z} \rho}=\frac{2 \cdot 3.9008\left(10^{-4}\right)(11.8 \cdot 10.56)^{2}}{0.2 \cdot 1.0857}=55.787 \mathrm{~m}^{-1} \\
1 / \alpha_{z}=\frac{5.8943\left(10^{-2}\right)\left(L_{x} L_{y}\right)}{L_{z} \mu}=\frac{5.8943\left(10^{-2}\right) \cdot(11.8 \cdot 10.56)}{0.2 \cdot 1.7948\left(10^{-5}\right)}=2.046 \cdot 10^{6} \mathrm{~m}^{-2}
\end{gathered}
$$

\section{E.3 ACHE heat transfer model}

The radiator boundary condition in Fluent calculates the heat exchanger outlet temperature $\left(T_{a i r, d}\right)$ by implementation of a convective heat transfer coefficient specified by the user. The convective heat transfer coefficient is given as

$$
h=\frac{\dot{m} c_{p a}\left(T_{a i r, u p}-T_{a i r, d}\right)}{A\left(T_{a i r, d}-T_{s}\right)}
$$

The coefficient should be specified as a function of the average flow velocity. To obtain such a function the $\varepsilon$-NTU method was implemented together with the characteristic heat transfer parameters and specifications of the finned tube bundles to calculate the outlet temperature, $T_{a i r, d}$ at a range of flow rates. 
Table E.3: Finned tube bundle specifications

Total number of bundles

$$
\begin{aligned}
& \text { Total number of bundles } \\
& \mathrm{n}_{\mathrm{b}}=8 \\
& \text { Total number of tubes per bundle (first row) } \\
& \mathrm{n}_{\mathrm{tb} 1}=57
\end{aligned}
$$$$
\text { Total number of tubes per bundle (second row) } \mathrm{n}_{\mathrm{tb} 2}=58
$$

The outlet temperature could then be used in equation $(\mathrm{E} .8)$ to calculate $h$. A sample calculation is shown to demonstrate the process followed.

A mass flow rate of $\dot{m}=600 \mathrm{~kg} / \mathrm{s}$ is chosen for the sample calculation. Table E.3 lists specifications of the finned tube bundles which are applicable to the sample calculation.

The characteristic heat transfer parameter, $N y$, for tube row 1 and 2 is provided by Louw (2011) as

$$
N y_{1}=583.8307 R y_{1}^{0.4031}, \quad \mathrm{~m}^{-1}
$$

and

$$
N y_{2}=1277.72 R y_{2}^{0.3806}, \quad \mathrm{~m}^{-1}
$$

respectively.

Kröger (2004) defines the heat transfer parameter, $N y$, and the flow parameter, $R y$, as

$$
N y_{i}=\frac{(h A)_{i}}{k_{a} A_{f r, i} P r^{0.333}}, \quad \mathrm{~m}^{-1}
$$

and

$$
R y_{i}=\frac{\dot{m}}{\mu_{a} A_{f r, i}}, \quad \mathrm{~m}^{-1}
$$

respectively.

Using the specified mass flow rate the flow parameters for tube rows 1 and 2 are

$$
R y_{1}=\frac{\dot{m}}{\mu_{a}\left(n_{b} \cdot \frac{n_{t b 1}}{n_{t b 2}}\right) A_{f r}}=\frac{600}{1.7948\left(10^{-5}\right)\left(8 \cdot \frac{57}{58}\right) 27.434}=154.992\left(10^{3}\right) \mathrm{m}^{-1}
$$

and

$$
R y_{2}=\frac{\dot{m}}{\mu_{a} n_{b} A_{f r}}=\frac{600}{1.7948\left(10^{-5}\right) \cdot 8 \cdot 27.434}=152.320\left(10^{3}\right) \mathrm{m}^{-1}
$$

respectively.

The flow rate parameter values are then substituted into equations (E.9) and (E.10) to obtain the heat transfer parameters of tube rows 1 and 2 


$$
\begin{aligned}
& N y_{1}=583.8307\left[154.992\left(10^{3}\right)\right]^{0.4031}=72.194\left(10^{3}\right) \mathrm{m}^{-1} \\
& N y_{2}=1277.72\left[152.320\left(10^{3}\right)\right]^{0.3806}=119.948\left(10^{3}\right) \mathrm{m}^{-1}
\end{aligned}
$$

To calculate the effectiveness values $\left(\varepsilon_{1}\right.$ and $\left.\varepsilon_{2}\right)$ of the two tube rows the overall heat transfer coefficients, $U_{1}$ and $U_{2}$, needs to be determined for the two rows. For the numerical heat exchanger model it is assumed that the overall heat transfer coefficients are equal to the convective heat transfer coefficients, $h_{1}$ and $h_{2}$. Equation (E.11) can then be used to determine the two overall heat transfer coefficients

$$
\begin{aligned}
& (U A)_{1} \approx(h A)_{1}=N y_{1} k_{a} A_{f r, 1} \operatorname{Pr}^{0.333}=352.682\left(10^{3}\right) \mathrm{W} / \mathrm{K} \\
& (U A)_{2} \approx(h A)_{2}=N y_{2} k_{a} A_{f r, 2} \operatorname{Pr}^{0.333}=596.251\left(10^{3}\right) \mathrm{W} / \mathrm{K}
\end{aligned}
$$

Next the effectiveness values for tube rows 1 and 2 are calculated as follows

$$
\varepsilon_{1}=1-\exp \left[\frac{-(U A)_{1}}{\dot{m} c_{p a}}\right]=1-\exp \left[\frac{-352.682\left(10^{3}\right)}{600 \cdot 1006.609}\right]=0.442
$$

similarly,

$$
\varepsilon_{2}=1-\exp \left[\frac{-(U A)_{2}}{\dot{m} c_{p a}}\right]=0.627
$$

The heat transfer equations for the two tube rows are

$$
Q_{1}=\dot{m} c_{p a}\left(T_{a i r, d 1}-T_{a i r, u p 1}\right)=\varepsilon_{1} \dot{m} c_{p a}\left(T_{s}-T_{a i r, u p 1}\right)
$$

and

$$
Q_{2}=\dot{m} c_{p a}\left(T_{a i r, d 2}-T_{a i r, u p 2}\right)=\varepsilon_{2} \dot{m} c_{p a}\left(T_{s}-T_{a i r, u p 2}\right)
$$

The heat exchanger outlet temperature $T_{a i r, d}=T_{a i r, d 2}$ can be calculated from equations $(\mathrm{E.13})$ and $(\mathrm{E.14})$. First equation $(\mathrm{E.13})$ is rearranged and expressed in terms of the row 1 downstream temperature, $T_{a i r, d 1}$, which is equal to the row 2 inlet temperature, $T_{\text {air }, u p 2}$

$$
T_{a i r, u p 2}=T_{a i r, d 1}=T_{a i r, u p 1}+\varepsilon_{1}\left(T_{s}-T_{a i r, u p 1}\right)
$$

Equation (E.15) is then substituted into equation E.14 and rearranged to obtain a solution for the heat exchanger outlet temperature

$$
T_{a i r, d 2}=T_{a i r, u p 1}\left(1-\varepsilon_{1}\right)\left(1-\varepsilon_{2}\right)+T_{s}\left[\varepsilon_{1}+\varepsilon_{2}\left(1-\varepsilon_{1}\right)\right]
$$

Substituting the steam temperature, inlet air temperature and effectiveness values in equation E.16 gives 
$T_{a i r, d 2}=288.75(1-0.442)(1-0.627)+333.15[0.442+0.627(1-0.442)]=323.91 \mathrm{~K}$

Finally the heat exchanger total convective heat transfer can be calculated by substituting the air outlet temperature in equation (E.8)

$$
h=\frac{600 \cdot 1006.609 \cdot(288.75-323.91)}{11.8 \cdot 10.56 \cdot(323.91-333.15)}=18443.49 \mathrm{~W} / \mathrm{m}^{2} \mathrm{~K}
$$

This procedure was applied in a spreadsheet and the convective heat transfer coefficient determined at various flow rates. A heat exchanger convective heat transfer coefficient function could then be obtained which was finally used in the Fluent radiator boundary condition. 


\section{Appendix F}

\section{Experimental results}

\section{F.1 Individual fan performance results}

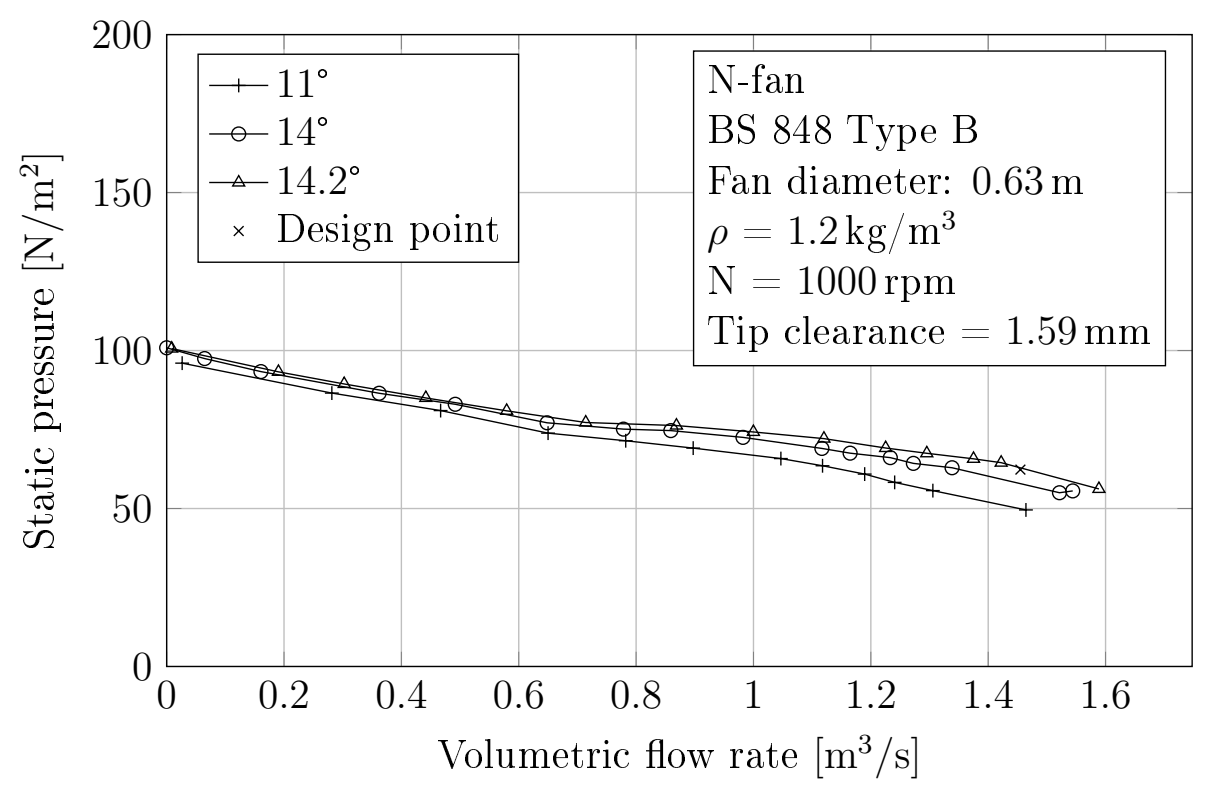

Figure F.1: N-fan static pressure experimental results 


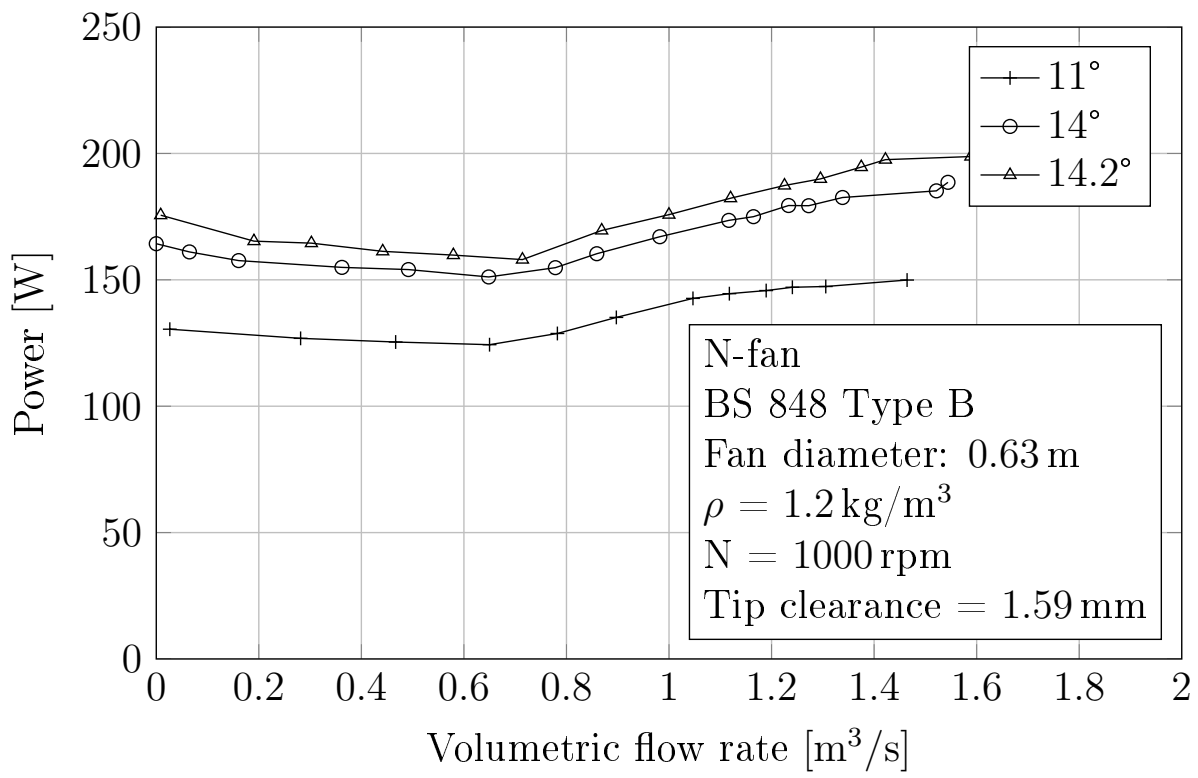

Figure F.2: N-fan power experimental results

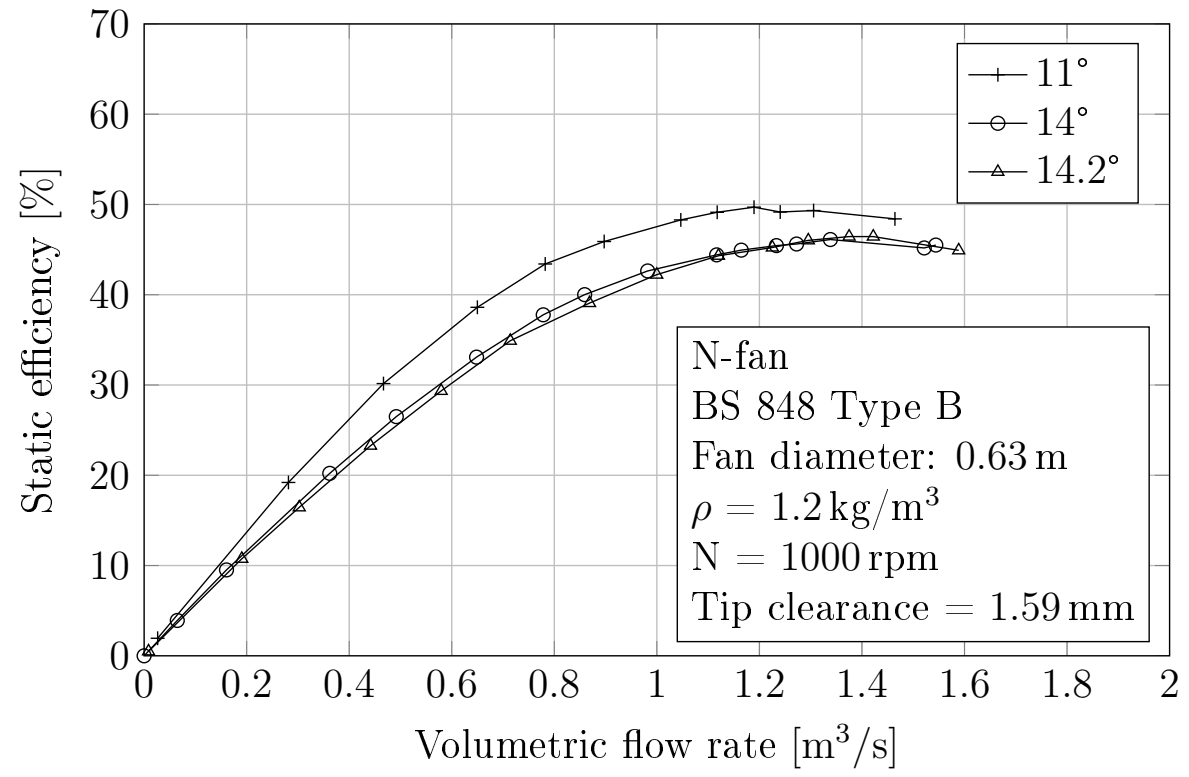

Figure F.3: N-fan static efficiency experimental results 


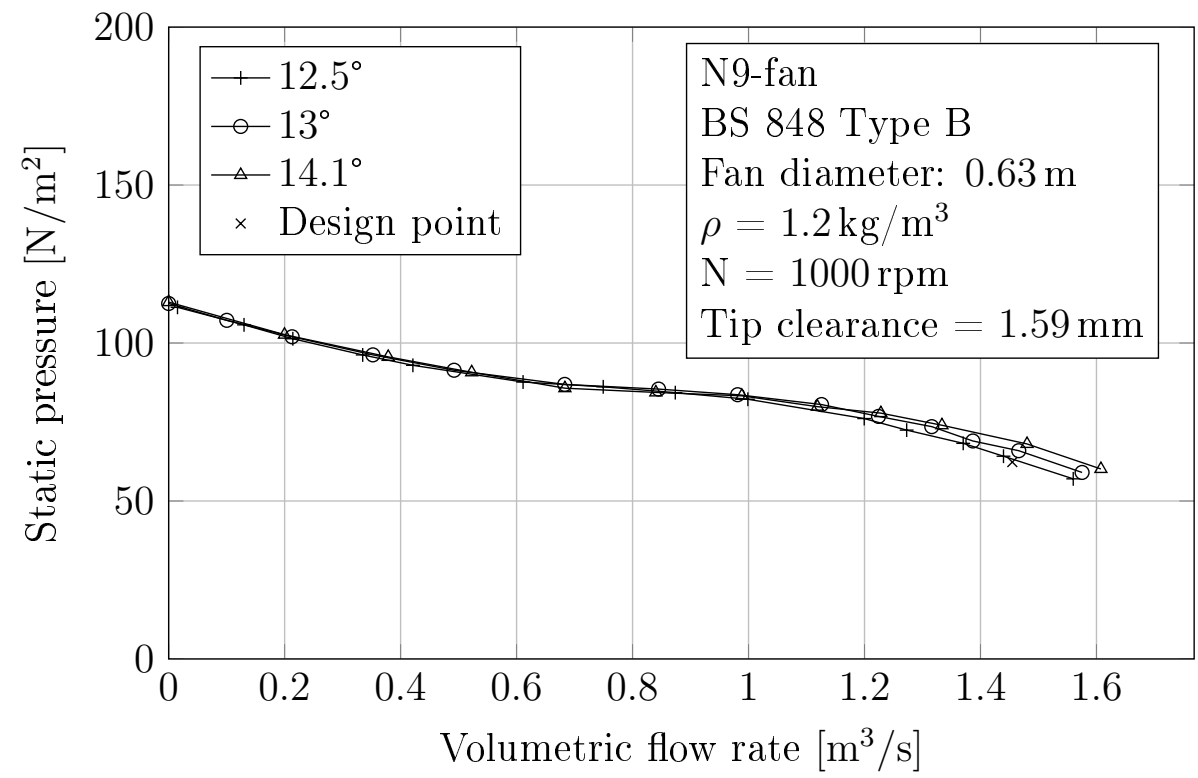

Figure F.4: N9-fan static pressure experimental results

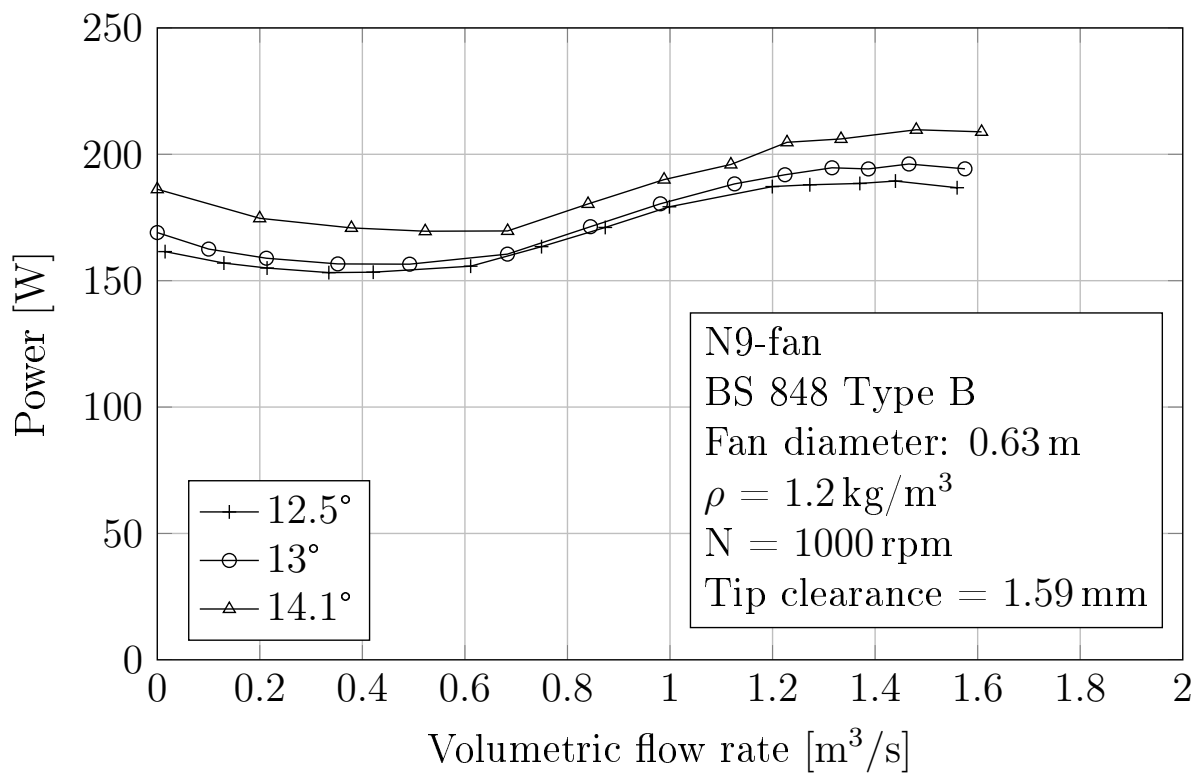

Figure F.5: N9-fan power experimental results 


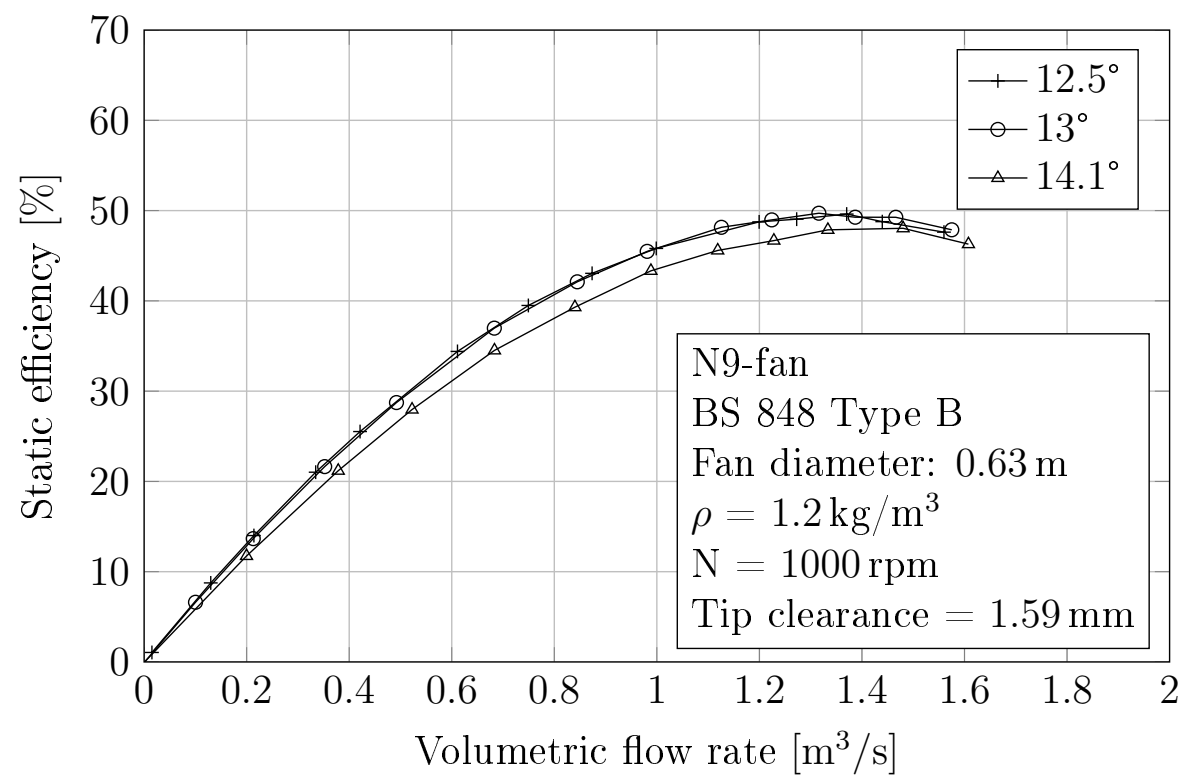

Figure F.6: N9-fan static efficiency experimental results

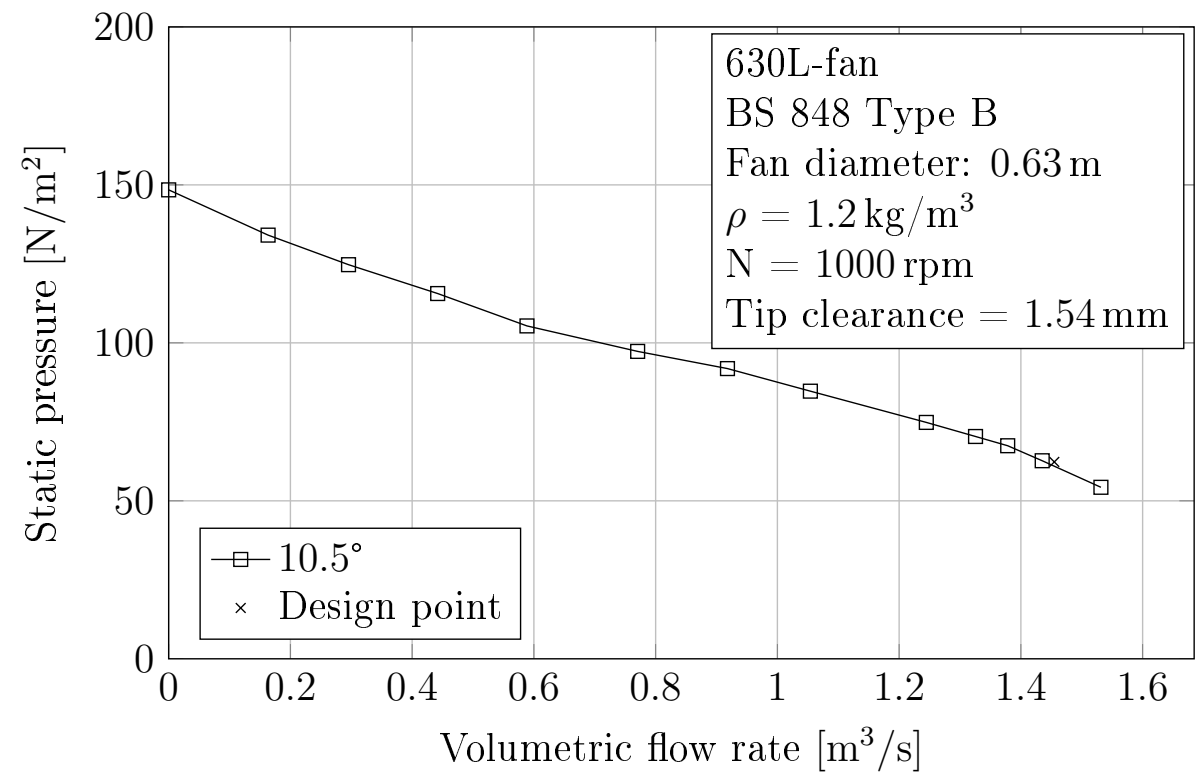

Figure F.7: 630L-fan static pressure experimental results 


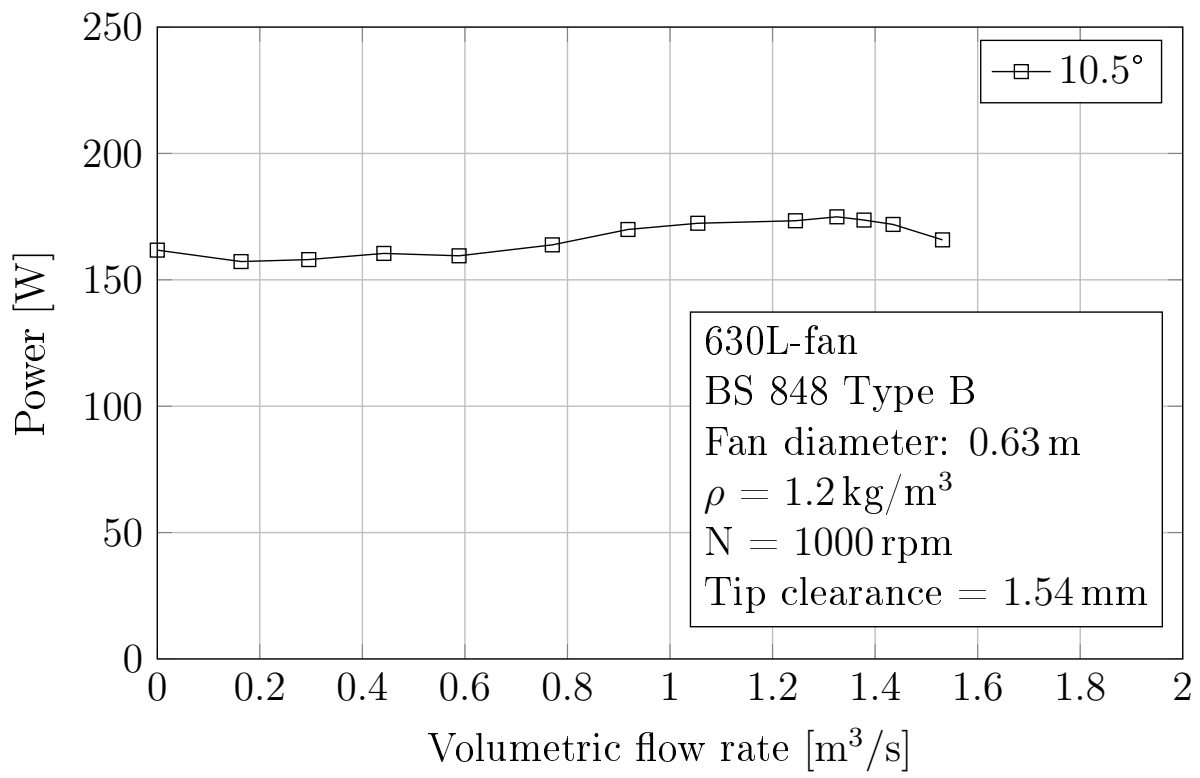

Figure F.8: 630L-fan power experimental results

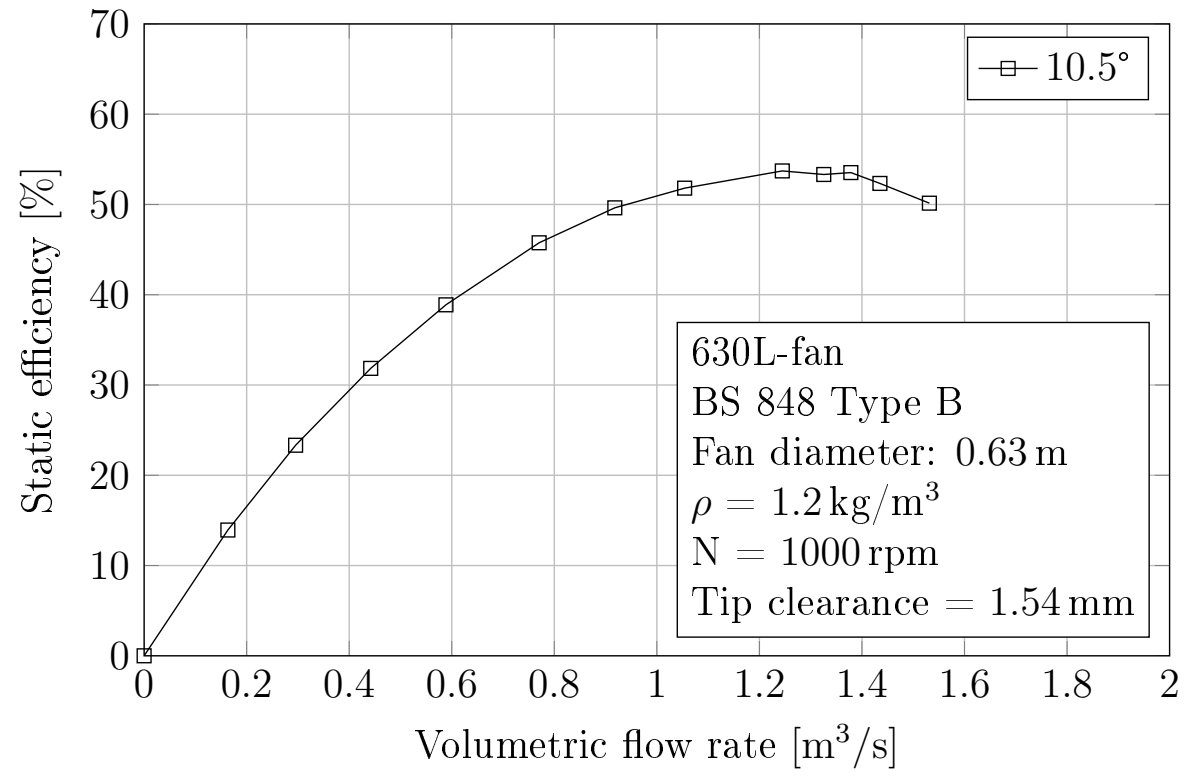

Figure F.9: 630L-fan static efficiency experimental results 


\section{F.2 Multiple fan performance results}

Table F.1: 3-Fan volumetric flow rate results for N-fan system

\begin{tabular}{llll}
\hline & Fan 1 & Fan 2 & Fan 3 \\
Ideal volumetric flow rate, $\dot{V}_{i d}\left[\mathrm{~m}^{3} / \mathrm{s}\right]$ & 1.427 & 1.450 & 1.427 \\
\hline $\begin{array}{l}\text { Dimensionless } \\
\text { height, } H_{f} / D_{\text {fan }}\end{array}$ & \multicolumn{3}{c}{ Volutformetric flow rate $\left[\mathrm{m}^{3} / \mathrm{s}\right]$} \\
\hline & & & \\
Infinite & Fan 1 & Fan 2 & Fan 3 \\
4.5 & 1.420 & 1.421 & 1.413 \\
3.5 & 1.417 & 1.404 & 1.427 \\
2.5 & 1.409 & 1.409 & 1.439 \\
1.5 & 1.385 & 1.407 & 1.428 \\
1 & 1.276 & 1.392 & 1.368 \\
\end{tabular}

Table F.2: N-fan system edge fan power consumption results

\begin{tabular}{lr}
\hline Dimensionless platform height, $H_{f} / D_{f a n}$ & Edge fan power consumption [W] \\
\hline Infinite & 186.3 \\
4.5 & 187.0 \\
3.5 & 187.8 \\
2.5 & 186.7 \\
1.5 & 195.7 \\
1 & 174.6 \\
\hline
\end{tabular}


Table F.3: 3-Fan volumetric flow rate results for N9-fan system

\begin{tabular}{|c|c|c|c|}
\hline Ideal volumetric flow rate, $\dot{V}_{i d}\left[\mathrm{~m}^{3} / \mathrm{s}\right]$ & $\begin{array}{l}\text { Fan } 1 \\
1.425\end{array}$ & $\begin{array}{l}\text { Fan } 2 \\
1.448\end{array}$ & $\begin{array}{l}\text { Fan } 3 \\
1.436\end{array}$ \\
\hline $\begin{array}{l}\text { Dimensionless platform } \\
\text { height, } H_{f} / D_{f a n}\end{array}$ & \multicolumn{3}{|c|}{ Volumetric flow rate $\left[\mathrm{m}^{3} / \mathrm{s}\right]$} \\
\hline & Fan 1 & Fan 2 & Fan 3 \\
\hline Infinite & 1.398 & 1.435 & 1.436 \\
\hline 4.5 & 1.387 & 1.426 & 1.444 \\
\hline 3.5 & 1.387 & 1.423 & 1.449 \\
\hline 2.5 & 1.365 & 1.418 & 1.449 \\
\hline 1.5 & 1.261 & 1.392 & 1.408 \\
\hline 1 & 0.685 & 1.372 & 1.331 \\
\hline
\end{tabular}

Table F.4: N9-fan system edge fan power consumption results

\begin{tabular}{lr}
\hline Dimensionless platform height, $H_{f} / D_{\text {fan }}$ & Edge fan power consumption $[\mathrm{W}]$ \\
\hline Infinite & 174.5 \\
4.5 & 175.9 \\
3.5 & 175.4 \\
2.5 & 176.4 \\
1.5 & 177.2 \\
1 & 168.5 \\
\hline
\end{tabular}

Table F.5: 3-Fan volumetric flow rate results for 630L-fan system

\begin{tabular}{|c|c|c|c|}
\hline Ideal volumetric flow rate, $\dot{V}_{i d}\left[\mathrm{~m}^{3} / \mathrm{s}\right]$ & $\begin{array}{l}\text { Fan } 1 \\
1.420\end{array}$ & $\begin{array}{l}\text { Fan } 2 \\
1.466\end{array}$ & $\begin{array}{l}\text { Fan } 3 \\
1.450\end{array}$ \\
\hline $\begin{array}{l}\text { Dimensionless platform } \\
\text { height, } H_{f} / D_{f a n}\end{array}$ & \multicolumn{3}{|c|}{ Volumetric flow rate $\left[\mathrm{m}^{3} / \mathrm{s}\right]$} \\
\hline & Fan 1 & Fan 2 & Fan 3 \\
\hline Infinite & 1.433 & 1.442 & 1.433 \\
\hline 4.5 & 1.430 & 1.432 & 1.437 \\
\hline 3.5 & 1.426 & 1.437 & 1.454 \\
\hline 2.5 & 1.407 & 1.440 & 1.466 \\
\hline 1.5 & 1.311 & 1.421 & 1.442 \\
\hline 1 & 0.979 & 1.404 & 1.386 \\
\hline
\end{tabular}


Table F.6: 630L-fan system edge fan power consumption results

\begin{tabular}{lr}
\hline Dimensionless platform height, $H_{f} / D_{\text {fan }}$ & Edge fan power consumption $[\mathrm{W}]$ \\
\hline Infinite & 170.6 \\
4.5 & 171.1 \\
3.5 & 171.8 \\
2.5 & 172.0 \\
1.5 & 174.1 \\
1 & 169.6 \\
\hline
\end{tabular}

Table F.7: 3-Fan volumetric flow rate results for 630L-N9-N9 fan system

\begin{tabular}{llll}
\hline & Fan 1 & Fan 2 & Fan 3 \\
Ideal volumetric flow rate, $\dot{V}_{i d}\left[\mathrm{~m}^{3} / \mathrm{s}\right]$ & 1.420 & 1.448 & 1.436 \\
\hline $\begin{array}{l}\text { Dimensionless } \\
\text { height, } H_{f} / D_{\text {fan }}\end{array}$ & \multicolumn{3}{c}{ platform } \\
\hline
\end{tabular}

Table F.8: 630L-N9-N9 fan system edge fan power consumption results

\begin{tabular}{lr}
\hline Dimensionless platform height, $H_{f} / D_{\text {fan }}$ & Edge fan power consumption $[\mathrm{W}]$ \\
\hline Infinite & 172.2 \\
4.5 & 173.1 \\
3.5 & 173.0 \\
2.5 & 172.4 \\
1.5 & 176.1 \\
1 & 164.0 \\
\hline
\end{tabular}




\section{F.3 Flow velocity measurement results}

Table F.9: N-N-N fans velocity measurement results

\begin{tabular}{llrr}
\hline Platform height & Position & Flow magnitude $(\mathrm{m} / \mathrm{s})$ & Flow angle, $\theta\left(^{\circ}\right)$ \\
\hline \multirow{4}{*}{ Open } & 1 & 1.490 & 51.001 \\
& 2 & 1.981 & 35.819 \\
& 3 & 5.020 & 101.653 \\
& 4 & 2.817 & 108.125 \\
& 5 & 2.533 & 126.906 \\
& 1 & 2.701 & 47.647 \\
$2.5 \mathrm{D}$ & 2 & 3.477 & 26.600 \\
& 3 & 7.825 & 88.245 \\
& 4 & 4.711 & 95.014 \\
& 5 & 4.076 & 118.893 \\
& 1 & 3.730 & 41.347 \\
& 2 & 4.706 & 28.750 \\
& 3 & 9.463 & 68.363 \\
& 4 & 6.791 & 81.708 \\
& 5 & 6.071 & 105.660 \\
\hline
\end{tabular}


Table F.10: N9-N9-N9 fans velocity measurement results

\begin{tabular}{llrr}
\hline Platform height & Position & Flow magnitude $(\mathrm{m} / \mathrm{s})$ & Flow angle, $\theta\left(^{\circ}\right)$ \\
\hline \multirow{4}{*}{ Open } & 1 & 1.114 & 48.993 \\
& 2 & 1.601 & 27.770 \\
& 3 & 5.207 & 106.853 \\
& 4 & 5.307 & 105.524 \\
& 5 & 2.816 & 103.928 \\
1 & 2.411 & 49.267 \\
& 2 & 3.261 & 24.189 \\
& 3 & 8.164 & 90.202 \\
& 4 & 4.554 & 97.189 \\
& 5 & 3.848 & 117.252 \\
& 1 & 3.402 & 48.028 \\
& 2 & 4.373 & 20.161 \\
& 3 & 10.649 & 77.790 \\
4 & 5 & 6.726 & 89.710 \\
& 4 & 5.974 & 107.079 \\
\hline
\end{tabular}

Table F.11: 630L-630L-630L fans velocity measurement results

\begin{tabular}{llrr}
\hline Platform height & Position & Flow magnitude $(\mathrm{m} / \mathrm{s})$ & Flow angle, $\theta\left(^{\circ}\right)$ \\
\hline \multirow{4}{*}{ Open } & 1 & 1.635 & 45.869 \\
& 2 & 2.091 & 30.627 \\
& 3 & 5.375 & 106.118 \\
& 4 & 2.810 & 102.983 \\
& 5 & 2.593 & 129.278 \\
& 1 & 2.659 & 43.196 \\
$2.5 \mathrm{D}$ & 2 & 3.654 & 28.236 \\
& 3 & 7.918 & 83.482 \\
& 4 & 4.640 & 87.483 \\
& 5 & 3.947 & 111.902 \\
& 1 & 3.599 & 37.292 \\
& 2 & 4.636 & 25.050 \\
& 3 & 9.856 & 62.405 \\
& 4 & 6.755 & 81.106 \\
& 5 & 6.077 & 106.429 \\
\hline
\end{tabular}




\section{Appendix G \\ CFD results}

\section{G.1 Multiple fan performance CFD results}

Table G.1: 3-Fan CFD volumetric flow rate results for N-fan system

\begin{tabular}{|c|c|c|c|}
\hline \multicolumn{3}{|c|}{ Ideal volumetric flow rate, $\dot{V}_{i d}\left[\mathrm{~m}^{3} / \mathrm{s}\right]$} & 1.455 \\
\hline \multirow{2}{*}{$\begin{array}{l}\text { Dimensionless platform } \\
\text { height, } H_{f} / D_{f a n}\end{array}$} & \multicolumn{3}{|c|}{ Volumetric flow rate $\left[\mathrm{m}^{3} / \mathrm{s}\right]$} \\
\hline & Fan 1 & Fan 2 & Fan 3 \\
\hline Infinite & 1.364 & 1.413 & 1.418 \\
\hline 4.5 & 1.289 & 1.389 & 1.402 \\
\hline 3.5 & 1.248 & 1.378 & 1.391 \\
\hline 2.5 & 1.167 & 1.363 & 1.369 \\
\hline 1.5 & 0.967 & 1.328 & 1.319 \\
\hline 1 & 0.600 & 1.246 & 1.255 \\
\hline
\end{tabular}


Table G.2: 3-Fan CFD volumetric flow rate results for N9-fan system

\begin{tabular}{|c|c|c|c|}
\hline \multicolumn{2}{|c|}{ Ideal volumetric flow rate, $\dot{V}_{i d}\left[\mathrm{~m}^{3} / \mathrm{s}\right]$} & & 1.455 \\
\hline \multirow{2}{*}{$\begin{array}{l}\text { Dimensionless platform } \\
\text { height, } H_{f} / D_{f a n}\end{array}$} & \multicolumn{3}{|c|}{ Volumetric flow rate $\left[\mathrm{m}^{3} / \mathrm{s}\right]$} \\
\hline & Fan 1 & Fan 2 & Fan 3 \\
\hline Infinite & 1.377 & 1.419 & 1.423 \\
\hline 4.5 & 1.311 & 1.399 & 1.409 \\
\hline 3.5 & 1.274 & 1.390 & 1.400 \\
\hline 2.5 & 1.203 & 1.375 & 1.381 \\
\hline 1.5 & 1.020 & 1.344 & 1.335 \\
\hline 1 & 0.659 & 1.272 & 1.278 \\
\hline
\end{tabular}

Table G.3: 3-Fan CFD volumetric flow rate results for 630L-fan system

\begin{tabular}{|c|c|c|c|}
\hline \multicolumn{2}{|c|}{ Ideal volumetric flow rate, $\dot{V}_{i d}\left[\mathrm{~m}^{3} / \mathrm{s}\right]$} & & 1.455 \\
\hline \multirow{2}{*}{$\begin{array}{l}\text { Dimensionless platform } \\
\text { height, } H_{f} / D_{f a n}\end{array}$} & \multicolumn{3}{|c|}{ Volumetric flow rate $\left[\mathrm{m}^{3} / \mathrm{s}\right]$} \\
\hline & Fan 1 & Fan 2 & Fan 3 \\
\hline Infinite & 1.383 & 1.421 & 1.425 \\
\hline 4.5 & 1.322 & 1.402 & 1.412 \\
\hline 3.5 & 1.290 & 1.394 & 1.403 \\
\hline 2.5 & 1.227 & 1.380 & 1.385 \\
\hline 1.5 & 1.071 & 1.352 & 1.341 \\
\hline 1 & 0.780 & 1.287 & 1.290 \\
\hline
\end{tabular}




\section{G.2 ACSC CFD results}

Table G.4: N-fans ACSC volumetric flow rate CFD results at cross-wind velocities of $0 \mathrm{~m} / \mathrm{s}, 3 \mathrm{~m} / \mathrm{s}, 6 \mathrm{~m} / \mathrm{s}$ and $9 \mathrm{~m} / \mathrm{s}$

\begin{tabular}{lllll}
\hline \multicolumn{5}{c}{ N-fans } \\
\hline \multicolumn{5}{c}{ Ideal volumetric flow rate $\left[\mathrm{m}^{3} / \mathrm{s}\right]$} \\
\hline \multicolumn{5}{c}{ Volumetic flow rate $\left[\mathrm{m}^{3} / \mathrm{s}\right]$} \\
\hline Fan & $v_{w}=0 \mathrm{~m} / \mathrm{s}$ & $v_{w}=3 \mathrm{~m} / \mathrm{s}$ & $v_{w}=6 \mathrm{~m} / \mathrm{s}$ & $v_{w}=9 \mathrm{~m} / \mathrm{s}$ \\
\hline 1,1 & 560 & 436 & 294 & 142 \\
1,2 & 602 & 561 & 510 & 501 \\
1,3 & 610 & 578 & 537 & 503 \\
1,4 & 610 & 591 & 557 & 509 \\
1,5 & 603 & 598 & 569 & 541 \\
1,6 & 560 & 609 & 586 & 559 \\
2,1 & 565 & 452 & 314 & 164 \\
2,2 & 599 & 569 & 524 & 507 \\
2,3 & 603 & 581 & 548 & 517 \\
2,4 & 602 & 592 & 563 & 533 \\
2,5 & 599 & 598 & 574 & 551 \\
2,6 & 565 & 604 & 588 & 571 \\
3,1 & 554 & 478 & 391 & 281 \\
3,2 & 555 & 545 & 523 & 497 \\
3,3 & 550 & 551 & 534 & 513 \\
3,4 & 550 & 556 & 541 & 530 \\
3,5 & 556 & 562 & 555 & 539 \\
3,6 & 554 & 573 & 572 & 561 \\
\hline
\end{tabular}

Table G.5: N-fans ACSC peripheral inlet average cross-flow velocity CFD results at cross-wind velocities of $0 \mathrm{~m} / \mathrm{s}, 3 \mathrm{~m} / \mathrm{s}, 6 \mathrm{~m} / \mathrm{s}$ and $9 \mathrm{~m} / \mathrm{s}$

\begin{tabular}{llll}
\hline \multicolumn{4}{l}{ Peripheral inlet average cross-flow velocity, $v_{x}[\mathrm{~m} / \mathrm{s}]$} \\
$v_{w}=0 \mathrm{~m} / \mathrm{s}$ & $v_{w}=3 \mathrm{~m} / \mathrm{s}$ & $v_{w}=6 \mathrm{~m} / \mathrm{s}$ & $v_{w}=9 \mathrm{~m} / \mathrm{s}$ \\
\hline 1.958 & 5.366 & 7.760 & 10.136 \\
\hline
\end{tabular}


Table G.6: N9-fans ACSC volumetric flow rate CFD results at cross-wind velocities of $0 \mathrm{~m} / \mathrm{s}, 3 \mathrm{~m} / \mathrm{s}, 6 \mathrm{~m} / \mathrm{s}$ and $9 \mathrm{~m} / \mathrm{s}$

\begin{tabular}{lllll}
\hline \multicolumn{5}{c}{ N9-fans } \\
\hline \multicolumn{5}{c}{ Volumetic flow rate $\left[\mathrm{m}^{3} / \mathrm{s}\right]$} \\
\hline Fan & $v_{w}=0 \mathrm{~m} / \mathrm{s}$ & $v_{w}=3 \mathrm{~m} / \mathrm{s}$ & $v_{w}=6 \mathrm{~m} / \mathrm{s}$ & $v_{w}=9 \mathrm{~m} / \mathrm{s}$ \\
\hline 1,1 & 563 & 457 & 330 & 172 \\
1,2 & 597 & 565 & 525 & 510 \\
1,3 & 602 & 577 & 548 & 517 \\
1,4 & 602 & 587 & 560 & 523 \\
1,5 & 597 & 593 & 571 & 549 \\
1,6 & 563 & 601 & 585 & 563 \\
2,1 & 566 & 474 & 348 & 194 \\
2,2 & 594 & 571 & 535 & 517 \\
2,3 & 597 & 580 & 554 & 527 \\
2,4 & 597 & 588 & 565 & 541 \\
2,5 & 594 & 593 & 575 & 555 \\
2,6 & 567 & 598 & 586 & 572 \\
3,1 & 558 & 494 & 418 & 314 \\
3,2 & 559 & 551 & 533 & 509 \\
3,3 & 555 & 555 & 541 & 525 \\
3,4 & 555 & 559 & 547 & 538 \\
3,5 & 559 & 564 & 559 & 546 \\
3,6 & 558 & 573 & 572 & 564 \\
\hline
\end{tabular}

Table G.7: N9-fans ACSC peripheral inlet average cross-flow velocity CFD results at cross-wind velocities of $0 \mathrm{~m} / \mathrm{s}, 3 \mathrm{~m} / \mathrm{s}, 6 \mathrm{~m} / \mathrm{s}$ and $9 \mathrm{~m} / \mathrm{s}$

\begin{tabular}{llll}
\hline \multicolumn{4}{l}{ Peripheral inlet average cross-flow velocity, $v_{x}[\mathrm{~m} / \mathrm{s}]$} \\
$v_{w}=0 \mathrm{~m} / \mathrm{s}$ & $v_{w}=3 \mathrm{~m} / \mathrm{s}$ & $v_{w}=6 \mathrm{~m} / \mathrm{s}$ & $v_{w}=9 \mathrm{~m} / \mathrm{s}$ \\
\hline 1.953 & 5.445 & 7.865 & 10.225 \\
\hline
\end{tabular}


Table G.8: 630L-fans ACSC volumetric flow rate CFD results at cross-wind velocities of $0 \mathrm{~m} / \mathrm{s}, 3 \mathrm{~m} / \mathrm{s}, 6 \mathrm{~m} / \mathrm{s}$ and $9 \mathrm{~m} / \mathrm{s}$

\begin{tabular}{lllll}
\hline \multicolumn{5}{c}{$630 \mathrm{~L}-$ fans } \\
\hline \multicolumn{5}{c}{ Volumetic flow rate $\left[\mathrm{m}^{3} / \mathrm{s}\right]$} \\
\hline Fan & $v_{w}=0 \mathrm{~m} / \mathrm{s}$ & $v_{w}=3 \mathrm{~m} / \mathrm{s}$ & $v_{w}=6 \mathrm{~m} / \mathrm{s}$ & $v_{w}=9 \mathrm{~m} / \mathrm{s}$ \\
\hline 1,1 & 556 & 464 & 363 & 247 \\
1,2 & 586 & 557 & 522 & 496 \\
1,3 & 592 & 569 & 540 & 515 \\
1,4 & 592 & 578 & 552 & 520 \\
1,5 & 587 & 583 & 564 & 543 \\
1,6 & 556 & 591 & 575 & 556 \\
2,1 & 559 & 478 & 384 & 265 \\
2,2 & 584 & 563 & 531 & 508 \\
2,3 & 587 & 571 & 547 & 524 \\
2,4 & 587 & 578 & 557 & 535 \\
2,5 & 584 & 583 & 566 & 549 \\
2,6 & 559 & 587 & 576 & 564 \\
3,1 & 551 & 495 & 431 & 350 \\
3,2 & 552 & 545 & 529 & 507 \\
3,3 & 548 & 549 & 536 & 522 \\
3,4 & 549 & 552 & 542 & 534 \\
3,5 & 553 & 557 & 552 & 540 \\
3,6 & 551 & 565 & 564 & 557 \\
\hline
\end{tabular}

Table G.9: $630 \mathrm{~L}-$ fans ACSC peripheral inlet average cross-flow velocity CFD results at cross-wind velocities of $0 \mathrm{~m} / \mathrm{s}, 3 \mathrm{~m} / \mathrm{s}, 6 \mathrm{~m} / \mathrm{s}$ and $9 \mathrm{~m} / \mathrm{s}$

\begin{tabular}{llll}
\hline \multicolumn{4}{l}{ Peripheral inlet average cross-flow velocity, $v_{x}[\mathrm{~m} / \mathrm{s}]$} \\
$v_{w}=0 \mathrm{~m} / \mathrm{s}$ & $v_{w}=3 \mathrm{~m} / \mathrm{s}$ & $v_{w}=6 \mathrm{~m} / \mathrm{s}$ & $v_{w}=9 \mathrm{~m} / \mathrm{s}$ \\
\hline 1.925 & 5.424 & 7.957 & 10.326 \\
\hline
\end{tabular}




$$
v_{x}=-0.0305 v_{w}^{2}+1.1844 v_{w}+1.9925
$$

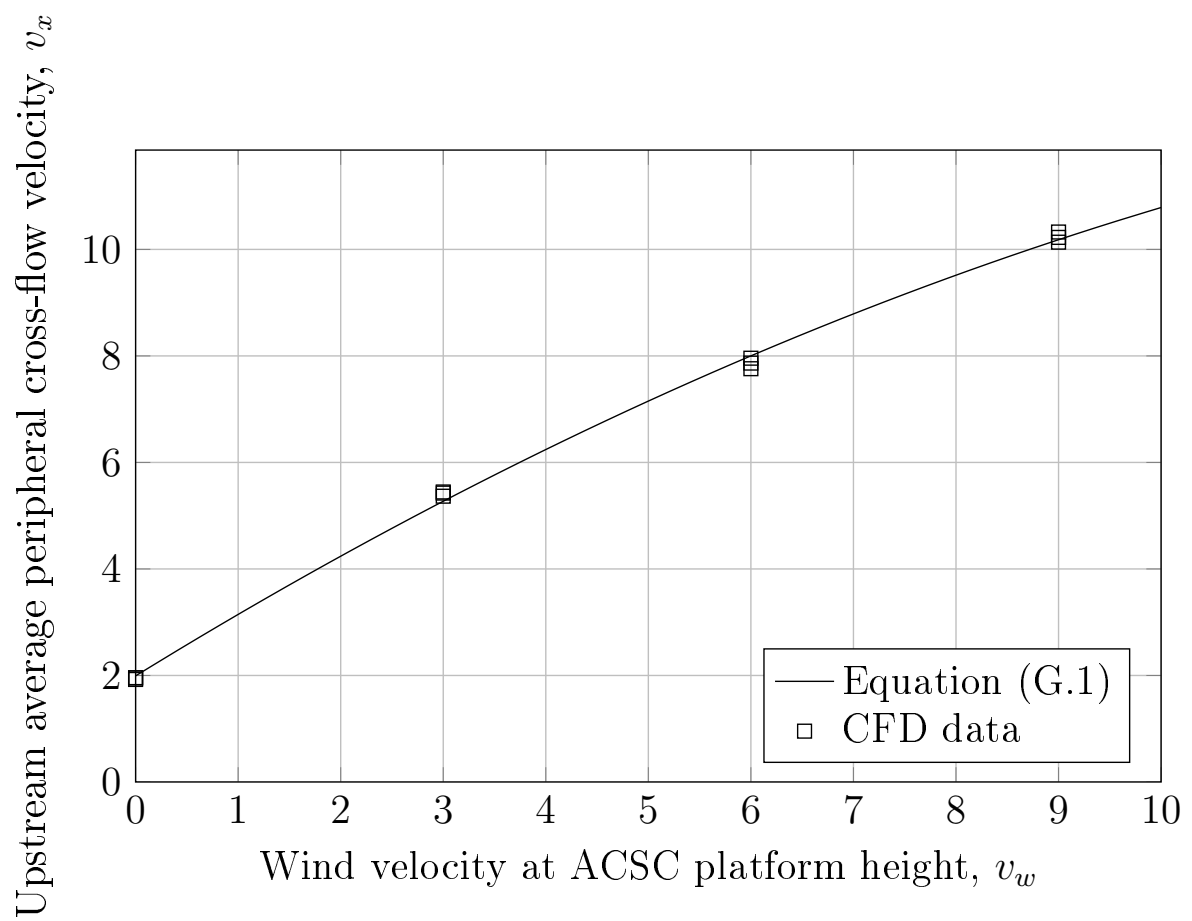

Figure G.1: Upstream average peripheral cross-flow velocity results 


\section{List of References}

Augustyn, O.P.H. (2013). Experimental and numerical analysis of axial flow fans. Master's thesis, University of Stellenbosch.

Bredell, J. (2005). Numerical investigation of fan performance in a forced draft aircooled steam condenser. Master's thesis, University of Stellenbosch.

Bredell, J., Kröger, D. and Thiart, G. (2006). Numerical investigation of fan performance in a forced draft air-cooled steam condenser. Applied Thermal Engineering, vol. 26 , pp. $846-852$.

British Standards Institute (2007). British standards institute part 1: Methods for testing performance: Fans for general purposes. BS 848 .

Bruneau, P. (1994). The design of a single rotor axial flow fan for a cooling tower application. Master's thesis, University of Stellenbosch.

Cengel, Y.A. and Boles, M.A. (2007). Thermodynamics, An Engineering Approach (6th Edition). McGraw Hill.

Conradie, P. (2010). Edge fan performance in air-cooled condensers. Master's thesis, University of Stellenbosch.

Duvenhage, K. and Kröger, D. (1996). The influence of wind on the performance of forced draught air-cooled heat exchangers. Journal of Wind Engineering and Industrial Aerodynamics, vol. 62, pp. 259-277.

Duvenhage, K., Vermeulen, J., Meyer, C. and Kröger, D. (1996). Flow distortions at the fan inlet of forced-draught air-cooled heat exchangers. Applied Thermal Engineering, vol. 16, pp. 741 - 752. ISSN 1359-4311.

Fluent (2009). Ansys Fluent 12.0 User's Guide. ANSYS, Inc.

Goldschagg, H. (1993). Winds of change at eskom's matimba plant. Modern Power Systems, vol. 19 (1), p. 43.

Jorgensen, F. (1971). Directional sensitivity of wire and fibre-film probes. DISA Info., vol. 11, pp. 31-7.

Joubert, R. (2010). Influence of geometric and environmental parameters on aircooled steam condenser performance. Master's thesis, University of Stellenbosch. 
King, L. (1914). On the convection of heat from small cylinders in a stream of fluid: determination of convection constants of small platinum wires with applications to hot-wire anemometry. Philosophical Transactions of the Royal Society, vol. 214, pp. 373-432.

Kröger, D. (2004). Air-cooled Heat Exchangers and Cooling Towers. PenWell Corporation, Tulsa, USA.

Louw, F. (2011). Performance trends of a large air-cooled steam condenser during windy conditions. Master's thesis, University of Stellenbosch.

Menet, J.-L., Valdes, L.-C. and Menert, B. (1999). An improved model for the directional sensitivity of single yawed hot-wire probes. Measurement Science and Technology, vol. 10, pp. N47-N50.

Meyer, C. (2005). Numerical investigation of the effect of inlet flow distortions on forced draught air-cooled heat exchanger performance. Applied Thermal Engineering, vol. 25, pp. 1634-1649.

Owen, M. (2010). A numerical investigation of air-cooled steam condenser performance under windy conditions. Master's thesis, University of Stellenbosch.

Salta, C. and Kröger, D. (1995). Effect of inlet flow distortions on fan performance in forced draught air-cooled heat exchangers. Heat Recovery Systems \& $C H P$, vol. 15 , pp. $555-561$.

Shih, T.-H., Liou, W., Shabbir, A., Yang, Z. and Zhu, J. (1995). A new $k-\epsilon$ eddyviscosity model for high reynolds number turbulent flows - model development and validation. Computers Fluids, vol. 24(3), pp. 227-238.

Stinnes, W. and von Backström, T. (2002). Effect of cross-flow on the performance of air-cooled heat exchanger fans. Applied Thermal Engineering, vol. 22, pp. 14031415 .

Tawney, R., Khan, Z. and Zachary, J. (2005). Economic and performance evaluation of heat sink options in combined cycle applications. Journal of Engineering for Gas Turbines and Power, ASME, vol. 127, pp. 397-403.

van der Spuy, S. (1997). The design of a low-noise rotor-only axial flow fan series. Master's thesis, University of Stellenbosch.

van der Spuy, S. (2011). Perimeter fan performance in forced draught air-cooled steam condensers. Ph.D. thesis, University of Stellenbosch.

van Rooyen, J. (2007). Performance trends of an air-cooled steam condenser under windy conditions. Master's thesis, University of Stellenbosch.

VDI (1978). VDI Guidelines, VDI 2049, Thermal acceptance and performance tests on dry-cooling towers. 
Venter, S. (1990). The effectiveness of axial flow fans in a-frame plenums. Ph.D. thesis, University of Stellenbosch.

Visser, J. (1990). Die invloed van versteurde inlaatvloeipatrone op aksiaalwaaiers. Master's thesis, University of Stellenbosch. 